\title{
Identifizierung und Charakterisierung extrazellulärer Proteine unter dem Einfluss von Verticillium longisporum in Arabidopsis thaliana und Raps (Brassica napus)
}

\author{
Dissertation \\ zur Erlangung des Doktorgrades \\ der Mathematisch-Naturwissenschaftlichen Fakultäten \\ der Georg-August-Universität zu Göttingen
}

\author{
vorgelegt von \\ Saskia Flörl \\ aus Bad Karlshafen
}

Göttingen 2007 
D 7

Referent:

Prof. Dr. Andrea Polle

Korreferent:

Prof. Dr. Christiane Gatz

Tag der mündlichen Prüfung: $\quad$ 01. November 2007 


\section{INHALTSVERZEICHNIS}

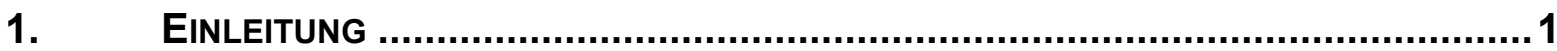

1.1 Verticillium spp.: Verbreitung und Lebenszyklus des Pathogens....................1

1.2 Brassica napus und Arabidopsis thaliana als Wirtspflanzen...........................

1.3 Pathogen induzierte Abwehrreaktionen in Pflanzen .....................................4

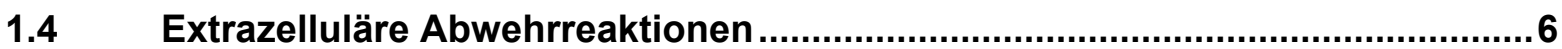

1.5 Die Funktion von Peroxidasen in der Pathogen-Abwehr.................................8

1.6 Die Funktion von Chitinasen in der Pathogen-Abwehr...................................9

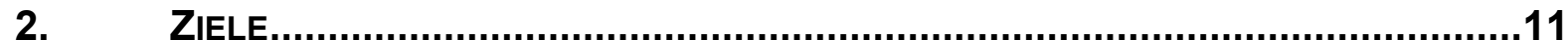

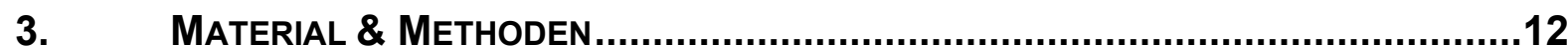

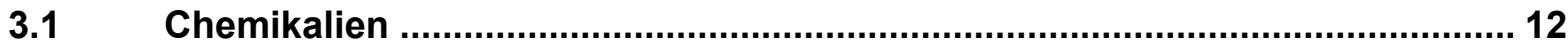

3.2 Pflanzenanzucht und Inokulation mit Verticillium longisporum .................... 13

3.2.1 Anzucht von Arabidopsis thaliana und Inokulation ............................................ 13

3.2.2 Anzuchtbedingungen für Raps und Inokulation .............................................. 14

3.2.3 Vorbereitung von Verticillium longisporum für die Inokulation ............................. 14

3.3 Ökophysiologische Methoden.................................................................. 15

3.3.1 Messung der Chlorophyllfluoreszenz.......................................................... 15

3.3.2 Messung der Elektrolytleitfähigkeit .......................................................... 16

3.3.3 Bestimmung des osmotischen Drucks............................................................. 16

3.3.4 Bestimmung des Chlorophyllgehaltes .......................................................... 16

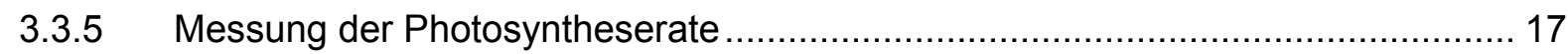

3.3.6 Blattflächenmessung bei Arabidopsis thaliana ................................................ 17

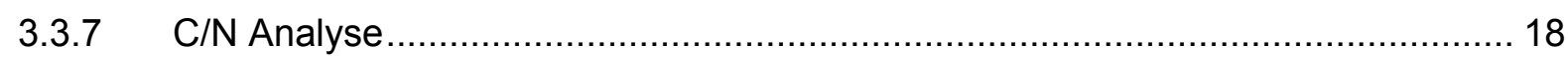

3.3.8 Optische ICP-Emissionsspektrometrie zur Elementanalyse............................... 19

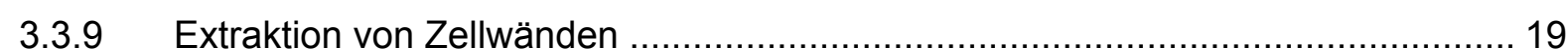

3.3.10 FTIR (Fourier-Transmissions-Infrarot) Spektrometrie ................................... 19

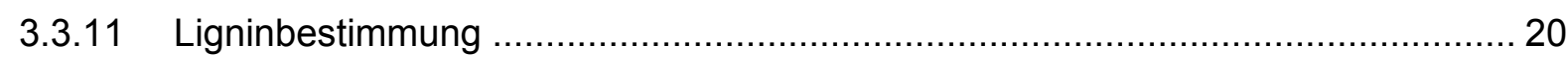

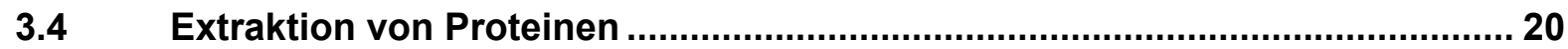

3.4.1 Gewinnung von apoplastischer Waschflüssigkeit (AWF) aus Arabidopsis thaliana Blättern ........................................................................... 20

3.4.2 Gewinnung von AWF aus Rapsblättern........................................................ 21

3.4.3 Gewinnung von Xylemsaft aus Raps............................................................. 21

3.4.4 Proteinextraktion aus Gesamtblattmaterial und Gelfiltration................................. 22

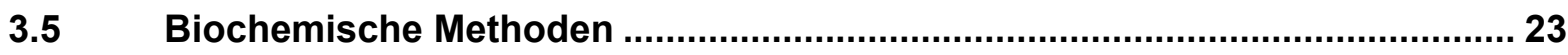

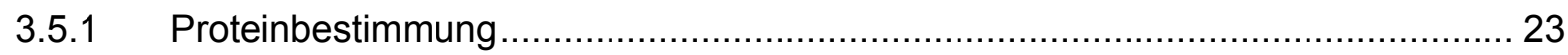




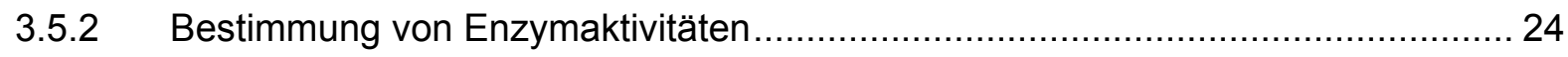

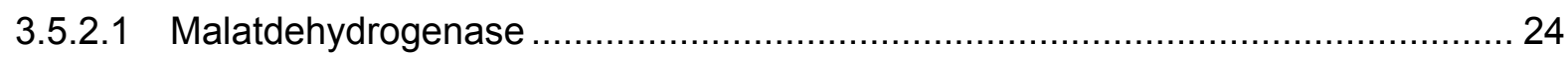

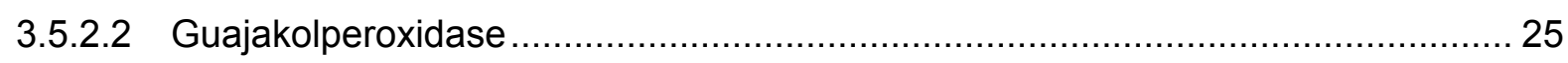

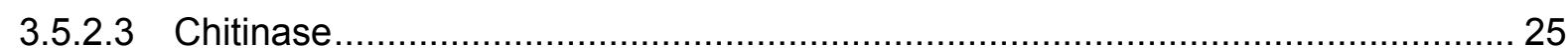

3.5.3 Trichloressigsäure (TCA)/Aceton-Fällung................................................... 26

3.5.4 Peroxidase Nachweis im PhastGel.............................................................. 26

3.5.5 Eindimensionale Elektrophorese ............................................................ 27

3.5.6 Molekulargewichtsmarker für die Elektrophorese ............................................. 29

3.5.7 Zweidimensionale Elektrophorese ................................................................ 30

3.5.7.1 Erste Dimension (Isoelektrische Fokussierung) ................................................ 30

3.5.7.2 Zweite Dimension (SDS-Polyacrylamidgelelektrophorese) ................................. 30

3.5.8 Färbung der Gele mit Silbernitrat oder Coomassie Brilliant Blue ......................... 31

3.5.9 Analyse der zweidimensionalen Gele......................................................... 32

3.5.10 Proteinverdau mit Trypsin und Proteinidentifizierung ........................................ 32

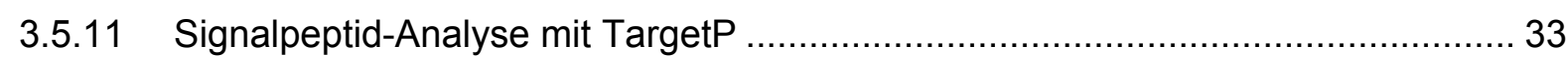

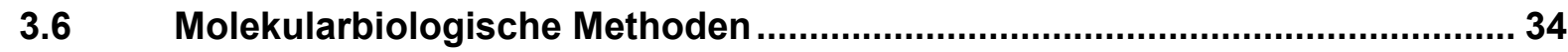

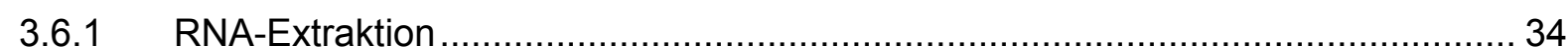

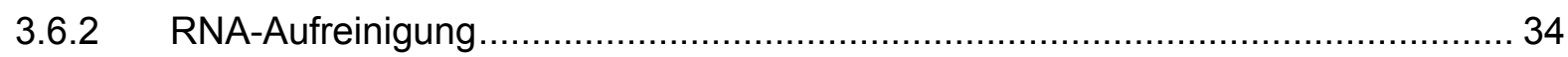

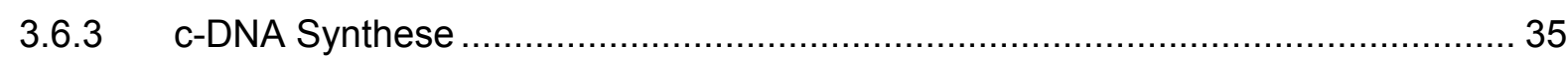

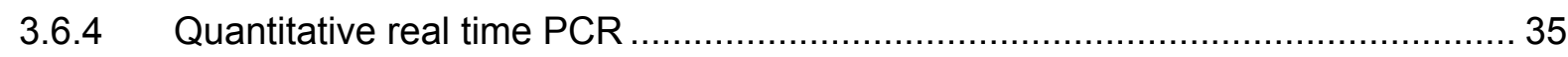

3.6.5 Quantifizierung von Verticillium-DNA in inokulierten Pflanzen ............................ 37

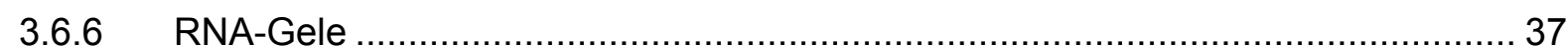

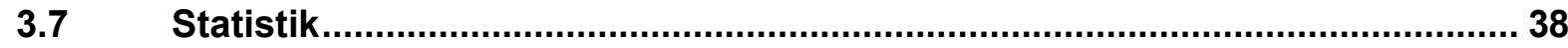

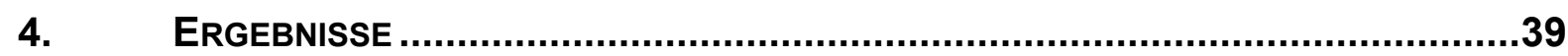

4.1 Einfluss von Verticillium longisporum auf Brassica napus ........................... 39

4.1.1 Entwicklung von Krankheitssymptomen bei Raps ........................................ 39

4.1.2 Charakterisierung von Proteinmustern unter dem Einfluss von Verticillium

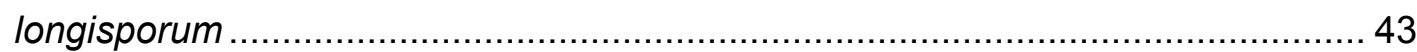

4.1.2.1 Kontaminationsbestimmung in der apoplastischen Waschflüssigkeit von Raps ... 43

4.1.2.2 Vergleich von Proteinmustern in apoplastischen und Gesamtblattextrakten........ 43

4.1.2.3 Vergleich von Proteinmustern und Proteinanalyse in AWF und Xylemsäften ....... 44

4.1.2.4 Zweidimensionale Auftrennung apoplastischer Rapsproteine .............................. 47

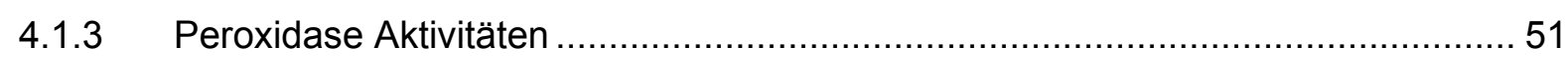

4.2 Einfluss von Verticillium longisporum auf die Modellpflanze

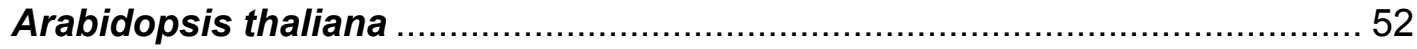

4.2.1 Ermittlung geeigneter Versuchsbedingungen.................................................. 52

4.2.1.1 Vergleich der Arabidopsis thaliana Ökotypen Columbia und Landsberg erecta.... 52 
4.2.1.2 Untersuchung des Arabidopsis thaliana Ökotyps Columbia unter Lang- und Kurztagsbedingungen

4.2.2 Krankheitssymptome und Nährstoffversorgung von Arabidopsis thaliana im Infektionsverlauf

4.2.2.1 Einfluss von Verticillium longisporum auf den Phänotyp von Arabidopsis.....

4.2.2.2 Einfluss von Verticillium longisporum auf die Nährelementsituation in

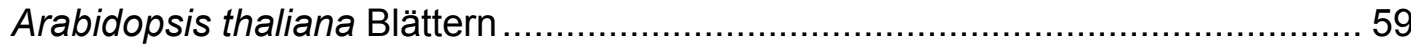

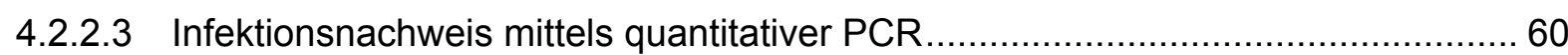

4.2.2.4 Ökophysiologische Charakterisierung Verticillium longisporum infizierter Arabidopsis thaliana

4.2.2.5 Kontaminationsbestimmung in der AWF von Arabidopsis thaliana ...................... 63

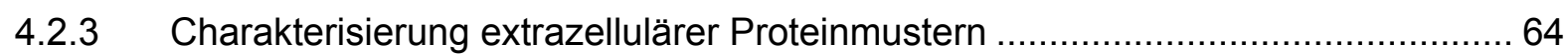

4.2.3.1 Vergleich von Proteinmustern in apoplastischen und Gesamtblattextrakten........ 64

4.2.3.2 Zweidimensionale Auftrennung apoplastischer Arabidopsis thaliana Proteine .... 65

4.2.3.3 Analyse der Hauptproteine in Gesamtblattextrakten von Arabidopsis thaliana ..... 68

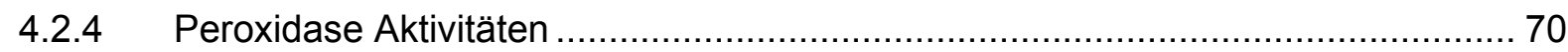

4.2.5 Expressionsanalyse differentiell auftretender Proteine..................................... 71

4.2.6 In silico Analyse der Expressionslevel der differentiell regulierten Proteine

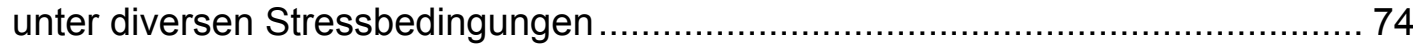

4.2.7 Untersuchungen zum Einfluss von Verticillium longisporum auf die Zellwandzusammensetzung von Arabidopsis thaliana.... 76

4.2.8 FTIR-Analyse zur Ermittlung des chemischen Fingerprints Verticillium longisporum infizierter Arabidopsis thaliana 76

4.3 Untersuchung des Einflusses von Verticillium longisporum auf eine Arabidopsis thaliana Chitinase

4.3.1 Expression eines sauren Endochitinase-Gens (At5g24090) in Verticillium longisporum infizierten Wildtyp Arabidopsis Pflanzen

4.3.2 Untersuchung einer Arabidopsis thaliana Chitinase-Mutante unter Einfluss von

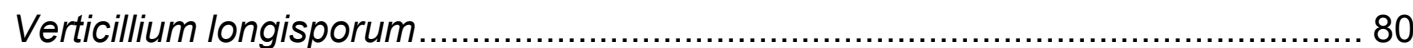

4.3.2.1 Chitinase-Aktivitätsmessungen in mock- und Verticillium-infizierten Pflanzen ...... 80

4.3.2.2 Untersuchung der Chitinase Insertionsmutante im Hinblick auf die Symptomausprägung unter Einfluss von Verticillium longisporum ................................ 81

4.3.2.3 Infektionsnachweis mittels quantitativer PCR .............................................. 82

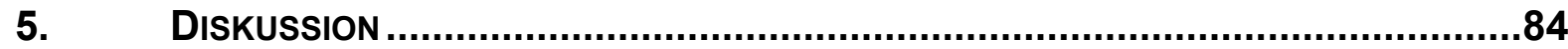

5.1 Verticillium-induzierte Schäden an Raps und Arabidopsis ............................. 84

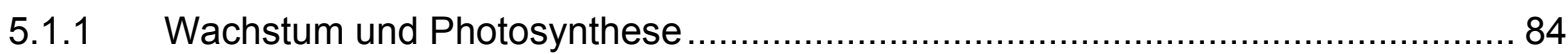

5.1.2 Die Nährelementsituation in Arabidopsis thaliana ........................................... 85

5.1.3 Der Wasserhaushalt in Arabidopsis thaliana ...................................................... 86 
5.2 Das extrazelluläre Proteom von Arabidopsis thaliana und Raps .................. 87

5.2.1 Apoplasten-spezifische Proteine in Arabidopsis thaliana .................................... 87

5.2.2 Apoplasten-spezifische Proteine in Raps ....................................................... 90

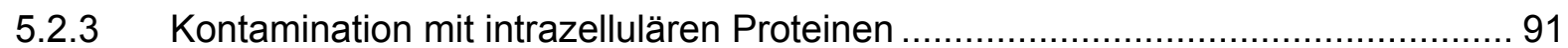

5.3 Proteinantworten auf $V$. longisporum Infektion und mögliche Funktionen der differentiell auftretenden Proteine ....................................... 92

5.3.1 Das extrazelluläre Proteom von Arabidopsis unter Verticillium-Einfluss ...............992

5.3.2 Das extrazelluläre Proteom von Raps unter Verticillium-Einfluss ......................... 98

5.3.3 Verticillium-induzierte Antworten in Raps und Arabidopsis im Vergleich.............. 99

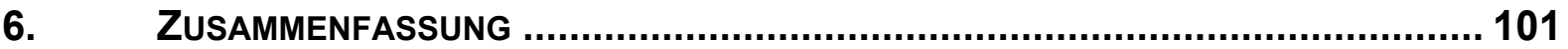

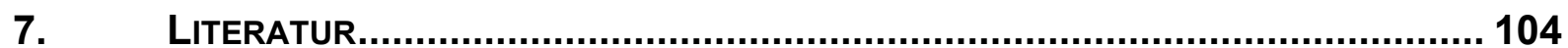

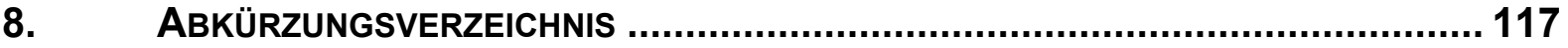

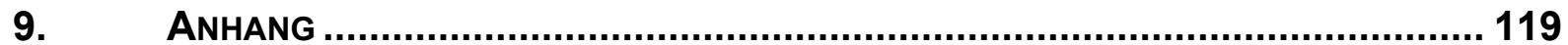

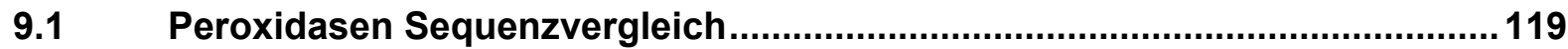

9.2 Überprüfung der T-DNA Insertion in das Chitinase-Gen At5g24090 ............121

9.3 Expressionsvergleich des Chitinase-Gens At5g24090 in Wildtyp- und Mutanten-Pflanzen............................................................................................ 121 


\section{EINLEITUNG}

\subsection{Verticillium spp.: Verbreitung und Lebenszyklus des Pathogens}

Verticillium-Arten sind bodenbürtige Pilze, die weltweit in gemäßigten und subtropischen Regionen verbreitet sind. Sie gehören zur Abteilung der Ascomyceten und sind für die sogenannte "Verticillium Welke“ verantwortlich. Die Verticillium Pilze gelten als wenig wirtsspezifisch und verursachen landwirtschaftlich bedeutsame Schäden (Bhat \& Subbarao 1999; Pegg \& Brady, 2002). Zusammen genommen befallen die Verticillium spp. über 200 Pflanzenarten weltweit (Agrios, 1997), darunter viele ökonomisch bedeutsame Kulturpflanzen wie Tomaten, Blumenkohl etc., aber auch Bäume wie z.B. Ahorn und Olivenbäume. Besonders $V$. dahliae und $V$. albo-atrum besitzen eine große Zahl von Wirtspflanzen. $V$. longisporum ist dagegen vor allem auf Brassicaceen spezialisiert (Karapapa et al., 1997; Zeise \& Tiedemann, 2002). Im Vergleich zu V. dahliae hat V. longisporum eine deutlich unterschiedliche Morphologie (Karapapa et al., 1997), wobei umstritten ist, ob es sich bei $V$. longisporum um eine eigene Art oder um eine Unterart von $V$. dahliae handelt (Barbara \& Clewes 2003). V. longisporum und V. dahliae können vor allem durch Form und Größe ihrer Sporen unterschieden werden. Die Sporen von V. dahliae sind klein, kugelig und ca. 3,5-6 $\mu \mathrm{m}$ groß, während die Sporen von V. longisporum länglich und 7$9 \mu \mathrm{m}$ lang sind (Karapapa et al., 1997). Der DNA-Gehalt von V. longisporum ist fast doppelt so hoch wie der DNA-Gehalt nicht-langsporiger Isolate (Steventon et al., 2002). Daher wurde diskutiert, ob V. longisporum ein Hybrid aus V. dahliae und V. albo atrum wäre (Karapapa et al., 1997; Collins et al., 2003). Dieses wurde widerlegt, indem Barbara et al. (2005) mit Hilfe von Mikrosatelliten Markern zeigten, dass V. albo atrum kein „Elternteil“ von V. Iongisporum ist.

Interaktionsstudien von Fluoreszenz-gefärbten V. longisporum oder V. dahliae mit Brassica napus (Eynck et al., 2007) zeigten, dass V. longisporum 36 Stunden nach Inokulation die Epidermiszellen der Wurzelhaare netzartig bedeckt und dann inter- und intrazellulär durch den Wurzelcortex zum Zentralzylinder wächst. Die Kolonisierung der Xylemgefäße mit V. longisporum ist auf einzelne Leitgefäße beschränkt, während benachbarte Gefäße nicht angegriffen werden. $V$. dahliae konnte zwar ebenfalls in die Wurzeln eindringen, war im Gegensatz zu V. longisporum aber nicht in der Lage sich systemisch in der Pflanze auszubreiten, ein Hinweis darauf, dass Brassica napus kein Wirt für $V$. dahliae ist (Eynck et al., 2007).
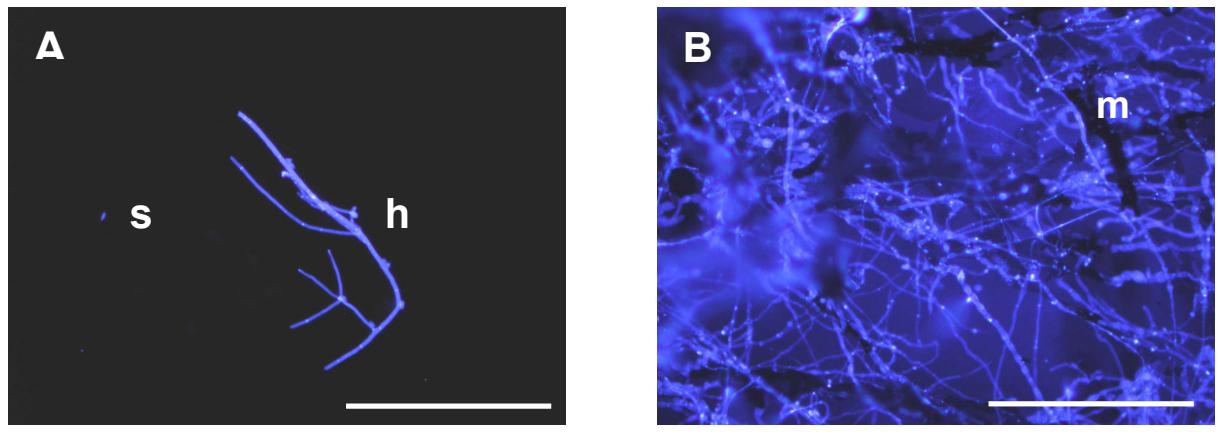

Abb. 1.1: Mikroskopische Aufnahmen einer einzelnen Spore (s) und Hyphe (h) von Verticillium longisporum (A) und vom Myzel (B) mit Mikrosklerotien (m). Der Pilz wurde mit Calcofluor white angefärbt. (Fotos: S. Flörl; Maßstab: $100 \mu \mathrm{m}$ ). 
Die Symptome, die durch Verticillium spp. hervorgerufen werden, variieren stark zwischen den verschiedenen Wirtspflanzen (Fradin \& Thomma, 2006). Es konnten Welkeerscheinungen, Kümmerwuchs und Stauchung (Abb. 1.2A) von befallenen Pflanzen beobachtet werden. Bei einigen Pflanzenarten zeigten sich Chlorosen und Nekrosen an Blättern. Neben den äußerlichen Schadsymptomen konnten in zahlreichen Pflanzenarten auch braune Verfärbungen von Leitgefäßen in Stängelquerschnitten nachgewiesen werden (Abb. 1.2B). Diese vaskulären Verfärbungen sind vermutlich auf die Anreicherung phenolischer Substanzen in befallenen Gefäßabschnitten zurückzuführen (Pegg, 1976).
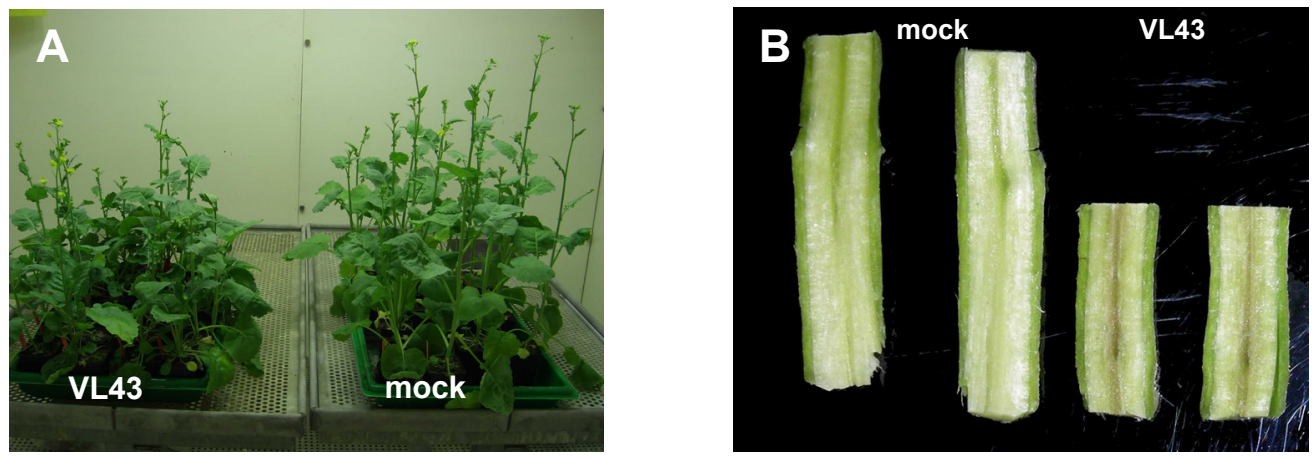

Abb. 1.2: Stauchung der Sprossachse $(A)$ und bräunliche Verfärbung von Leitgefäßen in Hypokotylsegmenten (B) von V. longisporum (VL43) infiziertem Raps im Vergleich zu gesunden Kontrollpflanzen (mock). (Fotos: S. Flörl).

Der vegetative Lebenszyklus von Verticillium (Abb. 1.3) besteht aus drei Phasen, der parasitischen, die saprophytischen und die ruhenden Phase. Im Boden befindliche Dauerformen von Verticillium, sogenannte Mikrosklerotien, werden durch Wurzelexudate, die von Pflanzen in die Rhizosphere abgegeben werden, zur Keimung angeregt (Mol \& van Riessen, 1995; Schreiber \& Green, 1969). Hyphen, die aus den keimenden Mikrosklerotien herauswachsen, können eine kurze Distanz überwinden, um eine potentielle Wirtspflanze zu erreichen. Für $V$. dahliae wurde gezeigt, dass die Keimrate der Mikrosklerotien mit zunehmendem Abstand zur Pflanzenwurzel abnimmt (Mol \& van Riessen 1995). Die Mikrosklerotienkeimung tritt sowohl bei Exudaten von Wirts- als auch von NichtWirtspflanzen auf, dabei wurde die beeinflusste Wurzelzone für die meisten untersuchten Pflanzen mit unter $2 \mathrm{~mm}$ berechnet (Mol 1995). Wenn die Hyphen die Wurzel einer Wirtspflanze erreichen, beginnt das parasitische Stadium mit dem Eindringen des Pilzes in die Wurzel. Um in die Xylemgefäße zu gelangen, muss der Pilz die Endodermis durchqueren, die der Pflanze unter anderem als physikalische Barriere gegen Infektionen dient. Daher findet die Infektion vor allem über das Apikalmeristem der Wurzelspitzen, bei denen die Endodermis noch nicht entwickelt ist oder über Wunden, die z.B. durch Nematoden hervorgerufen werden können, statt (Bowers et al.,1996). Wenn die Hyphen in den Wurzelcortex und das Xylem eingedrungen sind, können Sporen gebildet werden, die mit dem Xylemstrom in andere Pflanzenteile gelangen, wo sie in Aushöhlungen und am Ende von Gefäßen hängen bleiben, den sogenannten trapping sites (Heinz et al., 1998). Von dort keimt der Pilz erneut aus und dringt in benachbarte Gefäße ein. Es wurde gezeigt, dass es zwischen 2 und 4 Tagen dauert, bis der Pilz das Xylem erreicht und einen weiteren Tag um benachbarte Gefäße zu befallen und zu sporulieren (Chen et al., 2004; Gold \& Robb 
1995; Heinz et al., 1998). In dieser Phase ist der Pilz strikt apoplastisch lokalisiert. Erst im späteren saprophytischen Infektionsstadium kolonisiert der Pilz auch andere Pflanzengewebe. Der Pilz bildet Mikrosklerotien, die mit absterbendem Gewebe wieder in den Boden gelangen und dort in der ruhenden Phase für viele Jahre überdauern können (Wilhelm, 1955). Die Bekämpfung von Verticillium Pilzen in der Landwirtschaft wird durch die lange Lebensdauer der Mikrosklerotien und seine Lebensweise im Xylem erschwert.

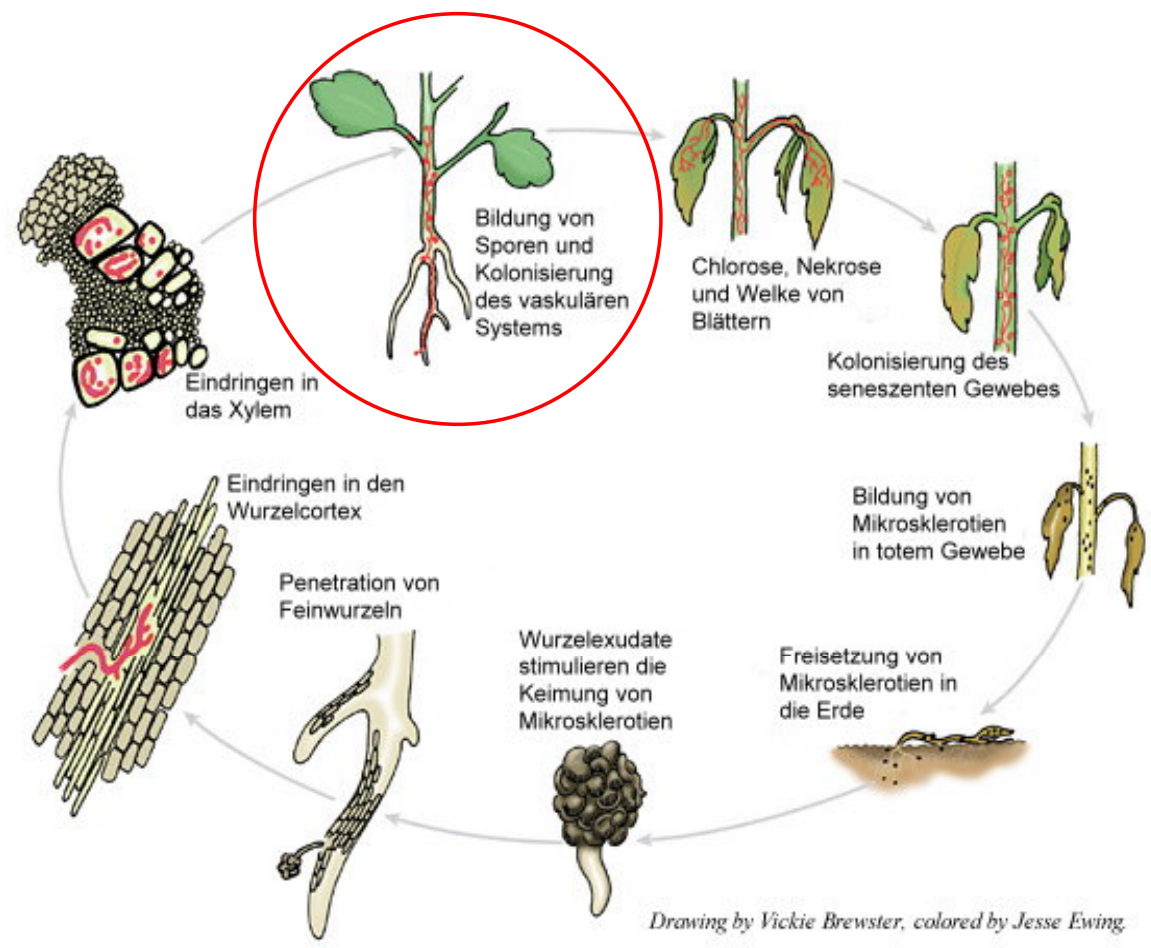

Abb. 1.3: Lebenszyklus von Verticillium in Raps, verändert nach http://www.apsnet.org/education/ lessonsPlantPath/Verticillium/discycleFull.htm. Der rote Kreis kennzeichnet das in der vorliegenden Arbeit untersuchte Stadium.

\subsection{Brassica napus und Arabidopsis thaliana als Wirtspflanzen}

Die Verticillium Welke an Raps (Brassica napus) wurde in Europa erstmals vor ca. 50 Jahren in Schweden beobachtet und wird seither als zunehmendes Problem wahrgenommen (Dixelius et al., 2005). Seit den 1980er Jahren hat der Rapsanbau in Deutschland auch aufgrund steigender Nachfrage nach nachwachsenden Rohstoffen stark zugenommen. Mit der Intensivierung des Rapsanbaus geht ein verstärktes Auftreten pilzlicher Pathogene, darunter auch Verticillium, einher (Krüger, 1989). Die Verticillium Welke an Raps wird durch den langsporigen, auf Brassicaceen spezialisierten Pilz V. longisporum verursacht (Karapapa et al., 1997).

Die meisten ökonomisch wichtigen Brassicaceen haben einen langen Lebenszyklus zwischen 0,5 und 2 Jahren, was die Untersuchung der Pathogenreaktion dieser Arten erschwert. Zur Untersuchung von Pflanzenkrankheiten wurden deshalb in den 1980er Jahren Brassica-Arten mit kurzem Lebenszyklus (rapid cycle) gezüchtet (Williams \& Hill 1986), darunter B. rapa, B. nigra, B. oleracea, B. juncea, B. carinata und B. napus. Wegen ihrer nahen Verwandtschaft zu den landwirtschaftlich wichtigen Brassica-Arten, finden die rapid 
cycling Brassicaceen ein weites Anwendungsgebiet in der Forschung (Musgrave, 2000). Rapid cycling Brassica napus kennzeichnen folgende Charakteristika: im Mittel 25 Tage bis zur ersten Blüte, 55 Tage bis zur Samenreife und eine Chromosomenanzahl von 38 (Musgrave, 2000).

Arabidopsis thaliana (Ackerschmalwand) gehört wie Raps zu den Brassicaceen, und ist eine nahe Verwandte nicht nur von Raps, sondern auch von anderen V. Iongisporum sensitiven Brassicaceen, wie Blumenkohl und Brokkoli. Verbreitet ist Arabidopsis thaliana sowohl in Europa, als auch in Asien und Nordamerika. In den letzten 25 Jahren wurde Arabidopsis thaliana, im Folgenden kurz als Arabidopsis bezeichnet, zum Modellorganismus in der Pflanzenbiologie. Da Arabidopsis relativ klein ist, wenig Anforderungen an Wachstumsbedingungen stellt und einen kurzen Lebenszyklus von ca. 8 Wochen hat, können die Pflanzen einfach unter Laborbedingungen kultiviert werden (Somerville \& Koornneef, 2002). Außerdem hat Arabidopsis für eine Blütenpflanze ein kleines Genom von ca. $125 \mathrm{Mb}$, dessen Sequenzierung im Dezember 2000 abgeschlossen wurde (Somerville \& Koornneef, 2002). Das Genom besteht aus 5 Chromosomenpaaren mit mehr als 25000 Genen, von denen detaillierte Karten erstellt wurden. Genetische Manipulationen können relativ einfach durch Transformation mit Agrobacterium tumefaciens durchgeführt werden.

Vor wenigen Jahren konnte gezeigt werden, dass die Modellpflanze Arabidopsis empfindlich für Verticillium ist (Steventon et al., 2001; Veronese et al., 2003). Verschiedene ArabidopsisÖkotypen wurden von Veronese et al. (2003) auf ihre Empfindlichkeit gegenüber Verticillium dahliae überprüft. Alle untersuchten Ökotypen, die mit Verticillium infiziert worden waren, wiesen Krankheitssymptome wie Verkümmerung, nachgewiesen durch Gewichtsverluste, und Vergilbungen an Blättern auf. Im Vergleich zum Ökotyp Columbia waren die Symptome beim Ökotyp C-24 weniger stark ausgeprägt, woraus gefolgert wurde, dass C-24 toleranter gegenüber Verticillium ist (Veronese et al., 2003).

\subsection{Pathogen induzierte Abwehrreaktionen in Pflanzen}

Pflanzen haben ein breites Spektrum an Schädlingen, darunter Bakterien, Pilze, Nematoden und Insekten. Obwohl Pflanzen kein Immunsystem besitzen, verfügen sie über eine große Anzahl von Abwehrmechanismen. Eine der effektivsten Abwehrreaktionen der Pflanzen wird durch Resistenz (R)-Gene vermittelt. Die R-Gene kodieren für Rezeptoren, die spezifische Moleküle von Pathogenen (Elicitoren) erkennen und binden. Bei den Elicitoren kann es sich z.B. um Proteine, Lipide oder Polysaccharidfragmente aus der Zellwand des Pathogens handeln. Pflanzen sind empfindlich für den Angriff bestimmter pathogener Stämme, aber resistent gegenüber anderen. Bei der pflanzlichen Pathogenabwehr unterscheidet man deshalb zwischen zwei Arten von Wirt-Parasit-Interaktion, der kompatiblen und der inkompatiblen Interaktion. Kompatibel bedeutet, dass es bei Befall der Pflanze mit einem Pathogen zur Krankheitsausprägung kommt, die Pflanze also anfällig ist. Das Pathogen bezeichnet man in diesem Fall als virulent. Wenn die Pflanze in der Lage ist die Ausbreitung und Vermehrung des Pathogens zu verhindern, handelt es sich um eine inkompatible Interaktion. Vermutlich wird diese Spezifität durch die Interaktion zwischen den Produkten der R-Gene und den Produkten der Avirulenz (avr) Gene der Pathogene, die für spezielle Elicitoren codieren, bestimmt. Verfügt der Wirt über ein bestimmtes R-Gen und das 
Pathogen über das entsprechende avr-Gen so kommt es zur Abwehrreaktion (Inkompatibilitätsreaktion). Fehlt allerdings das entsprechende R-Gen oder avr-Gen kann das Pathogen nicht erkannt werden und es kommt zur kompatiblen Reaktion und zur Krankheitsausprägung (Feys \& Parker, 2000; Dangl \& Jones, 2001; Hammond-Kosack \& Parker, 2003).

Häufig ist die inkompatible Reaktion dadurch gekennzeichnet, dass infizierte und benachbarte Zellen absterben und so die Ausbreitung des Pathogens verhindern. Dieser Zelltod um eine Infektionstelle dient dem Schutz der Pflanze und wird als hypersensitive Reaktion bezeichnet. Durch vermehrte Lignin- oder Kallosesynthese werden die Zellwände um das nekrotische Gewebe verstärkt, um ein Eindringen des Pathogens zu verhindern (Heath, 1998; Scheel, 1998; Thordal-Christensen et al., 1997). Ebenfalls relevant bei der Abwehr pathogener Pilze und Bakterien ist die Produktion von Phytoalexinen. Diese sehr heterogene Gruppe sekundärer Pflanzenstoffe hat eine starke antimikrobielle Wirkung. Zu den Phytoalexinen gehören unter anderem Isoprenoide, Stilbene und Flavonoide (Dixon, 2001). Nachdem die Pflanzenzelle über die Rezeptor-Elicitor-Bindung das Pathogen erkannt hat, kommt es zu Änderungen der Permeabilität der Plasmamembran. Calciumionen und Protonen strömen in die Zelle ein, während Kalium- und Chloridionen ausströmen (Scheel, 1998). Verschiedene Elicitor-abhängige $\mathrm{Ca}^{2+}$ Kanäle konnten identifiziert werden (Zimmermann et al., 1997; Gelli et al. 1997). Bei Fehlen von $\mathrm{Ca}^{2+}$ im Kulturmedium, war die Elicitor induzierte Abwehrreaktion in Zellen von Petersilie stark reduziert (Dietrich et al., 1990). Es wurde außerdem gezeigt, dass die lonenströme für die Induktion des sogenannten oxidative burst, für die Aktivierung von Abwehrgenen und die Produktion von Phytoalexinen erforderlich sind (Jabs et al., 1997; Pugin et al., 1997). Die extrazelluläre Produktion von reaktiven Sauerstoffspezies (ROS), wie Superoxid-Anionen $\left(\mathrm{O}_{2}^{-}{ }_{2}^{-}\right)$, Wasserstoffperoxid $\left(\mathrm{H}_{2} \mathrm{O}_{2}\right)$ und Hydroxylradikalen $(\bullet \mathrm{OH})$ spielt eine zentrale Rolle im pflanzlichen Abwehrmechanismus (Scheel, 1998). ROS wirken direkt gegen Pathogene, sind aber auch an der Signalweiterleitung für spätere Abwehrreaktionen beteiligt, z.B. an der Phytoalexinsynthese, an der Aktivierung von Abwehrgenen, am programmierten Zelltod und an der $\mathrm{H}_{2} \mathrm{O}_{2}$ vermittelten Vernetzung von Zellwänden (Baker \& Orlandi, 1995; Bradley et al., 1992; Jabs et al., 1996; Lamb \& Dixon, 1997).

Zusätzlich zu lokalen Resistenz Antworten können Pflanzen eine systemische Resistenz entwickeln. Die erfolgreiche lokale Pathogenabwehr führt dabei in nicht unmittelbar befallenen Pflanzenteilen ebenfalls zur Erhöhung der Resistenz und schützt so vor späteren Angriffen. Dieses Phänomen der systemisch erworbenen Resistenz (systemic acquired resistance, SAR) entwickelt sich im allgemeinen innerhalb mehrerer Tage nach der Infektion (Ryals et al., 1996). SAR wirkt gegen ein breites Spektrum von Pathogenen und erfordert das phenolische Signalmolekül Salicylsäure (SA) (Dempsey, 1999). Korrelierend mit der Aktivierung von SAR werden einige pathogen-related (PR) Proteine mit antimikrobieller Wirkung exprimiert (Feys \& Parker, 2000; Weigel et al., 2005). PR-Proteine können in 17 Familien (PR-1 bis PR-17) unterteilt werden (van Loon et al., 2006). Viele PR-Proteine werden durch die Signalmoleküle SA, Jasmonsäure (JA) und Ethylen (ET) induziert (van Loon et al., 2006), wobei die Signaltransduktionswege nicht im Einzelnen geklärt sind. Zu den PR-Proteinen gehören z.B. $\beta-1,3-E n d o g l u c a n a s e n$ (PR-2) und Endochitinasen (PR-3, 
PR-4, PR-8 und PR-11), die pilzliche Zellwände hydrolysieren können (Schröder et al., 1992; Hong et al., 2000; Jung \& Hwang, 2000). Ein breites Spektrum an antibakteriellen und antipilzlichen Aktivitäten weisen die kleinen (ca. $5 \mathrm{kDa}$ ) basischen cystein-reichen Defensine (PR-12) und Thionine (PR-13) auf (Lay \& Anderson, 2005; Bohlmann, 1994; Epple et al., 1997). Mitglieder der PR-1 und der PR-5 Familie (thaumatin-like proteins) wurden mit Aktivitäten gegen Oomyceten wie z.B. Phytophtera assoziiert (van Loon et al., 2006). Bei den PR-9 Proteinen handelt es sich um einen spezifischen Typ von Peroxidasen, die die Lignifizierung zur Verstärkung der Zellwand katalysieren (Passardi et al., 2004) und so die Resistenz gegen viele Pathogene erhöhen.

Tab. 1.1: Bekannte Familien von PR-Proteinen. Verändert nach van Loon et al. (2006, http://www.bio.uu.nl/ fytopath//PR-families.htm).

\begin{tabular}{|c|c|c|c|c|}
\hline Familie & Mitglied & Funktion & Symbol & Referenz \\
\hline PR-1 & Tabak PR-1a & Antifungale Aktivität & Ypr1 & Antoniw et al., 1980 \\
\hline PR-2 & Tabak PR-2 & $\beta$-1,3-Glucanase & Ypr2 & Antoniw et al., 1980 \\
\hline PR-3 & Tabak P, Q & $\begin{array}{l}\text { Chitinase Typ I,II, } \\
\text { IV,V,VI,VII }\end{array}$ & Ypr3, Chia & Van Loon, 1982 \\
\hline PR-4 & Tabak R & Chitinase Typ I,II & Ypr4, Chid & Van Loon, 1982 \\
\hline PR-5 & Tabak S & Thaumatin-ähnlich & Ypr5 & Van Loon, 1982 \\
\hline PR-6 & Tomate, Inhibitor I & Proteinase-Inhibitor & Ypr6, Pis & Green \& Ryan, 1972 \\
\hline PR-7 & Tomate P69 & Endoproteinase & Ypr7 & Vera \& Conejero, 1988 \\
\hline PR-8 & Gurke Chitinase & Chitinase Typ III & Ypr8, Chib & Métraux et al., 1988 \\
\hline PR-9 & $\begin{array}{l}\text { Tabak Lignin-bildende } \\
\text { Peroxidase }\end{array}$ & Peroxidase & Ypr9, Prx & Lagrimini et al., 1987 \\
\hline PR-10 & Petersilie PR-1 & Ribonuclease-ähnlich & Ypr10 & Somssich et al., 1986 \\
\hline PR-11 & $\begin{array}{l}\text { Tabak Klasse V } \\
\text { Chitinase }\end{array}$ & Chitinase & Ypr11, Chic & Melchers et al., 1994 \\
\hline PR-12 & Rettich Rs-AFP3 & Defensin & Ypr12 & Terras et al., 1992 \\
\hline PR-13 & Arabidopsis THI2.1 & Thionin & Ypr13, Thi & Epple et al., 1995 \\
\hline PR-14 & Gerste LTP4 & Lipid-Transfer Protein & Ypr14, Ltp & García-Olmedo et al., 1995 \\
\hline PR-15 & Gerste OxOa (Germin) & Oxalat Oxidase & Ypr15 & Zhang et al., 1995 \\
\hline PR-16 & Gerste OxOLP & $\begin{array}{l}\text { Oxalat Oxidase- } \\
\text { ähnlich }\end{array}$ & Yrp16 & Wei et al., 1998 \\
\hline PR-17 & Tabak PRp27 & unbekannt & Yrp17 & Okushima et al., 2000 \\
\hline
\end{tabular}

\subsection{Extrazelluläre Abwehrreaktionen}

Der apoplastische Raum von Pflanzen ist der extrazelluläre Bereich in dem die wässrige Phase frei diffundieren kann. Dieser Bereich besteht aus einer komplexen Mischung aus Kohlenhydraten, Proteinen, Wasser, anorganischen Komponenten und anderen Metaboliten. Mit dem Apoplasten werden verschiedene Funktionen verbunden, in erster Linie der apoplastische Transport, aber auch Abwehr, Entgiftung, Signalweiterleitung, Zell-Zell Erkennung, Zellstreckung, -adhäsion und -entwicklung (Grignon \& Sentenac 1991; Showalter, 1993; Dietz,1997). Eine bedeutende Rolle spielt der Apoplast bei der pflanzlichen Antwort auf biotischen und abiotischen Stress (Bolwell et al., 2002; Wilkinson \& Davies, 2002; Plöchl et al., 2000). Zum extrazellulären Raum wird außerdem der Xylemsaft gezählt. Der Wassertransport geschieht durch die toten und hohlen Xylemgefäße. In höheren Landpflanzen sind die Xylemsäfte ein wesentliches Transportmedium für die Versorgung der oberirdischen Pflanzenteile mit Wasser, Nährsalzen und anderen Metaboliten (DeBoer \& Volkov 2003). Da Xylemsäfte auch Aminosäuren und Proteine enthalten, bieten sie 
Mikroorganismen eine gute Lebensgrundlage. So wurden im Xylemsaft von Raps beispielsweise 4,8 mM Aminosäuren und 0,06 mM Saccharose gefunden (Zhou, 2000). Die Proteinzusammensetzung in Xylemsäften verschiedener Pflanzen ist weitgehend konserviert, wobei Proteasen, Chitinasen und Peroxidasen besonders häufig vorkommende Proteine sind (Buhtz et al., 2004).

Durch Infektion mit Verticillium Arten werden auch in den Xylemgefäßen verschiedene Abwehrreaktionen aktiviert, z.B. Suberinisierung der Xylemgefäße, Phytoalexin Synthese und Kallosebildung, sowie die Expression von PR-Genen (Dubery \& Slater, 1997; Gold \& Robb 1995; Tjamos \& Beckman 1989). In V. dahliae infizierten Baumwollpflanzen war die Expression von PR-Genen wie Glucanase (PR-2), Chitinase (PR-3) und Ypr10-like (PR-10) hochreguliert (McFadden et al., 2001). In Blattscheiben, die mit Verticillium Zellwandfragmenten behandelt worden waren, konnten höhere Aktivitäten von Chitinasen und 1,3- $\beta$-Glucanase nachgewiesen werden (Dubery \& Slater, 1997). Jedoch scheint die Proliferation des Pilzes im Xylem in keinem festen Zusammenhang mit der Ausbildung von Schadsymptomen zu stehen. So zeigten zum Beispiel Veronese et al. (2003), dass die Besiedelung mit $V$. dahliae in zwei unterschiedlich empfindlichen Ökotypen von Arabidopsis thaliana zunächst ähnlich verlief. Dennoch waren die Verluste an Biomasse und das Ausmaß der Vergilbung im Ökotyp Columbia deutlich stärker als bei C-24. Außerdem wurde durch die Infektion im Vergleich zu mock-inokulierten Kontrollen der Blühzeitpunkt bei Columbia deutlich nach vorne und bei C-24 nach hinten verschoben. Aus diesen Ergebnissen wurde gefolgert, dass die Reaktion der Pflanze auf Verticillium Arten nicht allein durch Pilz-bürtige Signale bedingt wird, sondern auch von der eigenen genetischen Konstitution abhängt (Veronese et al., 2003).

Bei vielen Pflanzen wurde beobachtet, dass Verticillium-Infektionen Thyllenbildung im Xylem auslösen (Benhamou, 1995). Dem Xylem benachbarte Parenchymzellen bilden Ausstülpungen in die Gefäße, durch die der Xylemfluss und damit die Ausbreitung des Pilzes verhindert werden soll (Fradin \& Thomma, 2006). Die Rolle von Thyllenbildung in der Verticillium-Abwehr wurde kontrovers diskutiert, da Thyllen sowohl bei kompatiblen als auch bei nicht kompatiblen Reaktionen vorkommen und häufig erst spät im Infektionsverlauf auftreten, wenn der Pilz sich im Xylem bereits systemisch ausgebreitet hat (Beckman, 1964; Pegg \& Brady, 2002). Die Blockade des Xylems durch die Thyllen und Pilzhyphen könnte zur Symptomausprägung und Welkeerscheinungen der Pflanzen im Krankheitsverlauf beitragen; alternativ dazu wurden vom Pilz ausgehende Signale für die Symptominduktion vorgeschlagen (Pegg \& Brady, 2002). Als potentielles Signalpeptid von Verticillium ist unter anderem ein Glycoprotein diskutiert worden, welches auch in Abwesenheit des Pilzes typische Symptome an Wirtspflanzen hervorrufen kann (Meyer et al., 1994; Nachmias et al., 1987; 1990).

Allgemein wurde in mit pilzlichen Pathogenen infizierten Pflanzen die Akkumulation potentiell antimikrobieller Komponenten, wie PR-Proteinen, Phytoalexinen und phenolischen Verbindungen in Wurzeln und Stämmen beobachtet (Benhamou, 1995; Cooper et al., 1996; Daayf et al., 1997; Williams et al., 2002). Auch im Blattapoplasten konnte schon die Akkumulation potentiell antimikrobieller Proteine beobachtet werden. So wurde beispielsweise im Blattapoplasten von Tomate nach Infektion mit Cladosporium fulvum die 
Bildung der PR-Proteine Chitinase und 1,3- $\beta$-Glucanase gezeigt (Joosten \& De Wit, 1989). Ein Germin-artiges Protein mit Aktivität als Protease-Inhibitor wurde im Blattapoplasten von Weizen nach Infektion mit Septoria tritici nachgewiesen (Segarra et al., 2003). In Reis führte die Infektion mit dem vaskulären Pathogen Xanthomonas oryzae zur Akkumulation einer kationischen Peroxidase im Apoplasten von Mesophyllzellen, in den Zellwänden und Gefäßlumina von Xylemelementen (Young et al., 1995).

Die Proteinzusammensetzung im Xylemsaft von Tomate änderte sich stark durch Infektion mit dem xylem-kolonisierenden Pilz Fusarium oxysporum (Rep et al., 2002). Es traten mit unterschiedlicher zeitlicher Kinetik neue Proteine auf, die neben einem pilz-bürtigen Protein, überwiegend pflanzlichen Ursprungs waren. Mit Hilfe von Massenspektrometrie wurden unter den neu auftauchenden Proteinen eine saure und eine basische Glucanase identifiziert (Rep et al., 2002), die durch Pathogene auch im Blattapoplasten induziert werden (Joosten \& De Wit, 1989). Außerdem wurde ein neues Mitglied der PR-5 Familie identifiziert, das eine hohe Homologie mit basischen, vakuolären Proteinen (auch bekannt als Osmotine) aufweist. Diese xylem-sezernierte Isoform von PR-5 akkumulierte zu einem relativ frühen Zeitpunkt nach Infektion und war das einzige Protein, das in hohen Mengen auch bei inkompatiblen Interaktionen auftrat, während die anderen Proteine erst zu späteren Zeitpunkten und nur bei kompatiblen Interaktionen, begleitend mit dem Auftreten von Krankheitssymptomen akkumulierten (Rep et al. 2002). Anders als im Blattapoplasten pathogen-infizierter Tomaten (Joosten und De Wit, 1989), konnte im Xylemsaft nach F. oxysporum Infektion keine starke Akkumulation der PR-3 Chitinase nachgewiesen werden, sondern diese wurde nur in geringen Mengen mittels Immunodetektion gefunden (Rep et al., 2002). Dies könnte ein Hinweis darauf sein, dass Xylem und Blattapoplast unterschiedlich auf Invasion mit Xylemlokalisierten Pilzen reagieren.

\subsection{Die Funktion von Peroxidasen in der Pathogen-Abwehr}

Peroxidasen kommen in Pflanzen, Tieren, Bakterien und Pilzen vor. Die Superfamilie der Pflanzenperoxidasen besteht aus drei Klassen. Die Klasse I der intrazellulären Peroxidasen beinhaltet die Cytochrom C Peroxidasen aus Hefen bzw. Bakterien, die AscorbatPeroxidasen aus höheren Pflanzen und die bakteriellen bzw. pilzlichen CatalasePeroxidasen. Die Klasse II wird von den sekretorischen pilzlichen Lignin-Peroxidasen und Mangan-abhängigen Peroxidasen gebildet, während die sekretorischen Pflanzenperoxidasen die Klasse III bilden (Hiraga et al., 2001; Welinder et al., 1992).

In Pflanzen spielen also zum einen die intrazellulären Ascorbat-Peroxidasen der Klasse I eine Rolle und zum anderen die klassischen Pflanzenperoxidasen (POX) der Klasse III, die über das Endoplasmatische Retikulum aus der Zelle sekretiert oder in die Vakuole transportiert werden (Hiraga et al., 2001). In Arabidopsis thaliana wurden 73 Volllängen Gene für Klasse III Peroxidasen identifiziert (Welinder et al., 2002), von denen 58 als Transkripte gefunden wurden. Alle Pflanzenperoxidasen haben die gleiche generelle Struktur, bestehend aus einem Häm-Zentrum ( $\mathrm{Fe}^{3+}$ Protoporphyrin IX) und zehn $\alpha$-Helices. Klasse III Peroxidasen enthalten außerdem drei zusätzliche $\alpha$-Helices, einige hochkonservierte Aminosäuren und vier Disulfidbrücken (Passardi et al., 2004, Welinder et al., 2002). POX katalysieren die Reduktion von $\mathrm{H}_{2} \mathrm{O}_{2}$, indem sie Elektronen von 
Donormolekülen wie phenolischen Substanzen, Ligninvorstufen, Auxin oder sekundären Metaboliten übertragen (Hiraga et al., 2001). Die Vielfalt der von POX oxidierbaren Substrate ist der Grund dafür, dass diese Enzyme in einer breiten Palette von physiologischen Prozessen involviert sind (De Gara, 2004). In zahllosen Studien wurde die Rolle der Pflanzenperoxidasen untersucht und es wurden innen unterschiedliche Funktionen zugeschrieben (Passardi et al., 2005), darunter Lignifizierung (Whetten et al., 1998), Suberinisierung (Espelie et al., 1986), Vernetzung von Strukturproteinen der Zellwand (Fry, 1986), Auxin-Katabolismus (Lagrimini et al., 1997), Abwehr gegen Pathogene (Chittoor et al., 1997), Salztoleranz (Amaya et al., 1999) und Seneszenz (Abeles et al., 1988).

Peroxidasen tragen zur indirekten Abwehr von Pathogenen bei. Unter Nutzung von $\mathrm{H}_{2} \mathrm{O}_{2}$ können Peroxidasen aus Monolignolen Phenoxy-Radikale generieren, die dann spontan zu Ligninpolymeren vernetzen. Die Verstärkung von Zellwänden bietet einen Schutz vor dem Eindringen von Pathogenen (Passardi et al., 2004). Abgesehen von der Oxidation von Substraten wurde eine weitere Funktion von Peroxidasen beschrieben: Native Peroxidasen können zu Oxyferroperoxidasen reagieren, was zur Bildung verschiedener reaktiver Sauerstoffspezies (ROS) führt (Passardi et al., 2004). Wie bereits unter 1.3 erwähnt, wirken ROS gegen Pathogene und sind an der Signalweiterleitung beteiligt. Eine weitere Funktion von Peroxidasen in der pflanzlichen Pathogen-Abwehr ist ihre Beteiligung an der Erhöhung der Synthese von Phytoalexinen (Kristensen et al., 1999). Zusammenfassend lässt sich festhalten, dass viele verschiedene Peroxidasen mit unterschiedlichen Funktionen durch Pathogen-Infektion induziert werden (Harrison et al., 1995; Chittoor et al., 1997).

\subsection{Die Funktion von Chitinasen in der Pathogen-Abwehr}

Chitin ist die Hauptkomponente im Exoskelett von Insekten und Crustaceen, sowie in echten Pilzen, kommt aber in Oomyceten nicht vor. Pflanzen besitzen kein Chitin, aber dafür eine große Anzahl an Chitinasen. Anhand ihren Funktionen werden Endo- und Exochitinasen unterschieden. Im folgenden soll nur auf die pflanzlichen Endochitinasen eingegangen werden, welche die Hydrolyse von Chitin, eines $\beta-1,4-H o m o p o l y m e r s ~ v o n ~ N-A c e t y l-D-$ Glucosamin, katalysieren (Cohen-Kupiec \& Chet, 1998). Die Chitinase-Aktivität in Pflanzen erhöht sich stark nach Befall mit Pilzen, Bakterien und Viren (Broekert \& Peumans, 1988; Kombrick et al., 1988; Legrand et al., 1987; Mauch et al., 1984). Chitinasen werden aber nicht nur durch biotischen Stress, sondern auch durch abiotischen Stress induziert, wie z.B. durch Schwermetalle (Rivera-Becerril et al., 2005), Ozon (Schraudner et al., 1992) und UVBestrahlung (Gerhardt et al., 2004). Außerdem spielen Chitinasen eine Rolle in Wachstumsprozessen und Symbiosen (Kasprzewska, 2003).

Viele Proteine mit chitinolytischer Aktivität wurden in Pflanzen beschrieben (Collinge et al., 1993; Hamel et al., 1997). Man findet sie in allen pflanzlichen Organen und Geweben sowohl im Apoplasten als auch in der Vakuole. Gemäß dem Klassifikationssystem der Glycosylhydrolasen, welches auf Sequenzähnlichkeiten der Aminosäuren der katalytischen Domäne basiert, werden Chitinasen in die Glycosylase-Familien 18 und 19 eingeteilt (Henrissat, 1991). Chitinasen der Familie 18 werden in Bakterien, Pilzen, Viren, Pflanzen und Tieren gefunden, während Mitglieder der Familie 19 fast ausschließlich in Pflanzen vorkommen. Höhere Pflanzen synthetisieren sieben verschiedene Klassen von Chitinasen, 
die sich einerseits in ihrer Proteinstruktur und Substratspezifität unterscheiden und andererseits in ihrem Katalysemechanismus und der Sensitivität gegenüber Inhibitoren (Brunner et al., 1998). Die Chitinasen der Klassen III und V gehören zu der Glycosidase Familie 18, während die anderen Chitinase Klassen in die Glycosidase Familie 19 eingeteilt werden (Hamel et al., 1997; Cohen-Kupiec \& Chet, 1998).

Im Hinblick auf ihre Eigenschaften und enzymatischen Aktivitäten in der Pathogenabwehr wurden pflanzliche Chitinasen als PR-Proteine eingestuft (Collinge et al., 1993). Chitinasen gehören zu vier Kategorien von PR-Proteinen. Die Kategorie PR-3 beinhaltet Chitinasen der Klassen Ia, Ib, II, IV, VI und VII. Chitinasen der Klasse III gehören zu den PR-8 Proteinen und Chitinasen der Klasse $V$ gehören zu den PR-11 Proteinen. Außerdem wurden in der Kategorie PR-4 einige chitin-bindende Proteine mit geringer Endochitinase-Aktivität gefunden (Neuhaus et al., 1996; Melchers et al., 1994). Die meisten Klasse la, III und VI Chitinasen haben einen basischen $\mathrm{pH}$-Wert und sind in den Vakuolen lokalisiert. Saure Chitinasen aus den Klassen Ib, II, III, IV und VI werden in den Apoplasten sekretiert (Kasprzewska, 2003).

Chitinasen haben anscheinend eine doppelte Funktion in der Abwehr pilzlicher Pathogene: Apoplastische Chitinasen können Elicitormoleküle im frühen Stadium der Pathogenese aus Hyphen im extrazellulären Raum freisetzen (Collinge et al., 1993; Gerhardt et al., 1997). Die Elicitoren binden an Rezeptoren, die Abwehrmechanismen aktivieren, so dass verstärkt apoplastische und vakuoläre Chitinasen gebildet und sekretiert werden. Die Zunahme der apoplastischen Chitinasen erhöht die Produktion der Elicitoren, was wiederum die Infektionssignale erhöht (Gerhardt et al., 1997). Wenn Hyphen in die Zelle eindringen und dabei den Protoplasten zerstören, treten die vakuolären Chitinasen in Aktion. Sie spalten die neu synthetisierten Chitinketten des Pilzes und unterdrücken so das Pilzwachstum (Collinge et al., 1993). Demnach hätten apoplastische Chitinasen Anteil an der Signalgebung, die Pflanzen über die Pathogenattacke informiert, während die vakuolären Chitinasen das Pathogenwachstum inhibieren. Diese Hypothese wird durch die Substratspezifität der apoplastischen und vakuolären Chitinasen unterstützt. Vakuoläre Chitinasen sind aktiver gegen kristallines Chitin als apoplastische Chitinasen, während die apoplastischen Chitinasen besser lösliches Chitin hydrolysieren (Collinge et al., 1993).

Passarinho und de Vries (2002) identifizierten mit Hilfe von Datenbankrecherchen 24 putative Chitinasen in Arabidopsis. Chitinase-Gene waren auf allen fünf Arabidopsis Chromosomen vorhanden. Alle gefundenen Chitinasen wiesen eine Länge von ungefähr 300 Aminosäuren auf und hatten ein vorausgesagtes Molekulargewicht zwischen 25 und $35 \mathrm{kDa}$. Basierend auf ihren Aminosäuresequenzen wurden alle Arabidopsis Chitinasen als Endochitinasen in fünf Klassen eingeordnet, wobei die Klassen I und III jeweils nur eine Chitinase beinhalten. Bei der Klasse III Chitinase handelt es sich um eine saure extrazellulär lokalisierte Endochitinase (At5g24090) mit einem Molekulargewicht von 33,1 kDa und einer Kettenlänge von 302 Aminosäuren. Eine Promotor-GUS Analyse zeigte, dass das Gen für diese Endochitinase durch Infektion mit dem Pathogen Rhizoctonia solani induziert wurde (Samac und Shah,1991). Chitinasen wurden auch als potentielle Faktoren in der Abwehr gegen V. dahliae beschrieben (Berg et al., 2001; McFadden et al., 2001). Es ist daher naheliegend zu vermuten, dass sie auch bei $V$. longisporum Reaktionen eine Rolle spielen. 


\section{ZIELE}

Das Hauptziel dieser Arbeit war die Untersuchung des extrazellulären Proteoms von Brassica napus und Arabidopsis thaliana unter Einfluss von Verticillium longisporum in Relation zur Ausprägung von Krankheitssymptomen.

Dazu mussten zunächst einige methodische Grundlagen, wie die Etablierung des Infektionssystems mit replizierbaren Infektionsverläufen, geschaffen werden. Die Gewinnung von Xylemsäften und apoplastischen Waschflüssigkeiten, verbunden mit der Minimierung der Kontamination durch symplastische Proteine, sollte optimiert werden. Weiterhin musste die Replizierbarkeit der Proteingele gegeben sein, um deren Auswertung mit einer speziellen Software zu ermöglichen.

Aufbauend auf diesen Grundlagen sollten die Verticillium longisporum bedingten Schäden an den Pflanzen Brassica napus und Arabidopsis thaliana umfassend charakterisiert und in Relation zur Ausbreitung des Pilzes gesetzt werden. Dafür wurden verschiedene ökophysiologische Parameter an Verticillium longisporum infizierten Pflanzen im Vergleich zu Kontrollpflanzen betrachtet. Dies sollte den Vergleich zweier Arabidopsis thaliana Ökotypen hinsichtlich ihrer Empfindlichkeit gegenüber Verticillium longisporum und die Auswahl geeigneter Anzuchtbedingungen für die Proteomanalysen beinhalten. Da im Zusammenhang mit Verticillium-Infektionen das verstärkte Auftreten von Chitinasen beschrieben wurde, war ein weiteres Ziel dieser Arbeit eine saure Endochitinase aus Arabidopsis thaliana funktionell zu charakterisieren. Dazu sollte eine Chitinase T-DNA Insertionsmutante aus Arabidopsis thaliana unter Einfluss von Verticillium longisporum untersucht werden.

Für die Proteomanalysen wurde ein geeigneter Zeitpunkt ermittelt zu dem differentiell auftretende Proteine im Xylemsaft und Blattapoplasten von Verticillium-infizierten Pflanzen durch Massenspektrometrie identifiziert werden sollten. Dabei diente Raps als Beispiel für eine landwirtschaftlich bedeutsame Pflanze, während die Modellpflanze Arabidopsis thaliana besonders als Plattform für molekulare Analysen herangezogen wurde. Ein weiteres Ziel war durch Verticillium-Infektion differentiell auftretende Proteine im Infektionsverlauf mittels Genexpressionsanalysen näher zu charakterisieren. 


\section{MATERIAL \& METHODEN}

\subsection{Chemikalien}

Alle Puffer und Lösungen wurden mit demineralisiertes Wasser $\left(\mathrm{dd} \mathrm{H}_{2} \mathrm{O}\right)$ aus dem Gerät Sartorius Arium 611 (Sartorius, Göttingen) angesetzt. Wenn nicht anders angegeben, wurden die Chemikalien bei der Firma Merck (Darmstadt) bezogen.

Aceton

Acetonitril

Acrylamid (30\%)

Agarose Seakem LE

Agarose (low melting point)

Ammoniumbicarbonat

Ammoniumpersulfat (APS)

$\beta$-Mercaptoethanol

BCA

CHAPS

Coomassie Brilliant Blue G250

CTAB

dNTPs

Dry-Strip cover fluid

DTT

EDTA

Ethanol

Ethidiumbromid

Fe-EDTA Natriumsalz

Formaldehyd (37\%)

Gelrite

Guajakol

Harnstoff

Inosit

lodoacetamid

IPG-Puffer

Isopropanol

Methanol

MOPS

Oxalessigsäure

Potato Dextrose Agar

Potato Dextrose Broth

Phosphorsäure

PVPP, unlöslich

PVPP, löslich, MW 30000

Saccharose

Schwefelsäure (96 \%)

SDS

Silbernitrat

TEMED

Triton X-100

Trypsin
AppliChem, Darmstadt

Fisher Scientific, Loughborough, GB

Biomol, Hamburg

Cambrex Bio Science, Rockland, USA

Amersham Biosciences, Uppsala, Schweden

Sigma-Aldrich, Steinheim

Sigma-Aldrich, Steinheim

Roth, Karlsruhe

Uptima, Montelucon, Frankreich

Fluka, Buchs, Schweiz

Serva, Heidelberg

Roth, Karlsruhe

MBI Fermentas, St.Leon-Rot

Amersham Biosciences, Uppsala, Schweden

Fluka, Buchs, Schweiz

Fluka, Buchs, Schweiz

GeReSO mbH, Einbeck

Roth, Karlsruhe

Sigma-Aldrich, Steinheim

Fluka, Buchs, Schweiz

Duchefa Biochemie, Haarlem, Niederlande

Fluka, Buchs, Schweiz

KMF, Lohmar

Serva, Heidelberg

Fluka, Buchs, Schweiz

Amersham Biosciences, Uppsala, Schweden

Roth, Karlsruhe

KMF, Lohmar

Sigma-Aldrich, Steinheim

ICN Biomedicals, Aurora, USA

Scharlau, Barcelona, Spanien

Scharlau, Barcelona, Spanien

KMF, Lohmar

Sigma-Aldrich, Steinheim

Sigma-Aldrich, Steinheim

Roth, Karlsruhe

Roth, Karlsruhe

Sigma-Aldrich, Steinheim

Fluka, Buchs, Schweiz

Serva, Heidelberg

Serva, Heidelberg

Promega, Madison WI, USA 


\subsection{Pflanzenanzucht und Inokulation mit Verticillium longisporum}

\subsubsection{Anzucht von Arabidopsis thaliana und Inokulation}

Zunächst wurden die Samen von Arabidopsis thaliana in einem 1,5 ml Gefäß sterilisiert. Unter der Sterilbank wurde eine kleine Menge Samen in $1 \mathrm{ml} 5 \%$ Calciumhypochlorid $\left(\mathrm{Ca}(\mathrm{OCl})_{2}\right) / 0,02 \%$ Triton $\mathrm{X}-100$ für mindestens 15 min inkubiert und anschließend dreimal mit sterilem dd $\mathrm{H}_{2} \mathrm{O}$ gewaschen. Einzelne Samen wurden dann mit einer sterilen Impföse oder Pipettenspitze aufgenommen und steril auf Wurzelmedium (Tab. 3.1; verändert nach Murashige \& Skoog, 1962) ausgelegt. Wenn nicht anders angegeben wurden die Arabidopsis-Samen in den Schalen mit Wurzelmedium nach drei Tagen Kältereiz bei $4{ }^{\circ} \mathrm{C}$ im Kühlschrank, in einen Klimaschrank (AR-75L, Percival Scientific, Perry, USA) überführt und für vier Wochen bei $20{ }^{\circ} \mathrm{C}, 60 \%$ Luftfeuchtigkeit und 8 Stunden Licht/16 Stunden Dunkel Zyklus wachsen gelassen. Die Lichtintensität im Klimaschrank betrug $120 \mu \mathrm{mol} /\left(\mathrm{m}^{-2} \mathrm{~s}^{-1}\right)$.

Tab. 3.1: Zusammensetzung des Wurzelmediums. Die Stamm-Lösungen wurden separat angesetzt und bei $4{ }^{\circ} \mathrm{C}$ gelagert. Für $1 \mathrm{~L}$ Wurzelmedium wurden von den Stamm-Lösungen $100 \mathrm{ml}$ Makroelemente, $1 \mathrm{ml}$ Mikroelemente, $1 \mathrm{ml}$ Vitamine und die anderen Zusätze wie in der Tabelle angegeben gemischt. Vor der Zugabe des Gelrites wurde der pH-Wert mit $\mathrm{NaOH}$ auf 5,8 eingestellt, anschließend wurde das vollständige Medium autoklaviert.

\begin{tabular}{lcc}
\hline & $\begin{array}{c}\text { Konzentration in der } \\
\text { Stamm-Lösung }\end{array}$ & Endkonzentration \\
\hline Stamm 1: Makroelemente & $250 \mathrm{mM}$ & $25 \mathrm{mM}$ \\
$\mathrm{KNO}_{3}$ & $13,7 \mathrm{mM}$ & $1,4 \mathrm{mM}$ \\
$\mathrm{CaCl}_{2} \times 2 \mathrm{H}_{2} \mathrm{O}$ & $16 \mathrm{mM}$ & $1,6 \mathrm{mM}$ \\
$\mathrm{MgSO}_{4} \times 7 \mathrm{H}_{2} \mathrm{O}$ & $26 \mathrm{mM}$ & $2,6 \mathrm{mM}$ \\
$\mathrm{NH}_{4} \mathrm{H}_{2} \mathrm{PO}_{4}$ & & \\
$\mathrm{Stamm}_{2}:$ Mikroelemente & $5 \mathrm{mM}$ & $5 \mu \mathrm{M}$ \\
$\mathrm{H}_{3} \mathrm{BO}_{3}$ & $6 \mathrm{mM}$ & $6 \mu \mathrm{M}$ \\
$\mathrm{MnSO}_{4} \times 7 \mathrm{H}_{2} \mathrm{O}$ & $1 \mathrm{mM}$ & $1 \mu \mathrm{M}$ \\
$\mathrm{ZnSO}_{4} \times 7 \mathrm{H}_{2} \mathrm{O}$ & $0,5 \mathrm{mM}$ & $0,5 \mu \mathrm{M}$ \\
$\mathrm{KJ}$ & $0,1 \mathrm{mM}$ & $0,1 \mu \mathrm{M}$ \\
$\mathrm{Na}_{2} \mathrm{MoO}_{4}$ & $0,1 \mathrm{mM}$ & $0,1 \mu \mathrm{M}$ \\
$\mathrm{CoCl}_{2} \times 6 \mathrm{H}_{2} \mathrm{O}$ & $0,1 \mathrm{mM}$ & $0,1 \mu \mathrm{M}$ \\
$\mathrm{CuSO}_{4} \times 5 \mathrm{H} \mathrm{H}_{2} \mathrm{O}$ & & \\
Stamm 3: Vitamine & $4 \mathrm{mM}$ & $4 \mu \mathrm{M}$ \\
Nicotinsäure & $2,4 \mathrm{mM}$ & $2,4 \mu \mathrm{M}$ \\
Pyridoxin-HCl & $0,3 \mathrm{mM}$ & $0,3 \mu \mathrm{M}$ \\
Thiamin-HCl $\mathrm{HCl}$ & \\
Andere Zusätze & $2 \mathrm{~g} / \mathrm{L}$ & $1 \mathrm{ml} \mathrm{Stock/L}$ \\
Glycin & $20 \mathrm{~g} / \mathrm{L}$ & $5 \mathrm{ml} \mathrm{Stock/L}$ \\
Inosit & $7,34 \mathrm{~g} / \mathrm{L}$ & $5 \mathrm{ml} \mathrm{Stock/L}$ \\
EDTA-Eisen (III)-Natriumsalz & & $25 \mathrm{~g} / \mathrm{L}$ \\
Saccharose & & $2,8 \mathrm{~g} / \mathrm{L}$ \\
Gelrite & & \\
\hline
\end{tabular}

Die Verticillium longisporum bzw. mock-Inokulation wurde beim Einpflanzen der Arabidopsis

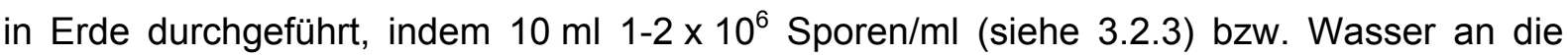
Wurzeln der Pflanzen gespritzt wurden. Dafür war von den Wurzeln vorher ca. $1 \mathrm{~cm}$ mit einer Schere abgeschnitten worden. Nach Einpflanzen und Inokulation wuchsen die Pflanzen bei 
$20{ }^{\circ} \mathrm{C}, 60 \%$ Luftfeuchtigkeit und $8 \mathrm{~h}$ Licht/16 h Dunkel Zyklus in dem Klimaschrank weiter. Einmal pro Woche wurden die Pflanzen mit je $10 \mathrm{ml}$ Wuxal (Aglucon, Düsseldorf; $500 \mu \mathrm{l} / \mathrm{L}$ Leitungswasser) gedüngt.
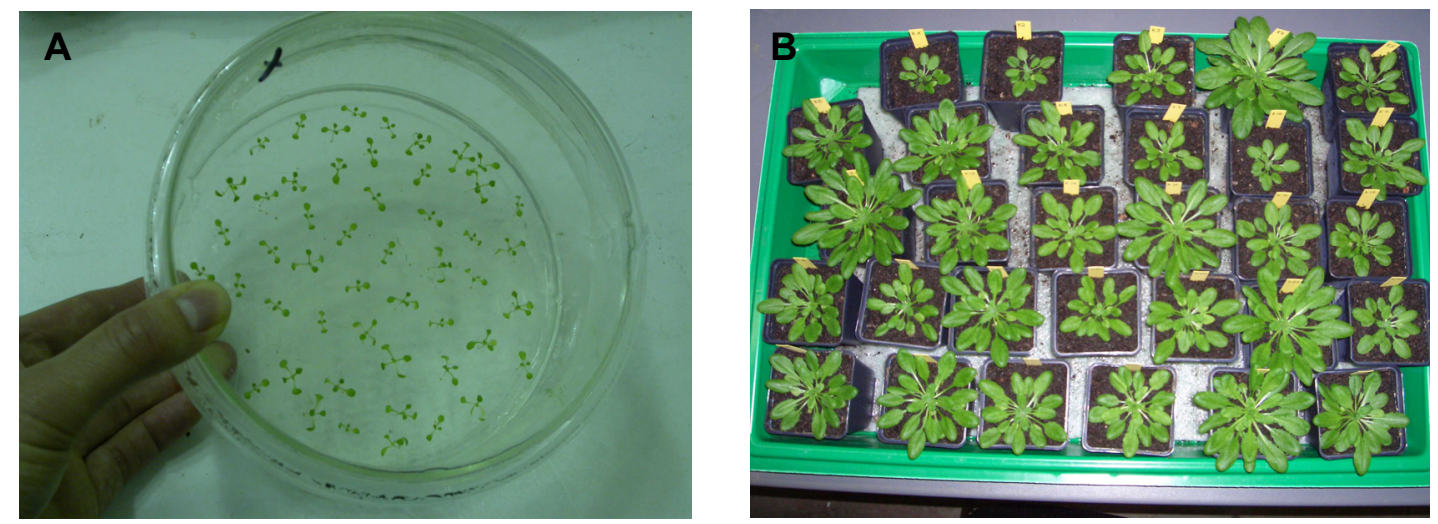

Abb. 3.1: Die Anzucht von Arabidopsis erfolgte zunächst auf Wurzelmedium (A), nach der Inokulation mit Verticillium longisporum in Erde (B).

\subsubsection{Anzuchtbedingungen für Raps und Inokulation}

Die Anzucht von Brassica napus (rapid cycle rape) erfolgte zunächst für zwei Wochen steril auf Wurzelmedium (Tab. 3.1). Die Sterilisation der Samen wurde wie für Arabidopsis unter 3.2.1 beschrieben durchgeführt. Danach wurde der Raps in ein 1:1 Erde/Sand-Gemisch gepflanzt und mit Verticillium longisporum inokuliert. Für die Inokulation wurden $10 \mathrm{ml}$ Sporensuspension (siehe 3.2.3) mit einer Konzentration von $2 \times 10^{6} / \mathrm{ml}$ direkt in das Erde/Sand-Gemisch zu vorher angeschnittenen Wurzeln gespritzt. Der Raps wuchs in einer Klimakammmer bei $20^{\circ} \mathrm{C}, 60 \%$ Luftfeuchtigkeit und $16 \mathrm{~h}$ Licht/8 h Dunkel Zyklus bei einer Lichtintensität von $200 \mu \mathrm{mol} /\left(\mathrm{m}^{-2} \mathrm{~s}^{-1}\right)$. Nach der Inokulation wurde der Raps wöchentlich mit $10 \mathrm{ml}$ Dünger pro Pflanze gedüngt (10 g/L Flory Basisdünger der Firma Euflor in München und $2,2 \mathrm{~g} \mathrm{NH}_{4} \mathrm{NO}_{3} / \mathrm{L}$ Leitungswasser).

\subsubsection{Vorbereitung von Verticillium longisporum für die Inokulation}

Verticillium longisporum (Stamm VL43 aus Brassica napus; zur Verfügung gestellt von der AG von Tiedemann, Department für Nutzpflanzenwissenschaften in Göttingen) wurde standardmäßig auf Potato Dextrose Agar (Scharlau, Barcelona, Spanien) angezogen und als Glycerinkultur bei $-20^{\circ} \mathrm{C}$ gelagert. Zur Vermehrung für die Inokulation wurden 3-4 Stanzen mit einem sterilen Korkbohrer (Durchmesser 0,8 cm) von den Agarplatten in $250 \mathrm{ml}$ flüssiges Potato Dextrose Medium (Scharlau, Barcelona, Spanien) mit 0,2 $\mu \mathrm{g} / \mathrm{ml}$ Streptomycin (Sigma, Steinheim) überführt. Unter leichtem horizontalem Schütteln bei $80 \mathrm{rpm}$ (G10 Gyrotory Shaker, New Brunswick Scientific, New Brunswick, USA) wuchsen die Kulturen für 2-3 Wochen bei $22{ }^{\circ} \mathrm{C}$ im Dunkeln wie bei Fahleson et al. (2003) beschrieben. Zur Pilzernte wurde die Suspension durch ein Sieb gegeben um das Myzel zu entfernen und nur die Sporen zu erhalten. Um die gewonnenen Sporen von Medium zu befreien, wurde die Sporensuspension anschließend in $50 \mathrm{ml}$ Röhrchen bei $900 \mathrm{xg}$ (Rotanta $96 \mathrm{R}$, Hettich, Tuttlingen) für 10 min zentrifugiert, der Überstand vollständig abgegossen und die Sporen in Leitungswasser aufgenommen. Die Anzahl der Sporen in der erhaltenen Suspension wurde 
mit Hilfe einer Thoma-Zählkammer bestimmt. Hierfür wurde die Sporenzahl in 16 Kleinquadraten gezählt und mit der Fläche $\left(0,04 \mathrm{~mm}^{2}\right)$ und Höhe $(0,1 \mathrm{~mm})$ multipliziert um Sporenzahl pro $\mu \mathrm{l}$ zu erhalten. Die Zellzahl wurde dann für die Inokulation mit Leitungswasser auf $1-2 \times 10^{6}$ Sporen/ml eingestellt.

\section{3 Ökophysiologische Methoden}

\subsubsection{Messung der Chlorophyllfluoreszenz}

Das Prinzip der Chlorophyllfluoreszenzanalyse beruht darauf, dass Lichtenergie von den Chlorophyllmolekülen in Blättern absorbiert wird und dann einen von drei verschiedenen Wegen gehen kann. Erstens kann sie für die Photosynthese genutzt werden, zweitens kann sie als Wärme verloren gehen oder drittens als Licht-Chlorophyllfluoreszenz wieder abgestrahlt werden. Da diese drei Prozesse in Konkurrenz zueinander stehen, bedeutet eine Änderung der Effizienz des einen auch eine Änderung der anderen beiden. So können durch Änderungen der Chlorophyllfluoreszenz Rückschlüsse auf die Aktivität der Photosynthese gezogen werden (Maxwell und Johnson 2000). Die Chlorophyllfluoreszenz wurde mit Hilfe des MINI-PAM Gerätes der Firma Walz (Effeltrich, Deutschland) an Blättern von Arabidopsis thaliana und Raps gemessen. Das Prinzip der Messung beruht darauf, dass ein kurzer, starker Lichtimpuls über eine Diode auf das Blatt appliziert wird. Bevor das Licht auf das Blatt trifft, wird es über einen Filter modifiziert, der Licht mit einer Wellenlänge von $\lambda<670 \mathrm{~nm}$ durchlässt. Der Lichtimpuls erzeugt im Blatt die Emission von Chlorophyllfluoreszenz. Das emittierte Signal wird durch zwei Filter, die Licht von einer Wellenlänge von $\lambda>700 \mathrm{~nm}$, aber keine Wärmestrahlung durchlassen, herausgefiltert, verstärkt und über einen Detektor gemessen (Betriebsanleitung Walz).

Die folgenden Parameter wurden gemessen: die maximale Fluoreszenz $\left(F_{m}\right)$, die Grundfluoreszenz $\left(F_{0}\right)$ und die aus der Differenz resultierte variable Fluoreszenz $\left(F_{v}=F_{m}-F_{0}\right)$. Dabei wurde unterschieden, ob die Messung der Chlorophyllfluoreszenz im Licht oder im Dunkeln erfolgte. Im Dunkeln sind alle Reaktionszentren offen. Ein sättigender Lichtimpuls führt zum sofortigen Schließen der Reaktionszentren und zur maximalen Chlorophyllfluoreszenzemission, die durch den zeitlich versetzt erfolgten Weitertransport der Energie über die Elektronentransportkette bald wieder gelöscht wird. Mit den Fluoreszenzwerten kann die maximale photosynthetische Aktivität, auch als maximale Quantenausbeute vom Photosystem II oder kurz als „Yield“ bezeichnet, berechnet werden.

Yield $=\left(F_{m}-F_{0}\right) / F_{m}=F_{v} / F_{m}$

(Kitajima and Butler 1975, Rohacek 2002)

Im Licht sind die Fluoreszenzwerte geringer und werden entsprechend mit $F_{m}$ ' und $F_{t}$ (Steady State Fluoreszenz) bezeichnet (Maxwell und Johnson 2000). Die sich daraus ergebene aktuelle Quantenausbeute wird mit $\Phi$ II bezeichnet und analog zur obigen berechnet:

$$
\Phi I I=\left(F_{m}^{\prime}-F_{t}\right) / F_{m}^{\prime} \text { (Maxwell und Johnson 2000). }
$$




\subsubsection{Messung der Elektrolytleitfähigkeit}

Elektrolyte kommen innerhalb der Zellmembranen von Pflanzenzellen vor. Diese Membranen sind sensitiv für Umweltstress, das heißt die Permeabilität der Membranen erhöht sich durch Stress (Campos et al., 2003). Ungestresste, unversehrte Pflanzen behalten die Elektrolyte innerhalb der Membran, während Zellen die Stress ausgesetzt sind Elektrolyte in die Umgebung abgeben. Eine Bestimmung von Membranschäden kann durch den Vergleich der Leitfähigkeit von ausgetretenen Elektrolyten aus beschädigten und unbeschädigten Geweben in demineralisiertem Wasser erfolgen (Mattson, 1996; McNabb \& Takahashi, 2000). Die Messung der Elektrolytleitfähigkeit (Electrolyte leakage) wurde nach Polle et al. (2001) modifiziert. Dazu wurden frische Blätter von Arabidopsis bzw. Raps geerntet und mit einem Korkbohrer ca. 25 Blattscheiben ausgestochen und in ein $50 \mathrm{ml}$ Reaktionsgefäß eingewogen; dann wurden $20 \mathrm{ml} \mathrm{dd} \mathrm{H}_{2} \mathrm{O}$ zugegeben. Die Leitfähigkeit in der Flüssigkeit $\left(\mathrm{L}_{0}\right)$ wurde nach 10 min mit einem Konduktometer (Model LF 315/SET, WTW, Wissenschaftliche Technik, Weilheim) gemessen, um den Anteil der Elektrolyte zu bestimmen, die durch die gestanzten Ränder ausgetreten waren. Die Proben wurden $24 \mathrm{~h}$ bei Raumtemperatur inkubiert und anschließend wurde die Leitfähigkeit $\left(L_{t}\right)$ erneut gemessen. Um die maximale Leitfähigkeit $\left(L_{\max }\right)$ zu bestimmen, wurden die Proben autoklaviert ( 5 min bei $121^{\circ} \mathrm{C}$ ) und nach dem Abkühlen auf Raumtemperatur erneut gemessen. Der prozentuale Anteil der in 24 Stunden ausgetretenen Elektrolyte $(E L)$ wurde nach der folgenden Gleichung berechnet:

$$
\operatorname{EL}(\%)=\left[\left(L_{t}-L_{0}\right) / L_{\max }\right] * 100
$$

\subsubsection{Bestimmung des osmotischen Drucks}

Für die Messung des osmotischen Drucks wurden ca. $0,5 \mathrm{~g}$ unter flüssigem Stickstoff pulverisiertes Blattmaterial in 1,5 ml Reaktionsgefäße eingewogen (Frischmasse, FM), gefriergetrocknet und anschließend das Trockenmasse (TM) bestimmt. Danach wurde als Lösungsmittel (LM) pro Probe $1 \mathrm{ml}$ demineralisiertes Wasser zugegeben, gemischt und $25 \mathrm{~min}$ bei $900 \times \mathrm{g}$ bei Raumtemperatur zentrifugiert. Vom Überstand wurden $50 \mu$ l blasenfrei in ein $0,5 \mathrm{ml}$ Reaktionsgefäß gefüllt und am Kryo-Osmometer (Osmomat 030, Ganotec, Berlin) gemessen (OS). Die Osmolarität bzw. Osmolalität und der osmotische Druck wurde nach folgenden Gleichungen berechnet:

Osmolalität $($ osmol $/ \mathrm{kg})=$ gemessene OS $(\mathrm{osmol} / \mathrm{kg}){ }^{*}$ Verdünnung

Osmotischer Druck (MPa) $=$ Osmolalität ${ }^{*} \mathrm{R} * \mathrm{~T}$

Wobei $\mathrm{R}=$ Gaskonstante $\left(0,00831 \mathrm{~L}^{*} \mathrm{MPa}^{*} \mathrm{~mol}^{-1 *} \mathrm{~K}^{-1}\right) ; \mathrm{T}=$ Temperatur $=295 \mathrm{~K}$ Verdünnung $=\mathrm{LM}(\mathrm{ml}) /$ Wasseranteil des Blattmaterials $(\mathrm{FM}-\mathrm{TM}(\mathrm{ml}))$

\subsubsection{Bestimmung des Chlorophyllgehaltes}

Für die Bestimmung des Chlorophyllgehaltes wurde Blattmaterial unter flüssigem Stickstoff pulverisiert. Von dem gefrorenem Pulver wurden ca. $30 \mathrm{mg}$ in ein Zentrifugenröhrchen aus Glas eingewogen, die Einwaage wurde notiert und pro Röhrchen wurden $5 \mathrm{ml} 80$ \%iges Aceton zugegeben. Die Proben wurden gut gemischt und anschließend 20 min im Dunkeln 
auf Eis inkubiert. Danach wurden die Röhrchen 15 min bei $4890 \times \mathrm{g}$ und $4{ }^{\circ} \mathrm{C}$ zentrifugiert und der Chlorophyllgehalt im Überstand photometrisch bei den Wellenlängen 663 und $646 \mathrm{~nm}$ bestimmt (Beckman DU 640, Beckman Coulter $\mathrm{GmbH}$, Krefeld, Deutschland).

Die Chlorophyllkonzentration wurde nach Lichtenthaler und Wellburn (1983) berechnet:

Chl a $(\mu \mathrm{g} / \mathrm{ml}$ Extrakt $)=12,21{ }^{*} \mathrm{~A}_{663}-2,81{ }^{*} \mathrm{~A}_{646}$

Chl b $(\mu \mathrm{g} / \mathrm{ml}$ Extrakt $)=20,13{ }^{*} A_{646}-5,03{ }^{*} A_{663}$

Die Chlorophyllgehalte wurden mit folgenden Formeln bestimmt:

$\mathrm{Chl} \mathrm{a}(\mu \mathrm{g} / \mathrm{g} \mathrm{FM})=\mathrm{Chl}$ a $(\mu \mathrm{g} / \mathrm{ml}$ Extrakt $){ }^{*} \mathrm{~V}_{\mathrm{e}}(\mathrm{ml}) / \mathrm{FM}$

$\mathrm{Chl} \mathrm{b}(\mu \mathrm{g} / \mathrm{g} F M)=\mathrm{Chl} b(\mu \mathrm{g} / \mathrm{ml}$ Extrakt $){ }^{*} \mathrm{~V}_{\mathrm{e}}(\mathrm{ml}) / \mathrm{FM}$

$$
\text { Wobei: } \begin{aligned}
\mathrm{A}_{663} & =\text { Absorption bei } \lambda=663 \mathrm{~nm} \\
\mathrm{~A}_{646} & =\text { Absorption bei } \lambda=646 \mathrm{~nm} \\
\mathrm{~V}_{\mathrm{e}} & =\text { Volumen der Extraktion }(5 \mathrm{ml}) \\
\mathrm{FM} & =\text { eingewogene Frischmasse }
\end{aligned}
$$

\subsubsection{Messung der Photosyntheserate}

Zwischen der Pflanze und der Umgebung findet ein Austausch von Gasen statt, den man als Gaswechsel bezeichnet. Die Gase denen die größte Bedeutung zukommt sind Kohlendioxid $\left(\mathrm{CO}_{2}\right)$, Sauerstoff $\left(\mathrm{O}_{2}\right)$ und Wasserdampf $\left(\mathrm{H}_{2} \mathrm{O}\right)$. Der Austausch von Kohlendioxid und Sauerstoff ist an primäre Prozesse der Photosynthese gekoppelt, während die Wasserdampfabgabe eine wichtige Rolle für den Wasserhaushalt der Pflanze spielt. Die Photosyntheserate und die Transpiration wurde mit Hilfe des Photosynthese Systems HCM 1000 der Firma Walz (Effeltrich, Deutschland) nach Herstellerangaben gemessen. Dafür wurde das zu untersuchende Blatt in eine Luft-durchströmte Küvette eingespannt. Die aus der Küvette austretende Luft unterscheidet sich durch die $\mathrm{H}_{2} \mathrm{O}$-Abgabe und $\mathrm{CO}_{2}$-Aufnahme des Blattes von der einströmenden Luft. Durch einen Infrarot-Gasanalysator (IRGA) wurden die $\mathrm{H}_{2} \mathrm{O}$ und $\mathrm{CO}_{2}$ Konzentration gemessen und anhand der Differenz in der einströmenden und austretenden Luft konnten die Photosyntheserate und Transpiration berechnet werden. Mit Hilfe eines Beleuchtungsaufsatzes wurde das zu untersuchende Blatt während der Messung mit einer konstanten Lichtintensität von $800 \mu \mathrm{mol} /\left(\mathrm{m}^{-2} \mathrm{~s}^{-1}\right)$ bestrahlt.

\subsubsection{Blattflächenmessung bei Arabidopsis thaliana}

Zur Messung der projizierten Blattfläche der Rosetten von Arabidopsis thaliana wurden die Pflanzen nach mock bzw. Verticillium-Inokulation zweimal wöchentlich fotografiert (DigitalKamera QV R52) und mittels einer speziell entwickelten Software (DatInf GmbH, Tübingen) analysiert. Die Diagonale des Topfes diente als Maßstab und betrug für die verwendeten Töpfe $91 \mathrm{~mm}$. So konnte direkt über die Pixelzahl die sichtbare Gesamtrosettenfläche einer Pflanze berechnet werden. 


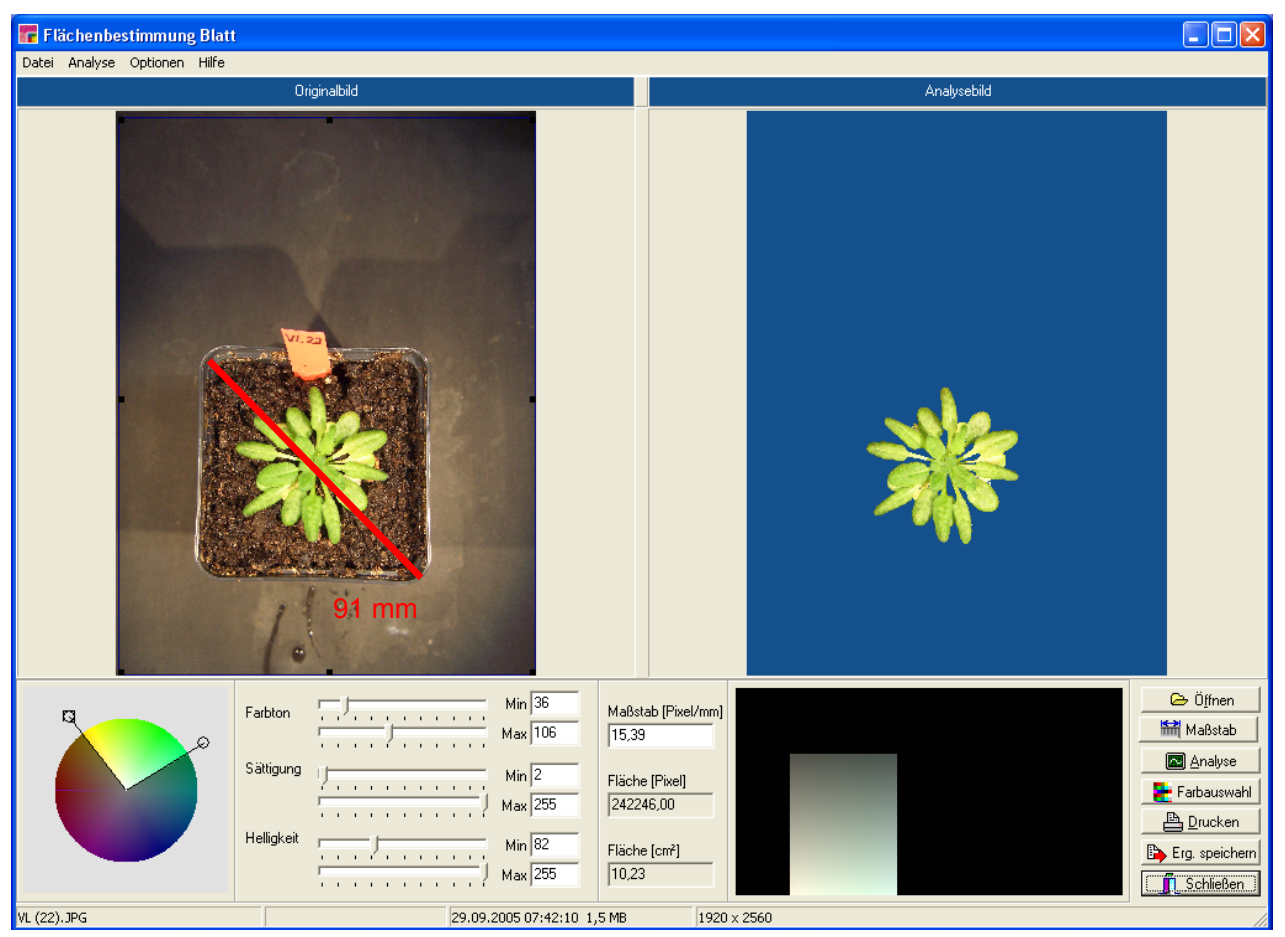

Abb. 3.2: Screenshot des Programms zur Blattflächenauswertung. Links das Foto einer Verticilliuminfizierten Arabidopsis Pflanze. Die Topfdiagonale, hier in rot, diente als Maßstab. Rechts ist das mit Hilfe der Software analysierte Bild zu sehen. Farbton, Helligkeit und Sättigung konnten so eingestellt werden, dass die gesamte Rosette, nicht jedoch die Erde etc. erfasst wurde.

\subsubsection{C/N Analyse}

Gefrorene Blattproben von Arabidopsis wurden unter flüssigem Stickstoff in einer Mühle (Typ MM 2, Retsch, Haan) zu feinem Pulver gemahlen und anschließend gefriergetrocknet. Der $\mathrm{C} / \mathrm{N}-$ Gehalt wurde mit Hilfe eines Elemental Analyser EA-1108 (Carlo Erba Instruments, Rodano, Italien) bestimmt. Zur Analyse wurden ca. 0,8 mg getrocknetes Blattpulver in eine Zinnkapsel (HEKAtech GmbH, Wegberg) eingewogen, wobei das genaue Gewicht jeweils protokolliert und bei der späteren Berechnung der Stoffkonzentration berücksichtigt wurde. Dann wurden die Proben in einen Probenteller des Elementanalysators gegeben. Zur Messung fallen die Proben in ein Verbrennungsrohr, wo sie bei $1020{ }^{\circ} \mathrm{C}$ verbrannt werden. Der im Verbrennungsrohr befindliche Oxidationskatalysator (Chrom-III-Oxid) spaltet die in der Probe vorhandenen Stoffe unter Zugabe von Sauerstoff auf, wobei $\mathrm{N}_{2}, \mathrm{CO}_{2}$ und $\mathrm{H}_{2} \mathrm{O}$ reduziert werden, während im Verbrennungsrohr befindliches reduziertes Kupfer oxidiert wird. Diese Produkte werden anschließend chromatographisch getrennt. Ein an die Säule angeschlossener Wärmeleitfähigkeitsdetektor gibt elektrische Signale der aufgetrennten Elemente an einen Integrator weiter. Der Integrator erzeugt je nach Stärke der empfangenen Signale unterschiedliche hohe Peaks. Anhand der Flächen unter den Peaks wurden die Konzentration von Stickstoff und Kohlenstoff mit Hilfe der Standardsubstanz Acetanilid ( $\mathrm{C}_{8} \mathrm{H}_{9} \mathrm{NO}$, HEKAtech $\mathrm{GmbH}$, Wegberg) berechnet. 


\subsubsection{Optische ICP-Emissionsspektrometrie zur Elementanalyse}

Die ICP-OES (inductively coupled plasma - optical emission spectrometry) dient zur quantitativen Analyse von Elementen in wässrigen Lösungen. Die Methode beruht auf der Verwendung eines sehr heißen (ca. $8000^{\circ} \mathrm{C}$ ) Argonplasmas zur Anregung der optischen Emission der zu analysierenden Elemente. Die ICP-OES Messungen wurden in einem ICPSpektrometer (Spectroflame, Spectro Analytical Instuments, Kleve, Deutschland) durchgeführt, indem die Proben als Aerosol durch eine Argon-Plasmaflamme geleitet wurden. Wenn die austretenden Atome in ihren niedrigen Energiezustand zurückkehren, werden die spezifischen Spektren emittiert, die auch quantifiziert werden können. Für die Elementanalyse wurden $50 \mathrm{mg}$ pulverisiertes, getrocknetes Blattmaterial mit $2 \mathrm{ml}$ einer $65 \%$ igen $\mathrm{HNO}_{3}$-Lösung versetzt und in einem Drucksystem (PDS-6; Loftfield's Analytical Solutions) bei $140^{\circ} \mathrm{C}$ nach Heinrichs et al. (1986) aufgeschlossen. Nach Abkühlen auf Raumtemperatur wurden die Proben mit dd $\mathrm{H}_{2} \mathrm{O}$ auf $25 \mathrm{ml}$ aufgefüllt im ICP-Spektrometer analysiert.

\subsubsection{Extraktion von Zellwänden}

Für die Extraktion von Zellwandmaterial wurden $200 \mathrm{mg}$ gefrorenes Blattpulver mit $1,5 \mathrm{ml}$ $100 \mathrm{mM}$ KPP/0,5\% Triton X-100 (pH 7,8) gut gemischt und 30 min bei Raumtemperatur geschüttelt. Danach wurden die Proben 10 min bei $14000 \mathrm{xg}$ zentrifugiert, der Überstand wurde verworfen. Das Pellet wurde noch einmal mit $100 \mathrm{mM}$ KPP/0,5\% Triton X-100 (pH 7,8) gewaschen, worauf ein Waschschritt mit 1,5 ml Methanol folgte. Das erhaltene Zellwandmaterial wurde bei $70{ }^{\circ} \mathrm{C}$ getrocknet und konnte anschließend bei Raumtemperatur bis zur weiteren Analyse gelagert werden.

\subsubsection{FTIR (Fourier-Transmissions-Infrarot) Spektrometrie}

Durch FTIR-Analyse kann die chemische Zusammensetzung organischer Präparate untersucht werden. Das Messprinzip beruht auf der Tatsache, dass Infrarotstrahlung von Molekülbindungen wie $\mathrm{C}-\mathrm{H}, \mathrm{O}-\mathrm{H}, \mathrm{N}-\mathrm{H}, \mathrm{C}=\mathrm{O}, \mathrm{C}-\mathrm{C}$ etc. absorbiert wird. Diese absorbierte Energie führt zu charakteristischen Veränderungen der Bindungen, die spezifische Transmissions- und Reflektionsmuster hervorrufen (Chalmers \& Griffiths, 2002; Günzler \& Gremlich, 2002). FTIR Transmissions Spektren von Arabidopsis Blattmaterial wurden mit einem FTIR-Spektrometer Equinox 55 (Bruker Optics, Ettlingen, Germany) mit einer ATREinheit (attenuated total reflectance unit) gemessen. Die Spektren wurden aus 32 scans im Wellenlängenbereich von 600-4200 $\mathrm{cm}^{-1}$ wie in Naumann et al. (2005) beschrieben, aufgenommen. Die Auswertung der Spektren wurde mit der Software OPUS Version 5.5 (Bruker Optics, Ettlingen) durchgeführt. Die Spektren wurden einer Grundlinienkorrektur und einer Normierung unterzogen. Für die Normierung wurde die Vektornormierung ausgewählt, bei der ein Spektrum normiert wird, indem für die y-Werte ein Mittelwert berechnet wird und anschließend dieser Wert vom Spektrum subtrahiert wird. Dann wird die Summe der Quadrate aller Y-Werte berechnet und anschließend das entsprechende Spektrum durch die Wurzel dieser Summe dividiert.

Mit Hilfe der OPUS-Software wurde anschließend eine Clusteranalyse von den gemessenen Spektren durchgeführt. Zur Berechnung der spektralen Distanzen zwischen den Spektren in 
der Clusteranalyse wurde der Ward's Algorithmus verwendet und die erste und zweite Ableitung des Spektrums berechnet. Durch die Berechnung der Ableitung gewinnen Signale mit einem steilen Anstieg eine größere Bedeutung als vergleichsweise flache Strukturen. Diese Methode wird verwendet, wenn scharfbandige aber relativ kleine Signale von einem relativ hohen, breiten Untergrund überlagert werden. Allerdings wird dadurch auch das spektrale Rauschen verstärkt.

\subsubsection{Ligninbestimmung}

Lignin wurde nach einer modifizierten Acetylbromid Methode von Brinkmann et al. (2002) bestimmt. 0,5 mg, $1 \mathrm{mg}$ und $2 \mathrm{mg}$ Zellwandpulver wurden mit $250 \mu \mathrm{l} 25 \%$ igem Acetylbromid in Essigsäure gemischt und $30 \mathrm{~min}$ bei $70^{\circ} \mathrm{C}$ inkubiert. Danach wurden die Proben sofort auf Eis gekühlt, mit $250 \mu \mathrm{l} 2 \mathrm{M} \mathrm{NaOH}$ vermischt und $5 \mathrm{~min}$ bei $16000 \times \mathrm{g}$ zentrifugiert. Vom Überstand wurden $139 \mu \mathrm{l}$ in ein neues $2 \mathrm{ml}$ Gefäß mit 2,8 $\mu$ l Hydroxylamin-Lösung (50\% (w/v) transferiert. Vor der Absorptionsmessung bei $280 \mathrm{~nm}$ (Beckman DU 640, Beckman Coulter $\mathrm{GmbH}$, Krefeld) wurden die Proben mit 1,25 ml Essigsäure gemischt. Für die Standardkurve wurde käufliches Lignin (Coniferyl Alkohol) von 18-270 $\mu$ g verwendet. Der Extinktionskoeffizient für Lignin wurde anhand der Eichkurve zu $\varepsilon=8.41 /\left(\mathrm{g}^{*} \mathrm{~cm}\right)$ bestimmt.

\subsection{Extraktion von Proteinen}

\subsubsection{Gewinnung von apoplastischer Waschflüssigkeit (AWF) aus Arabidopsis thaliana Blättern}

Die Extraktion der apoplastischen Waschflüssigkeit wurde für Arabidopsis thaliana Blätter optimiert (modifiziert nach Polle et al., 1990). Dafür wurden verschiedene Infiltrationslösungen und Infiltrationszeiten, sowie verschiedene Zentrifugationsgeschwindigkeiten und -zeiten getestet. Zur Ermittlung der Kontaminationsrate der AWF mit symplastischen Proteinen wurde jeweils die Malatdehydrogenase-Aktivität gemessen (3.5.2.1). Außerdem wurde der Anteil der rückgewonnenen Infiltrationsflüssigkeit und der Proteingehalt (3.5.1) überprüft. Letztendlich führte die Methodenoptimierung zu folgendem Protokoll:

Für die Gewinnung der AWF wurden pro Probe zunächst ca. 50 Blätter von 5-10 Pflanzen mit einem Skalpell abgeschnitten und bis zur weiteren Bearbeitung in einer feuchten Kammer aufbewahrt. Die Blätter wurden gewogen, um das Frischgewicht zu bestimmen und mit demineralisiertem Wasser gewaschen, um ausgetretenes Cytoplasma zu entfernen. Zur Infiltration wurden die Blätter in Schalen mit jeweils $250 \mathrm{ml} 100 \mathrm{mM}$ Kaliumchloridlösung mit $0,005 \%$ Triton $X-100$ gelegt und mit einem Netz

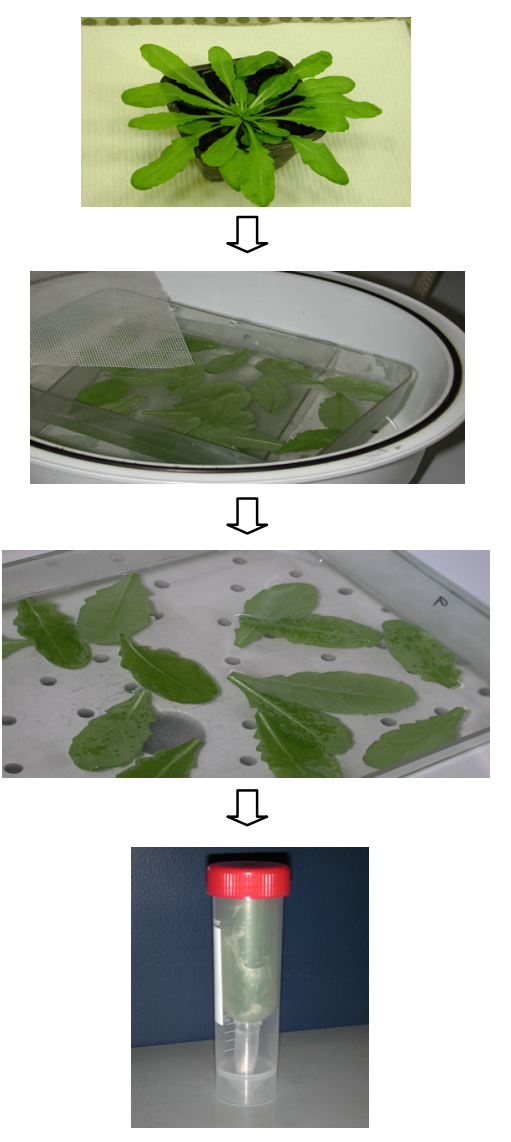

Abb. 3.3: Gewinnung von AWF 
bedeckt (Abb. 3.3). Die Schalen wurden in einen Exsikkator platziert und für 5 Minuten wurde ein Vakuum angelegt, hierfür wurde der Druck um $-80 \mathrm{kPa}$ auf $20 \mathrm{kPa}$ reduziert. Anschließend wurde der Druck langsam wieder auf Normaldruck erhöht, so dass die Infiltrationslösung in die Blätter einströmen konnte. Waren noch nicht alle Blätter infiltriert, wurde die Prozedur mit den noch nicht infiltrierten Blättern wiederholt. Danach wurden die Blätter mit Tüchern vorsichtig trocken getupft, gewogen, in eine Folie eingerollt und in ein Zentrifugenröhrchen mit einem Loch im Boden platziert. In ein $50 \mathrm{ml}$ Röhrchen wurde dann ein 1,5 ml Reaktionsgefäß und darüber das Zentrifugenröhrchen mit den eingerollten Blättern gestellt (Abb. 3.3) und bei $4{ }^{\circ} \mathrm{C}, 900 \times \mathrm{g}, 8 \mathrm{~min}$ zentrifugiert (Rotanta $96 \mathrm{R}$, Hettich, Tuttlingen). Zum Schluss wurde die Menge an gewonnener AWF ermittelt. Die AWF wurde bei $-20{ }^{\circ} \mathrm{C}$ bis zur weiteren Analyse gelagert.

\subsubsection{Gewinnung von AWF aus Rapsblättern}

Für die Gewinnung von AWF aus Rapsblättern wurde das Protokoll für Arabidopsis-Blätter etwas modifiziert. Pro Probe wurden 5-10 Rapsblätter geerntet, die Mittelrippe wurde entfernt und große Blätter in der Mitte durchgeschnitten. Die Infiltrationslösung enthielt $100 \mathrm{mM} \mathrm{KCl}$ mit $0,01 \%$ Triton X-100. Die Menge an Detergenz in der Infiltrationslösung wurde für die Rapsblätter etwas erhöht, weil diese sehr wasserabweisend waren. Ansonsten wurde die AWF-Gewinnung wie unter 3.4 .1 beschrieben durchgeführt.

\subsubsection{Gewinnung von Xylemsaft aus Raps}

Der Xylemsaft wurde mit Hilfe einer Scholander-Druckbombe gewonnen (Scholander, 1965; Kruse et al. 2003). Dazu wurden Wurzeln von mock- bzw. Verticillium-inokulierten Rapspflanzen (siehe 3.2.2) unter fließendem Wasser von Sand und Erde befreit und anschließend in Wasser gestellt. Oberhalb des Hypokotyls wurde mit einer Rasierklinge ein sauberer Schnitt gemacht und die Schnittfläche gut mit dd $\mathrm{H}_{2} \mathrm{O}$ abgespült. Die Wurzeln wurden etwas trocken getupft, locker in Aluminiumfolie eingeschlagen und in den Zylinder der Druckbombe gehängt. Der Stängel wurde durch den Gummiring in der Druckbombe gedrückt und der Zylinder gut verschlossen. An der Schnittfläche austretender Xylemsaft wurde für 10-15 min bei einem Druck von ca. 0,2 MPa gesammelt. Bis zur weiteren Analyse wurden die Xylemsäfte bei $-20{ }^{\circ} \mathrm{C}$ gelagert.

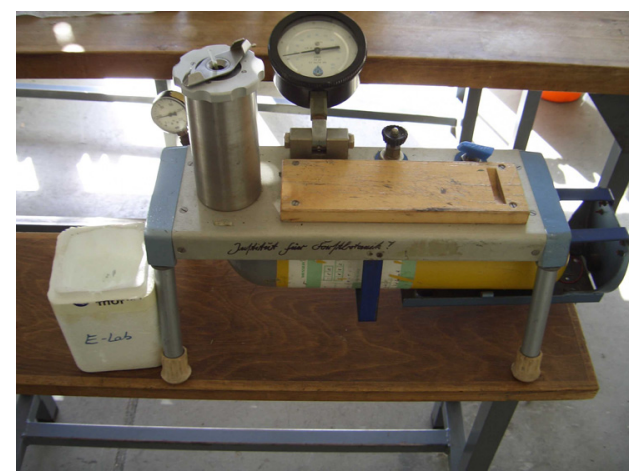

Abb. 3.4: Scholander Druckbombe zur Gewinnung von Xylemsaft aus Raps. Mit einem Druck von $0,2 \mathrm{MPa}$ wurde der Xylemsaft aus den Wurzeln nach oben gedrückt und konnte dann an der Stängelschnittfläche gesammelt werden. 


\subsubsection{Proteinextraktion aus Gesamtblattmaterial und Gelfiltration}

Am Vortag der Extraktion wurden $100 \mathrm{mg}$ unlösliches Polyvinylpolypyrrolidon (PVPP) pro Blattprobe in Zentrifugenröhren eingewogen, mit $2 \mathrm{ml}$ Extraktionspuffer $(0,1 \mathrm{M}$ $\mathrm{KH}_{2} \mathrm{PO}_{4} / \mathrm{K}_{2} \mathrm{HPO}_{4}$ Puffer/0,5 \% Triton X-100, pH 7,8) gemischt und für 4 Stunden oder über Nacht bei $4{ }^{\circ} \mathrm{C}$ inkubiert. Das PVPP wird eingesetzt, da es in gequollenem Zustand die Eigenschaft hat, Phenole zu binden.

Für die Extraktion wurden $100 \mathrm{mg}$ gefrorenes, gemahlenes Blattpulver in die am Vortag vorbereiteten Röhrchen eingewogen, die Einwaage protokolliert und die Proben gut gemischt. Nach einer 15-minütigen Inkubation auf Eis wurden die Proben $30 \mathrm{~min}$ bei $4{ }^{\circ} \mathrm{C}$ und $24700 \times \mathrm{g}$ (Beckmann J2-HS, Rotor JA 20.1, Beckmann Coulter GmbH, Krefeld) zentrifugiert. Um niedermolekulare Substanzen zu entfernen wurde anschließend eine Gelfiltration durchgeführt. Dafür wurden $500 \mu \mathrm{l}$ des Überstandes aus der Zentrifugation auf vorher dreimal mit dd $\mathrm{H}_{2} \mathrm{O}$ gespülte Sephadex G-25 Säulen (NAP 5 Säulen, Amersham Biosciences, Uppsala, Schweden) gegeben. Dabei wird ausgenutzt, dass Makromoleküle (DNA/Proteine), da sie nicht in die Sephadex-Gelpartikel eindringen, sofort mit dem Ausschlussvolumen eluiert werden. Wohingegen niedermolekularen Substanzen vollständig in das Sephadex-Gel eindringen, sehr spät aus der Säule austreten und damit abgetrennt werden. Mit einem Ausschlussvolumen von $1 \mathrm{ml} d d \mathrm{H}_{2} \mathrm{O}$ wurden die Proteine aus den Säulen eluiert und in 1,5 ml Gefäßen aufgefangen. 


\subsection{Biochemische Methoden}

\subsubsection{Proteinbestimmung}

Die Proteinbestimmung erfolgte mittels Bicinchoninic acid Reagenz (BCA-Test, Uptima, Montelucon, Frankreich). Das Prinzip des BCA-Tests beruht darauf, dass in einer ersten Reaktion zweiwertige Kupferionen $\left(\mathrm{Cu}^{2+}\right)$ aus Kupfersulfat quantitativ von Peptidbindungen aus Proteinen zu einwertigen Kupferionen $\left(\mathrm{Cu}^{1+}\right)$ reduziert werden. Danach bilden zwei Moleküle Bicinchoninsäure-Chelator mit jeweils einem Molekül einwertiger Kupferionen einen violetten Farbstoff, dessen Absorption bei einer Wellenlänge von 562 nm photometrisch erfasst werden kann.

Für den BCA-Test wurden die Gesamtblattextrakte 1:4 mit dd $\mathrm{H}_{2} \mathrm{O}$ verdünnt, während $\mathrm{AWF}$ und Xylemsäfte unverdünnt eingesetzt wurden. Je $30 \mu$ einer Probe bzw. Verdünnung wurde mit $600 \mu \mathrm{l}$ BCA-Nachweisreagenz (nach Herstellerangaben vorbereitet) versetzt. Die Proben wurden gemischt und 30 min bei $60{ }^{\circ} \mathrm{C}$ inkubiert. Nach Abkühlung auf Raumtemperatur erfolgte die Bestimmung der Proteinkonzentration photometrisch (Beckman DU 640, Beckman Coulter $\mathrm{GmbH}$, Krefeld, Deutschland) bei einer Extinktion von $\lambda=562 \mathrm{~nm}$. Die Proben wurden jeweils in Dreifachbestimmung gemessen. Eine Eichreihe von 10-300 $\mu \mathrm{g} / \mathrm{ml}$ mit Rinderserumalbumin (BSA; Uptima, Montelucon, Frankreich), die genau wie die Proben behandelt wurde, diente zur Berechnung der Proteinkonzentrationen in den Extrakten. Ebenfalls mitgeführt wurde eine Kontrolle bei der statt Extrakt dd $\mathrm{H}_{2} \mathrm{O}$ eingesetzt wurde und deren Extinktion ( $\left.E_{\text {Kontrolle}}\right)$ bei der Berechnung der Extinktion der Proben und der Eichreihe abgezogen wurde.

Die Berechnungen der Proteinkonzentration erfolgte mit Hilfe folgender Gleichungen:

Proteinkonzentration der Probe $(\mu \mathrm{g} / \mathrm{ml})=\left[\left(\mathrm{E}_{\text {Probe }}-\mathrm{E}_{\text {Kontrolle }}\right){ }^{*} \operatorname{Verd}_{\mathrm{P}}\right] /$ Steigung $_{\text {Standard }}$

Proteinkonzentration im Extrakt $(\mu \mathrm{g} / \mathrm{ml})=\left[\left(E_{\text {Probe }}-E_{\text {Kontrolle }}\right){ }^{*}\right.$ Verd $\left._{P}{ }^{*} V_{e r d}\right] /$ Steigung $_{\text {standard }}$

Proteingehalt $(\mathrm{mg} / \mathrm{g} \mathrm{FM})=\left[\right.$ Proteinkonzentration des Extraktes $\left.{ }^{*} \mathrm{~V}_{\mathrm{KPP}}\right] / \mathrm{FM}$

Wobei: $\quad \begin{array}{ll}\mathrm{E} & =\text { Extinktion } \\ \mathrm{V}_{\mathrm{KPP}} & =\text { Volumen Extraktionspuffer }(\mathrm{ml})(\text { siehe 3.4.4) } \\ \text { Verd }_{\mathrm{G}} & =\text { Verdünnung Gelfiltration }(\text { siehe 3.4.4) } \\ \text { Verd }_{\mathrm{P}} & =\text { Verdünnung der Probe im Test } \\ \mathrm{FM} & =\text { Frischmasse }(\mathrm{mg})(\text { siehe } 3.4 .4) \\ \text { Steigung }_{\text {Standard }} & =\text { Steigung der BSA-Standardkurve }[1 /(\mu \mathrm{g} / \mathrm{ml})]\end{array}$




\subsubsection{Bestimmung von Enzymaktivitäten}

\subsubsection{Malatdehydrogenase}

Die Messung der Malatdehydrogenase (MDH) Aktivität (Bergmeyer, 1974) diente zur Erfassung von symplastischen Kontaminationen in der apoplastischen Waschflüssigkeit. Gesamtblattextrakte wurden für die Messung 1:10 verdünnt eingesetzt, während die AWF unverdünnt gemessen wurden. Die Testansätze wurden wie in Tab. 3.2 angegeben, gemischt. Zuletzt wurde für den Reaktionsstart die NADH-Lösung zugegeben, kurz mit einem Rührspatel gemischt und sofort mit der photometrischen Messung begonnen. Die Aktivität wurde über die Extinktionsabnahme durch die Umsetzung von NADH bei $\lambda=340 \mathrm{~nm}$ und $25^{\circ} \mathrm{C}$ für $5 \mathrm{~min}$ photometrisch gemessen (Ultraspec 4000, Amersham Pharmacia Biotech, Cambridge, England). Eine Kontrollrate wurde mit Extrakt, aber ohne Oxalessigsäure gemessen (Tab. 3.2) und bei der Berechnung abgezogen.

Tab. 3.2: Zusammensetzung eines Testansatzes für die Messung der MDH-Aktivität. Die Oxalessigsäure und die NADH-Lösung wurden jeweils frisch angesetzt.

\begin{tabular}{lcccc}
\hline & $\begin{array}{c}\text { Konzentration } \\
\text { der } \\
\text { Stammlösung } \\
(\mathrm{mM})\end{array}$ & $\begin{array}{c}\text { Konzentration } \\
\text { der Lösung } \\
\text { im Test } \\
(\mathrm{mM})\end{array}$ & $\begin{array}{c}\text { Volumen } \\
\text { der Lösung } \\
\text { im Test } \\
(\mu \mathrm{L})\end{array}$ & $\begin{array}{c}\text { Volumen } \\
\text { der Lösung } \\
\text { in der Kontrolle } \\
(\mu \mathrm{L})\end{array}$ \\
\hline $0,1 \mathrm{M} \mathrm{KPP}, \mathrm{pH} 7,5$ & 100 & 50 & 500 & 500 \\
dd H $\mathrm{H}_{2} \mathrm{O}$ & 1 & 0,1 & 200 & 300 \\
Oxalessigsäure & 1 & & 100 & 0 \\
Extrakt & & & 100 & 100 \\
Reaktionsstart: & 1 & 0,1 & 100 & 100 \\
NADH-Lösung & & & &
\end{tabular}

Durch Anpassung einer Regressionsgeraden an die Messpunkte, wurde die Extinktionsänderung pro Zeiteinheit bestimmt $(\Delta \mathrm{E})$. Daraus wurden die Enzymaktivitäten folgendermaßen berechnet:

Aktivität $($ nkat/g $F M)=\left(\Delta E{ }^{*} V_{T}{ }^{*} \operatorname{Verd}_{G}{ }^{*} \operatorname{Verd}_{P}{ }^{*} V_{K P P}{ }^{*} C\right) /\left(\varepsilon{ }^{*} V_{E}{ }^{*} F M{ }^{*} d\right)$

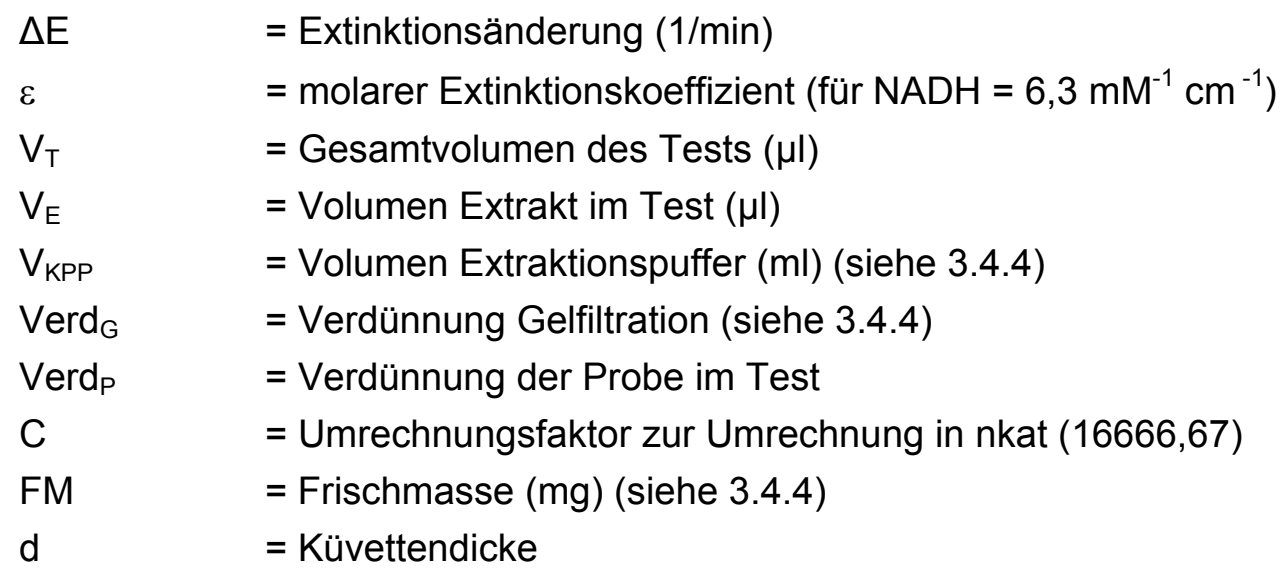




\subsubsection{Guajakolperoxidase}

Als Guajakolperoxidasen (GuPOD) werden alle Enzyme bezeichnet, die Guajakol als Kosubstrat zur Umsetzung von $\mathrm{H}_{2} \mathrm{O}_{2}$ verwenden können. Die GuPOD-Bestimmung erfolgte nach der Methode von Pütter (1970), die von Polle et al. (1990) modifiziert wurde. Die Aktivität wurde über die Extinktionszunahme bei $\lambda=436 \mathrm{~nm}$ und $25{ }^{\circ} \mathrm{C}$ photometrisch (Ultraspec 4000, Amersham Pharmacia Biotech, Cambridge, England) bestimmt. Als Extrakte wurden unverdünnte Gesamtblattextrakte und AWF eingesetzt (siehe 3.4.1, 3.4.2 und 3.4.4). Zur Bestimmung der Kontrollrate wurde die Messung ohne Extrakt mit einer Zusammensetzung wie in Tab. 3.3 angegeben, durchgeführt.

Tab. 3.3: Zusammensetzung eines Testansatzes für die Messung der GuPOD-Aktivität. Die Guajakollösung und die $\mathrm{H}_{2} \mathrm{O}_{2}$-Lösung wurden jeweils frisch angesetzt indem $218 \mu \mathrm{l} 98$ \%iges Guajakol in $20 \mathrm{ml} \mathrm{dd} \mathrm{H}_{2} \mathrm{O}$ und $453 \mu \mathrm{l} 30$ \%iges $\mathrm{H}_{2} \mathrm{O}_{2}$ in $20 \mathrm{ml} \mathrm{dd} \mathrm{H}_{2} \mathrm{O}$ verdünnt wurden.

\begin{tabular}{lcccc}
\hline & $\begin{array}{c}\text { Konzentration } \\
\text { der } \\
\text { Stammlösung } \\
(\mathrm{mM})\end{array}$ & $\begin{array}{c}\text { Konzentration } \\
\text { der Lösung } \\
\text { im Test } \\
(\mathrm{mM})\end{array}$ & $\begin{array}{c}\text { Volumen } \\
\text { der Lösung } \\
\text { im Test } \\
(\mu \mathrm{L})\end{array}$ & $\begin{array}{c}\text { Volumen } \\
\text { der Lösung } \\
\text { in der Kontrolle } \\
(\mu \mathrm{L})\end{array}$ \\
\hline 0,1 M KPP, pH 5,25 & 100 & 50 & 500 & 500 \\
dd $\mathrm{H}_{2} \mathrm{O}$ & 100 & & $50-\mathrm{X}$ & 50 \\
Extrakt & 100 & 40 & $\mathrm{X}$ & 0 \\
Guajakol & & 400 & 400 \\
Reaktionsstart: & 200 & 10 & & 50 \\
$\mathrm{H}_{2} \mathrm{O}_{2}$ & & & 50 & \\
\hline
\end{tabular}

Die Extinktionsänderung $(\Delta \mathrm{E})$ wurde durch Anpassung einer Regressionsgeraden an die Messpunkte, die vom Photometer über 15 min aufgenommen worden waren, bestimmt. Bei zu niedrigen oder zu hohen Enzymkonzentrationen war die Linearität der Messung nicht gewährleistet, weshalb unterschiedliche Volumina des Extrakts eingesetzt wurden. Die Regressionsgrade wurde so gelegt, dass die Steigung ca. 0,1 betrug und im Extinktionsbereich zwischen 0,1 und 1,1 lag. Die Berechnung der GuPOD-Aktivtät erfolgte mit der unter 3.5.2.1 angegebenen Formel und einem molaren Extinktionskoeffizient für Guajakol von $25,5 \mathrm{mM}^{-1} \mathrm{~cm}^{-1}$.

\subsubsection{Chitinase}

Die Messung der Chitinase Aktivität wurde mit Hilfe des Substrats 4-Methylumbelliferyl N-

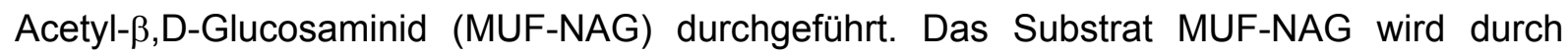

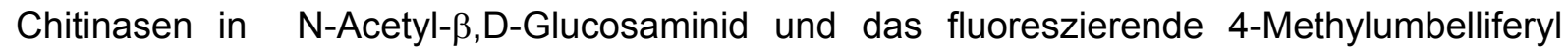
gespalten. Das MUF-NAG-Pulver (Sigma, Steinheim) wurde mit dem Lösungsmittel 2Methoxyethanol auf eine Konzentration von $5 \mathrm{mM}$ eingestellt und für die Verwendung im Test mit dd $\mathrm{H}_{2} \mathrm{O}$ auf eine $1,5 \mathrm{mM}$ Lösung eingestellt. Da MUF-NAG lichtempfindlich ist, wurde es im Dunkeln bei $-20^{\circ} \mathrm{C}$ gelagert. Der Test wurde in schwarzen Mikrotiterplatten (Nunc, Wiesbaden) mit $100 \mu \mathrm{l}$ Probe (AWF, Gesamtblattextrakte) und $50 \mu \mathrm{l}$ 1,5 mM MUFNAG in Dreifachbestimmung durchgeführt. Nach 30, 60 und 90 min Inkubation bei 
Raumtemperatur wurde die Reaktion durch Zugabe von $100 \mu \mathrm{l} 2,5 \mathrm{M}$ Tris (pH>10) gestoppt. Zur Quantifizierung wurde als Standard käufliche Chitinase (Sigma, Steinheim) im Konzentrationsbereich von 0,3 bis $20 \mathrm{mU} / \mu \mathrm{l}$ auf der Mikrotiterplatte mitgeführt. Die Emission wurde bei einer Wellelänge von $460 \mathrm{~nm}$ gemessen (CyBi-Screen-Machine, CyBio AG, Jena), die Anregungswellenlänge betrug $390 \mathrm{~nm}$. Die Chitinase-Aktivität wurde folgendermaßen berechnet:

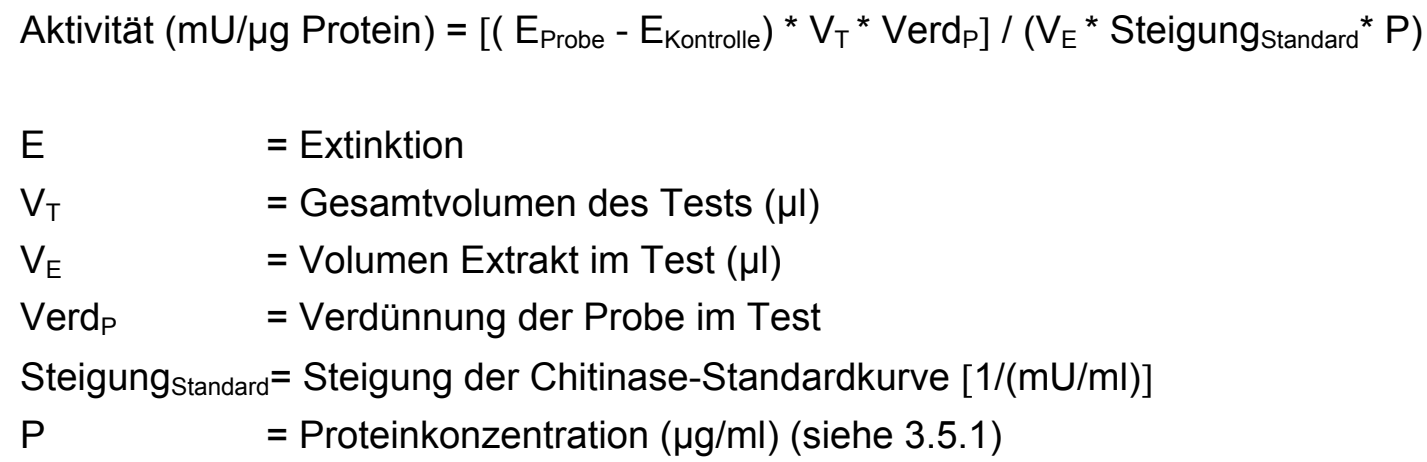

\subsubsection{Trichloressigsäure (TCA)/Aceton-Fällung}

Für die TCA/Aceton-Fällung wurden 5 Vol $10 \%$ iges TCA/Aceton (versetzt mit $0,14 \% \beta$ Mercaptoethanol) mit $1 \mathrm{Vol}$ AWF bzw. Gesamtblattextrakte vermischt und über Nacht bei $-20{ }^{\circ} \mathrm{C}$ inkubiert. Am nächsten Tag wurden die Proben $20 \mathrm{~min}$ bei $4{ }^{\circ} \mathrm{C}$ und $15000 \mathrm{xg}$ zentrifugiert, der Überstand wurde vorsichtig abgenommen und verworfen. Anschließend wurden die Proben durch Zugabe von $200 \mu \mathrm{l}$ Aceton (mit 0,07\% $\quad \beta$-Mercaptoethanol) und 15 -minütiges Zentrifugieren bei $4{ }^{\circ} \mathrm{C}$ und $15000 \times$ g gewaschen. Dieser Schritt wurde zweimal wiederholt und das Pellet wurde anschließend bei Raumtemperatur getrocknet. Die Proben wurden bei $-20^{\circ} \mathrm{C}$ gelagert.

\subsubsection{Peroxidase Nachweis im PhastGel}

Die isoelektrische Fokussierung (IEF) ist eine hochauflösende Technik zur Auftrennung von Proteinen auf der Basis ihres isoelektrischen Punktes. Der Vorteil des PhastSystems (Amersham Biosciences, Uppsala, Schweden) ist die schnelle Durchführbarkeit und der geringe Aufwand. Diese Methode zur isoelektrischen Fokussierung von Proteinen besteht aus drei Schritten:

1. Vorfokussierung (pH Gradient wird gebildet; währenddessen können die Kämme beladen und eingesetzt werden) $\rightarrow \quad$ Dauer ca. 10 min

2. Proben Applikation

3. Fokussierung $\quad \rightarrow \quad 500$ Vh oder ca. $30 \mathrm{~min}$

Jeweils $300 \mu \mathrm{l}$ Probe wurde gefriergetrocknet und nach der Trocknung in $30 \mu \mathrm{ldd} \mathrm{H}_{2} \mathrm{O}$ resuspendiert (Peroxidasen sind auch nach der Gefriertrocknung noch aktiv). Die Proteinkonzentration wurde in einer 1:10 Verdünnung, wie unter 3.5.1 beschrieben, bestimmt. Die Minigele mit einem $\mathrm{pH}-$ Gradienten von $\mathrm{pH} 3$ bis $\mathrm{pH} 9$ (Amersham Biosciences, 
Uppsala, Schweden) wurden mit 3,6 $\mu$ grotein pro Probe beladen. Die elektrophoretische Auftrennung wurde unter folgenden Bedingungen durchgeführt:

$\begin{array}{lllll}2000 \mathrm{~V} & 2,5 \mathrm{~mA} & 3,5 \mathrm{~W} & 15^{\circ} \mathrm{C} & 75 \mathrm{Vh} \\ 200 \mathrm{~V} & 2,5 \mathrm{~mA} & 3,5 \mathrm{~W} & 15^{\circ} \mathrm{C} & 15 \mathrm{Vh} \\ 2000 \mathrm{~V} & 2,5 \mathrm{~mA} & 3,5 \mathrm{~W} & 15^{\circ} \mathrm{C} & 410 \mathrm{Vh}\end{array}$

Nach der elektrophoretischen Auftrennung wurde das Gel in eine Glaspetrischale mit $50 \mathrm{ml}$ $100 \mathrm{mM}$ Natriumacetatpuffer (pH 5,5) mit $100 \mu \mathrm{l}$ Guajakol (98\%) und $100 \mu \mathrm{H}_{2} \mathrm{O}_{2}(30 \%)$ überführt. Vorhandene Peroxidasen verknüpften mit Hilfe von $\mathrm{H}_{2} \mathrm{O}_{2}$ das farblose Guajakol zu rotbraunen Komplexen, welche im Gel als braune Banden sichtbar wurden. Die Färbung war nach ca. $15 \mathrm{~min}$ am stärksten. Da die Färbung wieder verblasste wurde das Gel sofort gescannt (Fluor-S Multiimager, Bio-Rad).

\subsubsection{Eindimensionale Elektrophorese}

Für die elektrophoretische Auftrennung wurden die Xylemsäfte (siehe 3.4.3) zuvor sterilfiltriert um möglicherweise vorhandene Verticillium-Sporen oder Hyphen zu entfernen. Danach wurde der Xylemsaft gefriergetrocknet und anschließend in $500 \mu \mathrm{l} \mathrm{ddH}_{2} \mathrm{O}$ aufgenommen und über Gelelutionssäulen gereinigt. Damit gleiche Mengen an Protein auf das Gel aufgetragen werden konnten, wurde die Proteinkonzentration bestimmt (siehe 3.5.1). Die apoplastischen und Gesamtblattproteine wurden mittels TCA/Aceton gefällt (siehe 3.5.3) und anschließend wurde ebenfalls die Proteinkonzentration gemessen.

Die Elektrophorese wurde in einer Anlage von Biometra (Whatman Biometra, Göttingen) durchgeführt. Die Gelplatten hatten eine Größe von $14 \times 15 \mathrm{~cm}$ und es wurde ein $1 \mathrm{~mm}$ dicker Kamm mit 12 Taschen verwendet. Vor dem Gießen der Gele wurden die Glasplatten mit Wasser und Ethanol gereinigt, gut mit fusselfreien Tüchern getrocknet und anschließend zusammengesetzt. Das Gießen der Polyacrylamid (PAA)-Gele erfolgte mit Hilfe eines Gradientenmischers, wobei in den vorderen Zylinder eine 20 \%ige Trenngellösung und in den hinteren Zylinder eine 7,5\%ige Trenngellösung pipettiert wurde (Zusammensetzung siehe Tab. 3.4). Nach Anschalten des Mischers wurden durch einen Schlauch die Gellösungen zwischen die Glasplatten gefüllt, so dass von unten nach oben ein Gradient von $20 \%$ Acrylamid bis 7,5\% Acrylamid entstand. Danach wurde das Trenngel mit wassergesättigtem Butanol überschichtet und mindestens eine Stunde zum Polymerisieren stehen gelassen. Anschließend wurde das Butanol durch Dekantieren und Nachreinigen mit dd $\mathrm{H}_{2} \mathrm{O}$ entfernt. Das Sammelgel (Tab. 3.4) wurde über das Trenngel zwischen die Glasplatten gegossen, der Kamm eingesetzt und wiederum mindestens eine Stunde zum Polymerisieren stehen gelassen. 
Tab. 3.4: Pipettierschema für ein Gradientengel. Der Polyacrylamidgradient von $20-7,5 \%$ wurde mit Hilfe eines Gradientenmischers erzeugt.

\begin{tabular}{lcc|c}
\hline & \multicolumn{2}{c|}{ Trenngel } & Sammelgel \\
& $\mathbf{7 , 5} \%$ & $\mathbf{2 0} \%$ & $\mathbf{7} \%$ \\
\hline $30 \%$ Acrylamid (w/v wässrige Lösung) & $7,5 \mathrm{ml}$ & $20 \mathrm{ml}$ & $2,33 \mathrm{ml}$ \\
Trenn-bzw. Sammelgelpuffer & $7,5 \mathrm{ml}$ & $7,5 \mathrm{ml}$ & $2,55 \mathrm{ml}$ \\
$10 \%$ SDS & $0,3 \mathrm{ml}$ & $0,3 \mathrm{ml}$ & $0,1 \mathrm{ml}$ \\
$\mathrm{dd} \mathrm{H}_{2} \mathrm{O}$ & $14,5 \mathrm{ml}$ & $2,05 \mathrm{ml}$ & $5,02 \mathrm{ml}$ \\
\multicolumn{1}{c|}{ entlüften und je $6,5 \mathrm{ml}$ in Gradientenmischer pipettieren } & entlüften \\
$10 \%$ Ammoniumpersulfat (APS) & $65 \mu \mathrm{l}$ & $65 \mu \mathrm{l}$ & $50 \mu \mathrm{l}$ \\
TEMED & $5 \mu \mathrm{l}$ & $5 \mu \mathrm{l}$ & $5 \mu \mathrm{l}$ \\
\hline
\end{tabular}

Je nachdem, ob anschließend eine Silbernitrat- oder CBB-Färbung geplant war, wurden pro Spur 1,8 $\mu$ g bzw. 50-100 $\mu$ g Protein aufgetragen und in dem PAA-Gradientengel (Laemmli, 1970) aufgetrennt.

Die Elektrophoreseanlage wurde für die Auftrennung der Proteine auf $10{ }^{\circ} \mathrm{C}$ vorgekühlt. Die Proteinproben wurden mit Ladepuffer (Tab. 3.5) versetzt, 3 min bei $70{ }^{\circ} \mathrm{C}$ inkubiert und anschließend auf das Gel aufgetragen. Als Protein-Molekulargewichtsmarker wurde ein Proteinkit (siehe 3.5.6, Tab. 3.6; LMW 17-0446-01, Amersham Biosciences, Freiburg) verwendet. Die Elektrophorese erfolgte mit $20 \mathrm{~mA}$ pro Gel (Power Pac 3000, Bio-Rad Laboratories, München, Deutschland). Anschließend wurden die Gele nach Blum et al. (1987) mit Silber oder nach Neuhoff (1990) mit Coomassie-Brilliant-Blue gefärbt (siehe 3.5.7).

Tab 3.5: Zusammensetzung des Ladepuffers für die PAA-Elektrophorese. Die Komponenten wurden in dd $\mathrm{H}_{2} \mathrm{O}$ gelöst.

\begin{tabular}{lcc}
\hline & Konzentration & Ansatz für $\mathbf{1 0 ~} \mathbf{~ m l}$ \\
\hline $0,5 \mathrm{M}$ Tris-HCl, pH 6,8 & $0,125 \mathrm{M}$ & $2,5 \mathrm{ml}$ \\
$10 \%$ SDS & $4 \% \mathrm{v} / \mathrm{v}$ & $4 \mathrm{ml}$ \\
Glycerin & $20 \% \mathrm{v} / \mathrm{v}$ & $2 \mathrm{ml}$ \\
DTT & $0,2 \mathrm{M}$ & $0,31 \mathrm{~g}$ \\
Bromphenolblau & $0,002 \% \mathrm{w} / \mathrm{v}$ & $2 \mathrm{mg}$ \\
\hline
\end{tabular}




\subsubsection{Molekulargewichtsmarker für die Elektrophorese}

Je eine Portion Protein-Molekulargewichtsmarker (576 $\mu$ g/Portion; Tab. 3.5; LMW 17-044601, Amersham Biosciences, Freiburg) wurde in $200 \mu$ Ladepuffer gelöst. Bei einer geplanten CBB-Färbung (siehe 3.5.8) wurde der Marker unverdünnt verwendet, bei einer geplanten Silberfärbung (siehe 3.5.8) wurde der Marker 1:20 in Ladepuffer verdünnt. Für die eindimensionalen Elektrophorese (siehe 3.5.5) wurden jeweils $5 \mu l$ Markerprotein pro Spur aufgetragen. Für die zweidimensionale Elektrophorese (siehe 3.5.7) wurden je $10 \mu \mathrm{l}$ Markerproteine auf ein $5 \times 5 \mathrm{~mm}$ großes Filterpapierstück pipettiert, mit $0,5 \%$ iger leichtschmelzender Agarose (Amersham Biosciences, Uppsala, Schweden) überschichtet und in Portionen zu jeweils sechs Filterstücken bis zur weiteren Verwendung bei $-20{ }^{\circ} \mathrm{C}$ gelagert. Das Molekulargewicht der zu analysierenden Proteine wurde aus der Gleichung der Geraden, die aus der relativen Laufweite der Markerproteine und deren Molekulargewicht resultierte, berechnet (Abb. 3.5).

Tab. 3.6: Zusammensetzung des Protein-Markers mit Molekulargewichten von 14400 bis $97000 \mathrm{Da}$.

\begin{tabular}{llc}
\hline Protein & Organismus/Organ & Molekulargewicht (Da) \\
\hline Phosphorylase b & Kaninchenmuskel & 97000 \\
Albumin & Rinderserum & 66000 \\
Ovalbumin & Hühnereiweiß & 45000 \\
Carbonische Anhydrase & Rindererythrozyten & 30000 \\
Trypsin Inhibitor & Sojabohne & 20100 \\
$\alpha$-Lactalbumin & Kuhmilch & 14400 \\
\hline
\end{tabular}

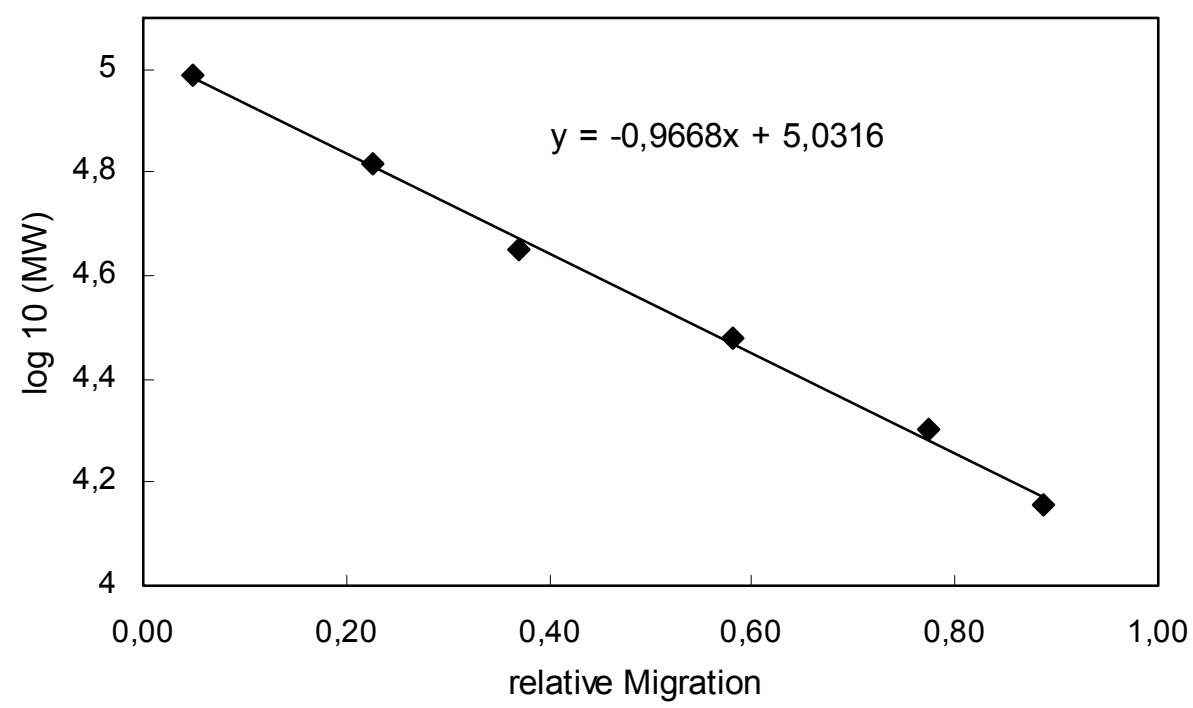

Abb. 3.5: Beispiel für eine Eichgerade zur Bestimmung der Molekulargewichte von Proteinen im Gel. Die relative Migration der Markerproteine zur Lauffront wurde gegen den Logarithmus $(\log 10)$ der Molekulargewichte (MW) der Markerproteine aufgetragen. 


\subsubsection{Zweidimensionale Elektrophorese}

\subsubsection{Erste Dimension (Isoelektrische Fokussierung)}

Die TCA/Aceton gefällten Proteine wurden mit $380 \mu \mathrm{l}$ Rehydrationspuffer [8 M Harnstoff, 0,5\% w/v CHAPS, $15 \mathrm{mM}$ DTT, 0,5\% v/v IPG-Puffer $\mathrm{pH} \quad 3-10$ und 0,2\% v/v Bromphenolblau (Görg \& Weis, 2000)] versetzt und anschließend $30 \mathrm{~min}$ bei Raumtemperatur durch Schütteln gelöst. Danach erfolgte eine 5 minütige Zentrifugation bei $12000 \times \mathrm{g}$ und $4{ }^{\circ} \mathrm{C}$ um störende Reste zu entfernen. $350 \mu$ des Überstandes wurden in einen sogenannten Stripholder (Amersham Biosciences, Uppsala, Schweden) gefüllt. Die IPG-Strips mit immobilisiertem pH-Gradient (Immobiline DryStrip, $180 \mathrm{~mm} \times 3 \mathrm{~mm} \times 0,5 \mathrm{~mm}$, pH 3-10; Amersham Biosciences, Uppsala, Schweden) wurden vorsichtig mit der Gelseite nach unten über die Probenlösung geschoben, so dass sich die Probe über den gesamten Strip verteilte. Anschließend wurde der Strip mit $1 \mathrm{ml}$ einer öligen Lösung (plus one Dry Strip Cover Fluid) überschichtet, um ein Austrocknen der Proben zu verhindern. Die isoelektrische Fokussierung wurde in einer Ettan IPGphor-Einheit unter folgenden Bedingungen durchgeführt (Betriebsanleitung von Amersham; Görg et al. 2000): Rehydrierung $12 \mathrm{~h}$ mit $20 \mathrm{~V}$, dann $2 \mathrm{~h}$ mit $150 \mathrm{~V}, 1 \mathrm{~h}$ mit $200 \mathrm{~V}, 1 \mathrm{~h}$ mit $500 \mathrm{~V}$, dann konstant $1000 \mathrm{~V}$ für $1000 \mathrm{Vh}$ und anschließend eine lineare Erhöhung der Spannung auf 8000 V. Zum Schluss wurde die Spannung von $8000 \mathrm{~V}$ gehalten, damit die Proteine in ihrer Position blieben. Nach der isoelektrischen Fokussierung wurden die Strips bis zur weiteren Verwendung, in der Regel über Nacht, bei $-20^{\circ} \mathrm{C}$ eingefroren.

\subsubsection{Zweite Dimension (SDS-Polyacrylamidgelelektrophorese)}

Die Glasplatten für die zweite Dimension wurden mit Glasreiniger (Viss, Lever Faberge, Hamburg) gereinigt und einige Stunden zum Trocknen stehen gelassen. Je zwei Glasplatten wurden zusammengelegt, in der Gießkassette (Amersham Biosciences, Uppsala, Schweden) gestapelt und die Kassette mit Klemmen dicht verschlossen. Für die zweite Dimension wurden sechs $12 \%$ ige Acrylamid-Gele parallel gegossen. Dafür wurden $500 \mathrm{ml}$ Trenngellösung (Tab. 3.7) benötigt. Die Trenngellösung wurde zügig über einen Schlauch von unten in die Gelkassette gefüllt und danach mit einer Verdrängungslösung (Tab. 3.7) nach oben geschoben. Die Gele wurden mit wassergesättigtem Butanol überschichtet, mit einer Plastikfolie luftdicht verschlossen und zum Polymerisieren über Nacht bei Raumtemperatur stehengelassen.

Am nächsten Tag wurden die IPG-Strips für die zweite Dimension in zwei Schritten äquilibriert, wofür $125 \mathrm{ml}$ Äquilibrierungspuffer (6 M Harnstoff, 30 \% (w/v) Glycerol, $2 \%$ (w/v) SDS) benötigt wurden. Im ersten Schritt wurden die Strips in jeweils $10 \mathrm{ml}$ Äquilibrierungspuffer mit $1 \% \mathrm{w} / \mathrm{v}$ DTT $15 \mathrm{~min}$ bei Raumtemperatur in Glasröhrchen geschüttelt. Durch die DTT Zugabe wurden die Proteine in ihrem reduzierten Zustand gehalten. Der Überstand wurde verworfen und der Schüttelvorgang mit $10 \mathrm{ml}$ Äquilibrierungspuffer mit $4 \% \mathrm{w} / \mathrm{v}$ lodoacetamid wiederholt. Das lodoacetamid verhindert durch Alkylierung der Thiol-Gruppen eine Reoxidation der Proteine während der Elektrophorese. Die Strips wurden anschließend mit dd $\mathrm{H}_{2} \mathrm{O}$ kurz gespült, mit Filterpapier auf 
der Rückseite etwas getrocknet, in zweifach konzentriertem Elektrophoresepuffer (25 mM Tris, $192 \mathrm{mM}$ Glycin, 0,1\% SDS, 0,03 \% w/v Bromphenolblau) getaucht und vorsichtig mit Hilfe eines Spatels zwischen die Glasplatten geschoben. Je ein Filterstück mit Markerproteinen (siehe 3.5.6, Tab. 3.6; LMW 17-0446-01, Amersham Biosciences, Freiburg) wurde neben dem Strip platziert und der Strip und das Filterstück wurden mit 0,5\%-iger heißer flüssiger Agarose (low-melting point) in einfach konzentriertem Elektrophoresepuffer (25 mM Tris, $192 \mathrm{mM}$ Glycin, 0,1 \% SDS) überschichtet, um einen besseren Übergang vom Strip in das Acrylamidgel zu ermöglichen. Die Trennung der Proteine nach Größe erfolgte in einer Ettan Dalt six Einheit bei $10^{\circ} \mathrm{C}$ unter folgenden Bedingungen: $600 \mathrm{~V}, 400 \mathrm{~mA}, 13 \mathrm{~W}$ für 30 min und 3000 V, 400 mA, $100 \mathrm{~W}$ für 4,5 h (Power Pac 3000, Bio-Rad Laboratories, München). Hierfür wurden ca. $1 \mathrm{~L}$ eines zweifach konzentrierten und ca. $5 \mathrm{~L}$ eines einfach konzentrierten Elektrophoresepuffers (25 mM Tris, $192 \mathrm{mM}$ Glycin, 0,1\% SDS) in den oberen bzw. den unteren Tank der Anlage gefüllt.

Tab. 3.7: Pipettierschema für die Acrylamidlösung, ausreichend für sechs Acrylamidgele und für die Verdrängungslösung.

\begin{tabular}{lr|lr}
\hline für $\mathbf{5 0 0} \mathbf{~ m l ~ 1 2} \%$ Acrylamidgel & & für $\mathbf{2 5 0} \mathbf{~ m l ~ V e r d r a ̈ n g u n g s l o ̈ s u n g ~}$ & \\
\hline Acrylamid (30 \% w/v wässrige Lösung) & $210 \mathrm{ml}$ & dd $\mathrm{H}_{2} \mathrm{O}$ & $90 \mathrm{ml}$ \\
Tris-Puffer (1,5 M Tris, pH 8,8, & & Tris-Puffer (1,5 M Tris, pH 8,8, & \\
$0,4 \%$ SDS) & $125 \mathrm{ml}$ & $0,4 \%$ SDS $)$ & $50 \mathrm{ml}$ \\
Glycerol & $25 \mathrm{ml}$ & Glycerol & $60 \mathrm{ml}$ \\
dd $\mathrm{H}_{2} \mathrm{O}$ & $136 \mathrm{ml}$ & Bromphenolblau $(0,1 \%)$ & $50 \mu \mathrm{l}$ \\
$\rightarrow$ rühren und enlüften & & & \\
TEMED (1:10 verdünnt) & $250 \mu \mathrm{l}$ & & \\
APS 10 \% & $4 \mathrm{ml}$ & & \\
\hline
\end{tabular}

\subsubsection{Färbung der Gele mit Silbernitrat oder Coomassie Brilliant Blue}

Nach der Elektrophorese wurden die Gele für die Silberfärbung über Nacht fixiert (50\% v/v Ethanol, $12 \%$ v/v Eisessig, 0,05 \% v/v 37\%iges Formaldehyd) und am nächsten Tag nach Blum et al. (1987) gefärbt. Die Färbung von je zwei Gelen erfolgte bei Raumtemperatur in $500 \mathrm{ml}$ Lösung. Die Gele wurden $3 \times 20$ min mit $30 \% \mathrm{v} / \mathrm{v}$ Ethanol gewaschen, dann $1 \mathrm{~min}$ mit $0,01 \%$ w/v Natriumthiosulfatpentahydrat imprägniert, $3 \times 20 \mathrm{~s}$ mit $\mathrm{dd}_{2} \mathrm{O}$ gewaschen und danach $20 \mathrm{~min}$ in einer Färbelösung aus 0,1\% w/v Silbernitrat und 0,075\% v/v 37 \%igem Formaldehyd geschüttelt. Anschließend wurden die Gele noch zweimal mit dd $\mathrm{H}_{2} \mathrm{O}$ gewaschen und mit einer Lösung aus $3 \% \mathrm{w} / \mathrm{v}$ Natriumcarbonat, 0,0002 \% w/v Natriumthiosulfatpentahydrat und $0,05 \%$ v/v $37 \%$ iges Formaldehyd entwickelt. Die Färbung wurde nach 1-5 min durch Austausch des Entwicklers gegen eine Stopplösung (10 mM EDTA) beendet.

Die kolloidale CBB-Färbung erfolgte nach Neuhoff (1990) über Nacht in 500 ml Färbelösung $(0,1 \% \mathrm{w} / \mathrm{v}$ Coomassie Brilliant Blue G-250, $2 \% \mathrm{w} / \mathrm{v}$ Phosphorsäure (85\%), $10 \%$ Ammoniumsulfat, $20 \% \mathrm{v} / \mathrm{v}$ Methanol) unter leichtem Schütteln. Anschließend wurde der 
Hintergrund durch mehrmaliges Austauschen mit dd $\mathrm{H}_{2} \mathrm{O}$ entfärbt. Die Gele wurden nach der Färbung gescannt (Fluor-S Multiimager, Bio-Rad).

\subsubsection{Analyse der zweidimensionalen Gele}

Die silbergefärbten Gele dienten zu einer generellen Übersicht über das Muster der Proteine und zur Erkennung von Differenzen zwischen Proteinspots in Gelen von mock- und Verticillium-inokulierten Pflanzen. Die Analyse der Gelbilder erfolgte mithilfe der Proteomweaver Software (Version 3.1.0.7, Definiens Cognitionware, München). Aus den Coomassie-gefärbten Gelen wurden Spots ausgestochen und anschließend mittels Massenspektrometrie analysiert (3.5.10).

Für die Analyse der silbergefärbten Gele mit der Proteomweaver Software wurden die Gelbilder als 16 bit TIFF-Datei in das Programm geladen, so dass zusammengehörige Gele eine Gruppe bildeten. Zu einer Gruppe gehörten die Gele der Verticillium-infizierten Pflanzen, zu der anderen Gruppe die Gele der Kontrollpflanzen. Es folgte eine automatische Erkennung der Proteinspots in den Gelbildern und wenn nötig eine manuelle Bearbeitung. Danach wurden die Gele mittels Pair Matching und Multi Matching angepasst und einer Normierung unterzogen, wofür die Standardparameter des Programms verwendet wurden. Erst nach der Normierung wurden die Intensitäten der Spots in Gelen von Verticilliuminfizierten Pflanzen mit denen von Kontrollpflanzen verglichen und mittels Student's T-Test statistisch ausgewertet, wobei Werte unter $p \leq 0,05$ als signifikant unterschiedlich angesehen wurden.

\subsubsection{Proteinverdau mit Trypsin und Proteinidentifizierung}

Der Proteinverdau erfolgte wie in Blödner et al. (2007) beschrieben nach einem modifizierten Protokoll von Havlis et al. (2003). Die einzelnen mit Coomassie gefärbten Proteinspots (siehe 3.5.7 und 3.5.8) wurden auf einer sauberen, fusselfreien Glasplatte mit einer abgeschnittenen Pipettenspitze (1000 $\mu \mathrm{l})$ aus dem Gel ausgestochen und mit einer sauberen Rasierklinge in ca. $1 \times 3 \mathrm{~mm}$ große Stücke geschnitten, um später ein besseres Diffundieren des Trypsins in das Gel zu ermöglichen. Anschließend wurden die Gelstücke in ein 0,5 $\mu \mathrm{l}$ Gefäß (low binding tube, Eppendorf, Hamburg) überführt und bis zur weiteren Verarbeitung bei $-20{ }^{\circ} \mathrm{C}$ gelagert.

Für den Verdau wurden die Proben zunächst gewaschen, indem sie zweimal für 15 min in $200 \mu \mathrm{ldd} \mathrm{H}_{2} \mathrm{O}$ geschüttelt wurden. Es folgte ein 15 minütiger Waschschritt mit $200 \mu \mathrm{l}$ 50 \%igem Methanol zur Reduzierung der Blaufärbung der Spots. Bei stark gefärbten Spots wurde dieser Schritt wiederholt. Danach wurden die Proben in reinem Acetonitril geschüttelt, nach 20 min wurde der Überstand sorgfältig abgenommen und das restliche Acetonitril unter Vakuum abgedampft.

Das Trypsin wurde in $86 \mu \mathrm{l}$ des mitgelieferten Resuspensionspuffer (Promega, Mannheim) gelöst und mit $50 \mathrm{mM}$ Ammoniumhydrogencarbonat $(\mathrm{pH} \mathrm{8,0)} \mathrm{1:5} \mathrm{verdünnt,} \mathrm{so} \mathrm{dass} \mathrm{eine}$ $2 \mu \mathrm{M}$ Trypsinlösung entstand. Je nach Größe der Gelstücke wurden 15-20 $\mu$ l Trypsinlösung zu den Proben gegeben und für 10 min auf Eis inkubiert. Dann wurde kontrolliert, ob die 
Gelstücke von der Flüssigkeit ausreichend bedeckt waren, sonst wurden noch bis zu $10 \mu \mathrm{l}$ nachpipettiert. Der Ansatz wurde für eine Stunde bei $4{ }^{\circ} \mathrm{C}$ im Kühlschrank inkubiert, um eine vollständige Aufnahme des Trypsins durch die Gelstücke zu erreichen. Danach folgte der eigentliche Trypsin-Verdau der Proteine für $30 \mathrm{~min}$ bei $58{ }^{\circ} \mathrm{C}$ im Wasserbad. Der Verdau wurde durch die Zugabe von $200 \mu \mathrm{l} 5$ v/v Ameisensäure und 30 minütiges Schütteln bei Raumtemperatur gestoppt. Die Überstände wurden in ein neues Gefäß (low binding tube, Eppendorf, Hamburg) überführt, die Gelstücke mit $200 \mu \mathrm{l} \mathrm{50 \%} \mathrm{v/v} \mathrm{Acetonitril} \mathrm{und} \mathrm{5 \%} \mathrm{v/v}$ Ameisensäure versetzt und wiederum 30 min geschüttelt um die Proteine aus dem Gel zu lösen. Die Überstände wurden vereinigt und in einer Vakuumzentrifuge eingeengt (SPD speed vac, Thermo Savant, Holbrook, USA). Anschließend wurden die Proben bei $-20^{\circ} \mathrm{C}$ gelagert.

Für die Auftrennung wurden die Proben in $5 \mu \mathrm{l} 0.1 \% \mathrm{v} / \mathrm{v}$ Ameisensäure gelöst und davon wurden $4 \mu \mathrm{l}$ auf eine $180 \mathrm{~cm}$ lange Kapillarsäule, gepackt mit 218MS-C18 Substanz (Vydac, Columbia, USA), injiziert und flüssigkeitschromatographisch (ESI-LC-MS, HP 1100 Agilent, Palo Alto, USA; Esquire 3000, Bruker Daltonik, Bremen) aufgetrennt. Die Trennung der Peptide erfolgte in einem Gradienten aus $0,1 \%$ Ameisensäure (Solvent A) und $95 \%$ Acetonitril in 0,1\% Ameisensäure (Solvent B): 20 min $2 \%$ Solvent B, gefolgt von einem Gradienten aus $50 \%$ Solvent B in 45 min, dann $95 \%$ Solvent B für 3 min und anschließend weitere $10 \mathrm{~min}$ in $95 \%$ B. Die lonisation der Peptide erfolgte mit Hilfe der Elektrosprayionisation (ESI). Massenspektren wurden mit einem lonenfallenMassenspektrometer (Esquire 3000, Bruker Daltonik, Bremen) aufgenommen. MS-Spektren wurden mit der Data Analysis Software (Bruker Daltonik) analysiert. Aus den erhaltenen Daten erfolgte die Proteinidentifizierung mittels Mascot Software (Matrix-Science, Boston, USA) und Recherche in der NCBI-Protein-Datenbank.

\subsubsection{Signalpeptid-Analyse mit TargetP}

Die meisten extrazellulären Proteine besitzen verschiedene Merkmale, die für ihre Translokation in den extrazellulären Raum verantwortlich sind. Eins dieser Merkmale ist das Vorhandensein eines abspaltbaren Signalpeptids am N-Terminus des Proteins. Das Signalpeptid ist für den gezielten Transport zum Endoplasmatischen Reticulum, welches die erste Organelle auf dem sekretorischen Weg darstellt, verantwortlich (Vitale \& Denecke, 1999). Das Signalpeptid besitzt keine übereinstimmende Sequenz, aber ist durch drei konservierte Domänen gekennzeichnet, die positiv geladene $\mathrm{n}$-Region auf dem N-Terminus und eine zentrale hydrophobe h-Region, gefolgt von einer polaren c-Region, die die Spaltstelle beinhaltet. Für die Analyse der Signalpeptide von Proteinen wurde die Vorhersageversion für Pflanzen des TargetP-Servers (Version 1.1) verwendet, die die subzellulare Lokalisierung von eukaryotischen Proteinen vorhersagt (Emanuelsson et al., 2000). Außerdem wird durch TargetP die Sicherheit der Vorhersage für das Signalpeptid in fünf reliabilty classes (RC) angegeben. Je kleiner die RC Nummer ist, umso sicherer ist die Vorhersage. 


\subsection{Molekularbiologische Methoden}

\subsubsection{RNA-Extraktion}

Für die quantitative real time PCR (3.6.4) wurde RNA nach der Methode von Chang et al. (1993) extrahiert. Es wurden $200 \mathrm{mg}$ gefrorenes, gemahlenes Blattmaterial in ein $13 \mathrm{ml}$ PPRöhrchen (Sarstedt) eingewogen und sofort mit $65^{\circ} \mathrm{C}$ warmem CTAB-Puffer (Tab. 3.8) und $24 \mu \mathrm{l} \beta$-Mercaptoethanol versetzt, gut gemischt und $15 \mathrm{~min}$ bei $65^{\circ} \mathrm{C}$ geschüttelt. Danach wurden die Proben zum Abkühlen 15 min bei Raumtemperatur stehen gelassen. Pro Probe wurden 1,2 ml Chloroform/lsoamylalkohol (24/1) zugegeben, 15 min bei Raumtemperatur geschüttelt und anschließend für $15 \mathrm{~min}$ bei $10000 \mathrm{x}$ g zentrifugiert. Dann wurde die obere Phase mit einer $1 \mathrm{ml}$ Eppendorf-Pipette in ein neues Röhrchen überführt. Das Auswaschen der oberen Phase wurde so lange wiederholt bis keine Zwischenphase mehr sichtbar war (in der Regel eine Wiederholung). Die gewaschene obere Phase wurde schließlich in ein $2 \mathrm{ml}$ Gefäß überführt, mit $0,25 \mathrm{Vol}$ gekühltem $10 \mathrm{M}$ Lithiumchlorid versetzt, gemischt und über Nacht bei $4{ }^{\circ} \mathrm{C}$ gefällt.

Am nächsten Tag wurden die Proben $20 \mathrm{~min}$ bei $20000 \mathrm{xg}\left(4^{\circ} \mathrm{C}\right)$ zentrifugiert. Der Überstand wurde sorgfältig abgenommen und verworfen. Das Pellet wurde mit $400 \mu 165^{\circ} \mathrm{C}$ warmem SSTE-Puffer (Tab. 3.8) versetzt und zum Lösen $10 \mathrm{~min}$ bei $42{ }^{\circ} \mathrm{C}$ im Thermomixer (Eppendorf, Hamburg) geschüttelt. Die Proben wurden dann mit $1 \mathrm{Vol}$ Chloroform/Isoamylalkohol (24/1) gemischt und $5 \mathrm{~min}$ bei $20000 \times \mathrm{g}$ zentrifugiert. Anschließend wurde die obere Phase in ein neues $1,5 \mathrm{ml}$ Gefäß überführt und wiederum mit $1 \mathrm{Vol}$ Chloroform/lsoamylalkohol (24/1) vermischt. Dieser Vorgang wurde wiederholt, bis keine Zwischenphase mehr sichtbar war. Danach folgte eine Ethanolfällung bei der die ausgewaschene obere Phase mit $2 \mathrm{Vol}-20^{\circ} \mathrm{C}$ kaltem Ethanol $(96 \%)$ gemischt und $1 \mathrm{~h}$ bei $-80{ }^{\circ} \mathrm{C}$ gefällt wurde. Es folgte eine 20 minütige Zentrifugation bei $20000 \times \mathrm{g}$ und $4{ }^{\circ} \mathrm{C}$ und zwei Waschschritte mit $500 \mu \mathrm{l}$ bzw. $80 \mu \mathrm{l} 70$ \%igem Ethanol. Das Pellet wurde getrocknet, in $50 \mu \mathrm{l}$ RNase-freiem Wasser aufgenommen und bis zur weiteren Verwendung bei $-80^{\circ} \mathrm{C}$ gelagert.

Tab. 3.8: Zusammensetzung der Puffer CTAB und SSTE für die RNA-Extraktion.

\begin{tabular}{ll|ll}
\hline CTAB-Puffer & & SSTE-Puffer & \\
\hline NaCl & $2 \mathrm{M}$ & $\mathrm{NaCl}$ & $1 \mathrm{M}$ \\
EDTA & $25 \mathrm{mM}$ & EDTA $(\mathrm{pH} 8,0)$ & $1 \mathrm{mM}$ \\
Tris (pH 8,8) & $100 \mathrm{mM}$ & Tris $(\mathrm{pH} \mathrm{8,0)}$ & $10 \mathrm{mM}$ \\
PVPP (löslich) & $2 \%(\mathrm{w} / \mathrm{v})$ & SDS & $0,5 \%$ \\
CTAB & $2 \%(\mathrm{w} / \mathrm{v})$ & & \\
\hline
\end{tabular}

\subsubsection{RNA-Aufreinigung}

Um noch vorhandene DNA aus der extrahierten RNA zu entfernen, wurde diese mit 1/10 Vol $10 \times$ Turbo DNase Puffer und $1 \mu \mathrm{l}$ Turbo DNase (Ambion, Austin, USA) versetzt und 60 min bei $37^{\circ} \mathrm{C}$ inkubiert. Nach $30 \mathrm{~min}$ Inkubation wurde für die nächsten 30 min noch einmal $1 \mu \mathrm{l}$ 
Turbo DNase zugegeben. Danach wurde die DNase inaktiviert, indem 1/10 Vol Inaktivator (Ambion, Austin, USA) zugegeben, für 2 min inkubiert und anschließend 1,5 min bei $10000 \times$ g zentrifugiert wurde.

Eine weitere Aufreinigung wurde durch eine Phenol/Chloroform Extraktion erzielt. Dafür wurde pro Probe $1 \mathrm{Vol}$ Phenol/Chloroform/Isoamylalcohol (25/24/1 v/v/v) zu der DNase behandelten RNA gegeben und 2 min bei $18000 \times$ g zentrifugiert. Die obere Phase wurde in ein neues $1,5 \mathrm{ml}$ Gefäß transferiert, mit $1 \mathrm{Vol}$ Isopropanol und 1/10 Vol $3 \mathrm{M}$ Natriumacetat $\left(\mathrm{pH} \mathrm{4,8)}\right.$ gefällt und 15 min bei $18000 \times \mathrm{g}\left(4^{\circ} \mathrm{C}\right)$ zentrifugiert. Bevor das Pellet bei $37^{\circ} \mathrm{C}$ getrocknet wurde, wurde es einmal mit $1 \mathrm{ml}$ und ein weiteres mal mit $80 \mu \mathrm{l}$ Ethanol gewaschen. Das Pellet wurde zum Schluss in $30 \mu \mathrm{l}$ RNase-freiem Wasser gelöst und konnte dann bis zur weiteren Verwendung bei $-80{ }^{\circ} \mathrm{C}$ gelagert werden.

\subsection{3 c-DNA Synthese}

Zunächst wurde die Konzentration der aufgereinigten RNA (siehe 3.6.2) durch Messung der optischen Dichte bei $260 \mathrm{~nm}$ (BioPhotometer, Eppendorf, Hamburg) bestimmt. Eine $\mathrm{OD}_{260}$ von 1 entspricht für RNA $=25 \mu \mathrm{g} / \mathrm{ml}$ und für doppelsträngige DNA $=50 \mu \mathrm{g} / \mathrm{ml}$.

Für die cDNA (complementary DNA) Synthese wurden jeweils $5 \mu \mathrm{g}$ der aufgereinigten RNA mit Hilfe des Enzyms Reverse Transkriptase und oligo (dT) ${ }_{18}$ Primern (First Strand cDNA Kit \# K1612, MBI Fermentas, St. Leon-Rot) nach Herstellerangaben in cDNA umgeschrieben. Dafür wurde $1 \mu \mathrm{l}$ oligo (dT) ${ }_{18}$ Primer auf Eis zu der RNA zugegeben, auf $11 \mu \mathrm{l}$ aufgefüllt, gemischt und 5 min bei $70^{\circ} \mathrm{C}$ inkubiert. Auf Eis wurden anschließend folgende Reagenzien zugegeben: $4 \mu \mathrm{l} 5 \times$ Reaktionspuffer, $2 \mu \mathrm{l} 10 \mathrm{mM}$ dNTPs, $1 \mu \mathrm{l}$ Ribonuklease Inhibitor

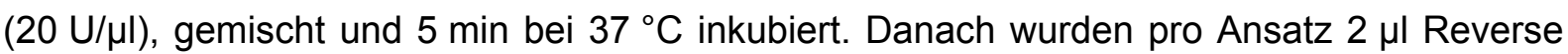
Transkriptase $(20 \mathrm{U} / \mu \mathrm{l})$ zugegeben. Es folgte eine Inkubation für $60 \mathrm{~min}$ bei $37^{\circ} \mathrm{C}$ und für 10 min bei $70^{\circ} \mathrm{C}$. Nach der Reaktion wurden die Proben bis zur weiteren Verwendung bei $-80^{\circ} \mathrm{C}$ gelagert.

\subsubsection{Quantitative real time PCR}

Die quantitative real time PCR basiert auf dem Prinzip der herkömmlichen PCR, bietet aber zusätzlich die Möglichkeit der Quantifizierung mithilfe von Fluoreszenz-Messungen während der PCR-Zyklen. SYBR-Green ist ein Fluoreszenzfarbstoff, der an doppelsträngige DNA bindet. Da das Fluoreszenzsignal von SYBR-Green proportional mit der Menge der PCRProdukte zunimmt, ist eine Quantifizierung möglich.

Die PCR wurde in einem iCycler (Bio-Rad, München) mit ABsolute SYBR green fluorescein (Abgene, Epsom, UK) durchgeführt. Ein $2 \mu$ l Aliquot aus der Reverse Transkriptase Reaktion (3.6.3) wurde als Template für die quantitative real time PCR verwendet. Die Genspezifischen Primer (Tab. 3.9; MWG, Ebersberg) wurden mit Hilfe der Primer 3 Software (http://frodo.wi.mit.edu/cgi-bin/primer3/primer3_www.cgi) konstruiert. 
Tab. 3.9: Sequenzen der für die real time PCR verwendeten Primer mit Schmelztemperatur $\left(T_{m}\right)$ und Produktgröße. Der Name des jeweiligen Primers enthält den Arabidopsis AGI-Code zur besseren Wiedererkennung.

\begin{tabular}{|c|c|c|c|}
\hline Name & Primersequenz $\left(5^{\prime}-3^{\prime}\right)$ & $\begin{array}{c}\mathrm{Tm} \text { in }{ }^{\circ} \mathrm{C} \text { (MWG- } \\
\text { Angaben) }\end{array}$ & Produktgröße \\
\hline PX_At3g49120_for & AGTTAAGGTCGGACCCTCGT & 59,4 & 243 \\
\hline PX_At3g49120_rev & GAGCTGCAATGGTGAGCATA & 57,3 & \\
\hline Cb_At3g16530_for & GCTTTATCCATGACCCGAGA & 57,3 & 159 \\
\hline Cb_At3g16530_rev & TTGACCGGAGTTAGGTTTGG & 57,3 & \\
\hline SC_At4g12910_for & TTACGCCGGAGTTTATGTCC & 57,3 & 243 \\
\hline SC_At4g12910_rev & TCGCACTCGAGTCCCTCTAT & 59,4 & \\
\hline PX_At4g37530_for & AAGCTACCCAAACCGACCTT & 57,3 & 220 \\
\hline PX_At4g37530_rev & GAGGACACGACGCTTTTAGC & 59,4 & \\
\hline PX_At5g05340_for & TTACGTCGTCGAAGCACAAC & 57,3 & 155 \\
\hline PX_At5g05340_rev & TGACAAAGCAATCGTGGAAG & 55,3 & \\
\hline PX_At5g06720_for & ACGCTGGTCCGAATGTAAAC & 57,3 & 234 \\
\hline PX_At5g06720_rev & TTTCGATGGGAGAAGGAATG & 55,3 & \\
\hline Ga_At5g08370_for & TCTCTCCTCAAATGGGATGG & 57,3 & 153 \\
\hline Ga_At5g08370_rev & TGAGTTCACCCCAACAATCA & 55,3 & \\
\hline G1_At5g20630_for & CCTCAAAGCCCATCAGGTTA & 57,3 & 236 \\
\hline G1_At5g20630_rev & ACCTCAGAAGCACCAGGATG & 59,4 & \\
\hline Ch_At5g24090_for & CCAAAACGGAAACGAAGGTA & 55,3 & 199 \\
\hline Ch_At5g24090_rev & AACCTTGATGCCACGAGACT & 57,3 & \\
\hline Actin2R & TTCTCGATGGAAGAGCTGGT & 57,3 & 190 \\
\hline Actin2L & TGCTGGACGTGACCTTACTG & 59,4 & \\
\hline
\end{tabular}

Die cDNA (siehe 3.6.3) und der Reaktionsmix (Abgene, Epsom, UK) wurden gemäß Tab. 3.10 auf eine Probenplatte (PCR 96er Well, Greiner bio-one, Frickenhausen) pipettiert, mit einer Abdeckfolie verschlossen und $3 \mathrm{~min}$ bei $1600 \mathrm{xg}$ zentrifugiert. Anschließend wurden die Proben im iCycler amplifiziert (Tab. 3.11) und mit dem MyiQ Single Color Real Time PCR Detection System analysiert. Um eine relative Quantifizierung zu ermöglichen, wurde das Referenzgen Actin ebenfalls in allen Proben gemessen. Die relative Expression der untersuchten Gene wurde mit dem Programm "Relative expression software tool (REST)“ berechnet und statistisch ausgewertet (Pfaffl, 2001; Pfaffl et al., 2002). 
Tab. 3.10: Zusammensetzung eines $25 \mu \mathrm{l}$ real time PCR Ansatzes für eine Probe.

\begin{tabular}{ll}
\hline cDNA & $2 \mu \mathrm{l}$ \\
$2 \times$ ABgene-Mix & $12,5 \mu \mathrm{l}$ \\
Forward Primer $10 \mu \mathrm{M}$ & $1 \mu \mathrm{l}$ \\
Reverse Primer $10 \mu \mathrm{M}$ & $1 \mu \mathrm{l}$ \\
$\mathrm{dd} \mathrm{H}_{2} \mathrm{O}$ & $8,5 \mu \mathrm{l}$ \\
\hline
\end{tabular}

Tab. 3.11: Amplifikationsprotokoll für die quantitative real time PCR. Die Annealingtemperatur richtet sich nach der Schmelztemperatur der Primer, da die verwendeten Primer (Tab. 3.9) ähnliche Schmelztemperaturen hatten, wurde die real time PCR standardmäßig bei $57^{\circ} \mathrm{C}$ durchgeführt.

\begin{tabular}{lcc|c}
\hline Schritt & Temperatur & Zeit & Zyklen \\
\hline Denaturierung & $95^{\circ} \mathrm{C}$ & $15 \mathrm{~min}$ & \\
Denaturierung & $95^{\circ} \mathrm{C}$ & $30 \mathrm{~s}$ & \\
Annealing & $57^{\circ} \mathrm{C}$ & $30 \mathrm{~s}$ & $45 \mathrm{x}$ \\
Elongation & $72^{\circ} \mathrm{C}$ & $30 \mathrm{~s}$ & \\
Kühlung & $4{ }^{\circ} \mathrm{C}$ & & \\
\hline
\end{tabular}

\subsubsection{Quantifizierung von Verticillium-DNA in inokulierten Pflanzen}

Die Quantifizierung der Verticillium-DNA wurde im Department für Nutzpflanzenwissenschaften von der Arbeitsgruppe von P. Karlovsky in Göttingen durchgeführt. Das Pflanzenmaterial wurde zunächst unter flüssigem Stickstoff zu einem feinen Pulver gemahlen. Die DNA-Extraktion wurde mit dem DNeasy Plant Mini Kit von Qiagen (Hilden, Deutschland) durchgeführt. Die Menge an Pilz-DNA im Probenmaterial wurde mit Hilfe von quantitativer real time PCR ermittelt. Dafür wurden folgende Verticillium spp. spezifischen Primer genutzt: 5'-CAGCGAAACGCGATATGTAG-3' und 5'GGCTTGTAGGGGGTTTAGA-3' (P. Karlovsky, Department für Nutzpflanzenwissenschaften, Göttingen). Für den Reaktionsansatz wurden BIOTaq DNA Polymerase (Bioline, Luckenwalde) in Standard Polymerase Puffer mit 0,01\% (v/v) Tween-20 und $3 \mathrm{mM} \mathrm{MgCl} 2$ verwendet. $10 \mathrm{nM}$ Fluorescein (BioRad, Hercules, CA, USA) wurde als interner FluoreszenzStandard zugegeben. Die Fluoreszenz von SYBR Green I (100000 fach verdünnt; Invitrogen, Karlsruhe) wurde bei $490 \pm 10 \mathrm{~nm}$ angeregt und die Emission bei $530 \pm 15 \mathrm{~nm}$ gemessen. Die PCR bestand aus folgenden Schritten: 2 min Denaturierung bei $94{ }^{\circ} \mathrm{C}$ gefolgt von 36 Zyklen $20 \mathrm{~s}$ bei $94^{\circ} \mathrm{C}, 30 \mathrm{~s}$ bei $59^{\circ} \mathrm{C}$ and $40 \mathrm{~s}$ bei $72^{\circ} \mathrm{C}$. Die Menge an Verticillium DNA wurde mit Hilfe einer Standardkurve aus gereinigter Pilz DNA ermittelt.

\subsubsection{RNA-Gele}

Zur Reinheitsüberprüfung wurde die RNA in 1,2 \%igen Agarosegelen aufgetrennt. Dafür wurden 1,2 \% (w/v) Agarose (SeaKem LE Agarose, Cambrex, Nottingham) in $10 \%$ des Gelvolumens MEA-Puffer (Tab. 3.12) und $70 \%$ dd $\mathrm{H}_{2} \mathrm{O}$ in der Mikrowelle ca. $3 \mathrm{~min}$ aufgekocht und anschließend mit $20 \%$ des Gelvolumens Formaldehyd vermischt. Vor dem 
Probenauftrag wurde den Proben jeweils 1 Vol 2 x Ladepuffer (Tab. 3.13) zugesetzt und 10 min bei $70{ }^{\circ} \mathrm{C}$ inkubiert um Sekundärstrukturen der RNA zu zerstören. Als Größenstandard diente ein Low Range RNA-Marker (Fermentas, St. Leon-Rot). Die Elektrophorese erfolgte bei 60 Volt in $1 \times$ MEA-Puffer.

Tab. 3.12: Zusammensetzung des $10 \times$ MEA-Puffers

\begin{tabular}{ll}
\hline MOPS & $0,2 \mathrm{M}$ \\
Natriumacetat & $50 \mathrm{mM}$ \\
EDTA & $10 \mathrm{mM}$ \\
\hline
\end{tabular}

Tab. 3.13: Zusammensetzung des 2 x RNA-Ladepuffers

\begin{tabular}{ll}
\hline Formamid & $66 \%(\mathrm{v} / \mathrm{v})$ \\
Formaldehyd & $0,3 \%(\mathrm{v} / \mathrm{v})$ \\
$10 \times$ MEA-Puffer & $10 \%(\mathrm{v} / \mathrm{v})$ \\
Bromphenolblau & $0,01 \%(\mathrm{w} / \mathrm{v})$ \\
Ethidiumbromid & $0,05 \%(\mathrm{w} / \mathrm{v})$ \\
\hline
\end{tabular}

\subsection{Statistik}

Für die statistischen Analysen wurden Mittelwerte und Standardfehler berechnet. Zur Überprüfung auf Signifikanz von zwei Varianten wurde der Student's T-Test mit $p \leq 0,05$ in Origin 6.OG verwendet. Wenn $p \leq 0,05$ war, wurden die Daten als signifikant unterschiedlich angesehen und mit einem Stern markiert. Zur Ermittlung signifikanter Unterschiede zwischen mehreren Varianten wurde eine einfache Varianzanalyse (ANOVA) gefolgt von einem „Multiple Range Test“ mithilfe des Programms Statgraphics Plus (Version 3, Manugistics, Rockville, USA) durchgeführt. Bei einer Irrtumswahrscheinlichkeit von 0,05 wurden Unterschiede als signifikant angesehen und mit unterschiedlichen Buchstaben markiert. 


\section{ERGEBNISSE}

\subsection{Einfluss von Verticillium longisporum auf Brassica napus}

\subsubsection{Entwicklung von Krankheitssymptomen bei Raps}

Zur Dokumentation der von Verticillium induzierten Schäden im Verlauf der Infektion wurden verschiedene Parameter erhoben. Die ersten äußerlich sichtbaren Krankheitssymptome bei Raps traten ca. 14 Tage nach Inokulation mit V. Iongisporum auf. Zu den sichtbaren Infektionssymptomen zählten Vergilbungen der unteren Blätter und eine Reduktion des Höhenwachstums. Bei Betrachtung des Sprossinneren konnte 21-28 Tage nach Inokulation im Hypokotyl eine braune Verfärbung der Leitgefäße beobachtet werden (Abb. 1.2).

Das Höhenwachstum von Raps wurde über den Infektionsverlauf bis 28 Tage nach Inokulation erfasst (Abb. 4.1A). Während die mock- und Verticillium-inokulierten Pflanzen 2 Tage nach Infektion noch gleich groß waren, zeigte sich bereits 14 Tage nach Pilzinokulation eine signifikante Minderung des Höhenwachstums, die sich bis 21 Tage nach Inokulation im Vergleich zu den mock-inokulierten Pflanzen noch deutlich verstärkte. Das Foto in Abbildung 4.1B zeigt exemplarisch den Phänotyp einer mock- und einer Verticillium inokulierte Pflanze 21 Tage nach Inokulation. Die Stauchung ist hier deutlich zu sehen, wobei nur die Höhe des Sprosses reduziert war, während die Größe und Anzahl der Blätter sich nicht unterschied.
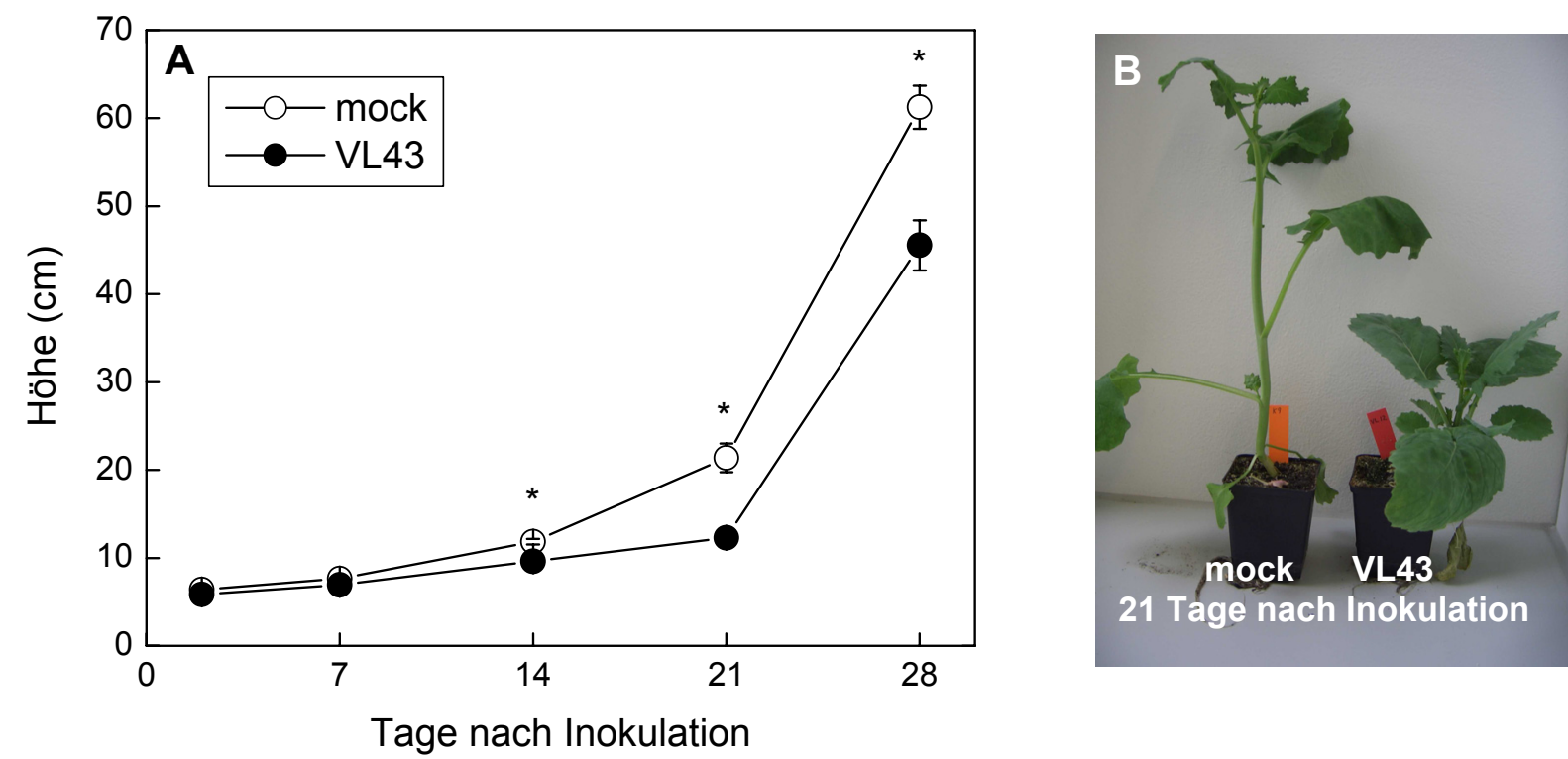

Abb. 4.1: (A) Sprosslänge von mock- und Verticillium-inokuliertem Raps im Infektionsverlauf. Die Symbole repräsentieren die Mittelwerte von jeweils 20 Pflanzen mit Standardfehler. Bei einigen Messzeitpunkten war der Standardfehler kleiner als das Symbol und ist daher in der Abbildung nicht zu sehen. Symbole mit einem Stern waren beim Vergleich von mock (weiße Symbole) und $V$. longisporum (VL43) inokuliertem Raps (schwarze Symbole) im T-Test $(p \leq 0,05)$ signifikant unterschiedlich. (B) Das Foto zeigt exemplarisch eine mock- und eine $V$. longisporum inokulierte Rapspflanze 21 Tage nach Inokulation. 
Wöchentlich wurden Pflanzen geerntet und die Frischmasse von Blättern, Spross und Wurzeln bestimmt (Abb. 4.2). Obwohl die infizierten Pflanzen nach 14 Tagen eine signifikante Stauchung zeigten, wirkte sich das zu diesem Zeitpunkt nicht auf die Frischmasse der einzelnen Pflanzenteile aus. Erst 28 Tage nach Inokulation war die Frischmasse des Sprosses der Verticillium infizierten Pflanzen signifikant reduziert (Abb. 4.2B). Bei der Frischmasse der Blätter konnten zu keinem Zeitpunkt Unterschiede zwischen mock- und Verticillium inokulierten Pflanzen festgestellt werden (Abb. 4.2A). Die Wurzelmasse der infizierten Pflanzen war 28 Tage nach Inokulation etwas erhöht, jedoch war dieser Unterschied nicht signifikant (Abb. 4.2C).
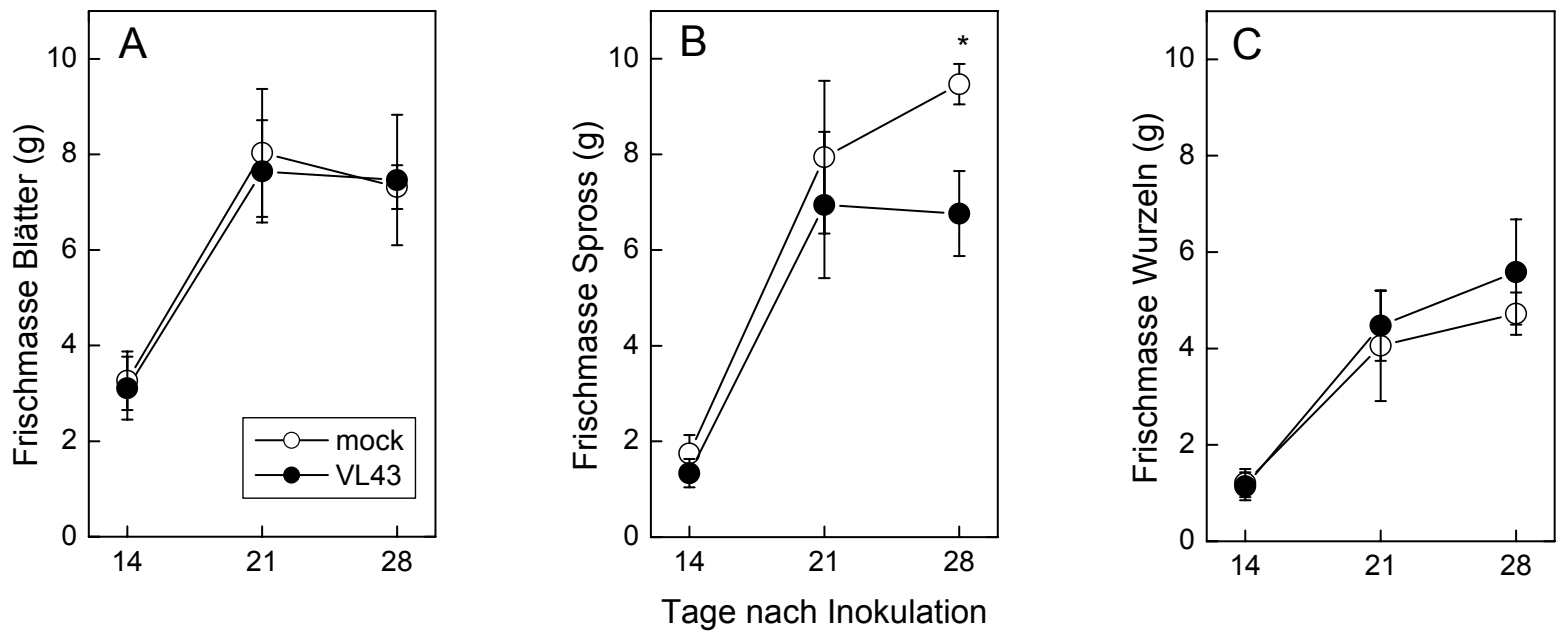

Abb. 4.2: Frischmasse von mock- und V. longisporum inokulierten Rapspflanzen. Blätter (A), Spross (B) und Wurzeln (C) jeweils einer Pflanze wurden getrennt gewogen. Die Symbole repräsentieren die Mittelwerte von jeweils 5 Pflanzen mit Standardfehler. Symbole mit einem Stern waren beim Vergleich von mock (weiße Symbole) und $V$. longisporum inokuliertem Raps (schwarze Symbole) im T-Test $(p \leq 0,05)$ signifikant unterschiedlich.

Weitere Parameter, die zur Dokumentation Verticillium induzierter Schäden untersucht wurden, waren Chlorophyllgehalt, Chlorophyllfluoreszenz, Photosynthese- und Transpirationsrate sowie Elektrolytleitfähigkeit zur Ermittlung von Membranschäden. Zum größten Teil wurden die folgenden Analysen 21 Tage nach Inokulation durchgeführt, da zu diesem Zeitpunkt deutliche Symptome wie Stauchung (Abb. 4.1) und Vergilbung (Abb. 4.3B) sichtbar waren, aber der Raps noch nicht blühte, was mit einem Verlust an Blättern einherging (Abb. 4.2A). Der Chlorophyllgehalt (siehe 3.3.4) war 21 Tage nach Inokulation bei Verticillium-inokulierten Pflanzen signifikant (um ca. $17 \%$ ) vermindert (Abb. 4.3A). Abbildung 4.3B zeigt exemplarisch die zugehörigen Blätter einer mock- und einer Verticilliuminokulierten Rapspflanze. Die unteren Blätter der infizierten Pflanzen (im Bild rechts) zeigen deutliche Vergilbungen im Vergleich zu den mock-Inokulierten. Zur Überprüfung des Einflusses der Verticillium-Infektion auf die Photosynthese von Raps, wurde über den Infektionsverlauf die Chlorophyllfluoreszenz (siehe 3.3.1) als Indikator für die Aktivität von Photosystems II gemessen (Abb. 4.3C). Die Messungen an den Verticillium-infizierten Pflanzen wiesen einen höheren Standardfehler auf als die mock-inokulierten. Zu allen 
Messzeitpunkten war die Chlorophyllfluoreszenz der Verticillium-infizierten Pflanzen geringfügig aber signifikant erniedrigt. Diese Ergebnisse sind ein deutlicher Hinweis darauf, dass der Raps Stress ausgesetzt ist.
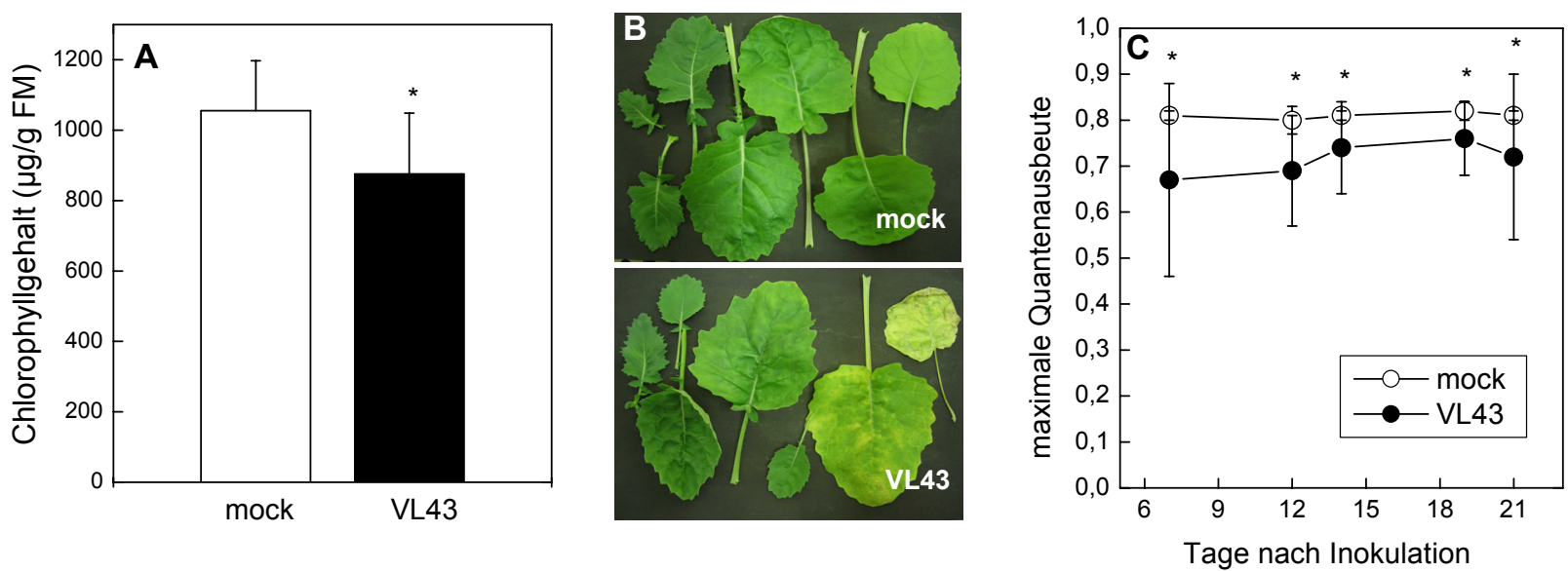

Abb. 4.3: Chlorophyllgehalt (A) von mock- und Verticillium longisporum (VL43)-inokulierten Pflanzen 21 Tage nach Infektion ( $n=9 \pm S E$ ). Der Chlorophyllgehalt wurde als Summe von Chlorophyll a und $b$ dargestellt. Blätter jeweils einer mock- und einer Verticillium-inokulierten Rapspflanze (B). (C) Einfluss von Verticillium auf die Aktivität von Photosystem II. Die Chlorophyllfluoreszenz wurde bei $20^{\circ} \mathrm{C}$ und $60 \%$ relativer Luftfeuchtigkeit als maximale photosynthetische Quantenausbeute an dunkeladaptierten Blättern über den Infektionsverlauf gemessen $(n=20 \pm$ SE). Signifikante Unterschiede im T-Test $(p \leq 0,05)$ sind mit einem Stern markiert.

Zur Bestimmung der aktuellen Photosyntheserate (siehe 3.3.5) wurden zu drei Zeitpunkten Gaswechselmessungen durchgeführt, wobei keine signifikante Änderung der Photosyntheserate durch Verticillium-Infektion festgestellt werden konnte (Abb. 4.4A). Aus der Messung konnte außerdem die Transpirationrate ermittelt werden, die aber ebenfalls keine signifikante Beeinflussung durch die Verticillium-Infektion zeigte (Abb. 4.4B).
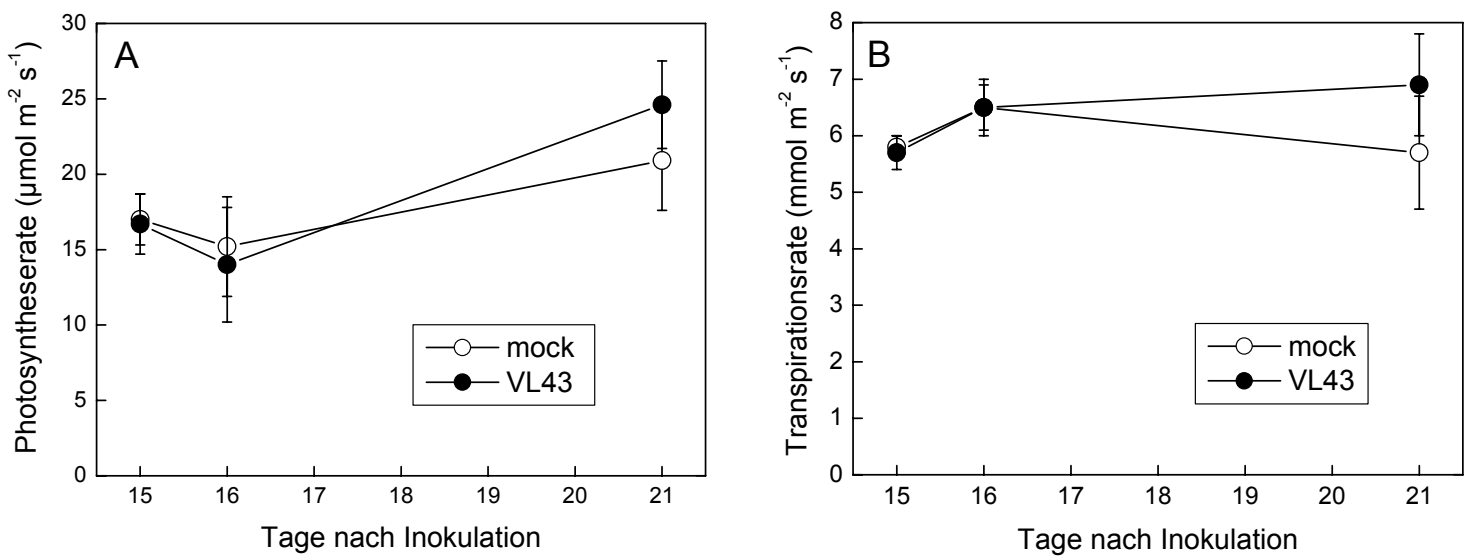

Abb. 4.4: Photosyntheserate $(A)$ und Transpirationsrate $(B)$ im Infektionsverlauf $(n=8 \pm S E)$. Weiße Symbole repräsentieren mock- und schwarze Symbole $V$. longisporum (VL43)-inokulierte Rapspflanzen. Die mikroklimatischen Bedingungen während der Messung betrugen durchschnittlich $22{ }^{\circ} \mathrm{C}, 54 \%$ relative Luftfeuchtigkeit und $1185 \mu \mathrm{mol} /\left(\mathrm{m}^{-2} \mathrm{~s}^{-1}\right)$ Lichtintensität. 
Zur Überprüfung, ob V. longisporum Membranschäden in den Rapsblättern verursacht, wurden Elektrolytleitfähigkeitsmessungen durchgeführt (siehe 3.3.2). Da das Austreten von Cytoplasma (leakage) durch geschädigte Membranen zu einer höheren Leitfähigkeit in der Messflüssigkeit führt, kann die Leitfähigkeit in Relation zur Gesamtleitfähigkeit als Indikator für Membranschäden genutzt werden. Mögliche Schädigungen der Membranen durch die Infektion mit Verticillium konnten 21 und 28 Tage nach Inokulation nicht nachgewiesen werden (Abb. 4.5). Es zeigte sich zwar bei der Messung 21 Tage nach Inokulation eine geringfügig erhöhte Elektrolytleitfähigkeit (um 2,4\%) bei den Verticillium-inokulierten Pflanzen; allerdings erwies sich diese als nicht signifikant.

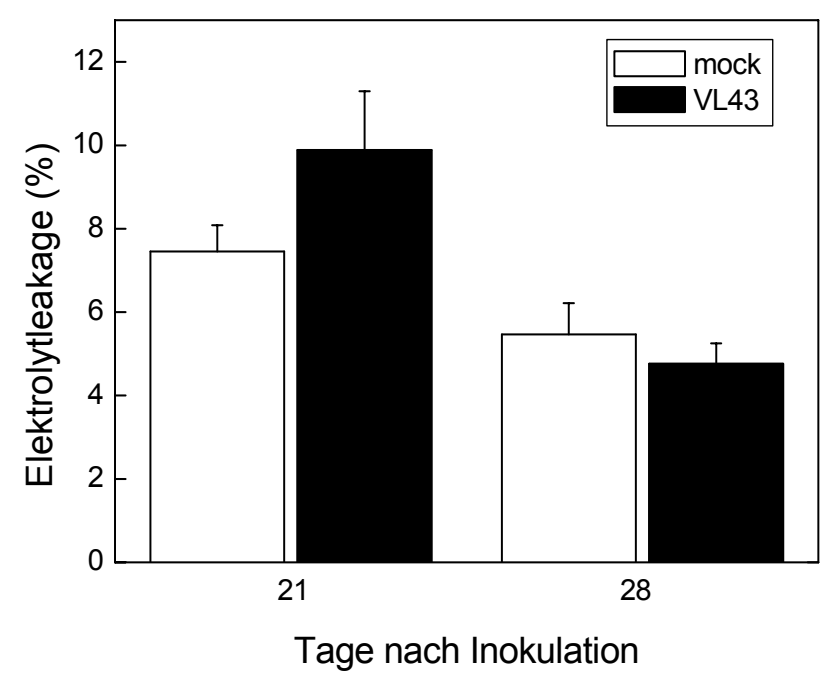

Abb. 4.5: Elektrolytleitfähigkeit von mock- und Verticillium-inokuliertem Raps 21 und 28 Tage nach Inokulation ( $\mathrm{n}=5 \pm \mathrm{SE}$ ). Die Messungen erfolgten nach 24-stündiger Inkubation von Blattscheiben in dd $\mathrm{H}_{2} \mathrm{O}$.

21 Tage nach Inokulation wurde außerdem überprüft, ob im unteren Stängelbereich der Rapspflanzen Verticillium-DNA mittels quantitativer real time PCR nachweisbar war. Dafür wurden jeweils 21 mock- und 21 Verticillium-infizierte Rapspflanzen analysiert. Die ermittelten Mittelwerte und Standardfehler für die gefundene Verticillium-DNA betrugen für die mock-inokulierten Rapspflanzen $0,23 \pm 0,08 \mathrm{ng} / \mathrm{g}$ Frischmasse und für die Verticilliuminfizierten Pflanzen 0,32 $\pm 0,22 \mathrm{ng} / \mathrm{g}$ Frischmasse. Diese Werte waren im T-Test $(p \leq 0,05)$ nicht signifikant unterschiedlich und lagen unterhalb des Detektionslimits für die PCR, das 0,5 ng/g Frischmasse betrug. Da die Werte an der Nachweisgrenze Methode lagen, kann man aus dem Ergebnis schließen, dass der Pilz 21 Tage nach Inokulation noch nicht bis in den Stängel vorgedrungen war. 


\subsubsection{Charakterisierung von Proteinmustern unter dem Einfluss von Verticillium longisporum}

\subsubsection{Kontaminationsbestimmung in der apoplastischen Waschflüssigkeit (AWF) von Raps}

Da ein Schwerpunkt der Arbeit auf der Analyse von apoplastischen Proteinen lag, war es nötig das Ausmaß der Kontamination mit symplastischen Proteinen in der AWF zu ermitteln. Dafür wurde die Aktivität des Markerenzyms Malatdehydrogenase (MDH), das nur im Zellinneren vorkommt, bestimmt (siehe 3.5.2.1). Die Extraktion der apoplastischen Waschflüssigkeiten wurde dahingehend optimiert (siehe 3.4.1 und 3.4.2), dass die Kontamination auf ein vernachlässigbares Maß reduziert war (Tab. 4.1). Die Aktivität des symplastischen Markerproteins war in der AWF der Verticillium-infizierten Pflanzen im Vergleich zu den mock-behandelten Pflanzen nicht signifikant erhöht. Dies spricht zusätzlich zu den Elektrolytleitfähigkeitsmessungen für intakte Plasmamembranen. Außerdem wurden die Proteingehalte in Gesamtblattextrakten und AWFs gemessen. Die Proteingehalte der Blattextrakte und der AWF lagen im Schnitt bei $13,5 \mathrm{mg} / \mathrm{g}$ Frischmasse und bei $0,015 \mathrm{mg}$ Protein pro Gramm Frischmasse (Tab. 4.1). Zwischen mock-behandeltem und Verticilliuminfiziertem Raps zeigten sich keine signifikanten Unterschiede im Proteingehalt.

Tab. 4.1: Kontaminationsbestimmung in den apoplastischen Waschflüssigkeiten aus mock- und Verticillium-infiziertem Raps mit Hilfe des Markerenzyms Malatdehydrogenase (MDH). Die Werte repräsentieren Mittelwerte aus fünf Messungen mit Standardfehler. Der P-Wert wurde mittels Student's T-Test berechnet. Zur Ermittlung der Kontamination wurde die MDH-Aktivität aus den AWF auf die jeweiligen MDH-Aktivitäten der Gesamtblattextrakte bezogen.

\begin{tabular}{ll|ccc|ccc}
\hline & & \multicolumn{3}{|c|}{ Gesamtblattextrakte } & \multicolumn{3}{c}{ AWF } \\
& & mock & VL43 & P-Wert & mock & VL43 & P-Wert \\
\hline Proteingehalt & (mg/g FM) & $13,7 \pm 2,1$ & $13,2 \pm 1,6$ & 0,8491 & $0,013 \pm 0,001$ & $0,017 \pm 0,002$ & 0,1142 \\
MDH-Aktivität & (nkat/g FM) & $417,1 \pm 31,7$ & $444,4 \pm 17,9$ & 0,4742 & $0,015 \pm 0,003$ & $0,038 \pm 0,022$ & 0,3439 \\
Kontamination & (\%) & & & & $0,004 \pm 0,001$ & $0,008 \pm 0,005$ & 0,3940 \\
\hline
\end{tabular}

\subsubsection{Vergleich von Proteinmustern in apoplastischen und Gesamtblattextrakten}

Apoplastische Proteine und Proteine aus Gesamtblattextrakten wurden 7, 14 und 21 Tage nach Inokulation mit Verticillium longisporum aus Raps gewonnen (siehe 3.4.2 und 3.4.3). Dafür wurden pro Probe die Blätter von jeweils fünf Rapspflanzen geerntet und zusammen extrahiert, wobei nur voll ausgebildete, aber noch nicht stark vergilbte oder geschädigte Blätter verwendet wurden. Die Proteinextrakte wurden elektrophoretisch in SDS-Polyacrylamidgradienten nach ihrem Molekulargewicht aufgetrennt (siehe 3.5.5) und anschließend mit Silbernitrat gefärbt (siehe 3.5.8). Bei den Gesamtblattextrakten waren zu keinem der untersuchten Zeitpunkte Unterschiede im Proteinmuster von mock-inokulierten 
Kontrollpflanzen $(K)$ und $V$. longisporum inokulierten Pflanzen $(V)$ zu sehen (Abb. 4.6). In der AWF dagegen zeigten sich deutliche Unterschiede im Bandenmuster von Proteinen aus Kontrollen und infiziertem Raps (Abb. 4.6). Zwar enthalten die Gesamtextrakte auch AWFProteine, aber da ihr Anteil an den Gesamtproteinen nur sehr gering ist (Tab. 4.1), sind sie in der Analyse der Gesamtextrakte nicht nachweisbar.

Die deutlichsten Unterschiede im Proteinmuster der AWF konnten 21 Tage nach Inokulation festgestellt werden. Zu diesem Zeitpunkt zeigten sich stärker, aber auch schwächer auftretende Banden der AWF aus Verticillium-infizierten Pflanzen im Vergleich zu mockinokulierten Kontrollen im Molekulargewichtsbereich von 14 bis 50 kDa. Die markantesten Unterschiede sind durch rote Pfeile markiert (Abb. 4.6).
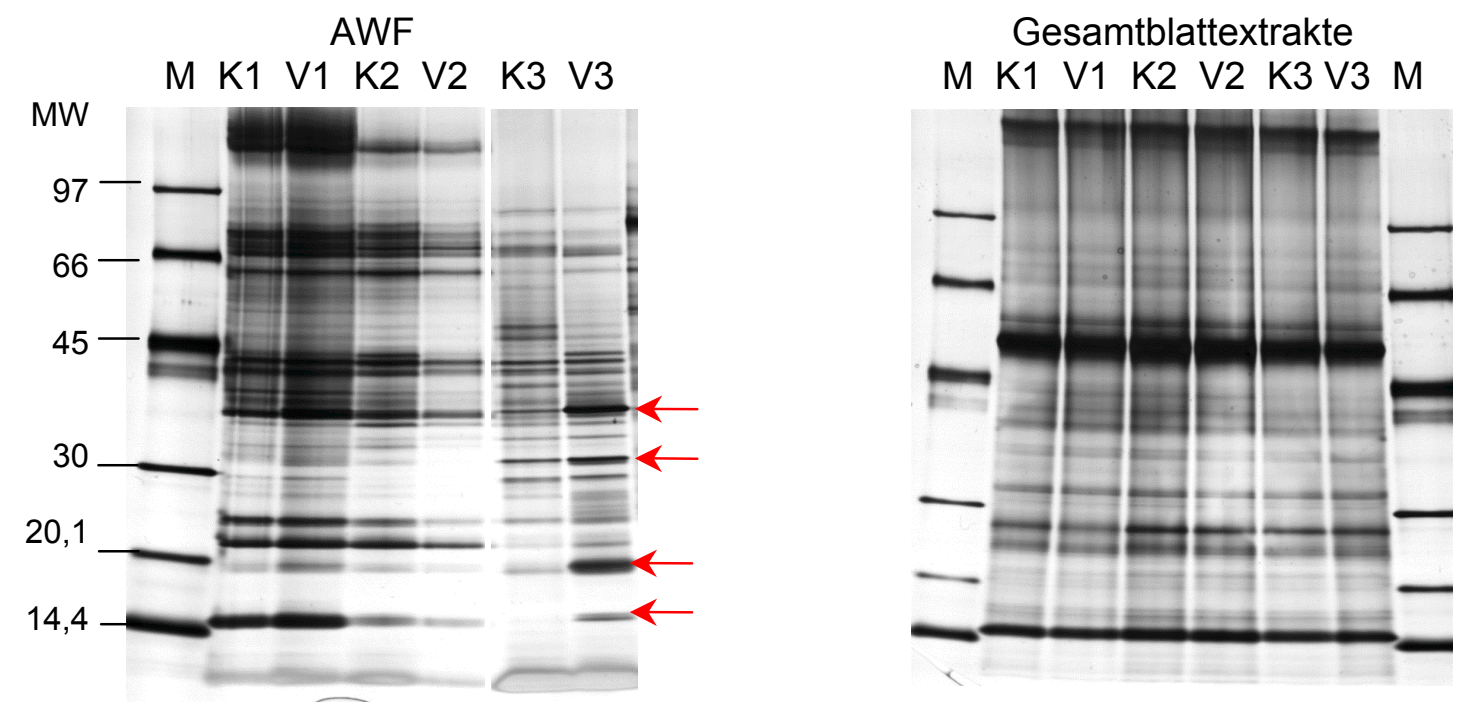

Abb. 4.6: Proteinmuster apoplastischer und Gesamtblattproteine von Raps in einem mit Sibernitrat gefärbten Gradientengel zu verschiedenen Zeitpunkten nach Infektion (Zeitpunkt 1: 7 Tage nach Inokulation, Zeitpunkt 2: 14 Tag nach Inokulation, Zeitpunkt 3: 21 Tage nach Inokulation; mockinokulierte Kontrollpflanzen $=\mathrm{K}, \mathrm{V}$. longisporum inokulierte Pflanzen $=\mathrm{V}$, Proteinstandard $=\mathrm{M})$. Die Trennung der Proteine erfolgte in einem 7,5-20 \% PAA-Gradienten; pro Spur wurden 1,8 $\mu$ grotein aufgetragen.

\subsubsection{Vergleich von Proteinmustern und Proteinanalyse in AWF und Xylemsäften}

Für weitere Analysen wurde der Zeitpunkt 21 Tage nach Inokulation gewählt. Dafür waren mehrere Gründe ausschlaggebend. Erstens traten 21 Tage nach Inokulation die deutlichsten Unterschiede im Proteinmuster von Kontrollen und infizierten Pflanzen in der AWF von Raps auf und zweitens waren die Pflanzen zu diesem Zeitpunkt groß genug, um zusätzlich zur apoplastischen Waschflüssigkeit auch noch Xylemsaft in ausreichender Menge für eine Proteinanalyse zu gewinnen. Spätere Zeitpunkte waren nicht geeignet, da der Raps dann anfing zu blühen und viele Blätter abwarf. 
Zur Untersuchung von Proteinmustern wurden neben der AWF auch Xylemsäfte gewonnen und die Proteinkonzentration der Extrakte bestimmt. Der Xylemsaft enthielt nur geringe Mengen an Protein (ca. $35 \mu \mathrm{g} / \mathrm{ml}$ ). Um für die Analysen ausreichende Proteinmengen zu erhalten, wurden ca. $15 \mathrm{ml}$ Xylemsaft aus 15 Rapspflanzen gewonnen. Der Xylemsaft wurde aufkonzentriert und ebenso wie die AWF in einem PAA-Gradienten aufgetrennt (siehe 3.5.5) In Abbildung 4.7 sind die Coomassie-gefärbten Gele mit den Proteinmustern von Xylemsaft und apoplastischer Waschflüssigkeit zu sehen. Beim Vergleich von Xylemsaft und AWF zeigte sich, dass die Proteinzusammensetzung des Xylemsaftes sich deutlich von der der AWF unterschied. Weitere deutliche Unterschiede waren auch im Proteinmuster von mockinokulierten und Verticillium-inokulierten Pflanzen sichtbar. Beim Xylemsaft traten drei Banden (XVL1-3) unter Verticillium-Infektion neu auf bzw. wesentlich stärker hervor als bei mock-Inokulation. In der AWF zeigten sich bei den gleichen Molekulargewichten ebenfalls drei stärkere Banden (AVL1, 2 und 7) unter Verticillium-Einfluss. Zusätzlich traten zwei weitere Banden in der AWF von Verticillium-infizierten Pflanzen stärker hervor als in den Kontrollen (AVL5 und AVL9). Außerdem war in der AWF unter Verticillium-Einfluss eine Bande schwächer als in der Kontrolle (AK6).
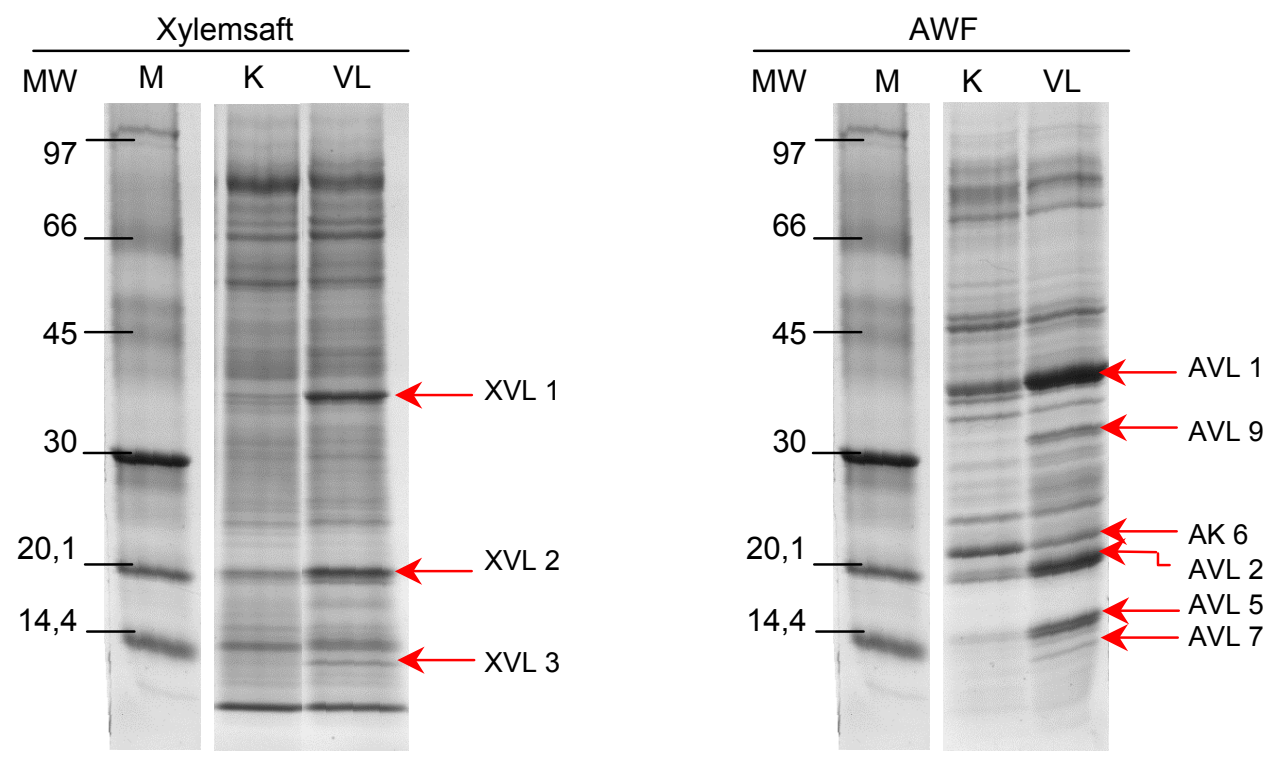

Abb. 4.7: Proteinmuster von Xylemsaft und AWF aus mock- und Verticillium-inokuliertem Raps. Pro Spur wurden $100 \mu \mathrm{g}$ Xylemsaftproteine bzw. apoplastischen Proteine in einem SDS-Polyacrylamidgel (PAA-Gradient: 7,5-20 \%) aufgetrennt und anschließend mit CBB gefärbt. Die roten Pfeile deuten auf Unterschiede im Proteinmuster von mock- $(\mathrm{K})$ und Verticillium-inokulierten (VL) Pflanzen hin.

Die in den Gelbildern (Abb. 4.7) mit roten Pfeilen markierten Banden wurden aus dem Gel ausgeschnitten und mit Trypsin verdaut (siehe 3.5.10). Mittels ESI-LC-Massenspektrometrie und anschließender Mascot-Suche in der NCBI-Datenbank wurden die Proteine identifiziert. Die Ergebnisse sind in Tabelle 4.2 zusammengefasst. 
Zwei der Xylemsaftproteine konnten identifiziert werden. Das Protein aus der Bande XVL1 wies eine starke Ähnlichkeit mit einer basischen Glucanase aus Brassica juncea (brauner Senf) und mit einer $\beta-1,3-G l u c a n a s e ~(A t 3 g 57240$ ) aus Arabidopsis thaliana auf. Das auf Basis von Sequenzdaten erwartete Molekulargewicht (MW) dieser Proteine lag laut NCBIAngaben bei $31 \mathrm{kDa}$, wobei die Bande des ausgeschnittenen Proteins bei $37 \mathrm{kDa}$ lag. Das andere identifizierte Protein mit der Bezeichnung XVL3 wies Ähnlichkeit mit einem pathogen related PR-4 Protein aus Brassica rapa auf. Hier lag das erwartete Molekulargewicht bei 16 kDa und das aus dem Gel, mittels einer Eichkurve der Markerproteinen berechnete (siehe 3.5.6) bei $14 \mathrm{kDa}$. Mit Hilfe des Programms TargetP (Server v1.01) wurde die Anwesenheit von möglichen Signalpeptiden überprüft (siehe 3.5.11). Für die basische Glucanase aus Brassica juncea bzw. $\beta-1,3-$ Glucanase aus Arabidopsis thaliana und das PR-4 Protein aus Brassica rapa wurde mit einer sehr guten Wahrscheinlichkeit ein Signalpeptid für den sekretorischen Weg gefunden.

Aus den Proteinbanden der apoplastischen Waschflüssigkeiten konnten fünf Proteine identifiziert werden (Tab. 4.2). AVL1 und AVL7 entsprachen den Proteinen XVL1 und XVL3, die im Xylemsaft identifiziert wurden. Das Protein AVL2 konnte als basische Endochitinase aus Brassica napus identifiziert werden, wobei eine Ähnlichkeit zu einer Chitinase aus Brassica rapa mit der gleichen Trefferwahrscheinlichkeit gefunden wurde. Beide Chitinasen hatten laut NCBI-Angaben ein Molekulargewicht von ungefähr 29 kDa, das aus dem Gel ermittelte lag nur bei $19 \mathrm{kDa}$. Die in NCBI angegebenen Molekulargewichte sind theoretisch berechnet und können von den tatsächlichen abweichen. Dafür können verschiedene Gründe verantwortlich sein, z.B. alternatives Splicing oder posttranslationale Modifikationen. Für Brassica napus allgemein und für die von uns verwendete rapid cycle Variation im Besonderen sind nur wenige Daten verfügbar, was eine Identifizierung von Proteinen erschwert. So war die Identifizierung der Chitinase mit einem Protein-Score von 58 auch nicht besonders eindeutig.

Die Proteinbande von AVL2 hatte das gleiche Molekulargewicht wie die Bande XVL2 aus dem Xylemsaft. Das Protein aus dem Xylemsaft konnte nicht identifiziert werden; möglicherweise handelt es sich hier aber auch um die in der AWF gefundene Chitinase. AVL5 konnte nicht identifiziert werden, aber AVL9 und AK6. Das Protein AVL9 wies starke Ähnlichkeit zu einer Peroxidase aus Raphanus sativus und zu einer Peroxidase aus Brassica rapa auf. Mit einer weniger guten Trefferwahrscheinlichkeit ergab sich auch eine Ähnlichkeit zu einer Peroxidase (At2g18150) aus Arabidopsis thaliana. Die Angaben für die Molekulargewichte dieser Peroxidasen liegen zwischen 31 und $38 \mathrm{kDa}$, in diesem Molekulargewichtsbereich liegt mit $31 \mathrm{kDa}$ auch die Bande für das analysierte Protein. Die unter Verticillium-Einfluss in ihrer Intensität abgeschwächte Proteinbande AK6 konnte einem Germin-ähnlichen Protein aus Arabidopsis thaliana zugeordnet werden. Hierfür stimmten die Angaben für das erwartete Molekulargewicht von $22 \mathrm{kDa}$ mit dem tatsächlichen von $21 \mathrm{kDa}$ relativ genau überein. Für alle identifizierten Proteine, außer für die Peroxidase P7 aus 
Brassica rapa, konnte ein Signalpeptid für den sekretorischen Weg nachgewiesen werden (Tab. 4.2).

Tab. 4.2: AWF und Xylemsaftproteine, die unter Verticillium-Einfluss differentiell auftraten. Die Proteine wurden mittels massenspektrometrischer Analyse und Mascot-Suche in der NCBI Datenbank identifiziert. Angegeben sind die Nummer der Bande in Abb. 4.7, die NCBI-Nummer, die Accession No (Acc. No), der Protein Score und das laut NCBI-Angaben erwartete Molekulargewicht (MW) des Proteins. Die Anwesenheit von Signalpeptiden wurde mit TargetP überprüft, wobei $\mathrm{C}=\mathrm{Chloroplast}$ und $S=$ Sekretorischer Weg bedeutet. RC steht für reliability class und ist ein Maß für die Zuverlässigkeit der Vorhersage, je kleiner der RC-Wert, desto sicherer die Vorhersage für das Signalpeptid.

\begin{tabular}{|c|c|c|c|c|c|c|c|}
\hline $\begin{array}{l}\text { Banden } \\
\mathrm{Nr} \text {. }\end{array}$ & Ähnlichkeit mit & Organismus & NCBI Nr. & Acc. No & $\begin{array}{l}\text { Protein } \\
\text { Score }\end{array}$ & MW & $\begin{array}{l}\text { Signal- } \\
\text { peptid }\end{array}$ \\
\hline \multirow[t]{2}{*}{ XVL 1} & basische Glucanase & Brassica juncea & gi|118763538 & ABC94638 & 510 & 30722 & $S(R C 1)$ \\
\hline & $\beta-1,3-G l u c a n a s e$ & $\begin{array}{l}\text { Arabidopsis } \\
\text { thaliana }\end{array}$ & gi|6735303 & At3g57240 & 222 & 37632 & $S(R C 1)$ \\
\hline XVL 2 & nicht identifiziert & & & & & & \\
\hline XVL 3 & PR4-Typ Protein & $\begin{array}{l}\text { Brassica rapa } \\
\text { subsp. pekinensis }\end{array}$ & gi|73671284 & AF528181 & 162 & 15950 & $S(R C 2)$ \\
\hline \multirow[t]{2}{*}{ AVL 1} & basische Glucanase & Brassica juncea & gi|118763538 & ABC94638 & 480 & 37906 & $S(R C 1)$ \\
\hline & $\beta$-1,3-Glucanase & $\begin{array}{l}\text { Arabidopsis } \\
\text { thaliana }\end{array}$ & gi|6735303 & At3g57240 & 201 & 30681 & $S(R C 1)$ \\
\hline \multirow[t]{2}{*}{ AVL 2} & $\begin{array}{l}\text { basische Endochitinase } \\
\text { CHB4 }\end{array}$ & Brassica napus & gi|584929 & Q06209 & 58 & 29684 & $S(R C 1)$ \\
\hline & Chitinase & $\begin{array}{l}\text { Brassica rapa } \\
\text { subsp. pekinensis }\end{array}$ & gi|116267545 & AB257452 & 58 & 29652 & $S(R C 1)$ \\
\hline AVL 5 & nicht identifiziert & & & & & & \\
\hline AVL 7 & PR4-Typ Protein & $\begin{array}{l}\text { Brassica rapa } \\
\text { subsp. pekinensis }\end{array}$ & gi|73671284 & AF528181 & 108 & 15950 & $\mathrm{~S}(\mathrm{RC} 2)$ \\
\hline \multirow[t]{3}{*}{ AVL 9} & $\begin{array}{l}\text { koreanische Rettich- } \\
\text { Isoperoxidase }\end{array}$ & Raphanus sativus & gi|1518388 & X91172 & 200 & 33993 & $S(R C 3)$ \\
\hline & Peroxidase P7 (TP7) & $\begin{array}{l}\text { Brassica rapa } \\
\text { subsp. rapa }\end{array}$ & gi|464365 & P00434 & 200 & 31523 & $\mathrm{C}(\mathrm{RC} 4)$ \\
\hline & $\begin{array}{l}\text { Peroxidase, putative; } \\
\text { Atperox P15 }\end{array}$ & $\begin{array}{l}\text { Arabidopsis } \\
\text { thaliana }\end{array}$ & gi|15224116 & At2g18150 & 52 & 37626 & $S(R C 2)$ \\
\hline AK 6 & Germin (GER3; GLP 3) & $\begin{array}{l}\text { Arabidopsis } \\
\text { thaliana }\end{array}$ & gi|1755154 & At5g20630 & 156 & 22020 & $S(R C 1)$ \\
\hline
\end{tabular}

\subsubsection{Zweidimensionale Auftrennung apoplastischer Rapsproteine}

Zusätzlich zur eindimensionalen wurden die apoplastischen Proteine auch zweidimensional nach ihrem isoelektrischen Punkt ( $\mathrm{pl}$ ) und ihrem Molekulargewicht (MW) aufgetrennt. Abbildung 4.8 zeigt die zweidimensionale Separation von je $80 \mu \mathrm{g}$ apoplastischen Proteinen aus mock- und Verticillium-inokuliertem Raps. 
mock

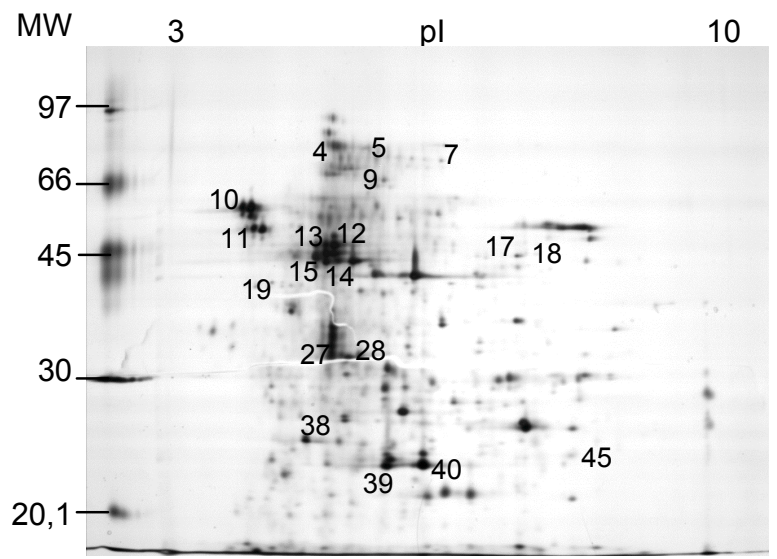

VL43

3

$\mathrm{pl}$ 10

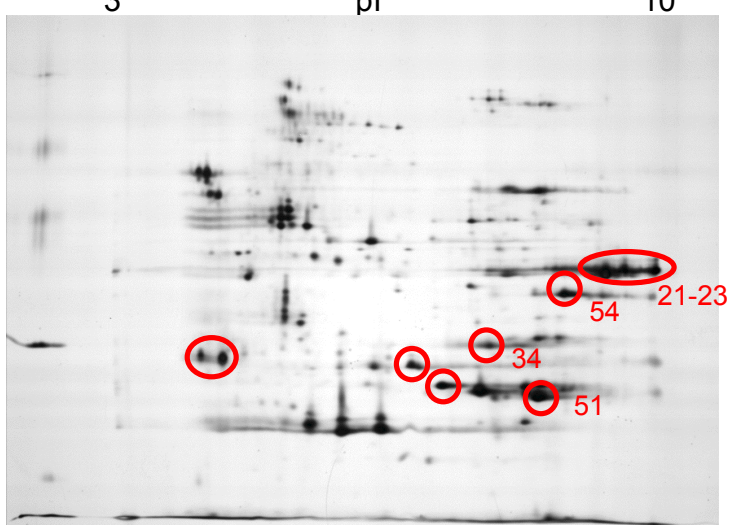

Abb. 4.8: Proteinmuster von mock- und Verticillium (VL43)-infiziertem Raps nach zweidimensionaler gelelektrophoretischer Auftrennung von je $80 \mu \mathrm{g}$ apoplastischen Proteinen. Es wurden fünf biologische Wiederholungen durchgeführt, von denen jeweils ein repräsentatives mit Silber gefärbtes Gel dargestellt ist. Die schwarzen Zahlen weisen auf Proteine hin, die in beiden Behandlungen vorkamen und identifiziert werden konnten. Die roten Kreise zeigen Proteine, die bei Analyse von jeweils fünf Gelen eine signifikant stärkere Expression in Verticillium-beeinflussten Proben aufwiesen. Nur Proteinspots, die mit Zahlen markiert sind, konnten identifiziert werden (Tab. 4.3 und 4.4).

Für eine statistische Auswertung wurden pro mock- bzw. V. longisporum-Behandlung fünf biologische Wiederholungen analysiert; dafür wurden die Gele mit Silber gefärbt. Bei den Silber-gefärbten Gelen wurden durchschnittlich $170 \pm 9$ Spots detektiert. Mit Hilfe der Proteomweaver-Software wurden die Gele von mock-inokulierten Kontrollpflanzen mit denen von Verticillium-inokulierten Pflanzen verglichen (siehe 3.5.9). So wurde nach Spots gesucht, die in mock- und Verticillium-inokulierten Pflanzen differentiell exprimiert waren. Gefunden wurden 10 Spots, die nach Verticillium-Infektion neu bzw. stärker auftraten. Von diesen Spots (in Abb. 4.8 durch rote Kreise gekennzeichnet), die aus einem Coomassie gefärbten Gel ausgestochen wurden, konnten sechs identifiziert werden (Tab. 4.3). Die Spots 21-23 zeigten, mit einem guten Protein-Score, Ähnlichkeit zu einer basischen Glucanase aus

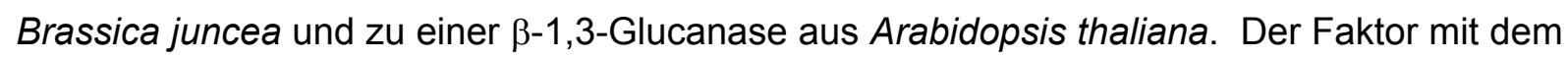
die drei Spots signifikant $(p \leq 0,05)$ unterschiedlich waren, betrug zwischen 3,1 und 4,8. Die Spots 34 und 51 wiesen Ähnlichkeit zu einer basischen Endochitinase (CHB4) aus Raps auf und wurden mit dem Faktor 7,2 bzw. 4,2 reguliert. Ein weiteres Protein, das signifikant um den Faktor 2,4 verändert war und identifiziert werden konnte, zeigte Ähnlichkeit zu einer Rettich-Peroxidase und mit dem gleichen Protein-Score zu einer Peroxidase aus Arabidopsis. Alle drei differentiell aufgetretenen Proteine Glucanase, Chitinase und Peroxidase waren ebenfalls aus dem eindimensionalen Gel als differentiell auftretend identifiziert worden (Abb. 4.7 und Tab. 4.2), so dass die vorherige Identifizierung bestätigt wurde. Die Überprüfung der identifizierten Proteine auf das Vorhandensein von Signalpeptiden ergab für alle Proteine laut Analyse mit TargetP eine hohe Wahrscheinlichkeit für ein sekretorisches Signalpeptid. 
Tab. 4.3: Unter Verticillium-Einfluss differentiell exprimierte Proteine in der AWF von Raps. Die Identifizierung erfolgte mittels MS-Analyse und Mascot-Suche in der NCBI Datenbank. Angegeben sind die NCBI-Nummer, die Accession No (Acc. No), der Protein Score und das laut NCBI-Angaben erwartete Molekulargewicht (MW) des Proteins. Die Anwesenheit von Signalpeptiden wurde mit TargetP überprüft, wobei $S=$ Sekretorischer Weg bedeutet. $\mathrm{RC}$ steht für reliability class und ist ein Maß für die Zuverlässigkeit der Vorhersage, je kleiner der RC-Wert, desto sicherer die Vorhersage für das Signalpeptid. Außerdem ist der Faktor angegeben, mit dem die Proteine verändert auftraten und das Ergebnis des Students T-Test für jeden Spot, wobei $p \leq 0,05$ als signifikant angesehen wurde.

\begin{tabular}{|c|c|c|c|c|c|c|c|c|c|}
\hline $\begin{array}{l}\text { Spot } \\
\text { Nr. }\end{array}$ & Ähnlichkeit mit & Organismus & $\begin{array}{c}\mathrm{NCBI} \\
\mathrm{Nr} .\end{array}$ & Acc. No & $\begin{array}{l}\text { Protein } \\
\text { Score }\end{array}$ & MW & $\begin{array}{l}\text { Signal- } \\
\text { peptid }\end{array}$ & Faktor & p-Wert \\
\hline \multirow[t]{2}{*}{21} & basische Glucanase & $\begin{array}{l}\text { Brassica } \\
\text { juncea }\end{array}$ & gi|86371164 & ABC94638 & 223 & 30722 & $S(R C 1)$ & 3,9 & 0,037 \\
\hline & $\beta-1,3-$ Glucanase & $\begin{array}{l}\text { Arabidopsis } \\
\text { thaliana }\end{array}$ & gi|6735303 & At3g57240 & 91 & 37632 & $S(R C 1)$ & & \\
\hline \multirow[t]{2}{*}{22} & basische Glucanase & $\begin{array}{l}\text { Brassica } \\
\text { juncea }\end{array}$ & gi|86371164 & ABC94638 & 405 & 30722 & $S(R C 1)$ & 3,1 & 0,001 \\
\hline & $\beta-1,3-$ Glucanase & $\begin{array}{l}\text { Arabidopsis } \\
\text { thaliana }\end{array}$ & gi|6735303 & At3g57240 & 180 & 37632 & $S(R C 1)$ & & \\
\hline \multirow[t]{2}{*}{23} & basische Glucanase & $\begin{array}{l}\text { Brassica } \\
\text { juncea }\end{array}$ & gi|86371164 & ABC94638 & 453 & 30722 & $S(R C 1)$ & 4,8 & 0,049 \\
\hline & $\beta-1,3-$ Glucanase & $\begin{array}{l}\text { Arabidopsis } \\
\text { thaliana }\end{array}$ & gi|6735303 & At3g57240 & 222 & 37632 & $S(R C 1)$ & & \\
\hline 34 & $\begin{array}{l}\text { basische Endo- } \\
\text { chitinase CHB4 }\end{array}$ & $\begin{array}{l}\text { Brassica } \\
\text { napus }\end{array}$ & gi|584929 & Q06209 & 95 & 29684 & $\mathrm{~S}(\mathrm{RC} 1)$ & 7,7 & 0,009 \\
\hline 51 & $\begin{array}{l}\text { basische Endo- } \\
\text { chitinase CHB4 }\end{array}$ & $\begin{array}{l}\text { Brassica } \\
\text { napus }\end{array}$ & gi|584929 & Q06209 & 159 & 29684 & $\mathrm{~S}(\mathrm{RC} 1)$ & 4,2 & 0,020 \\
\hline \multirow[t]{2}{*}{54} & $\begin{array}{l}\text { koreanische Rettich } \\
\text { Isoperoxidase }\end{array}$ & $\begin{array}{l}\text { Raphanus } \\
\text { sativus }\end{array}$ & gi|1518388 & X91172 & 94 & 33993 & $\mathrm{~S}(\mathrm{RC} 3)$ & 2,4 & 0,040 \\
\hline & Peroxidase, putative & $\begin{array}{l}\text { Arabidopsis } \\
\text { thaliana }\end{array}$ & gi|15239075 & At5g05340 & 94 & 34650 & $\mathrm{~S}(\mathrm{RC} 1)$ & & \\
\hline
\end{tabular}

Zusätzlich zu den differentiell exprimierten Spots, konnten noch 19 Proteine aus einem Coomassie-gefärbten Kontrollgel identifiziert werden (Tab. 4.4). Dabei handelte es sich um 11 unterschiedliche Proteine. Drei Spots (Nr. 4, 5, 7) wiesen Ähnlichkeit zu einer $\alpha$-LArabinofuranosidase aus Raphanus sativus bzw. Arabidopsis auf, vier Spots zeigten Ähnlichkeit zu einer Glucanase aus Brassica juncea (Spot Nr. 12-15). Jeweils drei Spots zeigten Ähnlichkeit zu einer Protease aus der Aspartyl Familie (Spot Nr. 10, 17, 18) und zu einem Germin (GLP3; Nr. 39, 40, 45) aus Arabidopsis. Die Spots 27 und 28 wiesen Ähnlichkeit zu einer Klasse 4 Chitinase aus Brassica napus auf. Weiterhin wurden eine Peroxidase (Spot Nr. 11), eine Carboxylester Hydrolase (Spot Nr. 19) und ein unbekanntes Protein (Spot Nr. 38) aus Arabidopsis identifiziert. Ähnlichkeit wurde auch zu einem hypothetischen Protein aus Brassica rapa (Nr. 9) gefunden, das ein Signalpeptid für chloroplastidäre Lokalisation aufwies. Die $\alpha$-L-Arabinofuranosidase aus Raphanus sativus besaß ein Signalpeptid für die Mitochondrien, allerdings mit einer geringen Vorhersagewahrscheinlichkeit (Reliability class 4). Ansonsten wiesen alle gefunden Proteine mit einer mehr oder weniger hohen Wahrscheinlichkeit ein Signalpeptid für den sekretorischen Weg auf. 
Tab. 4.4: Identifikation von Proteinspots aus Kontrollgelen der AWF von Raps mittels MS-Analyse und Mascot-Suche in der NCBI Datenbank. Zusätzlich zur NCBI-Nummer ist noch die Accession No und das erwartete Molekulargewicht der Proteine angegeben. Die Anwesenheit von Signalpeptiden wurde mit TargetP überprüft, wobei $\mathrm{C}=$ Chloroplast, $\mathrm{M}=$ Mitochondrium und $\mathrm{S}=$ Sekretorischer Weg bedeutet. RC steht für reliability class und ist ein Maß für die Zuverlässigkeit der Vorhersage, je kleiner der RC-Wert, desto sicherer die Vorhersage für das Signalpeptid.

\begin{tabular}{|c|c|c|c|c|c|c|c|}
\hline $\begin{array}{l}\text { Spot } \\
\text { Nr. }\end{array}$ & Ähnlichkeit mit & Organismus & NCBI-Nr. & Acc. No & $\begin{array}{c}\text { Protein } \\
\text { Score }\end{array}$ & MW & $\begin{array}{l}\text { Signal- } \\
\text { peptid }\end{array}$ \\
\hline 4 & $\begin{array}{l}\alpha \text {-L-Arabinofuranosidase } \\
\text { T7M13_18 }\end{array}$ & $\begin{array}{l}\text { Arabidopsis } \\
\text { thaliana }\end{array}$ & gi|13937191 & At3g10740 & 113 & 75437 & $\mathrm{~S}(\mathrm{RC} 2)$ \\
\hline 5 & $\alpha$-L-Arabinofuranosidase & Raphanus sativus & gi|74355968 & BAE44362 & 76 & 84750 & $\mathrm{M}(\mathrm{RC} 4)$ \\
\hline 7 & $\alpha$-L-Arabinofuranosidase & Raphanus sativus & gi|74355968 & BAE44362 & 195 & 84750 & $\mathrm{M}(\mathrm{RC} 4)$ \\
\hline 9 & hypothetisches Protein & $\begin{array}{l}\text { Brassica rapa } \\
\text { susp. pekinensis }\end{array}$ & gi|72384433 & $\begin{array}{l}\text { homolog of } \\
\text { At5g09770 }\end{array}$ & 84 & 60345 & $C(R C 1)$ \\
\hline 10 & $\begin{array}{l}\text { Pepsin A, Aspartyl } \\
\text { Protease Familie }\end{array}$ & $\begin{array}{l}\text { Arabidopsis } \\
\text { thaliana }\end{array}$ & gi|22326716 & $\begin{array}{l}\text { At5g10770 bzw. } \\
\text { At5g10760 }\end{array}$ & 46 & 50802 & $\begin{array}{l}S(R C 5) \\
S(R C 2)\end{array}$ \\
\hline 11 & Peroxidase & $\begin{array}{l}\text { Arabidopsis } \\
\text { thaliana }\end{array}$ & gi|15224116 & At2g18150 & 44 & 37626 & $S(R C 2)$ \\
\hline 12 & Glucanase & Brassica juncea & gi|86371166 & ABC94639 & 75 & 38120 & $S(R C 1)$ \\
\hline 13 & Glucanase & Brassica juncea & gi|86371166 & ABC94639 & 51 & 38120 & $S(R C 1)$ \\
\hline 14 & Glucanase & Brassica juncea & gi|86371166 & ABC94639 & 76 & 38120 & $S(R C 1)$ \\
\hline 15 & Glucanase & Brassica juncea & gi|86371166 & ABC94639 & 57 & 38120 & $S(R C 1)$ \\
\hline 17 & $\begin{array}{l}\text { Pepsin A, Aspartyl } \\
\text { Protease Familie }\end{array}$ & $\begin{array}{l}\text { Arabidopsis } \\
\text { thaliana }\end{array}$ & gi|22326716 & $\begin{array}{l}\text { At5g10770 bzw. } \\
\text { At5g10760 }\end{array}$ & 58 & 50802 & $\begin{array}{l}\text { S (RC 5) } \\
\text { S (RC 2) }\end{array}$ \\
\hline 18 & $\begin{array}{l}\text { Pepsin A, Aspartyl } \\
\text { Protease Familie }\end{array}$ & $\begin{array}{l}\text { Arabidopsis } \\
\text { thaliana }\end{array}$ & gi|22326716 & $\begin{array}{l}\text { At5g10770 bzw. } \\
\text { At5g10760 }\end{array}$ & 49 & 50802 & $\begin{array}{l}S(R C 5) \\
\text { S (RC 2) }\end{array}$ \\
\hline 19 & Carboxylester Hydrolase & $\begin{array}{l}\text { Arabidopsis } \\
\text { thaliana }\end{array}$ & gi|15220512 & At1g29660 & 87 & 40630 & $S(R C 2)$ \\
\hline 27 & $\begin{array}{l}\text { Chitinase } \\
\text { Klasse 4-Protein }\end{array}$ & Brassica napus & gi|14486393 & AAK62048 & 103 & 31219 & $S(R C 4)$ \\
\hline 28 & $\begin{array}{l}\text { Chitinase } \\
\text { Klasse 4-Protein }\end{array}$ & Brassica napus & gi|14486393 & AAK62048 & 90 & 31219 & $S(R C 4)$ \\
\hline 38 & $\begin{array}{l}\text { unbekanntes Protein } \\
\text { (plant basic secretory } \\
\text { protein (BSP) }\end{array}$ & $\begin{array}{l}\text { Arabidopsis } \\
\text { thaliana }\end{array}$ & gi|15226060 & At2g15130 & 81 & 25459 & $S(R C 1)$ \\
\hline 39 & $\begin{array}{l}\text { Germin } \\
\text { (GER 3, GLP3) }\end{array}$ & $\begin{array}{l}\text { Arabidopsis } \\
\text { thaliana }\end{array}$ & gi|1755154 & At5g20630 & 56 & 22020 & $S(R C 1)$ \\
\hline 40 & $\begin{array}{l}\text { Germin } \\
\text { (GER 3, GLP3) }\end{array}$ & $\begin{array}{l}\text { Arabidopsis } \\
\text { thaliana }\end{array}$ & gi|1755154 & At5g20630 & 98 & 22020 & $S(R C 1)$ \\
\hline 45 & $\begin{array}{l}\text { Germin } \\
\text { (GER 3, GLP3) }\end{array}$ & $\begin{array}{l}\text { Arabidopsis } \\
\text { thaliana }\end{array}$ & gi|1755154 & At5g20630 & 73 & 22020 & $S(R C 1)$ \\
\hline
\end{tabular}




\subsubsection{Peroxidase Aktivitäten}

Zwei der aus den Gelen identifizierten Apoplasten-Proteine wiesen Ähnlichkeit zu Peroxidasen auf. Eine der Peroxidasen war unter Verticillium-Einfluss hochreguliert, während die andere nicht differentiell reguliert war. Zur Überprüfung der Peroxidase-Aktivität wurden 21 Tage nach Inokulation, also zum gleichen Erntezeitpunkt, von dem auch Proteingele untersucht wurden, Aktivitätsmessungen mit dem unspezifischen Substrat Guajakol durchgeführt. Die Peroxidase Aktivität in der AWF war mit ca. 2 nkat/g Frischgewicht (FG) doppelt so hoch wie die Aktivität in den Gesamtblattextrakten (Abb. 4.9). Ein Veränderung der Peroxidase Aktivität in den Verticillium-inokulierten Rapspflanzen im Vergleich zu den mock-inokulierten Kontrollpflanzen konnte aber weder in der AWF noch in den Gesamtblattextrakten beobachtet werden.
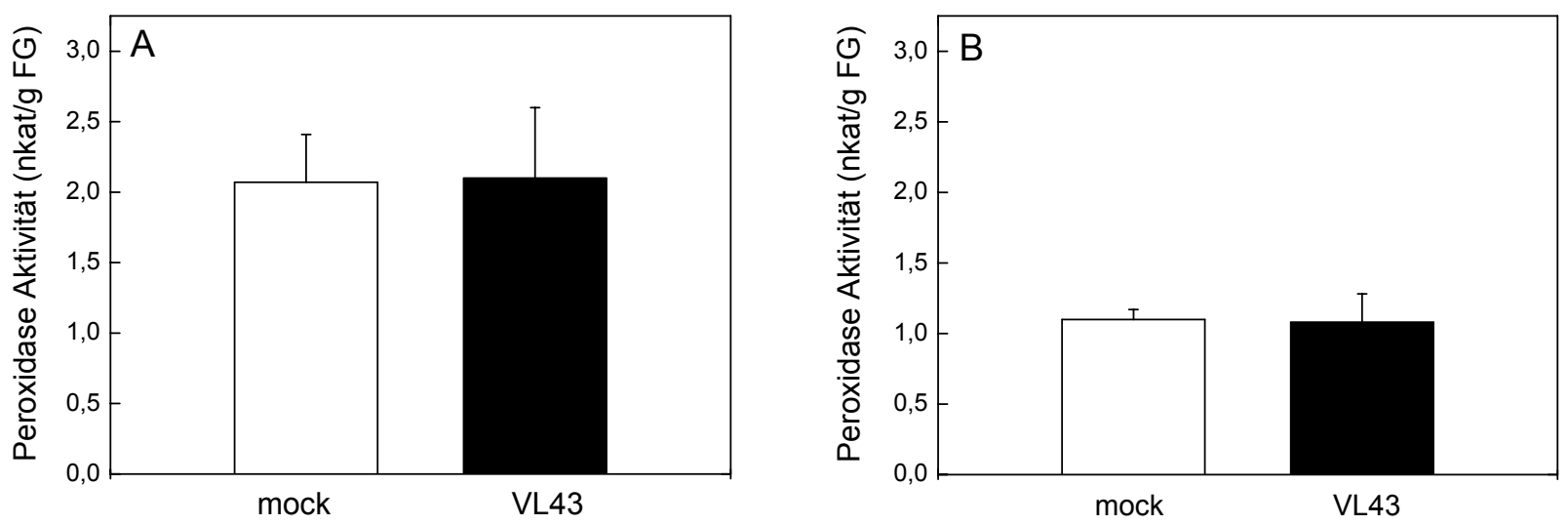

Abb. 4.9: Peroxidase Aktivität in der AWF (A) und in Gesamtblattextrakten (B) von mock- und Verticillium-inokulierten Rapspflanzen. Die Balken repräsentieren Mittelwerte mit Standardfehler von $\mathrm{n}=8$ Proben für die AWF und $\mathrm{n}=5$ für die Gesamtblattextrakte. Die Aktivität wurde photometrisch mit Guajakol als Substrat bestimmt. 


\subsection{Einfluss von Verticillium longisporum auf die Modellpflanze Arabidopsis thaliana}

\subsubsection{Ermittlung geeigneter Versuchsbedingungen}

\subsubsection{Vergleich der Arabidopsis thaliana Ökotypen Columbia und Landsberg erecta} Verschiedene Arabidopsis Ökotypen reagieren unterschiedlich auf Verticillium dahliae Infektion (Veronese et al., 2003). Der Ökotyp Landsberg erecta war im Vergleich zum Ökotypen Columbia geringfügig empfindlicher für $V$. dahliae. Dies zeigte sich zum Beispiel durch eine etwas stärkere Vergilbung von Blättern (Veronese et al., 2003).

$\mathrm{Ob}$ solche Unterschiede auch für die Infektion mit $V$. Iongisporum bestehen, ist nicht bekannt. Um dies zu prüfen wurden die beiden Ökotypen unter Verticillium longisporum Einfluss untersucht. Als Parameter wurden die Rosettenfläche, das Frischgewicht und der Chlorophyllgehalt gewählt. Der Infektionsverlauf wurde durch digitale Photos der einzelnen Pflanzen zu verschiedenen Zeitpunkten nach Inokulation dokumentiert (Abb. 4.10A). Mit einer speziell entwickelten Software zur Blattflächenanalyse konnten die Bilder einzeln ausgewertet und die projizierte Rosettenfläche vermessen werden (siehe 3.3.6). In Abbildung 4.10A verdeutlichen exemplarische Photos zu verschiedenen Zeitpunkten nach Inokulation von mock und Verticillium-infizierten Arabidopsis Ökotypen Columbia und Landsberg erecta Symptome, die durch die Verticillium-Infektion hervorgerufen wurden, wie die Beeinflussung der Rosettengröße und Vergilbung. Die Analyse des Rosettenwachstums über einen zeitlichen Verlauf von 3 bis 35 Tagen, zeigte deutliche Unterschiede zwischen den Kontrollen der Ökotypen Columbia und Landsberg (Abb. 4.10B und C). Die Rosettenfläche der mock-inokulierten Landsberg-Pflanzen war zum Endzeitpunkt der Untersuchung mit durchschnittlich $50 \mathrm{~cm}^{2}$ im Vergleich zu den mock-inokulierten Columbia Pflanzen mit durchschnittlich $76 \mathrm{~cm}^{2}$ deutlich kleiner. Schon 14 Tage nach Inokulation war der Unterschied zwischen Rosettengrößen der Ökotypen Columbia und Landsberg signifikant.

In Abbildung 4.10B und 4.10C sind die Blattflächen der Rosetten von mock- und Verticilliuminfizierten Arabidopsis im Vergleich dargestellt. Abbildung 4.10B zeigt den Einfluss von Verticillium longisporum auf die Rosettengröße des Ökotyps Columbia im Infektionsverlauf. Ab 21 Tage nach Inokulation waren die Unterschiede zwischen den Blattflächen der Verticillium-inokulierten und der mock-inokulierten Pflanzen signifikant unterschiedlich. Zum gleichen Zeitpunkt zeigte sich auch beim Ökotypen Landsberg eine signifikante Reduktion der Blattfläche von Verticillium-inokulierten Pflanzen im Vergleich zu den mock-inokulierten Kontrollpflanzen (Abb. 4.10C).

Um zu prüfen, ob die durch $V$. Iongisporum verursachte Stauchung im Vergleich zur Kontrollbehandlung bei den beiden Ökotypen unterschiedlich stark ausgeprägt war, wurde die relative Stauchung als Verhältnis von VL43/mock bestimmt (Abb. 4.11). Diese Analyse ergab keine durch die Infektion hervorgerufenen Unterschiede zwischen den beiden Ökotypen. 
A

Col

mock
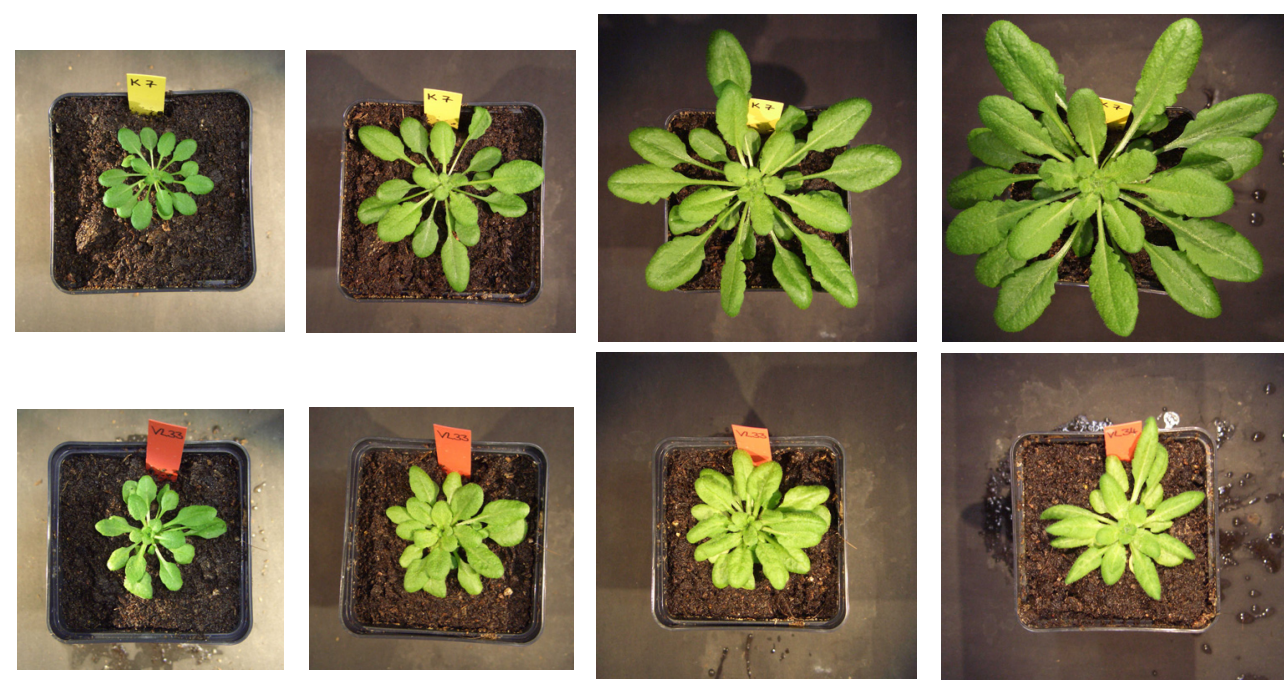

6

14

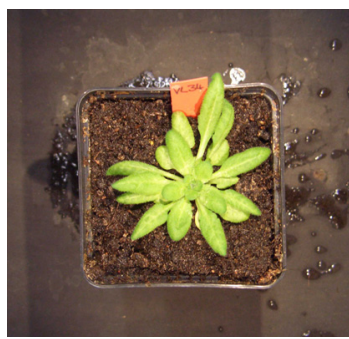

25

Tage nach Inokulation

Ler

mock
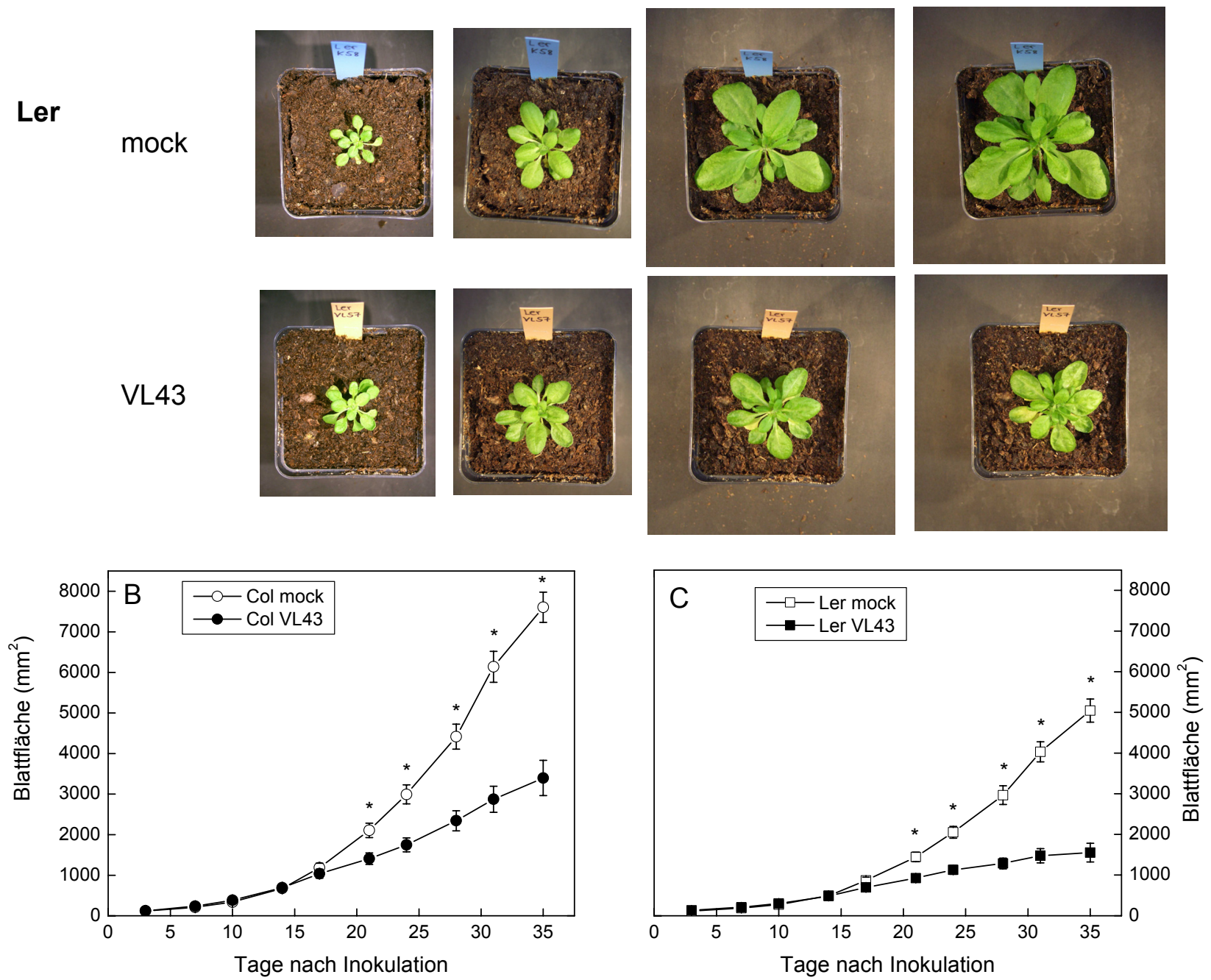

Abb. 4.10: Entwicklung der Rosettenfläche im Infektionsverlauf. (A) Repräsentative Bilder der mockund V. longisporum-inokulierten Arabidopsis Ökotypen Columbia (Col) und Landsberg erecta (Ler) zu verschiedenen Zeitpunkten nach Inokulation. Projizierte Blattfläche der Rosetten der Arabidopsis thaliana Ökotypen (B) Columbia (Col) und (C) Landsberg erecta (Ler). Zu jedem Zeitpunkt wurden $\mathrm{n}=20$ Photos pro Variante analysiert $( \pm \mathrm{SE})$. Werte mit einem Stern waren beim Vergleich von mock (weiße Symbole) und $V$. longisporum inokulierten Arabidopsis (schwarze Symbole) im T-Test $(p \leq 0,05)$ signifikant unterschiedlich. 


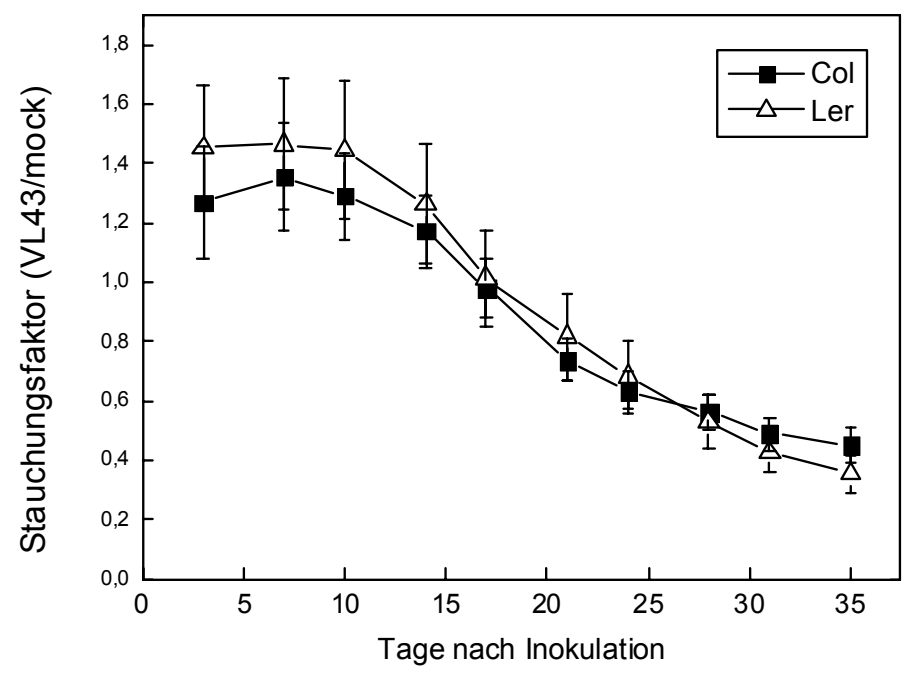

Abb. 4.11: Stauchungsfaktoren (VL43/mock) der Arabidopsis Ökotypen Columbia (Col) und Landsberg (Ler) unter Einfluss von Verticillium longisporum $(n=20 \pm$ SE) .

Weniger deutlich als bei der projizierten Blattflächenanalyse waren die Unterschiede zwischen den Ökotypen Columbia und Landsberg bei der Rosettenfrischmasse (Abb. 4.12). Nach 35 Tagen Wachstum hatten die Rosetten von Columbia Kontrollpflanzen ein durchschnittliches Gewicht von 3,0 g und die von Landsberg 2,5 g. Dieser Unterschied war nicht signifikant.

Trotz früher eintretender Stauchung konnten erst am Versuchsende deutliche Veränderungen der Frischmasse nachgewiesen werden. Die Frischmasse der Verticilliuminfizierten war im Vergleich zu den jeweiligen Kontrollen beim Ökotyp Columbia 35 Tage nach Inokulation um $42 \%$ reduziert, beim Ökotyp Landsberg bei $56 \%$. Die beiden Ökotypen waren nicht signifikant verschieden.
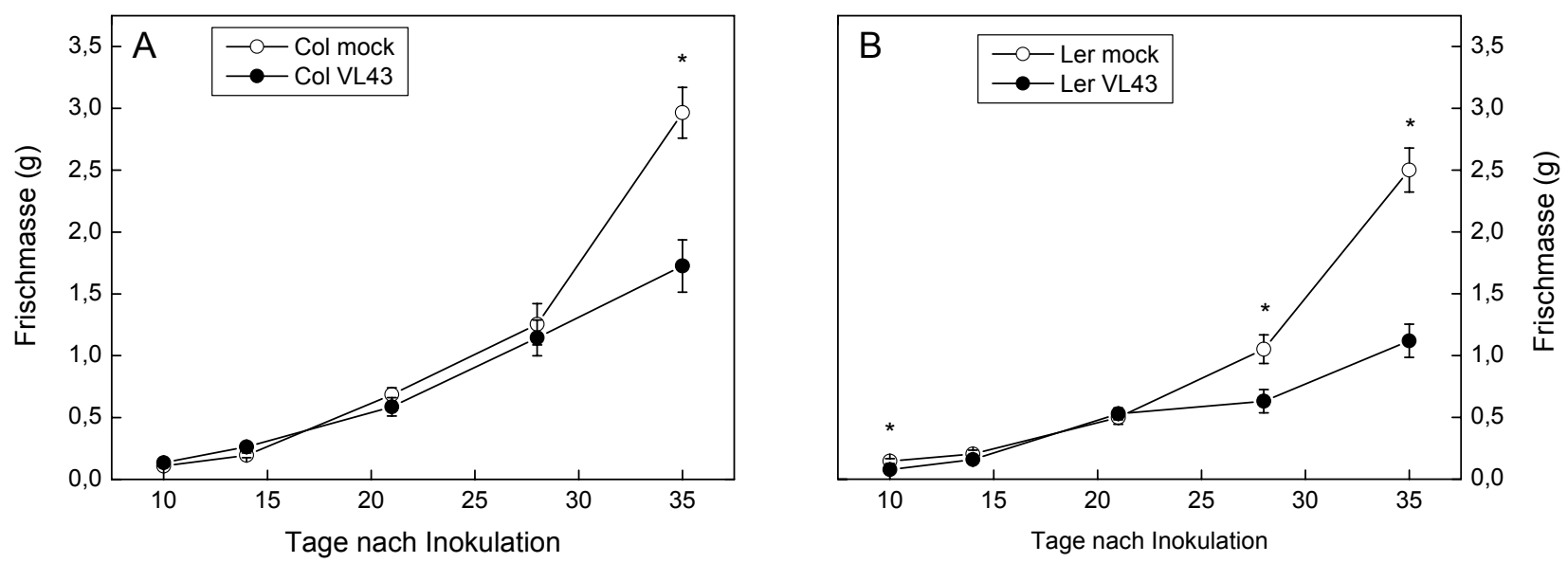

Abb. 4.12: Frischmasse der Rosetten im Infektionsverlauf. Die Rosettenfrischgewichte der Arabidopsis thaliana Ökotypen (A) Columbia (Col) und (B) Landsberg erecta (Ler) wurden zwischen 10 und 35 Tagen nach Inokulation bestimmt. Die Werte repräsentieren die Mittelwerte von jeweils 20 Pflanzen $( \pm \mathrm{SE})$, aus zwei unabhängigen Experimenten. Werte mit einem Stern waren beim Vergleich von mock (weiße Symbole) und $V$. Iongisporum inokulierten Arabidopsis (schwarze Symbole) im TTest $(p \leq 0,05)$ signifikant unterschiedlich. 
Als weiterer Parameter zur Analyse der Symptomentwicklung der Arabidopsis thaliana Ökotypen Columbia und Landsberg unter Verticillium longisporum Einfluss diente der Chlorophyllgehalt. Die Messungen wurden über den gesamten Zeitraum bis 35 Tage nach Inokulation durchgeführt (Abb. 4.13). Ein Vergleich der mock-inokulierten Kontrollpflanzen der Ökotypen Landsberg und Columbia zeigte zunächst, dass die Chlorophyllgehalte der Kontrollen nicht verschieden waren, aber altersbedingt etwas abnahmen. Beide Ökotypen zeigten eine geringe, aber signifikante Abnahme des Chlorophyllgehalts in Verticilliuminfizierten gegenüber mock-infizierten Pflanzen. 35 Tage nach Inokulation war der Chlorophyllgehalt des Ökotyps Columbia um $21 \%$ und der des Ökotyps Landsberg erecta um $14 \%$ gegenüber der jeweiligen Kontrolle gesunken.
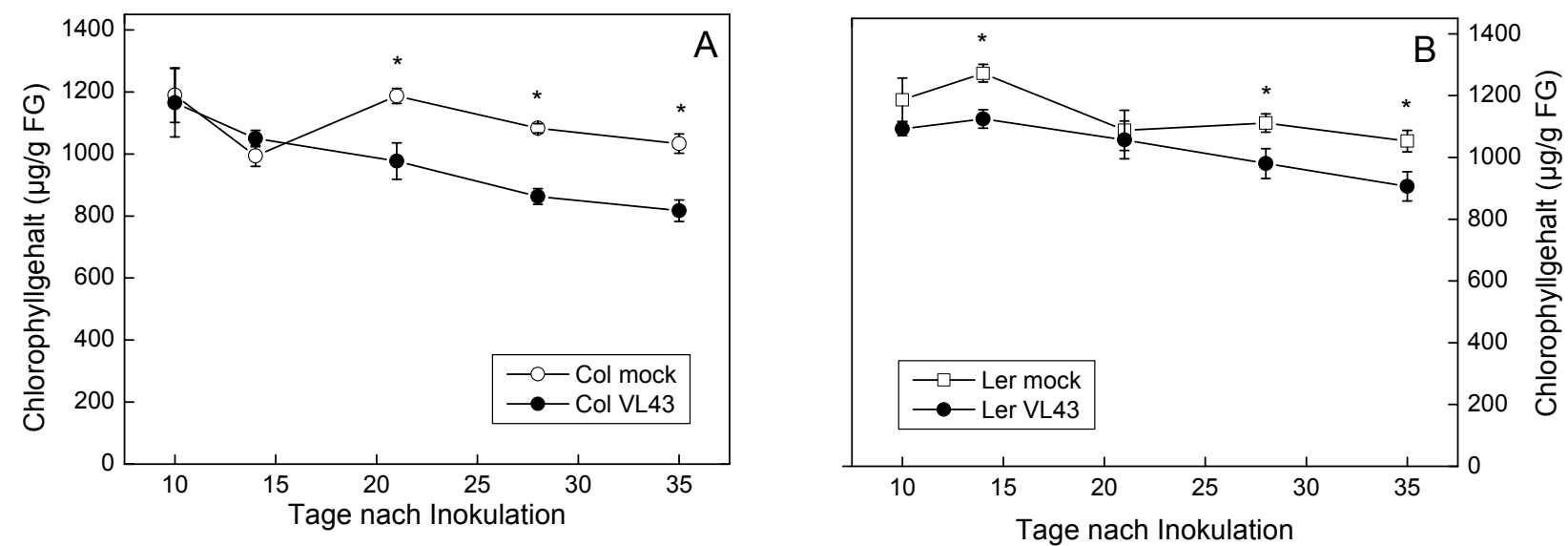

Abb. 4.13: Chlorophyllgehalt in Blättern von mock- und Verticillium-inokulierten Arabidopsis thaliana im Infektionsverlauf. Der Chlorophyllgehalt der Blätter der Arabidopsis thaliana Ökotypen (A) Columbia (Col) und (B) Landsberg erecta (Ler) wurde spektrophotometrisch bestimmt und als Summe von Chlorophyll $a$ und $b$ dargestellt. Es wurden zwischen zwei und sieben Proben in Dreifachbestimmung analysiert $( \pm \mathrm{SE}$ ). Werte mit einem Stern waren beim Vergleich von mock (weiße Symbole) und $V$. longisporum inokulierten Arabidopsis (schwarze Symbole) im T-Test $(p \leq 0,05)$ signifikant unterschiedlich.

Zusammengefasst zeigen die Ergebnisse dieser Untersuchung, dass es zwar Unterschiede im Wachstum zwischen den beiden Ökotypen gab, aber im Hinblick auf Verticillium longisporum Infektion zeigte sich keiner der Ökotypen deutlich empfindlicher bzw. resistenter. Für weitere Experimente wurde der Ökotyp Columbia ausgewählt, da er bei gleicher Symptomausprägung mehr Biomasse bildete.

\subsubsection{Untersuchung des Arabidopsis thaliana Ökotyps Columbia unter Lang- und Kurztagsbedingungen}

Die meisten in der Literatur beschriebenen Untersuchungen mit Verticillium-Pilzen an Arabidopsis thaliana wurden unter Langtagsbedingungen, d.h. 16 h Licht/8 h Dunkel Zyklus, durchgeführt (Steventon et al., 2001; Veronese et al., 2003). Unter diesen Bedingungen bleiben die Pflanzen relativ klein, da sie schnell die Blühreife erreichen. Da für die geplanten 
Untersuchungen des Apoplasten relativ viel Biomasse erforderlich war, wurde das Wachstum des Ökotyps Columbia unter Lang- und Kurztagsbedingungen ( $8 \mathrm{~h}$ Licht/16 h Dunkel Zyklus) verglichen, um die optimalen Anzuchtbedingungen herauszufinden.

Die Analyse der projizierten Blattfläche über den Infektionsverlauf bis 27 Tage nach Inokulation zeigte eine deutliche Stauchung der Pflanzen unter Verticillium-Einfluss (Abb. 4.14). Diese Stauchung durch Verticillium-Infektion war unter Kurztagsbedingungen (Abb. 4.14A) wesentlich deutlicher als unter Langtagsbedingungen (Abb. 4.14B). Um zu prüfen, inwiefern die durch $V$. longisporum verursachte Stauchung relativ zur Kontrollbehandlung verändert war, wurde die Stauchung als Verhältnis von VL43/mock zum letzten Untersuchungszeitpunkt bestimmt. Unter Langtagsbedingungen betrug der Stauchungsfaktor 27 Tage nach Inokulation 0,64 $\pm 0,09$ und unter Kurztagsbedingungen 0,26 $\pm 0,06$. Dieser Unterschied war im T-Test signifikant ( $p=0,0018)$.

Unter Langtagsbedingungen (Abb. 4.14B) zeigte sich in den ersten zwei Wochen nach Inokulation eine stärkere Zunahme der Blattfläche als unter Kurztagsbedingungen (Abb 4.14A). Danach nahm die Blattfläche unter Langtagsbedingungen kaum noch zu und betrug bei den mock-inokulierten Kontrollen nach 27 Tagen im Schnitt $12 \mathrm{~cm}^{2}$ (Abb. 4.14B). Die Blattfläche der mock- inokulierten Arabidopsis unter Kurztagsbedingungen nahm zwischen 10 und 27 Tagen Wachstum deutlich zu und betrug beim Versuchsende durchschnittlich $23 \mathrm{~cm}^{2}$ (Abb. 4.14A).

Eine Bonitur der Pflanzen ergab, dass alle unter Langtagsbedingungen gewachsenen Arabidopsis 7 Tage nach Inokulation Blütenansätze gebildet hatten. Unter Kurztagsbedingungen gewachsene Arabidopsis zeigten im gesamten Untersuchungszeitraum keine Blütenbildung.
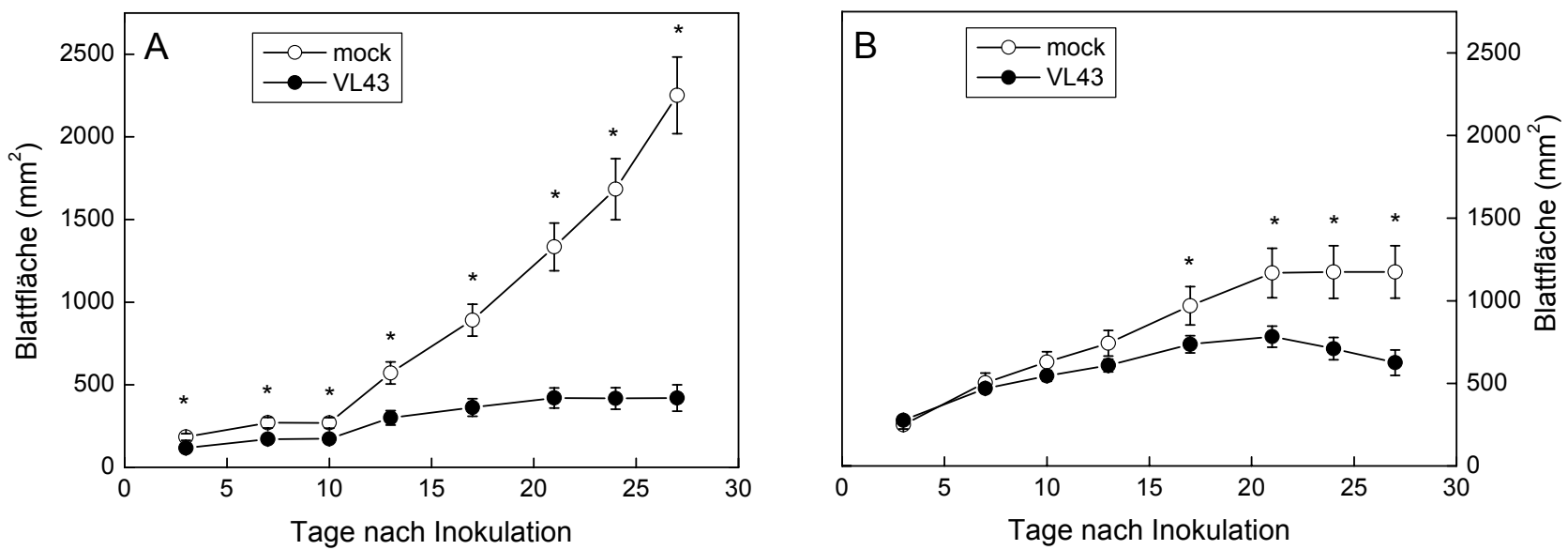

Abb. 4.14: Entwicklung der Rosettenfläche im Infektionsverlauf bei Anzucht von Arabidopsis thaliana unter Kurztagsbedingungen (A) oder unter Langtagsbedingungen (B). Dargestellt ist jeweils der Mittelwert der projizierten Blattfläche durch Auswertung von Photos $(n=12$ bis $27 \pm S E$ ). Werte mit einem Stern waren beim Vergleich von mock (weiße Symbole) und $V$. longisporum inokulierten Arabidopsis (schwarze Symbole) im T-Test $(p \leq 0,05)$ signifikant unterschiedlich. 
Am Versuchsende wurden die Pflanzen geerntet und ihre Frischmasse bestimmt. Dabei ergab sich sowohl unter Lang- als auch unter Kurztagsbedingungen eine signifikante Reduktion der Frischmasse unter Verticillium-Einfluss (Abb. 4.15). Diese war aber unter Kurztagsbedingungen wesentlich ausgeprägter.

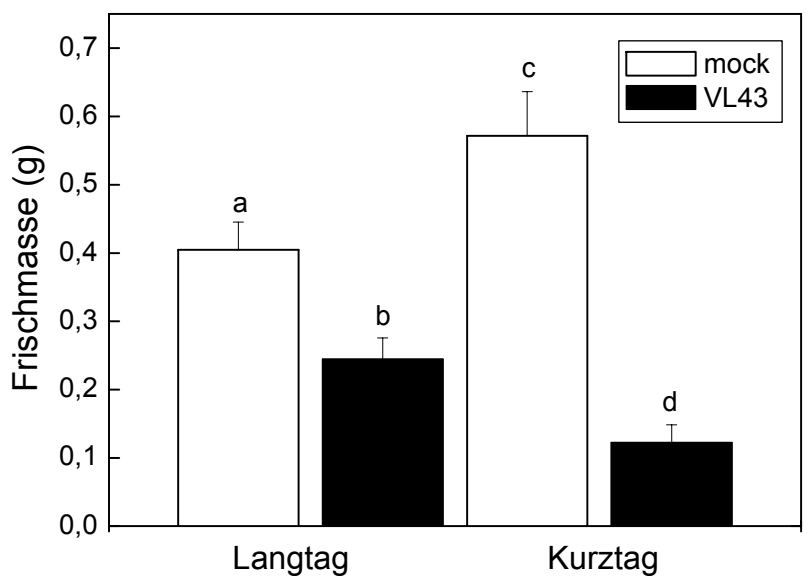

Abb. 4.15: Die Frischmasse der Arabidopsis thaliana Rosetten 28 Tage nach Inokulation. Die Säulen repräsentieren Mittelwerte von 12 bis 27 Pflanzen ( \pm SE). Die Pflanzen waren unter Lang- bzw. Kurztagsbedingungen gewachsen. Verschiedenen Buchstaben deuten auf signifikante Unterschiede hin.

Zusammenfassend gesehen, war die Biomasse unter Kurztagsbedingungen deutlich höher als unter Langtagsbedingungen. Die Verticillium-induzierte Reduktion der Rosettenfläche und der Frischmasse war unter Kurztagsbedingungen wesentlich stärker ausgeprägt als unter Langtagsbedingungen. Aufgrund dieser Ergebnisse wurden für weiterführende Experimente Kurztagsbedingungen für die Anzucht von Arabidopsis thaliana gewählt.

\subsubsection{Krankheitssymptome und Nährstoffversorgung von Arabidopsis thaliana im Infektionsverlauf}

\subsubsection{Einfluss von Verticillium longisporum auf den Phänotyp von Arabidopsis}

Die ersten Verticillium-induzierten Krankheitssymptome an Arabidopsis zeigten sich im allgemeinen 10-14 Tage nach Inokulation. Zu den frühen Symptomen zählten gelbe Blattadern, verkürzte Blattstiele und eine veränderte Morphologie der Blätter (Abb. 4.10A). Die Blätter der Verticillium-infizierten Pflanzen waren kleiner als die der mock-inokulierten Kontrollen und wiesen häufig eine nach unten gewölbte Form auf. 25 Tage nach Inokulation zeigten ca. 90 \% der Pflanzen Symptome. Die späten Symptome waren ein insgesamt verkümmertes, meist kugelförmiges Wachstum der Pflanzen und die zunehmende Vergilbung von Blättern (Abb. 4.10A). Ein häufig auftretendes Phänomen der Verticilliuminfizierten Arabidopsis war ein asymmetrisches Wachstum, wobei eine Hälfte der Pflanze einen gestauchten Phänotyp zeigte, während die andere Hälfte weiterhin größere Blätter bildete (Abb. 4.16). 

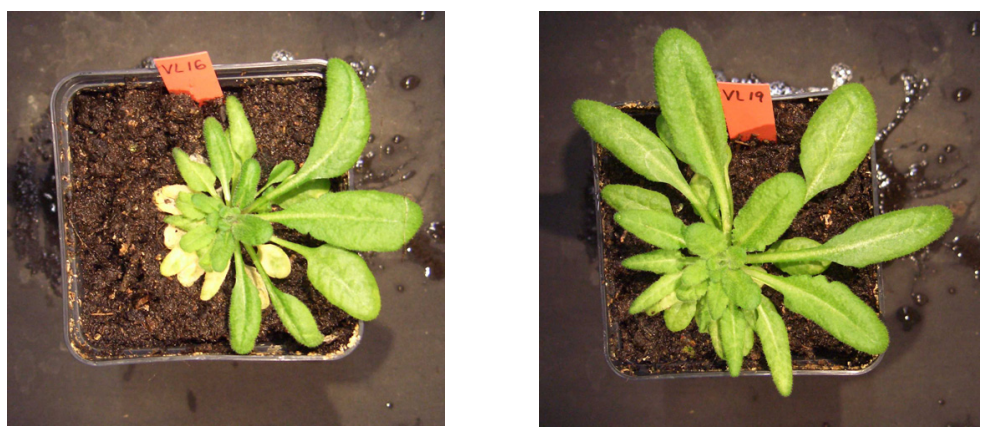

Abb. 4.16: Exemplarische Bilder von Verticillium longisporum infizierten Arabidopsis-Pflanzen mit asymmetrischem Phänotyp 25 Tage nach Inokulation.

Zur genaueren Charakterisierung der Krankheitssymptome wurden weitere Parameter gemessen. Da zu den Symptomen auch Vergilbungen von Blättern zählten und bereits gezeigt wurde, dass die Verticillium-Infektion Einfluss auf den Chlorophyllgehalt (Abb. 4.13) hat, wurde zusätzlich die Photosynthese-Aktivität untersucht.

Um den Einfluss der Verticillium-Infektion auf die Chlorophyllfluoreszenz und damit die Aktivität von Photosystem II im zeitlichen Verlauf zu charakterisieren, wurden bis zu sieben Wochen nach Inokulation Messungen an licht- und dunkeladaptierten Pflanzen durchgeführt (siehe 3.3.1). Sowohl im Licht als auch im Dunkeln konnten geringe, aber teilweise signifikante Unterschiede zwischen mock und Verticillium-inokulierten Pflanzen gemessen werden (Abb. 4.17). Signifikante Unterschiede zeigten sich bei den dunkeladaptierten Pflanzen vornehmlich zu den frühen Messzeitpunkten 14 bis 21 Tage nach Inokulation (Abb. 4.17A). Die Messung an den Verticillium-infizierten lichtadaptierten Arabidopsis zeigte über den gesamten Messzeitraum eine Reduktion der Quantenausbeute gegenüber den mockinokulierten Kontrollpflanzen, wobei die Differenz zwischen mock- und Verticilliuminokulierten Pflanzen im Verlauf größer wurde. Die Messzeitpunkte 21, 30 und 33 Tage nach Inokulation waren im T-Test signifikant unterschiedlich (Abb. 4.17B).
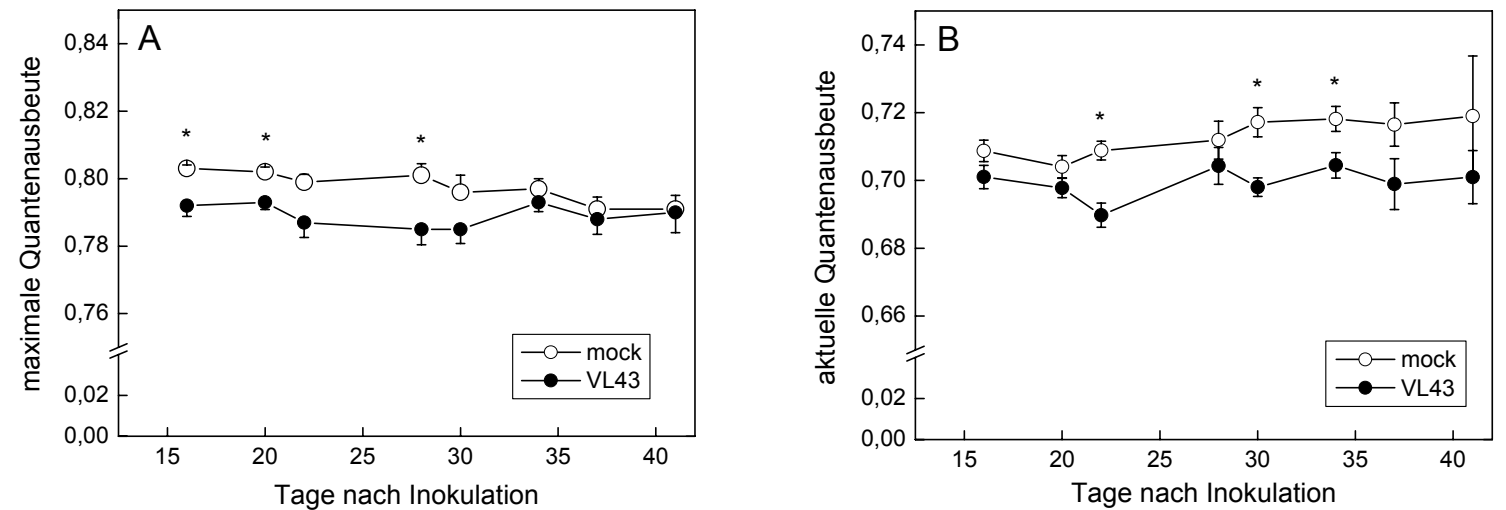

Abb. 4.17: Einfluss von Verticillium longisporum VL43 auf die Aktivität von Photosystem II. Die Chlorophyllfluoreszenz wurde bei $20^{\circ} \mathrm{C}$ und $60 \%$ relativer Luftfeuchtigkeit als maximale photosynthetische Quantenausbeute an dunkel-adaptierten Blättern (A) und als aktuelle photosynthetische Quantenausbeute im Licht bei $120 \mu \mathrm{mol} \mathrm{m}^{-2} \mathrm{~s}^{-1}$ (B) gemessen. Vollständig entwickelte Blätter wurden zu verschiedenen Zeitpunkten nach Inokulation untersucht. Die Anzahl der gemessenen Pflanzen reduzierte sich kontinuierlich von 40 Pflanzen zu Beginn der Messungen auf 6 Pflanzen zum Zeitpunkt 41 Tage nach Inokulation, da die Pflanzen für andere Analysen geerntet wurden. Werte mit einem Stern waren im T-Test $(p \leq 0,05)$ signifikant unterschiedlich. 


\subsubsection{Einfluss von Verticillium longisporum auf die Nährelementsituation in Arabidopsis thaliana Blättern}

Um zu prüfen, ob Nährstoffmangel an den Krankheitssymptomen beteiligt ist, wurde der Kohlenstoff- und Stickstoffgehalt (siehe 3.3.7) der Arabidopsis Blätter im Verlauf der Infektion mit Verticillium longisporum untersucht. Bis 28 Tage nach Inokulation wurden keine Unterschiede zwischen mock- und Verticillium-inokulierten Pflanzen gemessen. Der Kohlenstoffgehalt zeigte 35 Tage nach Inokulation eine leichte, aber signifikante Reduktion im T-Test $(p \leq 0,05)$ um $7,8 \%$ in den Blättern der Verticillium-infizierten Pflanzen. Ebenfalls nur eine geringfügige, aber signifikante Reduktion um 2,3\% war beim Stickstoffgehalt 28 Tage nach Inokulation bei den Verticillium-infizierten Pflanzen nachzuweisen. Das Verhältnis von Kohlenstoff zu Stickstoff blieb über den gesamten Messzeitraum stabil (Abb. 4.18C).
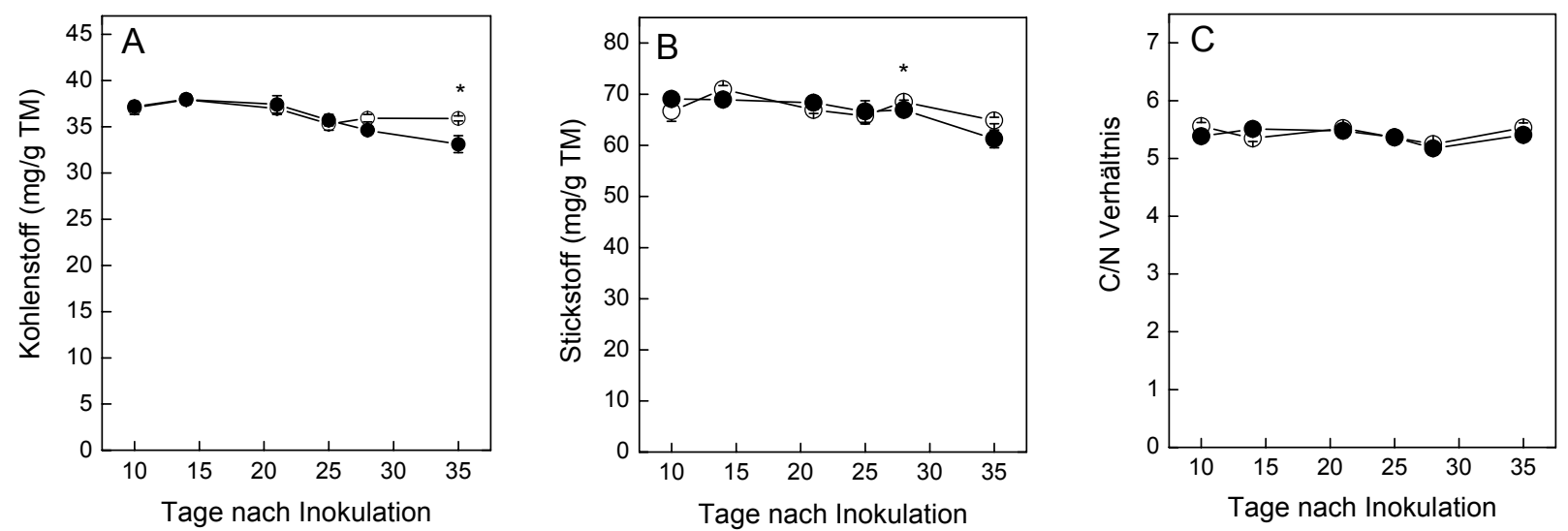

Abb. 4.18: Einfluss von V. longisporum auf den Kohlenstoff- $(A)$ und den Stickstoffgehalt $(B)$ und das Kohlenstoff/Stickstoff $\mathrm{C} / \mathrm{N}$ Verhältnis (C) in Arabidopsis thaliana Blättern zu unterschiedlichen Zeitpunkten nach Inokulation. Die Werte repräsentieren Mittelwerte aus jeweils drei unabhängigen Proben mit Standardfehler. Werte mit einem Stern waren im T-Test $(p \leq 0,05)$ signifikant unterschiedlich.

Um weitere Nährelemente zu untersuchen, wurden ICP-Analysen an Blattmaterial von mockund Verticillium-infizierten Arabidopsis durchgeführt (siehe 3.3.8). Dabei wurde der Gehalt der Hauptnährelemente Phosphor, Schwefel, Calcium, Kalium und Magnesium bestimmt sowie der Spurenelemente Mangan und Eisen. Schwefel und Kalium zeigten zu keinem Zeitpunkt signifikante Unterschiede zwischen mock- und Verticillium-infizierten Pflanzen (Abb. 4.19A und B). Magnesium war bei den Verticillium-infizierten Pflanzen im Vergleich zu den Kontrollen zum Zeitpunkt 21 Tage nach Inokulation signifikant reduziert; allerdings setzte sich dieser Trend zu späteren Zeitpunkten nicht fort (Abb. 4.19C). Die beiden Elemente Phosphor und Calcium wiesen in den Verticillium-infizierten Arabidopsis ab 21 bzw. 28 Tage nach Inokulation eine signifikante Erhöhung im Vergleich zu den mock-inokulierten Kontrollen auf (Abb. 4.19D und E). Bei den Spurenelementen gab es sowohl bei den mockals auch bei den Verticillium-infizierten Pflanzen Schwankungen, es konnte aber über den Untersuchungszeitraum kein eindeutiger Unterschied zwischen mock- und Verticilliuminfizierten Pflanzen nachgewiesen werden (Abb. 4.19F und G) . 

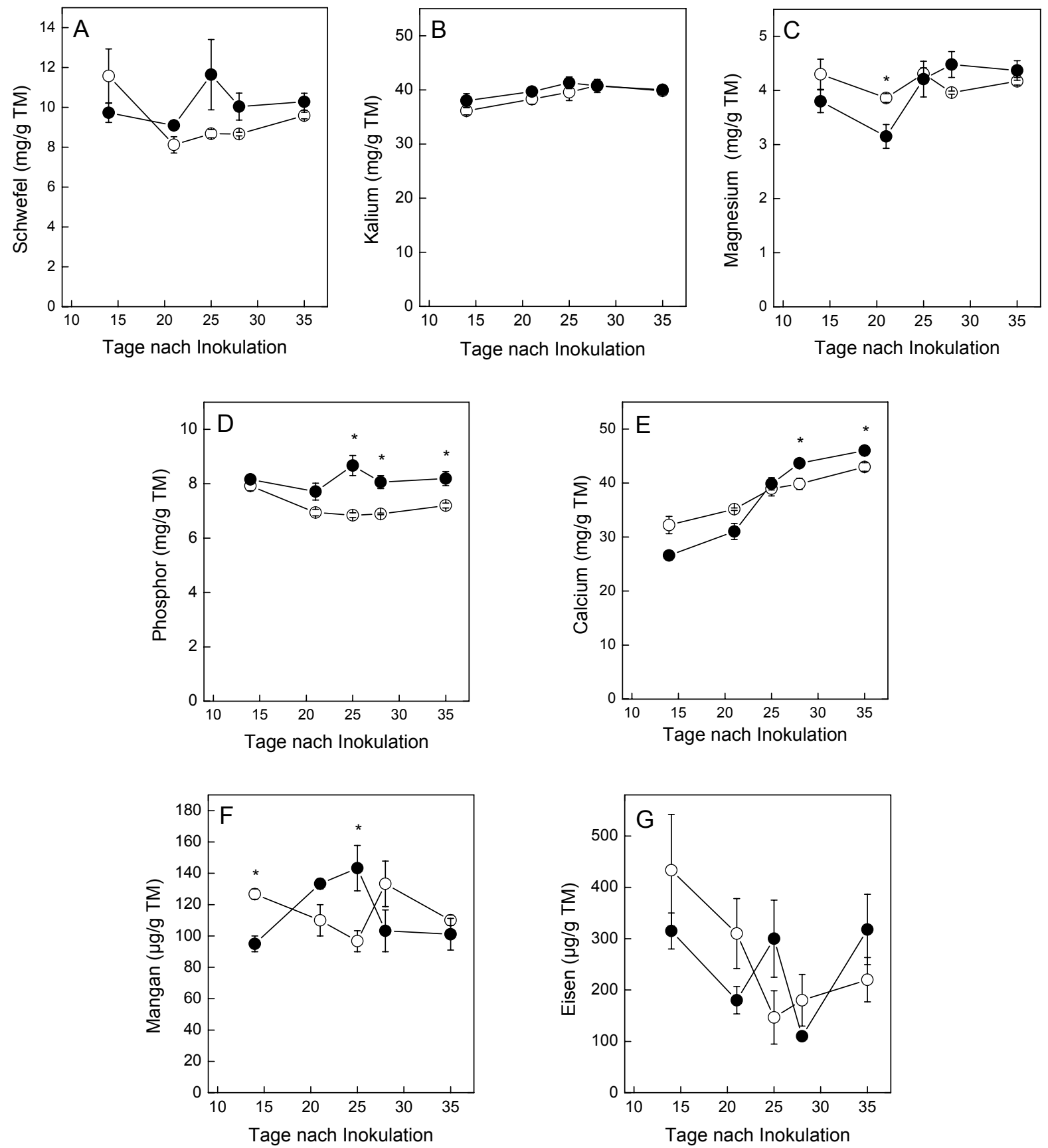

Abb. 4.19: Elementkonzentrationen von Schwefel (A), Kalium (B), Magnesium (C), Phosphor (D), Calcium (E), Mangan ( $F$ ) und Eisen $(G)$ in V. longisporum (schwarze Symbole) im Vergleich zu mockinokulierten Arabidopsis (weiße Symbole). Die Werte repräsentieren Mittelwerte aus jeweils drei unabhängigen Proben (beim Zeitpunkt 35 Tage nach Inokulation acht Proben) mit Standardfehler. Werte mit einem Stern waren im T-Test $(p \leq 0,05)$ signifikant unterschiedlich.

\subsubsection{Infektionsnachweis mittels quantitativer PCR}

Zur Überprüfung der Infektion, wurde eine quantitative real time PCR-Analyse durchgeführt. Mit dieser Methode konnte die Menge an Verticillium-DNA bestimmt werden. In Blättern Verticillium-infizierter Arabidopsis wurden zum Erntezeitpunkt nur sehr geringe Mengen Verticillium-DNA nachgewiesen (Abb. 4.20A). Im Mittel betrug die Verticillium-DNA Menge in den untersuchten Arabidopsis-Blätter 0,7 ng/g Frischmasse. In Blattstielen von Verticillium- 
infizierten Arabidopsis konnten 25 Tage nach Inokulation im Vergleich zu den mockinokulierten Kontrollen signifikante Mengen an Verticillium-DNA nachgewiesen werden (Abb. 4.20B). Im Mittel wurden $12 \mathrm{ng}$ Verticillium-DNA pro Gramm Blattstängelmaterial in den Verticillium-infizierten Pflanzen nachgewiesen. Die maximal nachgewiesene Menge an Verticillium-DNA betrug 107 ng pro Gramm Blattstängelmaterial. Die Ergebnisse zeigen, dass der Pilz 25 Tage nach Inokulation aus dem Wurzelxylem kommend, zum Teil bis in die Blattstängel, aber größtenteils noch nicht in das Mesophyll vorgedrungen ist. In Abbildung 4.20C ist die Pilzmenge in den Blattstängeln in Relation zur Rosettenfläche dargestellt. Es sollte geprüft werden, ob eine Korrelation zwischen Symptomentwicklung und Pilzmenge in der Pflanze bestand. Die mock-inokulierten Kontrollen wiesen Rosettengrößen im Bereich von 40 bis $110 \mathrm{~cm}^{2}$ auf und enthielten keine signifikanten Mengen an Pilz-DNA. Die Rosettengrößen der Verticillium-infizierten Pflanzen lagen zwischen 10 und $65 \mathrm{~cm}^{2}$. Eine lineare Korrelation zwischen Pilzmenge und Rosettengröße konnte nicht beobachtet werden, aber eine Exponentialfunktion durch alle Punkte ergab eine schwache Korrelation (Abb. 4.20C). Erstaunlich war, dass auch in sehr kleinen verkümmerten Pflanzen teilweise wenig oder gar keine Verticillium-DNA nachweisbar war (Abb. 4.20C).
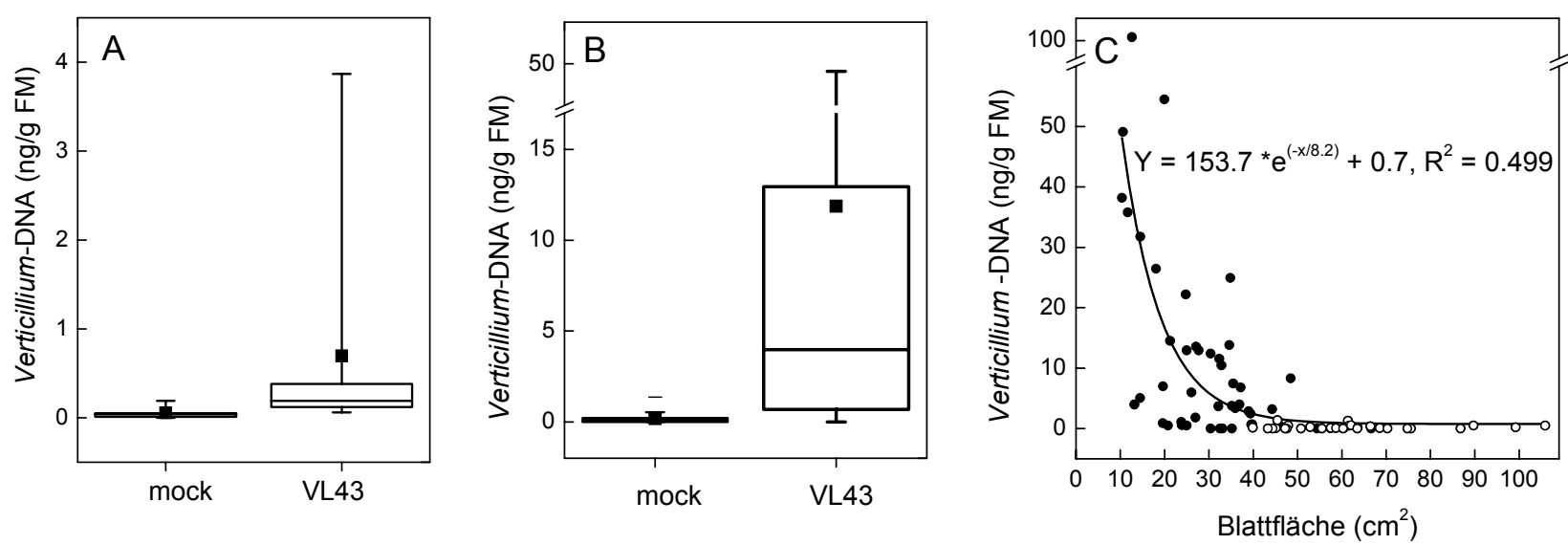

Abb. 4.20: Menge an Verticillium-DNA in Blättern (A) und in Blattstängeln (B) von mock- und Verticillium (VL43)-infizierten Arabidopsis-Pflanzen. Da die Werte nicht normalverteilt waren, wurden die Ergebnisse in Form von Box-Plots dargestellt. Die Boxen repräsentieren (A) $n_{(\text {mock })}=8, n_{(V L 43)}=10$ und (B) $n_{(\text {mock })}=36, n_{(V L 43)}=48$ Messungen. Innerhalb einer Box liegen $50 \%$ der Werte, die horzontale Linie stellt den Median-Wert und das schwarze Symbol den Mittelwert dar, die Gesamtverteilung wird durch die vertikalen Linien verdeutlicht. (C) Pilzmenge in Stängeln in Relation zur Blattfläche. Die Blattfläche von mock- (weiße Symbole) und V. Iongisporum-inokulierten Arabidopsis (schwarze Symbole) wurde 25 Tage nach Inokulation gemessen. Die Blattstiele der einzelnen Pflanzen $(n=84)$ wurden 25 Tage nach Inokulation geerntet und mittels quantitativer real time PCR die Menge an Verticillium-DNA bestimmt. Die Daten wurden durch eine abfallende Exponentialfunktion angepasst. 


\subsubsection{4 Ökophysiologische Charakterisierung Verticillium longisporum infizierter Arabidopsis thaliana}

Für weiterführende Experimente wurde der Zeitpunkt 25 Tage nach Inokulation ausgewählt, da die Arabidopsis Pflanzen zu diesem Zeitpunkt genügend Blattmaterial gebildet hatten, gleichzeitig aber auch eindeutige Infektionssymptome aufwiesen. Außerdem fingen die Pflanzen 25 Tage nach Inokulation noch nicht an zu Blühen und die Kontrollen zeigten noch keine Seneszenzerscheinungen. In Tabelle 4.5 sind einige bereits erwähnte und einige weitere ökophysiologische Parameter aufgelistet, die 25 Tage nach Infektion zur Charakterisierung der Pflanzen gemessen wurden. Während die Rosettenfläche um mehr als die Hälfte vermindert war, betrug die Frischmassenreduktion nur ca. $40 \%$. Dieser Unterschied war eventuell darauf zurückzuführen, dass übereinanderliegende Blätter bei der Analyse der projizierten Blattfläche nicht erfasst wurden. Der relative Anteil der Trockenmasse der Rosetten, berechnet aus Frisch- und Trockenmasse betrug ungefähr $7 \%$ und war bei mock- und Verticillium-infizierten Pflanzen nicht signifikant verschieden. Der Wassergehalt der Blätter war also nicht unterschiedlich.

Neben dem Chlorophyllgehalt war auch der Carotinoidgehalt in den Verticillium-infizierten Arabidopsis signifikant niedriger (Tab. 4.5). Auch die Aktivität von Photosystem II war geringer. Zur Überprüfung, ob 25 Tage nach Infektion Membranen durch den Pilz geschädigt waren, wurde die Elektrolytleitfähigkeit aus gestanzten Blattscheiben gemessen (siehe 3.3.2). Dazu wurden die Blattscheiben 24 Stunden in $\mathrm{ddH}_{2} \mathrm{O}$ inkubiert und anschließend wurde der Austritt von Elektrolyten gemessen. Da sich bei den Verticillium-infizierten Pflanzen keine erhöhte Leitfähigkeit ergab, wurde geschlossen, dass die Membranen 25 Tage nach Inokulation intakt waren. Der osmotische Druck in den Verticillium-infizierten Pflanzen war geringfügig niedriger im Vergleich zu den mock-inokulierten Kontrollen.

Tab. 4.5: Verticillium longisporum induzierte Krankheitssymptome in A. thaliana. Die Messungen wurden $25 \pm 3$ Tage nach Inokulation durchgeführt. Bei den Daten handelt es sich um Mittelwerte $( \pm$ $\mathrm{SE})$ der angegebenen Anzahl von Pflanzen (n). Werte mit $p \leq 0,05$ zeigen signifikante Unterschiede zwischen mock-inokulierten und Verticillium longisporum (VL43)-infizierten Pflanzen.

\begin{tabular}{|c|c|c|c|c|}
\hline Parameter & $\mathrm{n}$ & mock & VL43 & p-Wert \\
\hline Rosettenfläche (mm²/Pflanze) & 30 & $6402 \pm 276$ & $2750 \pm 181$ & $\leq 0,0001$ \\
\hline Frischmasse (g/Pflanze) & 15 & $1,09 \pm 0,08$ & $0,66 \pm 0,09$ & 0,0018 \\
\hline Trockenmasse (\%) & $\geq 9$ & $6,89 \pm 0,33$ & $7,33 \pm 0,23$ & 0,2807 \\
\hline Chlorophyllgehalt ( $\mu \mathrm{g} / \mathrm{g}$ FM) & 18 & $1135 \pm 21$ & $1005 \pm 28$ & 0,0008 \\
\hline Carotinoidgehalt ( $\mu \mathrm{g} / \mathrm{g} \mathrm{FM)}$ & 18 & $271 \pm 6$ & $245 \pm 6$ & 0,0058 \\
\hline$\Phi$ (PSII), dunkel & $\geq 25$ & $0,801 \pm 0,003$ & $0,785 \pm 0,005$ & 0,0181 \\
\hline Elektrolytleitfähigkeit (\%) & 5 & $15,5 \pm 0,9$ & $16,2 \pm 0,9$ & 0,6367 \\
\hline Osmotischer Druck (MPa) & 8 & $0,893 \pm 0,014$ & $0,843 \pm 0,018$ & 0,0461 \\
\hline
\end{tabular}




\subsubsection{Kontaminationsbestimmung in der AWF von Arabidopsis thaliana}

Da es 25 Tage nach Inokulation keine Hinweise auf erhebliche Schäden durch Verticillium gab, wurde geprüft, ob dieser Zeitpunkt zur Gewinnung von apoplastischer Waschflüssigkeit (AWF) geeignet war. Dazu wurden AWF aus mock- und Verticillium-infizierten Pflanzen mittels Infiltration und Zentrifugation gewonnen (siehe 3.4.1). Dabei kann es bei Beschädigung der Membranen zu Kontaminationen aus dem Symplasten kommen. Deshalb wurde die Aktivität des Enzyms Malatdehydrogenase (MDH) als Marker für symplastische Kontamination in den gewonnenen apoplastischen Extrakten bestimmt und mit der $\mathrm{MDH}-$ Aktivität in Gesamtblattextakten verglichen.

In den apoplastischen Waschflüssigkeiten lag die MDH-Aktivität bei 0,007 nkat pro Gramm Frischmasse, in den Gesamtblattextrakten bei durchschnittlich 231 nkat pro Gramm Frischmasse, was einer Kontamination von 0,003 \% entsprach und damit sehr gering war. Zwischen den ermittelten Kontaminationswerten für mock- und Verticillium-infizierte Pflanzen gab es keine signifikanten Unterschiede $(p=0,8481)$.

Tab. 4.6: $\mathrm{MDH}$-Aktivität in Gesamtblattextakten und AWF aus Blättern von mock- und Verticillium longisporum VL43 inokulierten Arabidopsis. Die Pflanzen wurden 25 Tage nach Inokulation geerntet, für die AWF-Gewinnung wurden pro Probe Blätter von 10 Arabidopsis Pflanzen zusammengefasst. Pro Behandlung wurden fünf unabhängige Proben analysiert. Bei den Daten handelt es sich um Mittelwerte mit Standardfehler.

\begin{tabular}{llcc}
\hline Behandlung & Extrakt & $\begin{array}{c}\text { MDH Aktivität } \\
\text { (nkat/g FM) }\end{array}$ & $\begin{array}{c}\text { Kontamination } \\
\%\end{array}$ \\
\hline mock & Gesamtblatt & $242,1 \pm 29,9$ & - \\
& AWF & $0,007 \pm 0,013$ & 0,0030 \\
VL43 & Gesamtblatt & $220,6 \pm 59,7$ & - \\
& AWF & $0,007 \pm 0,004$ & 0,0032 \\
\hline
\end{tabular}




\subsubsection{Charakterisierung extrazellulärer Proteinmustern}

\subsubsection{Vergleich von Proteinmustern in apoplastischen und Gesamtblattextrakten}

25 Tage nach Inokulation wurden apoplastische Waschflüssigkeiten (AWF) und Gesamtblattextrakte aus mock- und Verticillium-infizierten Arabidopsis gewonnen, über Gelfiltration (siehe 3.4.4) gereinigt und der Proteingehalt bestimmt (Tab. 4.7). Jede Probe zur AWF-Gewinnung bestand aus einem Pool von Blättern von ca. 10 Pflanzen. Der Proteingehalt der Gesamtblattextrakte lag bei $12,5 \mathrm{mg}$ pro Gramm Frischmasse und unterschied sich nicht zwischen mock- und Verticillium-infizierten Pflanzen. In der AWF der betrug der Proteingehalt zwischen 17,2 $\mu \mathrm{g}$ und 21,0 $\mu \mathrm{g}$ pro Gramm Frischmasse und unterschied sich nicht zwischen mock- und Verticillium-infizierten Arabidopsis.

Die Proteinextrakte wurden nach ihrem Molekulargewicht (MW) elektrophoretisch in SDS-Polyacrylamidgelen mit einem Gradienten von 7,5-20 \% Acrylamid aufgetrennt (siehe 3.5.5) und anschließend mit Silber gefärbt (siehe 3.5.8). Die Proteinmuster aus Gesamtblattextrakten von mock- und Verticillium-infizierten Pflanzen unterschieden sich nicht (Abb. 4.21). Der Vergleich der Bandenmuster der AWF von mock- und Verticilliuminfizierten Pflanzen zeigte dagegen einige deutliche Unterschiede im Molekulargewichtsbereich unter 45 kDa (Abb. 4.21, rote Pfeile).

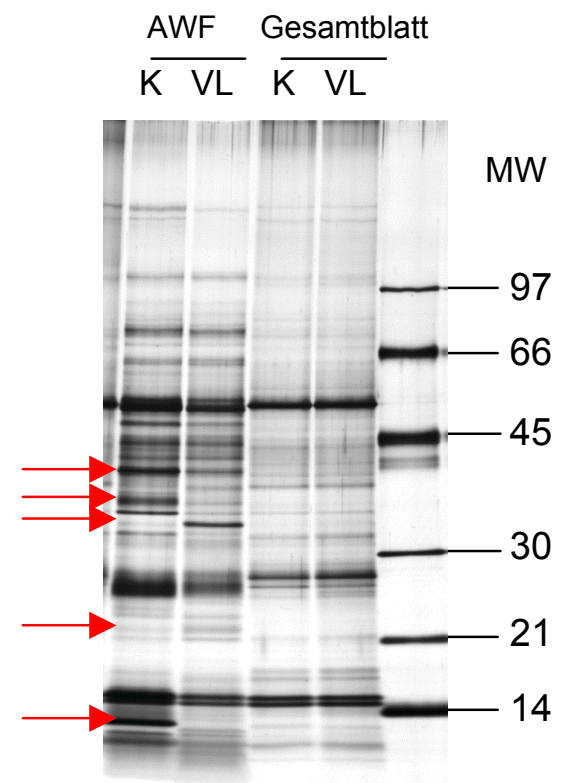

Abb. 4.21: Proteinmuster einer elektrophoretische Auftrennung von je 1,8 $\mu$ g Proteinen aus AWF und Gesamtblattextrakten von mock-inokulierten Kontrollpflanzen $(K)$ und $V$. longisporum-infizierten Pflanzen (VL) im PAA-Gradientengel. Die Extrakte wurden 25 Tage nach Inokulation gewonnen. Die Pfeile zeigen Proteinbanden, die sich in der AWF von mock- und Verticillium-inokulierten Pflanzen unterscheiden. Die Molekulargewichte (MW) des Proteinstandards sind neben dem Gelbild angegeben. 
4.2.3.2 Zweidimensionale Auftrennung apoplastischer Arabidopsis thaliana Proteine Nachdem die Auftrennung der apoplastischen Proteine im PAA-Gradientengel Unterschiede im Bandenmuster zwischen mock- und Verticillium-inokulierten Arabidopsis aufwies, wurden zweidimensionale Auftrennungen zur näheren Charakterisierung durchgeführt. Dabei wurden die Proteine nach ihrem isoelektrischen Punkt (pl) und ihrem Molekulargewicht (MW) aufgetrennt. Abbildung 4.22 zeigt die zweidimensionale Separation von je $80 \mu \mathrm{g}$ apoplastischen Proteinen aus mock- und Verticillium-inokulierten Arabidopsis. Pro Variante wurden sechs mit Silbernitrat gefärbte (siehe 3.5.8) Gele analysiert. Zusätzlich wurde jeweils ein präparatives Gel mit möglichst viel Protein geladen und für massenspektrometrische Analysen mit CBB gefärbt (siehe 3.5.8). Jeweils sechs Proben konnten parallel aufgetrennt werden, daher wurden zunächst jeweils drei unabhängige Proben von mock- und Verticillium-infizierten Pflanzen aus einem ersten Experiment untersucht. In einem zweiten Durchgang wurden dann noch einmal jeweils drei unabhängige Proben untersucht, die aus einem weiteren Experiment stammten. So ergaben sich pro Variante sechs biologische Wiederholungen für die statistische Auswertung. Der Vergleich aller silbergefärbten Gele mit der Proteomweaver Software (siehe 3.5.9) ergab eine durchschnittliche Anzahl von 217 Spots in den Silber-gefärbten Gelen. Die Anzahl der Spots unterschied sich nicht signifikant zwischen mock- und Verticillium-infizierten Pflanzen (Tab. 4.7).

Tab. 4.7: Einfluss von Verticillium longisporum Infektion auf den Proteingehalt und die Anzahl von Proteinspots nach 2D Separation von AWF. Die Pflanzen wurde für die Analysen 25 Tage nach Inokulation geerntet. Die Proteinspots wurden mittels Proteomweaver Software in silbergefärbten Gelen analysiert. Bei den Daten handelt es sich um Mittelwerte mit Standardfehler.

\begin{tabular}{lcccc}
\hline Parameter & $\mathrm{n}$ & mock & VL43 & p-Wert \\
\hline Gesamtblattprotein (mg/g FG) & 5 & $12,5 \pm 1,2$ & $12,3 \pm 0,5$ & 0,9192 \\
AWF-Protein ( $\mu \mathrm{g} / \mathrm{g}$ FG) & 5 & $17,2 \pm 1,0$ & $21,0 \pm 2,4$ & 0,1785 \\
Proteinspots AWF (pro Gel) & 6 & $214 \pm 10$ & $220 \pm 11$ & 0,7389 \\
\hline
\end{tabular}

Abbildung 4.22 zeigt repräsentative Gele mit apoplastischen Proteinen von mock- und Verticillium-infizierten Pflanzen aus den beiden unabhängigen Experimenten. Zunächst wurde versucht, möglichst viele Spots aus den Kontrollgelen der mock-inokulierten Arabidopsis zu identifizieren (siehe 3.5.10). Spots, die aus den präparativen CBB-gefärbten Gelen identifiziert werden konnten, sind mit Nummern markiert und in den Tabellen 4.8 und 4.9 aufgelistet. Die Identifizierung gelang bei 39 von $101 \mathrm{im}$ Coomassie-gefärbten Gel auftretenden Proteinspots (Tab. 4.8), von denen einige Isoformen der gleichen Proteine darstellten, so dass sich die Gesamtzahl unterschiedlicher identifizierter Proteine auf 30 reduzierte. Darunter waren proteolytische Enzyme wie die Subtilisin-ähnliche Serin(At5g67360) und die Aspartylproteasen (At5g10760, At1g09750), sowie Proteine mit Homologie zu Lektin (At1g78830, At3g16530, At3g15356). Außerdem konnten 
möglicherweise in Abwehrreaktionen involvierte Proteine wie ein Thaumatin ähnliche Protein PR5 (At1g75040), eine ß-1,3-Glucanase (PR2; At3g57260), eine Chitinase (At2g43590), eine Peroxidase (At5g06720) und ein Endopeptidase Hemmer (At1g17860) identifiziert werden. Die genannten Proteine und noch einige weitere wiesen laut Überprüfung mit TargetP (siehe 3.5.11) mit einer sehr hohen Vorhersagewahrscheinlichkeit (RC1 oder RC2) ein Signalpeptid für den sekretorischen Weg auf. Ebenfalls wurden zwei Proteine (At1g33640 und At3g08030) mit unbekannter Funktion nachgewiesen.

Bei den Proteinen Rubisco (AtCg00490), Sedoheptulose-bisphosphatase (At3g55800), Sauerstoffbindeprotein (At5g66570) und Sauerstoffbindeprotein 2 (PSBP, At1g06680), die normalerweise im Chloroplasten lokalisiert sind, handelt es sich mit hoher Wahrscheinlichkeit um Kontaminationen, die zwar sehr gering waren, aber nicht vollständig vermieden werden konnten.

A

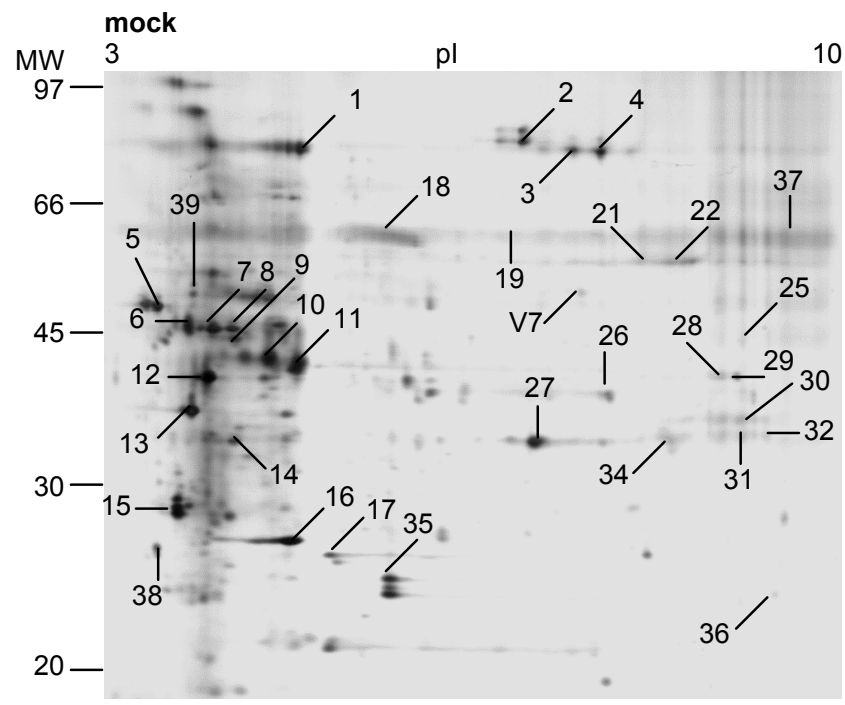

B

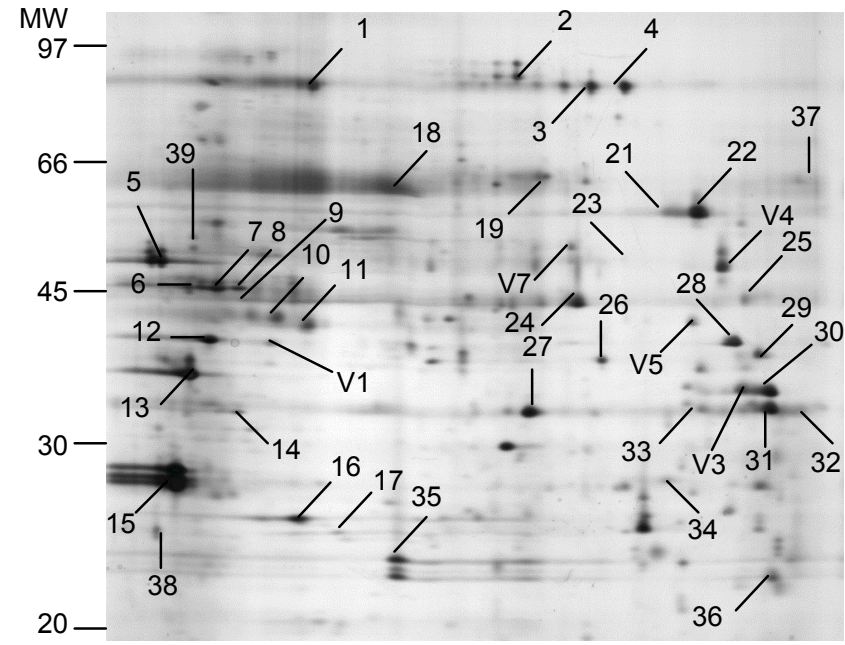

\section{VL43}

3
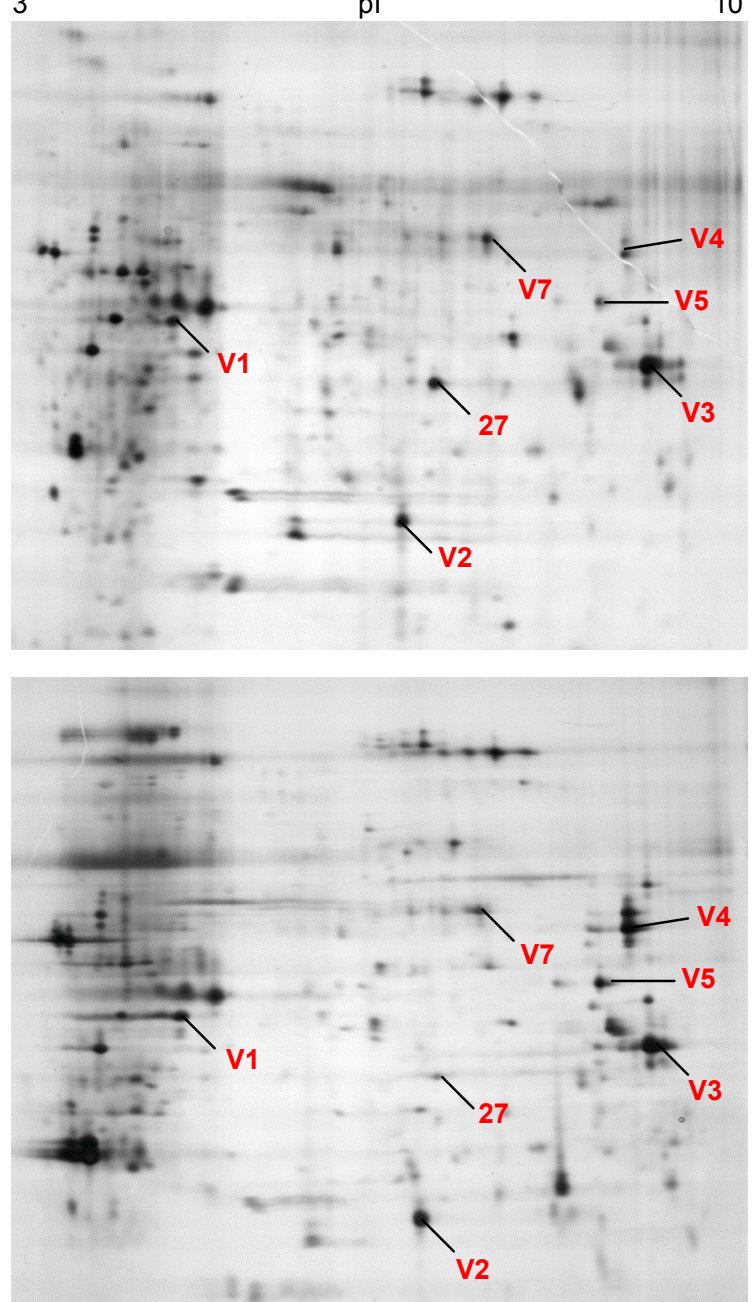

Abb. 4.22: Repräsentative Proteinmuster apoplastischer Extrakte aus Arabidopsis thaliana Blättern. Für die zweidimensionale Separation wurden je $80 \mu \mathrm{g}$ Protein, gewonnen aus einem Pool von ca. 10 Pflanzen, eingesetzt. Die Extrakte stammten aus zwei unabhängigen Experimenten (A und B) 25 Tage nach mock oder $V$. Iongisporum (VL43) Inokulation und wurden mit Silber gefärbt. Die Zahlen weisen auf Proteinspots hin, die mittels ESI-LC-MS aus einem präparativen Coomassie-Gel identifiziert wurden. Die eingezeichneten Molekulargewichte (MW) wurden durch einen mitgeführten Proteinstandard ermittelt, pl 3 und 10 markieren die Grenzen der isoelektrischen Fokussierung. 
Tab. 4.8: Liste der in apoplastischen Waschflüssigkeiten von Arabidopsis Blättern identifizierten Proteine. AWF aus mock-inokulierten Pflanzen wurde durch 2 D-Gelelektrophorese aufgetrennt. Die Spots wurden ausgestochen, mit Trypsin verdaut und mittels ESI-LC-MS mit anschließender MascotSuche in der NCBI-Datenbank identifiziert. Die identifizierten Proteine stammen alle aus Arabidopsis thaliana; je höher der Protein-Score desto sicherer die Identifizierung. Die Spotnummern beziehen sich auf die Zahlen in Abb. 4.22. Mit Hilfe von TargetP wurden die Aminosäuresequenzen auf Anwesenheit von Signalpeptiden überprüft. S, C, und M stehen für Lokalisation in den sekretorischen Weg, Chloroplasten und Mitochondrien, _ steht für anderer Weg. RC steht für reliability class und ist ein Maß für die Zuverlässigkeit der Vorhersage. Je kleiner die Zahl, desto sicherer ist die Vorhersage.

\begin{tabular}{|c|c|c|c|c|c|}
\hline $\begin{array}{l}\text { Spot } \\
\text { Nr. }\end{array}$ & Ähnlichkeit mit & $\begin{array}{c}\text { AGI } \\
\text { Nummer }\end{array}$ & $\begin{array}{l}\text { Protein } \\
\text { Score }\end{array}$ & $\begin{array}{c}\text { Molekular- } \\
\text { gewicht (Da) }\end{array}$ & $\begin{array}{l}\text { Signal- } \\
\text { peptid }\end{array}$ \\
\hline 1 & Thioglukosidase & At5g26000 & 123 & 61664 & $S(R C 1)$ \\
\hline 2 & Subtilisin-ähnliche Serinprotease & At5g67360 & 301 & 80050 & $S(R C 1)$ \\
\hline 3 & Subtilisin-ähnliche Serinprotease & At5g67360 & 241 & 80050 & $S(R C 1)$ \\
\hline 4 & $\beta-1,4-X y l o s i d a s e$ & At3g19620 & 243 & 97359 & $S(R C 1)$ \\
\hline 5 & Aspartylprotease & At5g10760 & 102 & 50411 & $S(R C 2)$ \\
\hline 6 & Peptidyl-prolyl cis-trans Isomerase & At3g01480 & 62 & 48180 & $C(\operatorname{RC} 1)$ \\
\hline 7 & Pepsin A, Aspartylprotease & $\begin{array}{l}\text { At3g18490 } \\
\text { At3g18500 }\end{array}$ & 62 & 53942 & $\begin{array}{l}C(R C 5) \\
M(R C 4)\end{array}$ \\
\hline 8 & Pepsin A, Aspartylprotease & $\begin{array}{l}\text { At3g18490 } \\
\text { At3g18500 }\end{array}$ & 63 & 53942 & $\begin{array}{l}C(R C 5) \\
M(R C 4)\end{array}$ \\
\hline 9 & Sedoheptulose-bisphosphatase & At3g55800 & 168 & 42787 & $\mathrm{C}(\mathrm{RC} 1)$ \\
\hline 10 & Curculin-ähnlich, Lektin-Familie & At1g78830 & 169 & 51007 & $S(R C 1)$ \\
\hline 11 & Curculin-ähnlich, Lektin-Familie & At1g78830 & 203 & 51007 & $S(R C 1)$ \\
\hline 12 & Carboxylische Ester Hydrolase & At1g29660 & 270 & 40630 & $S(R C 2)$ \\
\hline 13 & $\beta-1,3-$ Glucanase 2 (PR2) & At3g57260 & 389 & 37373 & $S(R C 1)$ \\
\hline 14 & Sauerstoffbildungsprotein (Oxygen-evolving) & At5g66570 & 66 & 35285 & $C(\operatorname{RC} 2)$ \\
\hline 15 & PR5; Taumatin ähnliches Protein & At1g75040 & 576 & 26148 & $S(R C 1)$ \\
\hline 16 & Chaperonin 10 & At1g14980 & 101 & 26913 & $M(\operatorname{RC} 3)$ \\
\hline 17 & Sauerstoffbildungsprotein 2 (PSBP) & At1g06680 & 136 & 28249 & $C(\operatorname{RC} 2)$ \\
\hline 18 & Rubisco (große Untereinheit) & AtCg00490 & 113 & 53424 & _(RC2) \\
\hline 19 & Serin Hydroxyl-methyltransferase (SHM 1) & At4g37930 & 44 & 57535 & $M(\operatorname{RC} 4)$ \\
\hline 21 & Pepsin A, Aspartylprotease & At1g09750 & 39 & 48429 & $S(R C 1)$ \\
\hline 22 & Pepsin A, Aspartylprotease & At1g09750 & 104 & 48429 & $S(R C 1)$ \\
\hline 23 & Carboxylische Ester Hydrolase & At2g46930 & 78 & 46827 & $S(R C 1)$ \\
\hline 24 & Unbekanntes Protein & At3g08030 & 83 & 39326 & _(RC 2) \\
\hline 25 & Protein Bindeprotein & At3g20820 & 54 & 40464 & $\mathrm{~S}(\mathrm{RC} 2)$ \\
\hline 26 & Pepsin A, Aspartylprotease & At1g09750 & 70 & 48429 & $S(R C 1)$ \\
\hline 27 & Lektin ähnliches Protein & At3g16530 & 287 & 30547 & $S(R C 1)$ \\
\hline 28 & $\beta-1,3-$ Glucanase 2 (PR2) & At3g57260 & 359 & 37722 & $S(R C 1)$ \\
\hline 29 & Carboxylische Ester Hydrolase & At1g29670 & 539 & 40417 & $S(R C 1)$ \\
\hline 30 & Lektin ähnliches Protein & At3g15356 & 238 & 29650 & $S(R C 1)$ \\
\hline 31 & Lektin ähnliches Protein & At3g15356 & 252 & 29650 & $S(R C 1)$ \\
\hline 32 & Kohlenhydrat-Bindeprotein, Lektin-ähnlich & At5g03350 & 91 & 30200 & $S(R C 2)$ \\
\hline 33 & MERI5b; Hydrolase & At4g30270 & 177 & 30850 & $S(R C 1)$ \\
\hline 34 & Chitinase & At2g43590 & 61 & 29304 & $S(R C 1)$ \\
\hline 35 & Peptidylprolyl Isomerase (ROC4) & At3g62030 & 44 & 28532 & $C(R C 1)$ \\
\hline 36 & Endopeptidase Hemmer & At1g17860 & 119 & 22410 & $\mathrm{~S}(\mathrm{RC} 2)$ \\
\hline 37 & Hypothetisches Protein & At1g33640 & 53 & 56113 & $S(R C 2)$ \\
\hline 38 & $\beta$-1,3-Glucanase 2 (PR2) & At3g57260 & 140 & 37373 & $S(R C 1)$ \\
\hline 39 & Peroxidase & At5g06720 & 69 & 32504 & $S(R C 2)$ \\
\hline
\end{tabular}


Die statistische Analyse (siehe 3.5.9) beim Vergleich von Gelen aus mock- und Verticilliuminfizierten Arabidopsis ergab, dass neun Spots differentiell auftraten. Sieben davon traten unter Verticillium-Einfluss stärker und zwei schwächer hervor. Sechs der Proteine, die in den Gelen von Verticillium-inokulierten Pflanzen im Vergleich zu den mock-inokulierten Pflanzen signifikant $(p<0,05)$ stärker auftraten, konnten identifiziert werden. Bei den Proteinen handelte es sich um Oxido-Reduktasen wie das Germin-ähnliche Protein (At5g20630) und die drei Peroxidasen (At5g05340, At3g49120, At4g37530). Weitere unter Verticillium Einfluss signifikant hochregulierte Proteine waren eine Serin-Carboxypeptidase (At4g12910) und eine $\alpha$-Galactosidase (At5g08370). Außerdem wurde ein Lektin ähnliches Protein (At3g16530) identifiziert, das bei Verticillium-Infektion um den Faktor 0,5 signifikant geringer vorkam als bei den Kontrollpflanzen. Für alle Proteine wurde mit hoher Wahrscheinlichkeit ein Signalpeptid für den sekretorischen Weg gefunden. Der in Tab. 4.9 angegebene ProteinScore setzt sich aus dem Score der einzelnen gefundenen Peptide zusammen und zeigt wie sicher die Identifizierung der Proteine war. Je höher der Protein-Score, desto sicherer ist die Identifizierung. Bei den Proteinen mit einem Protein-Score über 100 war Identifizierung relativ sicher, wohingegen die Identifizierung der Spots V 4 und $V 5$ als die Peroxidasen At3g49120 und At4g37530 mit einem Protein-Score von 54 und 64 wesentlich unsicherer war.

Tab. 4.9: Durch V. longisporum Einfluss differentiell auftretende apoplastische Proteine. Es wurden Spots aus Gelen von sechs biologischen Wiederholungen pro Variante verglichen. Die AWF stammten aus zwei unabhängigen Experimenten. Weitere Details auch in Tabelle 4.8. Spot Identifikationsnummern gehören zu denen in Abbildung 4.22. Angegeben ist der Faktor mit dem Proteine durch Verticillium-Infektion hoch- oder herabreguliert waren, sowie das Resultat des T-Tests, wobei $p \leq 0,05$ als signifikant angesehen wurde.

\begin{tabular}{|c|c|c|c|c|c|c|c|}
\hline $\begin{array}{l}\text { Spot } \\
\text { Nr. }\end{array}$ & Ähnlichkeit mit & $\begin{array}{c}\text { AGI } \\
\text { Nummer }\end{array}$ & $\begin{array}{c}\text { Protein } \\
\text { Score }\end{array}$ & $\begin{array}{l}\text { Molekular- } \\
\text { gewicht (Da) }\end{array}$ & $\begin{array}{l}\text { Signal- } \\
\text { peptid }\end{array}$ & Faktor & p-Wert \\
\hline V 1 & $\begin{array}{l}\text { Serin Carboxypeptidase } \\
\text { S10 }\end{array}$ & At4g12910 & 214 & 56238 & $S(R C 1)$ & 2,4 & 0,0002 \\
\hline V 2 & $\begin{array}{l}\text { Germin-ähnliches Protein } \\
\text { (GER3, GLP3) }\end{array}$ & At5g20630 & 95 & 22020 & $S(R C 1)$ & 3,1 & 0,0174 \\
\hline V 3 & Peroxidase 52 & At5g05340 & 373 & 34650 & $S(R C 1)$ & 4,1 & 0,0004 \\
\hline V 4 & $\begin{array}{l}\text { Peroxidase } 34 \\
\text { (Klasse III Peroxidase) }\end{array}$ & At3g49120 & 54 & 39440 & $S(R C 3)$ & 2,3 & 0,0396 \\
\hline V 5 & Peroxidase & At4g37530 & 64 & 36388 & $S(R C 1)$ & 2,2 & 0,0491 \\
\hline$\vee 7$ & $\alpha$-Galactosidase & At5g08370 & 122 & 44465 & $S(R C 1)$ & 2,2 & 0,0107 \\
\hline 27 & Lektin ähnliches Protein & At3g16530 & 287 & 30547 & $S(R C 1)$ & 0,5 & 0,0241 \\
\hline
\end{tabular}

\subsubsection{Analyse der Hauptproteine in Gesamtblattextrakten von Arabidopsis thaliana} In den AWF von Arabidopsis wurden auch Proteine gefunden, für die Signalpeptide für Mitochondrien und Chloroplasten vorhergesagt wurden (Tab. 4.8), obwohl in der AWF durch Malatdehydrogenase-Messung nur eine sehr geringe Kontamination nachgewiesen werden konnte (Tab. 4.6). Um herauszufinden wie stark die Kontamination durch symplastische Proteine war, wurden acht dominante Proteine identifiziert. Es wurde erwartet, dass sich diese Proteine auch in der AWF wiederfinden lassen müssten. Um die relative Kontamination 
abzuschätzen, wurden die relativen Intensitäten dieser Proteine in Gesamtblattextrakten analysiert (Abb. 4.23 und Tab. 4.10).

3

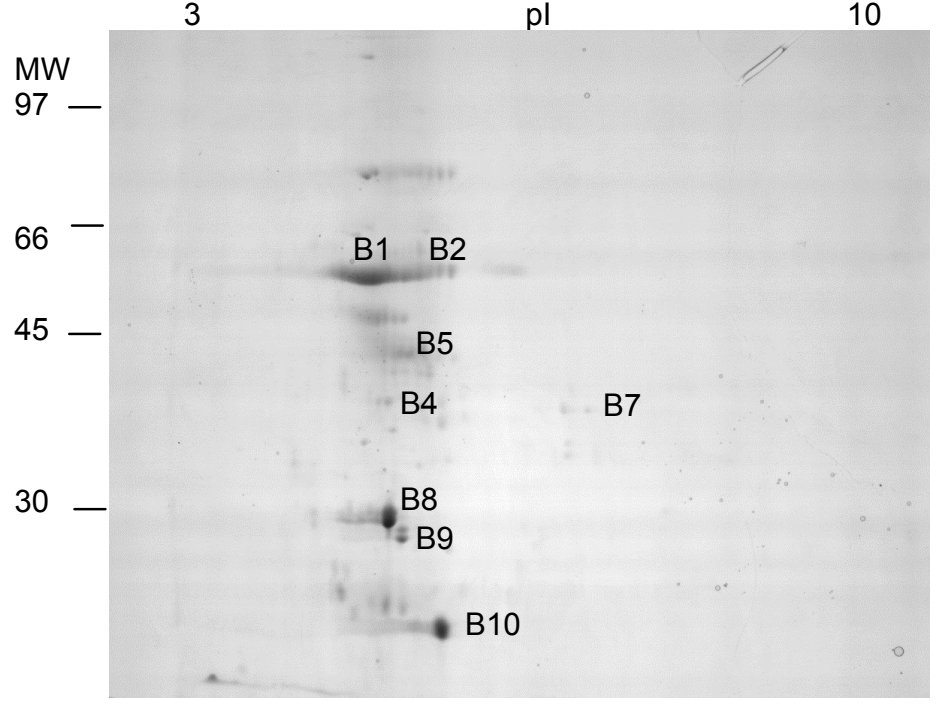

Abb. 4.23: Proteinmuster von Gesamtblattextrakten aus Arabidopsis thaliana 25 Tage nach Inokulation. Für die zweidimensionale Separation wurde ca. $1 \mathrm{mg}$ Protein eingesetzt. Die Zahlen weisen auf Proteinspots hin, die mittels ESI-LC-MS aus dem CBB-gefärbten Gel identifiziert wurden.

Die Proteine Rubisco, Sauerstoffbindeprotein, PSBP, RCA, PSBO-2, Malatdehydrogenase und SBP wurden aus dem Gel identifiziert (Abb. 4.23; Tab 4.10). Aus den Intensitäten der Proteine im Gel wurde berechnet, dass die drei Proteine Rubisco (16,5\%), Sauerstoffbindeprotein $(7,7 \%)$ und PSBP $(7,0 \%)$ relativ zur Gesamtintensität aller Proteinspots zusammen 31,2\% ausmachten. In den AWF war der Beitrag dieser Proteine zur Gesamtfärbeintensität 0,88 \% (Rubisco), 0,32\% (Sauerstoffbindeprotein) und 0,38\% (PSBP). Dies entspricht Kontaminationsfaktoren von jeweils 0,053, 0,041 und 0,054. Zusammengenommen bestätigt diese Analyse, dass die Kontamination gering, aber nachweisbar war. Daher wurden andere Kriterien wie die Überprüfung von Signalpeptiden bei der Untersuchung berücksichtigt. Die untersuchten AWF kann man also nicht als völlig reine, aber stark angereicherte AWF bezeichnen.

Tab. 4.10: Proteine, die durch Massenspektrometrie in Gesamtblattextakten von Arabidopsis thaliana aus einem CBB-gefärbten zweidimensionalen Gel (Abb. 4.23) identifiziert wurden. Die relative Intensität der Proteine, bezogen auf Rubisco, ist angegeben.

\begin{tabular}{llcccc}
\hline $\begin{array}{c}\text { Spot } \\
\text { Nr. }\end{array}$ & Ähnlichkeit mit & $\begin{array}{c}\text { Accession } \\
\text { number }\end{array}$ & $\begin{array}{c}\text { Protein } \\
\text { Score }\end{array}$ & $\begin{array}{c}\text { Molekular- } \\
\text { gewicht (Da) }\end{array}$ & $\begin{array}{c}\text { relative } \\
\text { Intensität }\end{array}$ \\
\hline B1 & Rubisco & AtCg00490 & 209 & 53435 & 1 \\
B2 & ATP-Synthase CF1 $\beta$-Kette & AtCg00480 & 536 & 53957 & 0,07 \\
B4 & SBPase; Phosphor-Ester-Hydrolase & At3g55800 & 259 & 42787 & 0,02 \\
B5 & RCA; Rubisco Aktivase & At2g39730 & 120 & 52347 & 0,15 \\
B7 & Malatdehydrogenase & At1g04410 & 176 & 35890 & 0,03 \\
B8 & Sauerstoffbindeprotein & At5g66570 & 298 & 35285 & 0,47 \\
B9 & PSBO-2 & At3g50820 & 229 & 35226 & 0,09 \\
B10 & PSBP (Sauerstoffbindeprotein 2) & At1g06680 & 221 & 28249 & 0,27 \\
\hline
\end{tabular}




\subsubsection{Peroxidase Aktivitäten}

Da unter den differentiell regulierten Proteinen drei Peroxidasen waren, wurde die Aktivität von Peroxidasen in den apoplastischen Waschflüssigkeiten (AWF) und in Gesamtblattextrakten von mock- und Verticillium-inokulierten Pflanzen gemessen (siehe 3.5.2.2). Sowohl in den apoplastischen als auch in den Gesamtblattextrakten wurden Aktivitätsunterschiede zwischen den mock- und Verticillium-inokulierten Arabidopsis festgestellt (Abb. 4.24A und B). In der AWF der Verticillium-inokulierten Pflanzen war die Aktivität ca. 10 fach erhöht. Während die Aktivität der Kontrollen bei 11 nkat/mg Protein lag, wiesen die AWF der Verticillium-inokulierten Pflanzen durchschnittlich eine Aktivität von 102 nkat/mg Protein auf. In den Gesamtblattextrakten war die spezifische Aktivität insgesamt wesentlich geringer als in der AWF. Die Verticillium-Infektion führte hier zu einer dreifachen Erhöhung der Peroxidase-Aktivität.

Zusätzlich wurde noch eine Peroxidase-Aktivitätsfärbung im Gel durchgeführt (siehe 3.5.4). Dafür wurden die Peroxidasen aus den AWF von mock- und Verticillium-inokulierten Pflanzen nach ihrem isoelektrischen Punkt aufgetrennt und anschließend mit Guajakol und $\mathrm{H}_{2} \mathrm{O}_{2}$ sichtbar gemacht (Abb. 4.24C). Während bei den mock-inokulierten Kontrollen keine Färbung zu sehen war, färbten sich bei den apoplastischen Extrakten aus Verticilliuminokulierten Pflanzen sowohl im sauren als auch im basischen Bereich Banden durch die Peroxidase-Aktivität deutlich an. Das Ergebnis zeigte, dass sowohl saure als auch basische Peroxidasen durch Verticillium-Einfluss eine erhöhte Aktivität aufwiesen, obwohl die drei Peroxidasen (At5g05340, At3g49120, At4g37530), die in den 2 D-Gelen eine stärkere Expression unter Verticillium-Einfluss aufwiesen, alle im basischen $\mathrm{pH}-$ Bereich zu finden waren. Dieses Ergebnis deutet darauf hin, dass nicht alle durch Verticillium-Einfluss differentiell regulierten Proteine in den zweidimensionalen Gelen erfasst wurden.
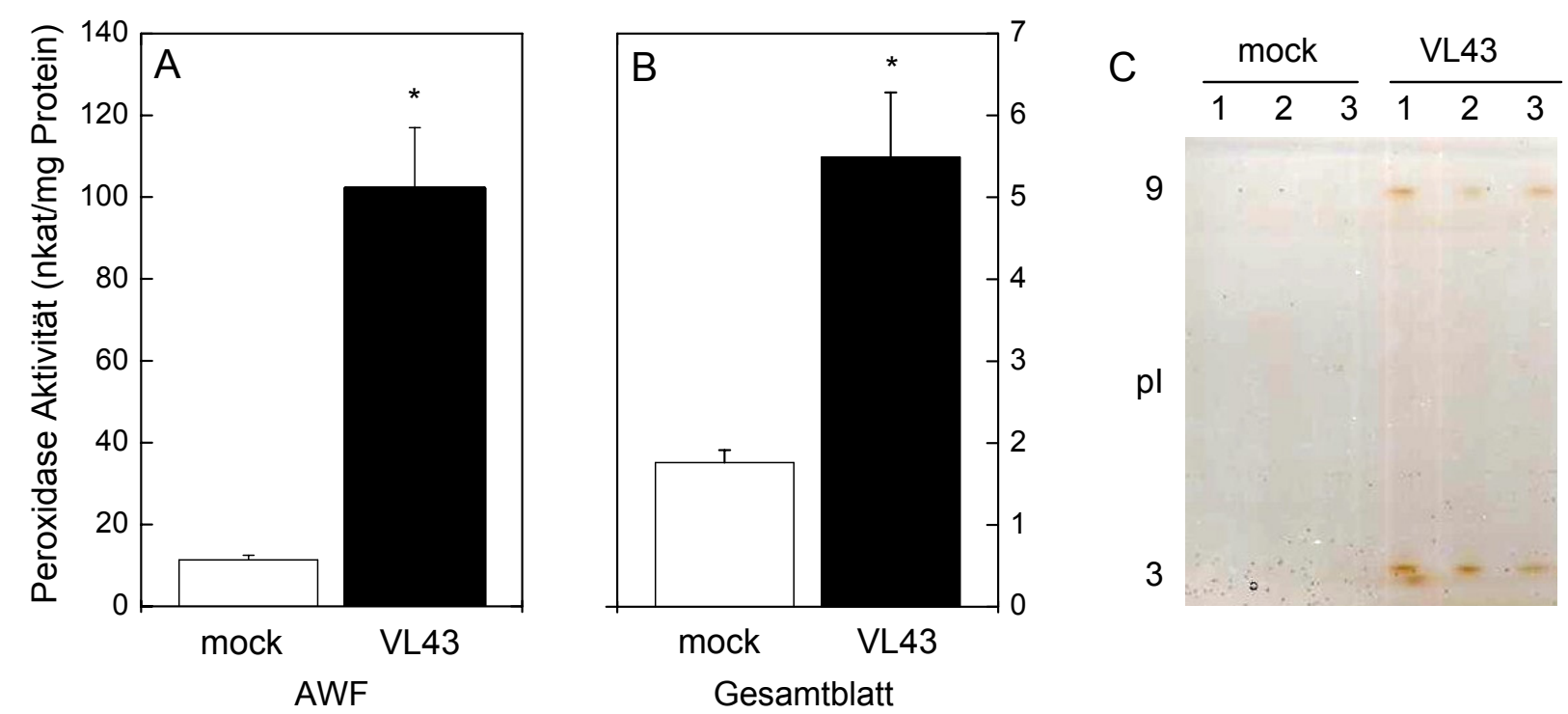

Abb. 4.24: (A) Peroxidase-Aktivität in AWF und (B) Gesamtblattextrakten von mock und V. longisporum inokulierten Arabidopsis-Pflanzen 25 Tage nach Inokulation. Die Säulen repräsentieren sechs Replikate aus zwei unabhängigen Experimenten mit Standardfehler. Werte mit einem Stern waren im T-Test $(p \leq 0,05)$ signifikant unterschiedlich. (C) Peroxidase Aktivitätsfärbung nach isoelektrischer Fokussierung der AWF von mock- und VL43-inokulierten Arabidopsis thaliana Pflanzen. Jede Spur wurde mit 3,5 $\mu$ g Protein geladen. Jeweils drei Spuren des Gels, das einen pHWert von 3 bis 9 abdeckt, zeigen unabhängige Proben aus mock- und aus VL43-inokulierten Pflanzen. 


\subsubsection{Expressionsanalyse differentiell auftretender Proteine}

Um zu untersuchen, ob sich die unter Verticillium-Einfluss im Proteingel differentielle Regulation der Proteine auch auf RNA-Ebene widerspiegelt, wurden die Transkriptmengen mittels quantitativer real time PCR untersucht (siehe 3.6.4). Dazu wurden zunächst durch Nutzung des Primer3-Servers (http://frodo.wi.mit.edu/cgi-bin/primer3/primer3_www.cgi) und dessen Standardeinstellungen spezifische Primer für die zu den Proteinen gehörenden Gensequenzen konstruiert. Um zu verhindern, dass ein Primer für eine der Peroxidasen auch an die anderen drei untersuchten Peroxidasen passte, wurde ein Sequenzabgleich mit ClustalW durchgeführt (siehe Anhang). Die Primer wurden dann so ausgewählt, dass sie spezifisch für jeweils eine der drei Peroxidase-Sequenzen waren. Zusätzlich zu den differentiell exprimierten Proteinen, wurde auch die Peroxidase (At5g06720) mit saurem pHWert, die im Vergleich der Proteingele von mock- und Verticillium-infizierten Pflanzen nicht differentiell auftrat, analysiert. Da durch die Peroxidase-Aktivitätsfärbung eine erhöhte Peroxidase-Aktivität auch im sauren pH-Bereich nachgewiesen wurde (Abb. 4.24), erschien eine nähere Untersuchung der einzigen im sauren $\mathrm{pH}$-Bereich gefundenen Peroxidase angebracht.

Tabelle 4.11 zeigt einen Vergleich der untersuchten Gene auf Protein- und RNA-Ebene zum Zeitpunkt 25 Tage nach Inokulation. Die Gene, die durch Verticillium-Infektion auf Proteinebene hochreguliert waren, waren auch auf RNA-Ebene hochreguliert. Allerdings unterschieden sich die Faktoren auf RNA- und Protein-Level zum Teil stark. Während für die Peroxidase At5g05340 unter Verticillium-Infektion auf Proteinebene ein Faktor von 4,1 nachgewiesen werden konnte, lag der Faktor auf RNA-Ebene bei 40,6. Dagegen waren die RNA-Mengen für die Serin-Carboxypeptidase und die Peroxidase At3g49120 nur leicht erhöht und zum Zeitpunkt 25 Tage nach Inokulation war die Erhöhung nicht signifikant. Das Lektin-ähnliche Protein, auf Proteinebene signifikant herabreguliert, wies auf RNA-Ebene eine Reduktion um den gleichen Faktor auf. Die Peroxidase At5g06720 ohne signifikante Erhöhung auf Proteinebene, zeigte auch auf RNA-Ebene keine signifikante Erhöhung unter Verticillium-Einfluss.

Für die unterschiedlichen Faktoren auf Protein- und RNA-Ebene gibt es mehrere Erklärungen. Einige Schwankungen kamen sehr wahrscheinlich dadurch Zustande, dass das auf Protein- und RNA-Ebene untersuchte Material aus zwei völlig unabhängigen Versuchen stammte. Auch technische Gründe kommen als Ursache für Unterschiede in Frage. So wurden möglicherweise bei der Gewinnung der AWF Proteine mehr oder weniger gut gelöst. Die Proportionalität zwischen Färbeintensität und Proteinkonzentration ist bei Silberfärbungen nicht so gut, so dass hier sicher keine absolut genauen Angaben möglich sind. Die Proportionalität von CBB-Färbungen ist zwar wesentlich besser, allerdings ist sie dafür wesentlich weniger sensitiv. Die Veränderung der Proteinmenge hängt auch davon ab, wie langlebig die Proteine sind bzw. wie schnell sie wieder abgebaut werden, so dass es auch daher zu Unterschieden zwischen Protein- und RNA-Level kommen kann. Auf RNAEbene wurden zum Teil hohe Standardabweichungen ermittelt, was darauf hindeutet, dass die Stärke der Reaktionen in den einzelnen Pflanzen schwankt. Nichtsdestotrotz zeigten die Ergebnisse, dass die im Proteingel differentiell auftretenden Proteine, auch auf RNA-Ebene verändert waren. Am Beispiel der zusätzlich untersuchten Peroxidase zeigte sich, dass ein 
im Proteingel nicht signifikant verändert auftretendes Protein auch auf RNA-Ebene nicht signifikant verändert auftrat.

Tab. 4.11: Relative Protein- und mRNA-Mengen unter Verticillium-Einfluss in Arabidopsis thaliana zum Zeitpunkt 25 Tage nach Verticillium-Inokulation bezogen auf mock-inokulierte Kontrollpflanzen im Vergleich. Die Werte repräsentieren sechs Replikate auf Proteinebene und sechs Replikate in Doppelbestimmung auf RNA-Ebene. Das Probenmaterial für die Protein- und die RNA-Analyse stammte aus unterschiedlichen Versuchen. Werte mit $p \leq 0,05 \mathrm{im}$ T-Test wurden als signifikant unterschiedlich angesehen.

\begin{tabular}{lcccc}
\hline Protein & $\begin{array}{c}\text { Faktor } \\
\text { Protein }\end{array}$ & $\begin{array}{c}\text { p-Wert } \\
\text { Protein }\end{array}$ & $\begin{array}{c}\text { Faktor } \\
\text { RNA }\end{array}$ & $\begin{array}{c}\text { p-Wert } \\
\text { RNA }\end{array}$ \\
\hline Serin-Carboxypeptidase & 2,4 & 0,000 & 1,4 & 0,131 \\
Germin-ähnliches Protein & 3,1 & 0,017 & 1,9 & 0,021 \\
Peroxidase (At5g05340) & 4,1 & 0,000 & 40,6 & 0,001 \\
Peroxidase (At3g49120) & 2,3 & 0,040 & 1,3 & 0,344 \\
Peroxidase (At4g37530) & 2,2 & 0,049 & 3,1 & 0,001 \\
$\alpha$-Galactosidase & 2,2 & 0,011 & 3,4 & 0,001 \\
Lektin-ähnliches Protein & 0,5 & 0,024 & 0,5 & 0,033 \\
Peroxidase (At5g06720) & 1,2 & 0,620 & 1,6 & 0,159 \\
\hline
\end{tabular}

Da aus Arabidopsis-Pflanzen in früheren Krankheitsstadien nicht ausreichend apoplastische Waschflüssigkeiten für Proteomanalysen aus den Blättern gewonnen werden konnten, war es interessant, die Veränderung der Transkriptmengen über den Infektionsverlauf zu analysieren.

In Abbildung 4.25 und 4.26 ist die Regulation der Gene der Verticillium-infizierten Pflanzen bezogen auf die Kontrollpflanzen auf RNA-Ebene im Infektionsverlauf dargestellt. Die reduzierte Expression des Lektin-ähnlichen Proteins war über den gesamten Untersuchungszeitraum nachzuweisen. Die Serin-Carboxypeptidase zeigte auf RNA-Ebene über den gesamten Infektionsverlauf eine leicht erhöhte Expression, die sich aber nur zum Zeitpunkt 35 Tage nach Inokulation als signifikant erwies (Abb. 4.25B). Die Expression der $\alpha-$ Galactosidase stieg im Verlauf der Infektion bis zum Zeitpunkt 28 Tage nach Infektion immer mehr an und fiel danach wieder ab. Die relative RNA-Menge des Germin-ähnlichen Proteins war unter Verticillium-Einfluss zu den beiden Zeitpunkten 25 und 35 Tage nach Inokulation signifikant erhöht, während zu den anderen Zeitpunkten keine bzw. eine geringe Veränderung im Vergleich zu den mock-inokulierten Kontrollen vorlag (Abb. 4.25B). 

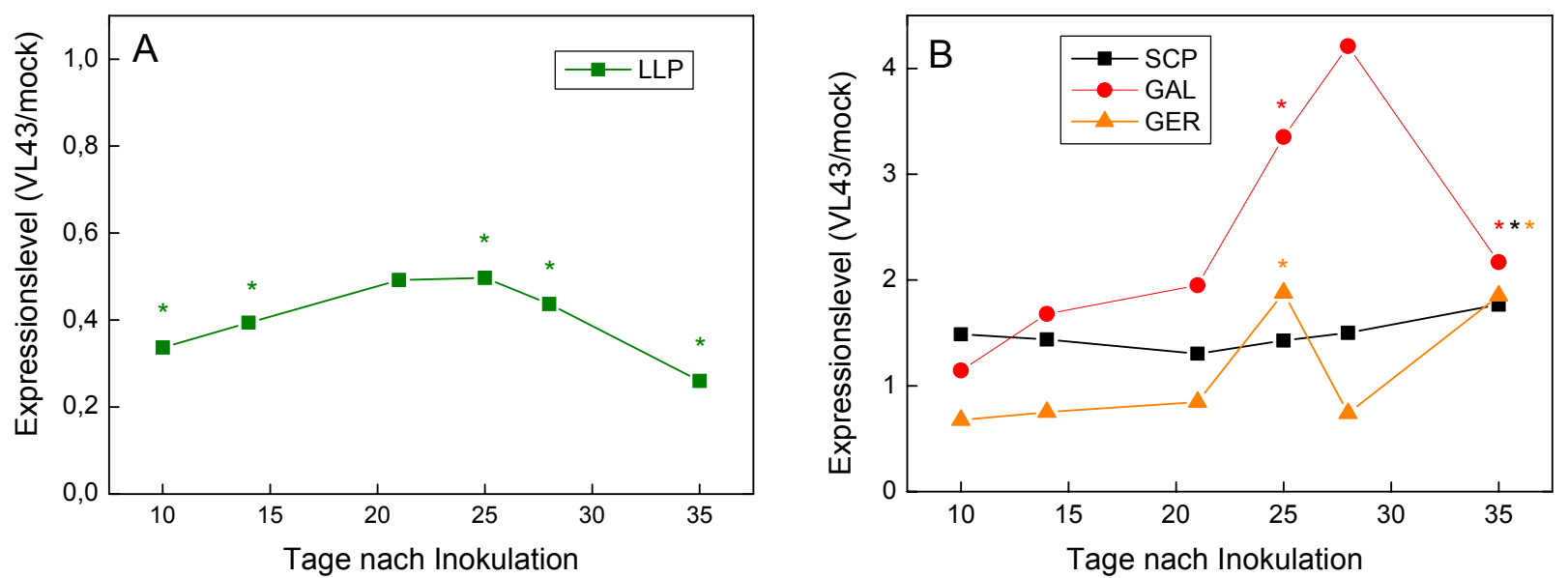

Abb. 4.25: Relative Genexpression in Verticillium-inokulierten im Vergleich zu mock-inokulierten Arabidopsis thaliana Pflanzen. Untersucht wurde die relative Expression der codierenden Gene für ein (A) Lektin-ähnliches Protein (LLP) und für (B) ein Germin-ähnliches Protein (GER), eine SerinCarboxypeptidase (SCP) und eine $\alpha$-Galactosidase (GAL) (Tab. 4.9). Die Symbole repräsentieren drei Replikate in Doppelbestimmung zu den Zeitpunkten 10, 14 und 35 Tage nach Inokulation und sechs Replikate in Doppelbestimmung zu den Zeitpunkten 21, 25 und 28 Tage nach Inokulation. Werte mit einem Stern waren im T-Test $(p \leq 0,05)$ signifikant unterschiedlich.

In Abbildung 4.26 sind die relativen Expressionlevel der untersuchten Peroxidasen im Infektionsverlauf dargestellt. Die Peroxidase At5g05340 zeigte die stärkste relative Expression unter Verticillium-Einfluss, sie erreichte 21 Tage nach Inokulation ein Maximum einer 97-fachen Erhöhung im Vergleich zu den Kontrollpflanzen und nahm danach wieder ab (Abb. 4.26A). Die beiden Peroxidasen At4g37530 und At3g49120 zeigten eine weniger starke Zunahme der relativen Transkriptmenge durch Verticillium-Infektion (Abb. 4.26B). Während die Peroxidase At3g49120 ein Expressionsmaximum 14 Tage nach Infektion mit einem Faktor von 3,2 aufwies, lag das Maximum der Peroxidase At4g37530 (Faktor 3,1) 25 Tagen nach Inokulation. Die Erhöhung zu diesen beiden Zeitpunkte erwies sich im T-Test auch als signifikant $(p<0,05)$. Keine signifikante Expressionserhöhung unter VerticilliumEinfluss konnte auf RNA-Ebene für die Peroxidase At5g06720 ermittelt werden, die auch auf Proteinebene keine signifikant erhöhte Expression aufwies (Abb. 4.26C). Es lässt sich also zusammenfassend festhalten, dass die Ergebnisse aus der Proteinanalyse durch die RNAAnalyse untermauert wurden. 

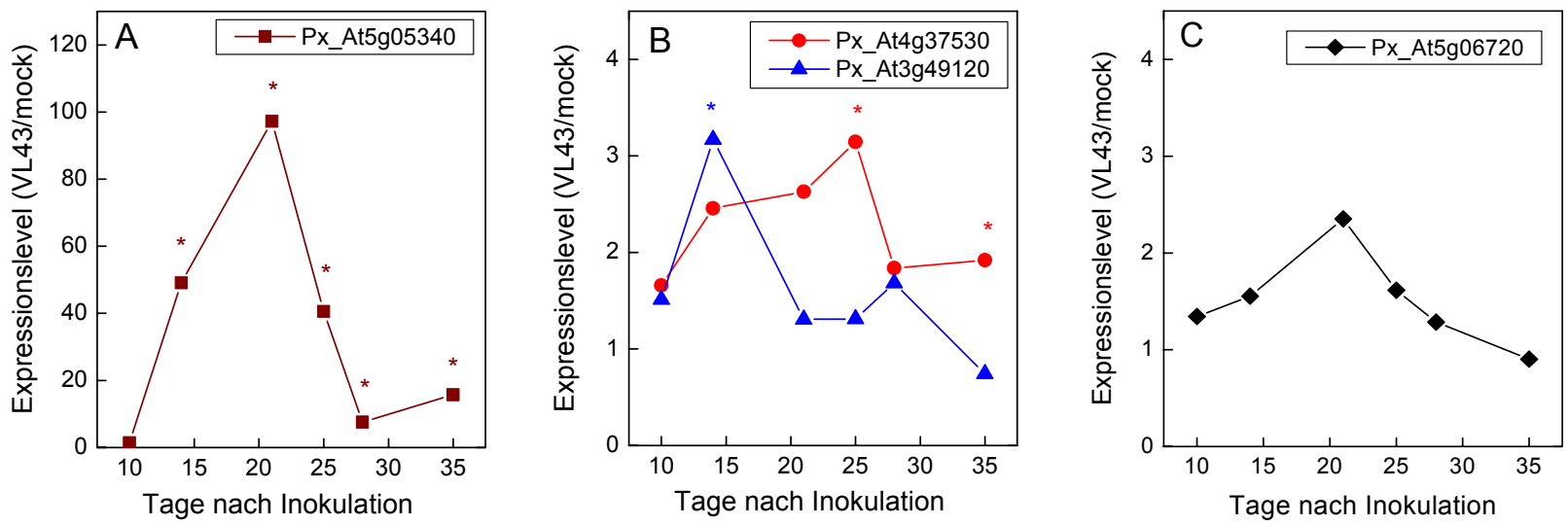

Abb. 4.26: Relative Genexpression in Verticillium-inokulierten im Vergleich zu mock-inokulierten Arabidopsis thaliana Pflanzen. Untersucht wurde die relative Expression der codierenden Gene für (A) die Peroxidase At5g05340, für (B) die Peroxidasen At4g37530 und At3g49120 und (C) die saure Peroxidase At5g06720. Die Symbole repräsentieren drei Replikate in Doppelbestimmung zu den Zeitpunkten 10, 14 und 35 Tage nach Inokulation und sechs Replikate in Doppelbestimmung zu den Zeitpunkten 21, 25 und 28 Tage nach Inokulation. Werte mit einem Stern waren im T-Test $(p \leq 0,05)$ signifikant unterschiedlich.

\subsubsection{In silico Analyse der Expressionslevel der differentiell regulierten Proteine unter diversen Stressbedingungen}

Abbildung 4.27 zeigt eine Genevestigator-Analyse der Proteine, die unter VerticilliumEinfluss differentiell reguliert waren. Dabei wurden alle in diesem Programm (https://www.genevestigator.ethz.ch/at/) vorgegebenen Stressfaktoren einbezogen und als Basis war der $22 \mathrm{~K}$ Chip vorgegeben. Mit Hilfe dieser Software wurde ein „elektronischer Northern Blot" durchgeführt, der zeigte wie die Verticillium-beeinflussten Gene unter biotischem, chemischem, hormonellem und abiotischem Stress, sowie unter Lichtstress und Nährstoffstress, reagierten. Bei näherer Betrachtung wird deutlich, dass unter keiner anderen Stressbedingung, dieselbe Kombination an Genen so verändert war wie unter VerticilliumInfektion. Die stärksten Gemeinsamkeiten traten bei biotischem Stress mit Agrobacterium tumefaciens und mit dem Pilz Botrytis cinerea auf und bei hormonellem Stress mit einer kombinierten Behandlung aus Brassinoliden und $\mathrm{H}_{3} \mathrm{BO}_{3}$, da hier jeweils vier der sieben Gene wie unter Verticillium-Einfluss verändert waren. In diesen Fällen war aber jeweils das Germin-ähnliche Protein (At5g20630) nicht hochreguliert und das Lektin-ähnliche Protein (At3g16530) nicht herabreguliert wie unter Verticillium-Einfluss. Das Lektin-ähnliche Protein (At3g16530) wies in der Genevestigator-Analyse vor allem unter Lichtstress eine Verringerung auf, aber auch unter Hitze- bzw. Salzstress und durch Mykorrhiza und Nematoden-Einfluss. Das Germin-ähnliche Protein wies in der Genevestigator-Analyse z.B. unter Licht- und $\mathrm{CO}_{2}$-Stress und unter Einfluss von Mykorrhiza, Mehltau (Erysiphe orontii) und Erysiphe cichoracearum eine erhöhte RNA-Menge auf. 


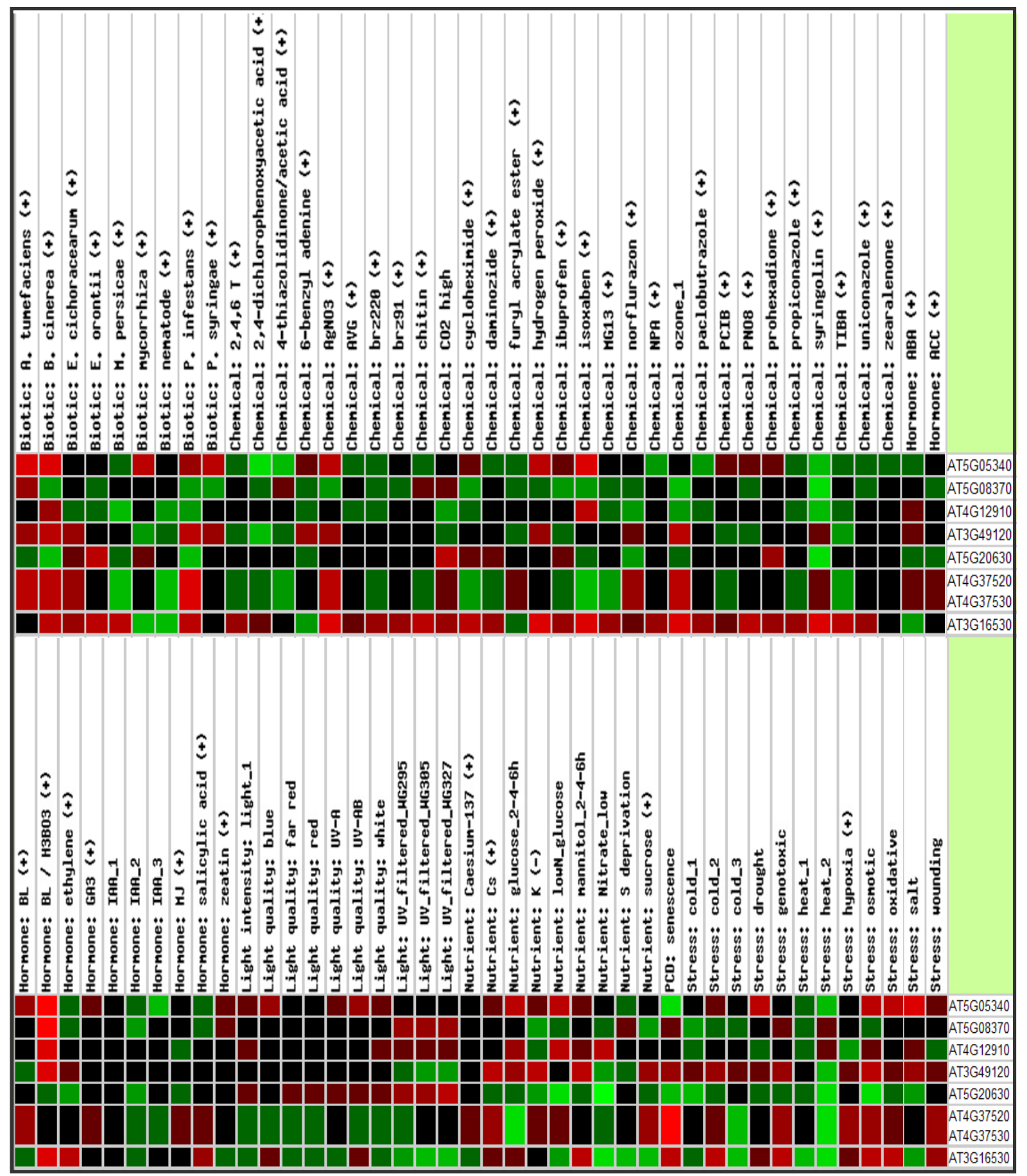

Abb. 4.27: Genevestigator-Analyse (https://www.genevestigator.ethz.ch/at/) der unter VerticilliumEinfluss differentiell regulierten Proteine (Tab. 4.9). Oben sind verschiedene getestete Stressbedingungen angegeben. Rot bedeutet hochreguliert, grün herabreguliert und schwarz keine Regulation unter dem jeweiligen Stress. Die AGI-Nummern der Proteine sind auf der rechten Seite aufgeführt. 


\subsubsection{Untersuchungen zum Einfluss von Verticillium longisporum auf die Zellwandzusammensetzung von Arabidopsis thaliana}

Peroxidasen können unterschiedliche Funktionen in Abwehr von Pathogen wahrnehmen. Die Verstärkung der Zellwand als Barriere für das Eindringen von Pathogenen durch Suberisierung und Lignifizierung ist eine mögliche Funktion (Passardi et al., 2004). Daher wurde der Einfluss von V. Iongisporum auf die Zellwand näher untersucht. Zunächst wurde der Anteil der Zellwandmasse, auch als strukturelle Biomasse bezeichnet, an der Frischmasse der Pflanze ermittelt (siehe 3.3.11). Der Anteil der strukturellen Biomasse an der Frischmasse der Pflanzen betrug bei den mock-inokulierten 3,3 \% und war bei den Verticillium-inokulierten um 24 \% erhöht, diese Erhöhung erwies sich im T-Test als signifikant $(p \leq 0,05)$. Zur weiteren Analyse wurde eine Ligninbestimmung in Zellwandextrakten von mock- und Verticillium-infizierten Pflanzen durchgeführt (Abb. 4.28B). Unter VerticilliumEinfluss stieg der Ligningehalt von $39 \mu \mathrm{g} / \mathrm{mg}$ Zellwand bei den mock-inokulierten Pflanzen um rund $20 \%$ auf $49 \mu \mathrm{g} / \mathrm{mg}$ Zellwand bei den Verticillium-infizierten Pflanzen.
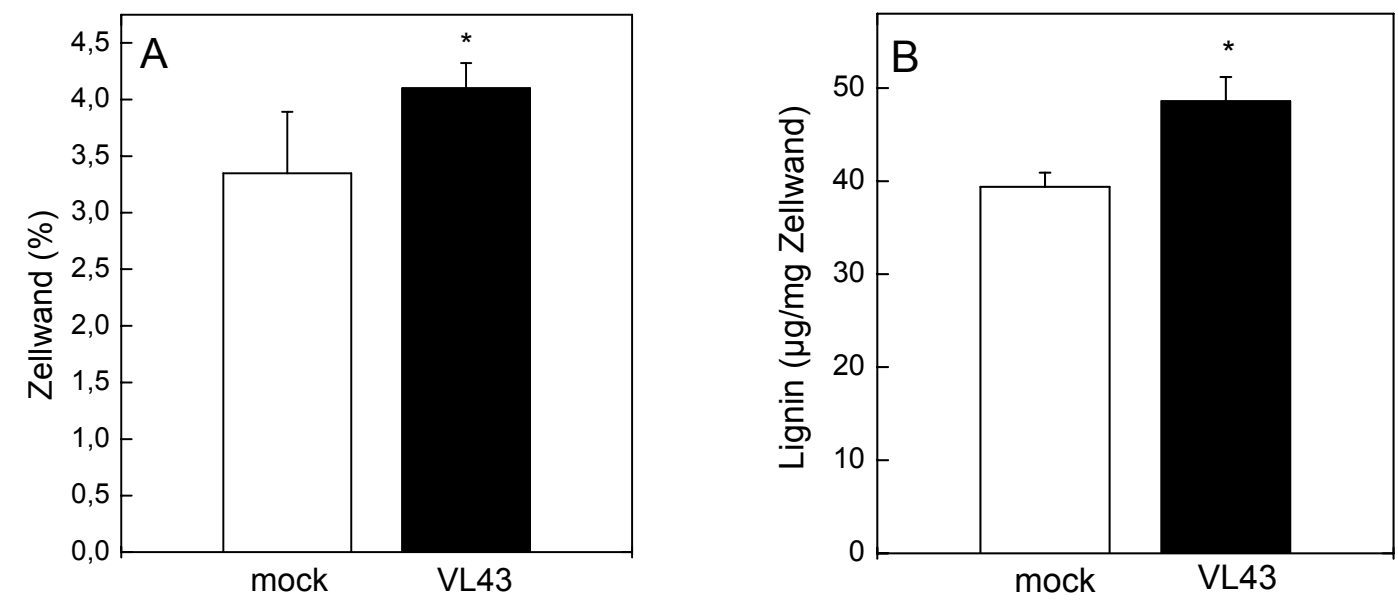

Abb. 4.28: (A) Strukturelle Biomasse und (B) Ligningehalt in Rosetten von mock- und Verticilliuminfizierten Pflanzen im Vergleich. Die Daten repräsentieren Mittelwerte und Standardfehler von $n=9$ Pflanzen. Werte mit einem Stern waren im T-Test $(p \leq 0,05)$ signifikant unterschiedlich.

\subsubsection{FTIR-Analyse zur Ermittlung des chemischen Fingerprints Verticillium longisporum infizierter Arabidopsis thaliana}

Um zu untersuchen, ob Verticillium longisporum Infektionen die Zusammensetzung der organischen Blattbestandteile verändern, wurden FTIR-Analysen durchgeführt (siehe 3.3.10). Dafür wurde Blattmaterial von mock- und Verticillium-infizierten Arabidopsis untersucht und zum Vergleich auch Pilzmaterial von Verticillium longisporum gemessen (Abb. 4.29). Die Hauptpeaks der Arabidopsis Blätter wurden nummeriert (Abb. 4.29A) und entsprechen vermutlich den Schwingungen von: (1) $1730 \mathrm{~cm}^{-1} \mathrm{C}=\mathrm{O}$ in Esterbindungen, (2 und 3) 1650 und $1550 \mathrm{~cm}^{-1}$ primären und sekundäre Amiden ( $\mathrm{NH}_{2}$ und $\mathrm{NH}$ in Proteinen), (4 und 5) $\mathrm{C}-\mathrm{H}$ Bindungen, wobei (5) $\mathrm{CH}_{2}$ Bindungen in Cellulose zugeordnet wird, (6) $1230 \mathrm{~cm}^{-1}$ 
tertiären Amidbindungen und (7-10) 1160-970 cm-1 C-O Bindungen im Rückgrat von Polysacchariden, wobei (7) $1150 \mathrm{~cm}^{-1} \mathrm{C}-\mathrm{O}-\mathrm{C}$ in Cellulose bzw. Hemicellulose und (9 und 10) 1060 und $1037 \mathrm{~cm}^{-1} \mathrm{C}-\mathrm{O}-\mathrm{C}$ und $\mathrm{C}-\mathrm{C}$ Bindungen in Cellulose Zuckerringen (Chalmers \& Griffiths 2002; Mouille et al., 2003; Naumann et al., 2005; Séné et al., 1994).

Da der Ligningehalt in Arabidopsis Blättern erhöht war (siehe 4.2.7), sollte versucht werden diese Mengenunterschiede auch mittels FTIR-Analyse zu detektieren. Die Wellenlängen für die aromatischen Schwingungen des Lignins liegen im Bereich 1530-1490 cm ${ }^{-1}$ und typische $\mathrm{C}=\mathrm{O}$ Schwingungen des Lignins bei $1166 \mathrm{~cm}^{-1}$ (Faix et al., 1991; Naumann et al., 2005). Unterschiede im Ligningehalt konnten mit der FTIR-Analyse aber nicht erfasst werden, da der Ligningehalt in den Arabidopsis-Blättern insgesamt unterhalb des Detektionslimits lag. Jedoch zeigten die Spektren von mock- und Verticillium-infizierten Pflanzen eine Reihe von Unterschieden. Die deutlichsten Unterschiede sind durch Pfeile gekennzeichnet (Abb. 4.29A) und befinden sich in den Wellenlängenbereichen 1650 bis $1550 \mathrm{~cm}^{-1}$ und um $1140 \mathrm{~cm}^{-1}$, welche vermutlich für Proteine und Cellulose bzw. Kohlenhydrate spezifisch sind. Bei den Wellenlängen 1650 und $1550 \mathrm{~cm}^{-1}$ befinden sich zwei Peaks, bei denen jeweils die Absorption der mock-inokulierten Kontrollen über der Absorption der Verticillium-infizierten Pflanzen liegt. Dazwischen, im Bereich um $1600 \mathrm{~cm}^{-1}$, fällt die Absorption sowohl der Kontrollen als auch der Verticillium-infizierten Arabidopsis ab, allerdings ist der Abfall beim Spektrum der Verticillium-infizierten Arabidopsis stärker. Im Wellenlängenbereich um 1140 $\mathrm{cm}^{-1}$ liegt die Absorption der Verticillium-infizierten Arabidopsis über der Absorption der Kontrollen. Diese Unterschiede wurden auch in einer Clusteranalyse von vektornormierten Spektren im Bereich 1800-800 $\mathrm{cm}^{-1}$ deutlich (Abb. 4.29B). Die Clusteranalyse ergab drei Hauptgruppen, die in Abbildung 4.29B durch die römische Zahlen I, II und III gekennzeichnet sind. Fünf der untersuchten mock-inokulierten Arabidopsis bilden die Gruppe I, während die Gruppe II noch in die Untergruppen Ila und IIb zerfällt. Ila wird aus jeweils drei mock- und drei Verticillium infizierten Arabidopsis gebildet; Cluster Ilb beinhaltet fünf Verticilliuminfizierte Arabidopsis. Die Gruppen I und Ilb zeigen, dass die mock- und Verticilliuminfizierten Arabidopsis unterscheidbar sind. Gruppe Ila scheint einen Übergangsbereich zu bilden und zerfällt in zwei Untergruppen zu jeweils drei mock- und drei Verticillium-infizierten Arabidopsis.

Das ebenfalls untersuchte Verticillium longisporum Material wies ein deutlich anderes Spektrum auf als das Pflanzenmaterial (Abb. 4.29A) und bildete auch in der Clusteranalyse eine eigene weit vom Pflanzenmaterial entfernte Gruppe (Abb. 4.29B, Cluster III). 
A

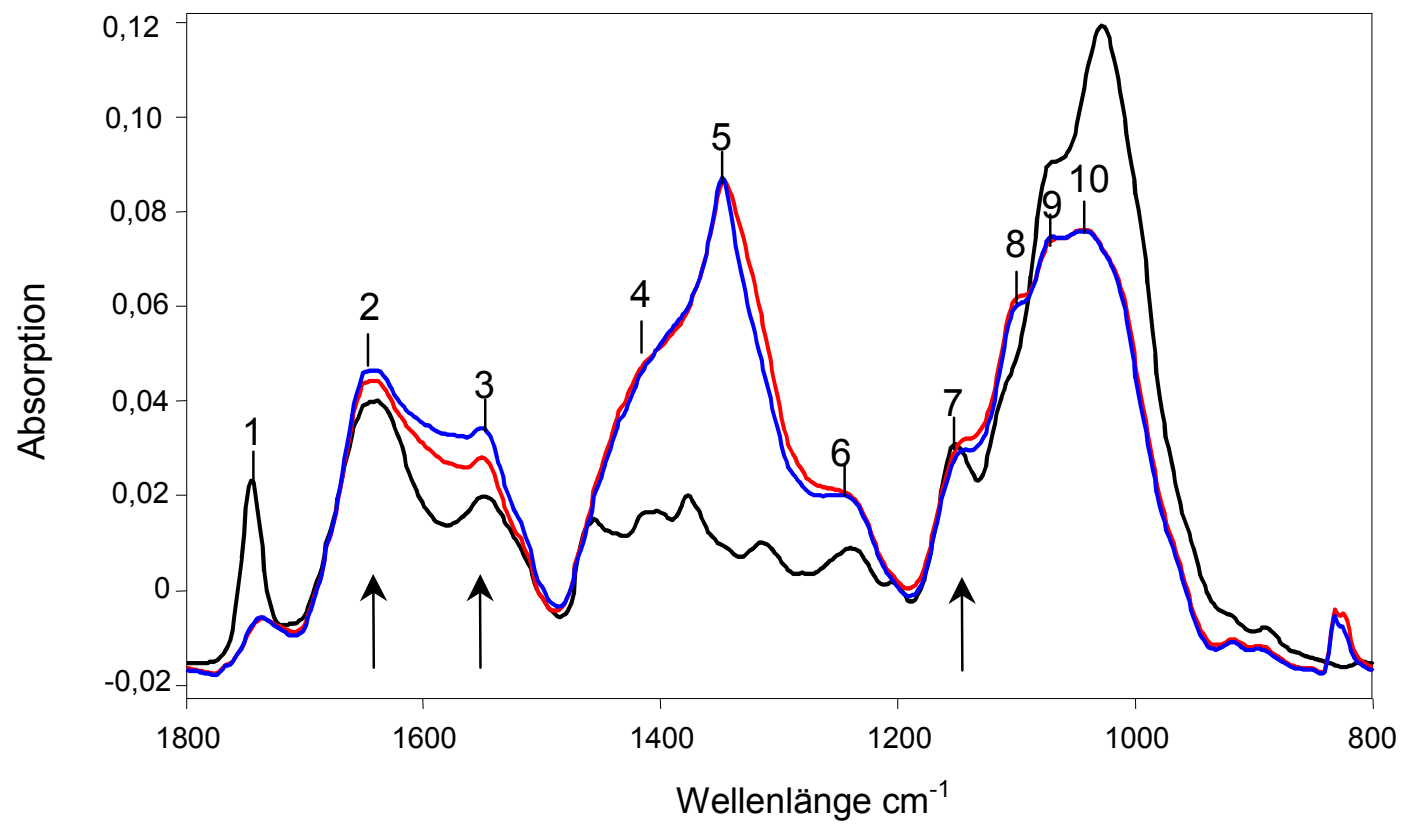

B

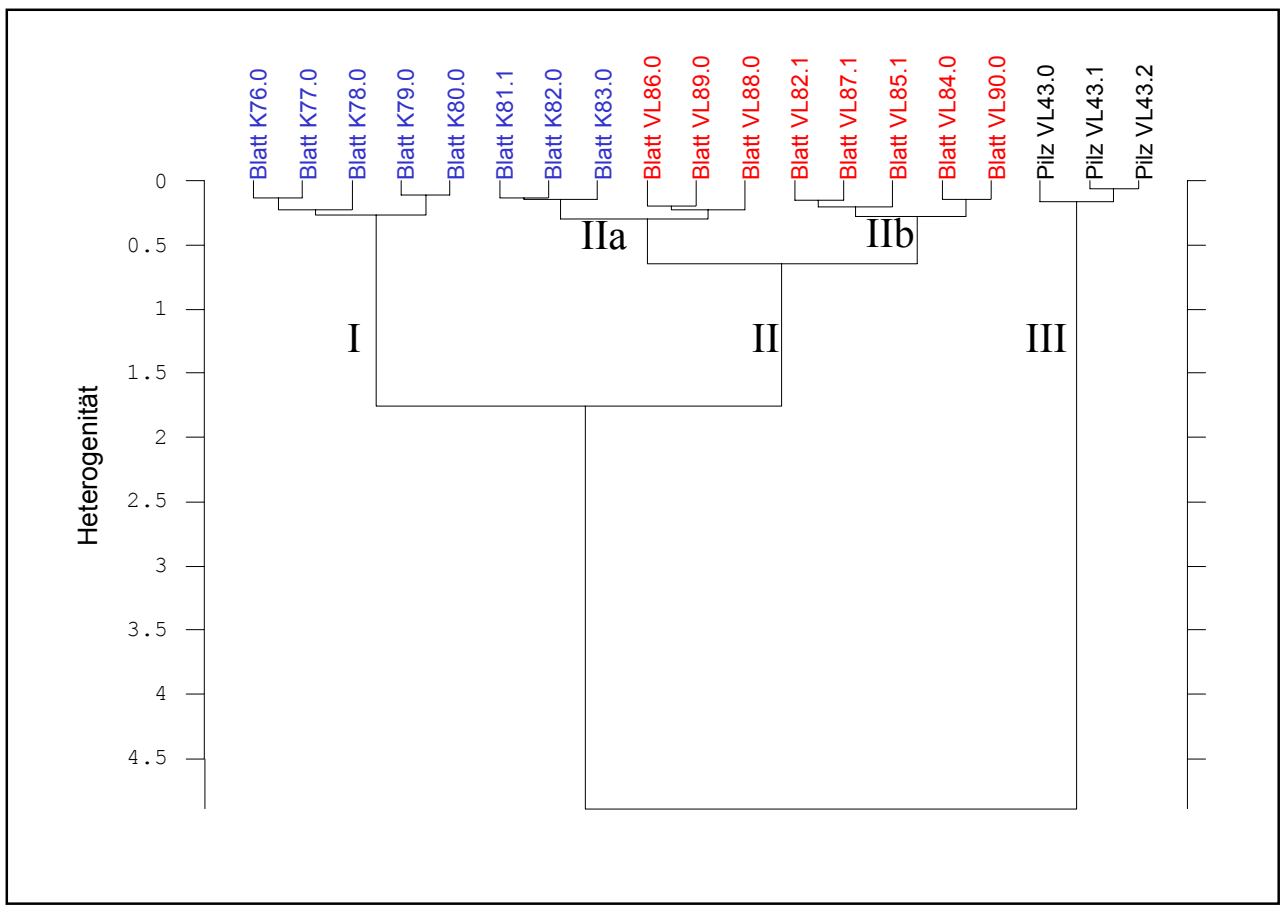

Abb. 4.29: (A) FTIR-ATR-Spektren von getrocknetem Blattmaterial im Bereich $800-1800 \mathrm{~cm}^{-1}$ von mock-inokulierten (blau), Verticillium-inokulierten Arabidopsis thaliana (rot) und zum Vergleich der Pilz (schwarz). Alle Spektren wurden Grundlinien korrigiert und Vektor normiert und repräsentieren Mittelwerte aus jeweils acht verschiedenen Pflanzen- bzw. drei Pilzproben. Den wesentlichen Peaks sind Nummern zugeordnet, die Pfeile deuten an, wo Schwingungen von Lignin auftreten können. (B) Clusteranalyse der mittels FTIR gemessenen mock-inokulierten Kontrollpflanzen (blau), Verticilliuminokulierten Pflanzen (rot) und wiederum zum Vergleich der Pilz (schwarz). Für die Clusteranalyse des Bereichs $800-1800 \mathrm{~cm}^{-1}$ wurden vektornormierte Spektren und die zweite Ableitung zugrunde gelegt und der Ward's Algorithmus verwendet. 


\subsection{Untersuchung des Einflusses von Verticillium longisporum auf eine Arabidopsis thaliana Chitinase}

Chitinasen katalysieren die hydrolytische Spaltung von $\beta$-1,4-glykosidischen Bindungen die hauptsächlich in Chitin vorhanden sind. In Pflanzen spielen Chitinasen eine Rolle in der Abwehr gegen pilzliche Pathogene (Kasprzewska, 2003). Da eine Aktivierung von Chitinasen schon häufiger in der Reaktion auf Verticillium-Infektionen nachgewiesen wurde, war das Fehlen von Chitinasen in der Proteomanalyse von Arabidopsis überraschend (siehe 4.2). Um zu prüfen, ob Chitinasen auch bei Arabidopsis auf Verticillium longisporum reagieren, wurde die Expression einer Chitinase (At5g24090) untersucht. Die transkribierte Sequenz für die saure Endochitinase (At5g24090) codiert für eine aktive sekretierte Klasse III Chitinase (Passarino und de Vries, 2002), die z.B. in die Pathogenantwort gegen Rhizoctonia solani beteiligt ist (Samac und Shah, 1991), aber ansonsten bislang nicht näher untersucht wurde.

\subsubsection{Expression eines sauren Endochitinase-Gens (At5g24090) in Verticillium longisporum infizierten Wildtyp Arabidopsis Pflanzen}

In Arabidopsis wurde untersucht, ob die Genexpression bei At5g24090 unter VerticilliumEinfluss verändert war. Abbildung 4.30 zeigt die mRNA-Gehalte über den Infektionsverlauf zu den Zeitpunkten 10,14, 21, 25, 28 und 35 Tage nach Inokulation in Verticillium-infizierten Pflanzen im Verhältnis zu mock-infizierten Kontrollpflanzen. Die Expression des ChitinaseGens in den Verticillium-infizierten Pflanzen stieg bis zu einem Maximum zum Zeitpunkt 25 Tage nach Inokulation an und fiel dann wieder ab. Im Vergleich zu den mock-inokulierten Pflanzen war die mRNA für die Chitinase bei den Verticillium-inokulierten Pflanzen, außer zum Zeitpunkt 10 Tage nach Inokulation, deutlich erhöht. 25 Tage nach Inokulation betrug die Expression des Chitinase-Gens in den Verticillium-infizierten Pflanzen das 17-fache der Expression in den mock-inokulierten Kontrollen. Die Hochregulierung zu den Zeitpunkten 25, 28 und 35 Tage nach Inokulation erwies sich im T-Test $(p \leq 0,05)$ als signifikant.

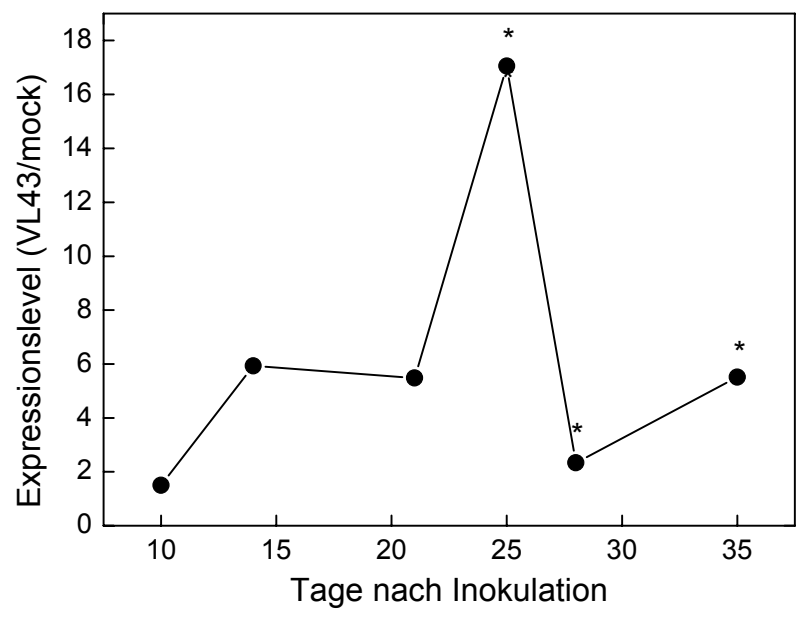

Abb. 4.30: Relative Genexpression der Endochitinase At5g24090 in Verticillium-inokulierten im Vergleich zu mock-inokulierten Pflanzen. Die Symbole repräsentieren drei Replikate in Doppelbestimmung zu den Zeitpunkten 10, 14 und 35 Tage nach Inokulation und sechs Replikate in Doppelbestimmung zu den Zeitpunkten 21, 25 und 28 Tage nach Inokulation. Werte mit einem Stern waren im T-Test $(p \leq 0,05)$ signifikant unterschiedlich. 


\subsubsection{Untersuchung einer Arabidopsis thaliana Chitinase-Mutante unter Einfluss von Verticillium longisporum}

Um die Funktion der unter $\mathrm{V}$. Iongisporum regulierten Chitinase näher zu charakterisieren, wurde die Arabidopsis thaliana T-DNA Insertionsmutante (SALK_095362) untersucht, bei der die T-DNA in die codierende Sequenz für die saure Endochitinase (At5g24090) inseriert war. Dies führt im allgemeinen zur Ausschaltung des Gens. Es sollte überprüft werden, ob diese Mutation die Empfindlichkeit für den Pilz Verticillium longisporum beeinflusst. Die Charakterisierung der Mutante erfolgte in der Arbeitsgruppe von Dr. T. Teichmann (Forstbotanik) und ist der vollständigkeit halber im Anhang aufgeführt. Die Basisergebnisse werden hier nur kurz referiert.

Die Überprüfung der T-DNA Insertion in das Chitinase-Gen At5g24090 zeigte, dass die TDNA homozygot in das Chitinase-Gen inseriert war (siehe Anhang, Abb. 8.1). In mockinokulierten Wildtyp-Pflanzen war keine sichtbare Expression des Chitinase-Gens At5g24090 nachzuweisen. Die Behandlung mit Verticillium (VL43) führte bei den Wildtyp-Pflanzen zu einer verstärkten Expression. Bei der Chitinase-Mutante wurde erwartet, dass eine Insertion von T-DNA in ein Exon die Transkription des Gens verhindern würde. Stattdessen zeigte die T-DNA Insertionsmutante eine konstitutiv hochregulierte Expression, die durch VerticilliumInfektion nicht weiter beeinflusst wurde (siehe Anhang, Abb. 8.2).

\subsubsection{Chitinase-Aktivitätsmessungen in mock- und Verticillium-infizierten Pflanzen}

Um zu prüfen, ob eine erhöhte Expression auch zu einer erhöhten Enzymaktivität führt, wurde die Chitinase-Aktivität in Gesamtblattextrakten und apoplastischen Waschflüssigkeiten (AWF) aus Blättern von Wildtyp-Pflanzen und Pflanzen mit T-DNA Insertion in das ChitinaseGen At5g24090 gemessen. Außerdem wurde der Einfluss von Verticillium longisporum auf die Chitinase-Aktivität überprüft. Abbildung 4.31A zeigt die Chitinase-Aktivität in den Gesamtblattextrakten. Die Wildtyp Kontrollpflanzen zeigten eine deutliche Chitinase-Aktivität von durchschnittlich $6,4 \mathrm{mU} / \mathrm{\mu g}$ Protein, die durch die Infektion mit Verticillium longisporum auf ca. das Doppelte anstieg. Die nicht-infizierte Chitinase T-DNA Insertionsmutante zeigte im Vergleich zum Wildtyp eine erhöhte Aktivität, die der Aktivität der Wildtyp-Pflanzen nach Verticillium-Infektion entsprach. Aktivitätsmessungen von Gesamtblattextrakten Verticilliuminfizierter Chitinase T-DNA Insertionsmutanten zeigten keine zusätzliche Aktivitätserhöhung. Die Aktivitätsmessungen in den apoplastischen Extrakten (Abb. 4.31B) zeigten ein anderes Bild als die Messungen in den Gesamtblattextrakten. Die Chitinase-Aktivität in den Wildtyp

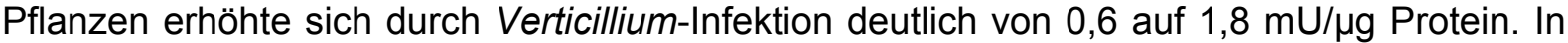
den Chitinase T-DNA Insertionsmutanten lag im Apoplasten im Gegensatz zu den Gesamtblattextrakten offenbar keine konstitutiv erhöhte Chitinase-Aktivität vor. Aus diesen Resultaten lässt sich schließen, dass die Insertionsmutante erhöhte Chitinase-Aktivität besitzt, aber vermutlich im Zellinneren und nicht im Apoplasten lokalisiert ist. 

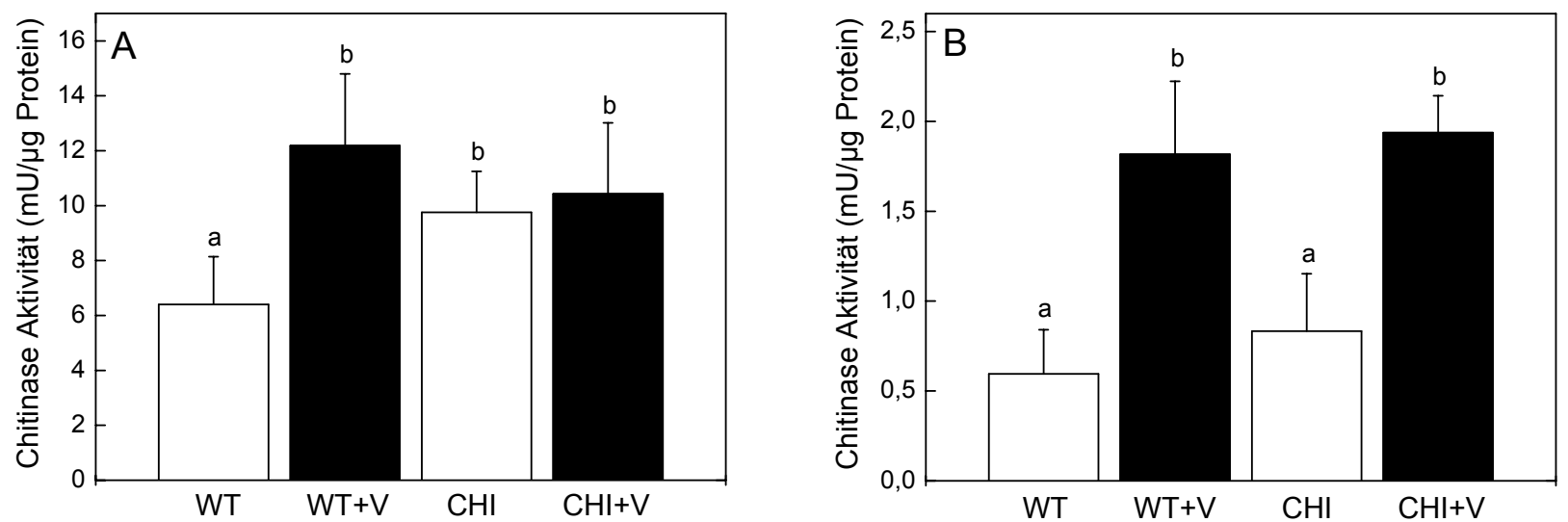

Abb. 4.31: Chitinase-Aktivität in (A) Gesamtblattextrakten und (B) apoplastischen Waschflüssigkeiten von Arabidopsis thaliana Blättern. Verglichen wurden Wildtyp Pflanzen (WT) und Chitinase Insertionsmutanten $(\mathrm{CHI})$ unter Einfluss von Verticillium longisporum $(+\mathrm{V})$. Die Pflanzen wurden 35 Tage nach Inokulation analysiert. Die Balken repräsentieren Mittelwerte aus $n=6$ Pflanzen mit Standardfehler. Die verschiedenen Buchstaben zeigen signifikante Unterschiede auf $(p \leq 0,05)$.

\subsubsection{Untersuchung der Chitinase Insertionsmutante im Hinblick auf die Symptom- ausprägung unter Einfluss von Verticillium longisporum}

Um zu testen, ob die erhöhte Chitinase-Aktivität der T-DNA Insertionsmutante eine Schutzwirkung gegen Verticillium longisporum erzeugt, wurde diese im Hinblick auf die Symptomausprägung untersucht. Dazu wurden wie zuvor beschrieben (siehe 3.3.6), die projizierten Blattflächen bis 33 Tage nach Inokulation analysiert. Abbildung 4.32C zeigt exemplarisch Photos von mock- und Verticillium-inokulierten Arabidopsis 33 Tage nach Inokulation

Sowohl beim Wildtyp als auch bei der Chitinase-Mutante konnte beim Versuchende eine signifikante Reduktion der Rosettengröße in den Verticillium-inokulierten im Vergleich zu den mock-inokulierten Pflanzen nachgewiesen werden (Abb. 32A und B). Die Chitinase-Mutanten zeigten eine etwas stärkere Reduktion der Blattfläche durch Verticillium-Infektion als der Wildtyp. Diese Unterschiede erwiesen sich aber bei näherer Untersuchung als nicht signifikant $(p \leq 0,05)$. Die mock-inokulierten Chitinase-Mutanten hatten durchschnittlich eine größere Rosettenfläche als die Wildtyp-Pflanzen, aber auch dieser Unterschied erwies sich im T-Test $(p \leq 0,05)$ als nicht signifikant.

Zusammenfassend ließen sich also keine Unterschiede in der Symptomausprägung zwischen Wildtyp Pflanzen und der Chitinase Insertionsmutante feststellen. Es liegt offenbar keine Schutzwirkung durch eine erhöhte Expression und Aktivität der untersuchten Chitinase vor. 

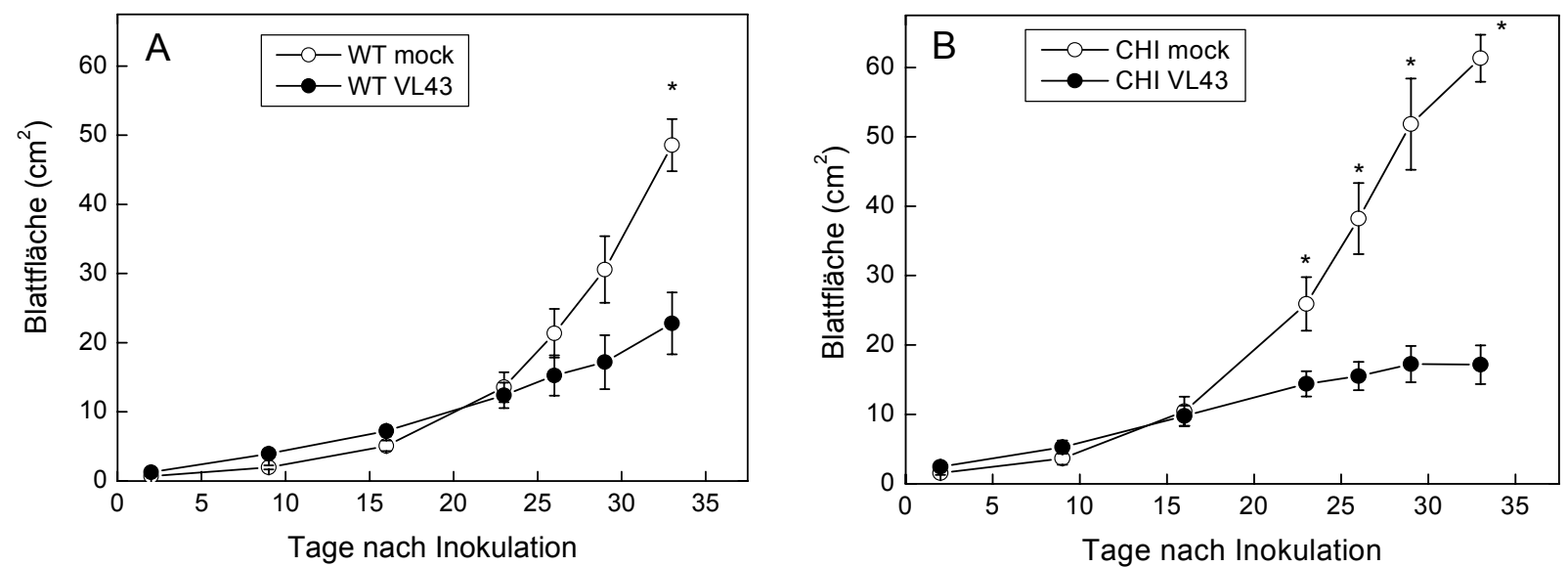

WT mock
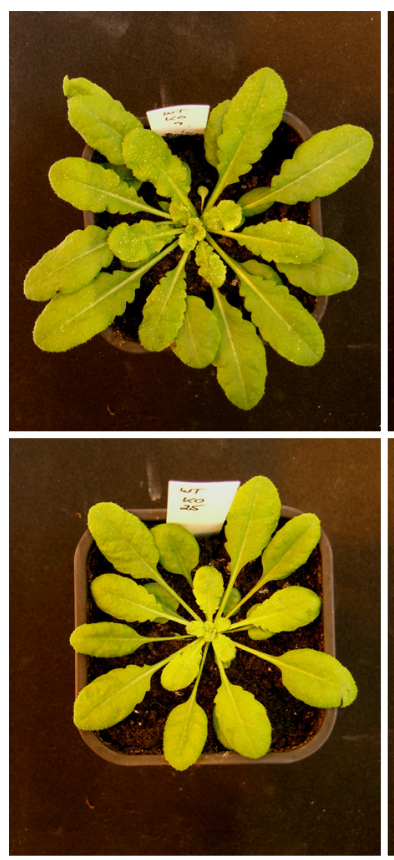

WT VL43
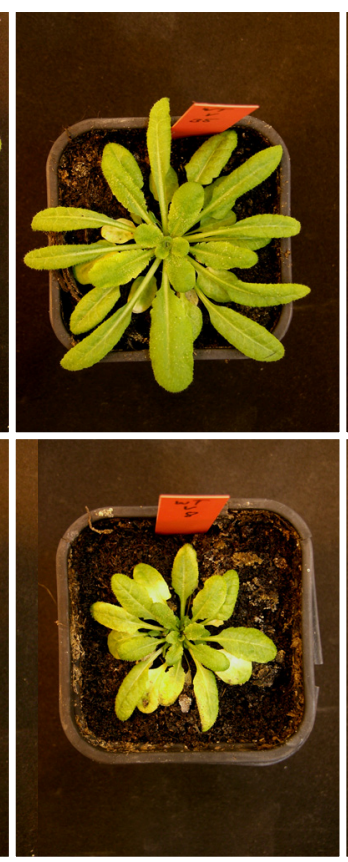

$\mathrm{CHI}$ mock
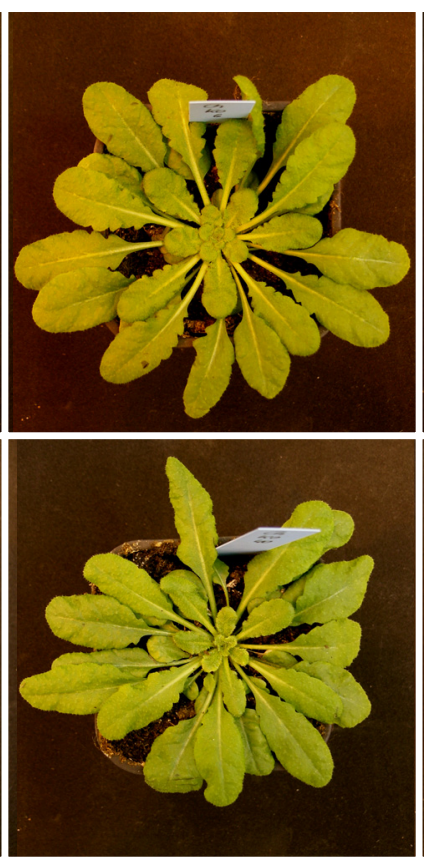

CHI VL

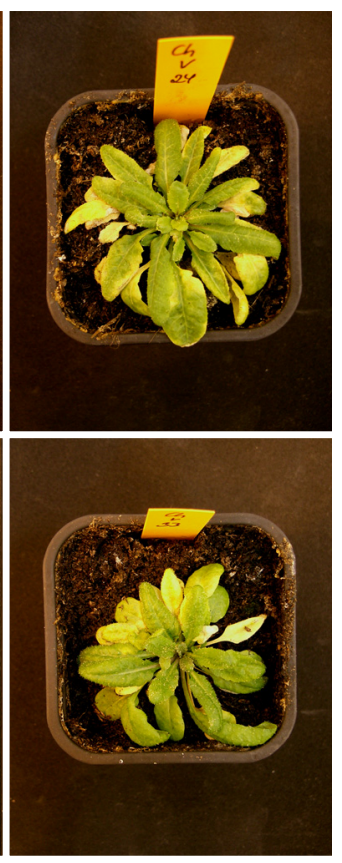

Abb. 4.32: Projizierte Blattfläche von mock- und Verticillium-inokulierten Wildtyp-Pflanzen (A) und Chitinase-Insertionsmutanten (B) im Infektionsverlauf. Es wurden jeweils 15-20 Pflanzen analysiert. Die Sterne zeigen signifikante Unterschiede an $(p \leq 0,05)$. (C) Repräsentative Bilder von Verticillium longisporum (VL43) inokulierten und mock-inokulierten Arabidopsis thaliana Wildtyp (WT) und Chitnase T-DNA Insertionsmutanten (CHI) 33 Tage nach Inokulation.

\subsubsection{Infektionsnachweis mittels quantitativer PCR}

Zur Überprüfung, ob die Arabidopsis Chitinase Insertionsmutante resistenter als der Wildtyp gegenüber Verticillium longisporum ist, wurde die Menge der Pilz-DNA in den Blättern mittels quantitativer real time PCR ermittelt. Abbildung 4.33 zeigt in einer Box-Plot Darstellung die Menge der Verticillium-DNA sowohl in Verticillium-infizierten als auch in mock-inokulierten Arabidopsis Wildtyp und Chitinase-Mutanten. Während die mock-inokulierten Pflanzen keine signifikanten Mengen an Verticillium-DNA aufwiesen, waren in den Verticillium-infizierten Pflanzen deutliche Mengen Pilz-DNA nachzuweisen. Ein signifikanter Unterschied im 
Hinblick auf die Pilz-DNA Menge zwischen den Wildtyp-Pflanzen und den ChitinaseInsertionsmutanten konnte nicht nachgewiesen werden. Daraus wurde geschlossen, dass die erhöhte Chitinase-Aktivität der T-DNA Insertionsmutante keinen entscheidenden Schutz im Hinblick auf Anfälligkeit gegenüber Verticillium longisporum Infektion bewirkt.

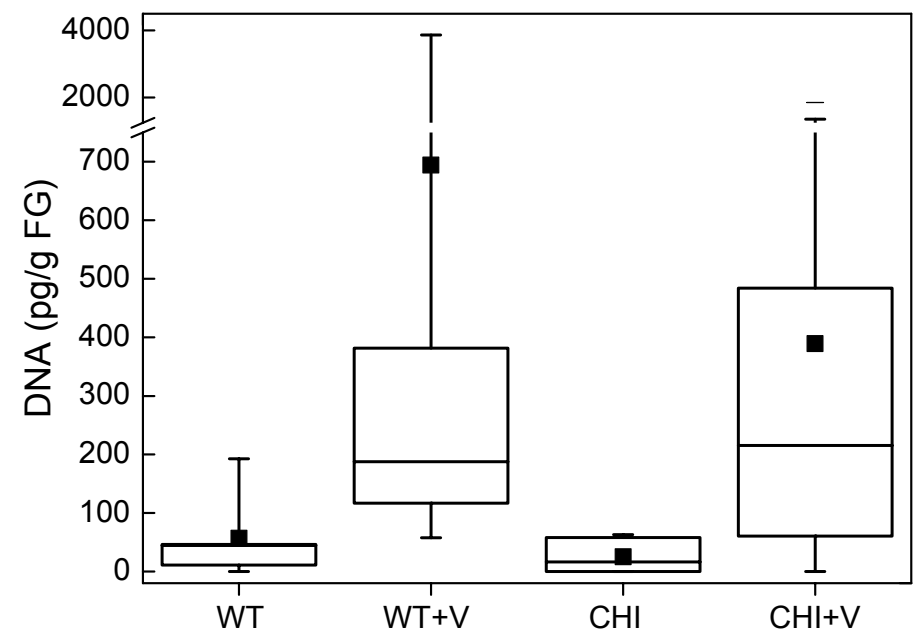

Abb. 4.33: Verticillium-DNA in Rosetten von mock- und Verticillium (+V)-infizierten Arabidopsis Wildtyp (WT) und Chitinase Insertionsmutanten (CHI). Die Verticillium-DNA Menge wurde mittels quantitativer real time PCR ermittelt. Die Boxen repräsentieren $n_{(\text {Kontrollen) }}=8, n_{(W T+V)}=10, n_{(C H I+V)}=18$. Innerhalb einer Box liegen $50 \%$ der Werte, die horzontale Linie stellt den Median-Wert und das schwarze Symbol den Mittelwert dar, die Gesamtverteilung wird durch die vertikalen Linien verdeutlicht. 


\section{DISKUSSION}

\subsection{Verticillium-induzierte Schäden an Raps und Arabidopsis}

\subsubsection{Wachstum und Photosynthese}

Die beiden untersuchten Brassicaceen Raps und Arabidopsis wiesen einige Ähnlichkeiten bei der Verticillium-induzierten Symptomentwicklung auf. Die ersten sichtbaren Symptome traten bei beiden Pflanzenarten ca. 14 Tage nach Inokulation mit Verticillium Iongisporum auf. Das ausgeprägteste Infektionsmerkmal war die Stauchung, die bei Raps durch ein reduziertes Höhenwachstum, bei Arabidopsis durch eine geringere Rosettengröße gekennzeichnet war. Auswirkungen auf die Frischmassen der Pflanzen konnten erst zu einem späteren Zeitpunkt nachgewiesen werden. So waren bei Verticillium-infizierten Arabidopsis die Blätter kleiner und die Petiole kürzer, was sich 35 Tage nach Inokulation auch deutlich auf die Frischmasse der Rosetten auswirkte. Bei Raps war 28 Tage nach Inokulation eine geringere Stängelmasse nachzuweisen, während Wurzel- und Blattmasse gegenüber den Kontrollen nicht reduziert waren. Der Effekt der Verticillium-Infektion auf die Frischmasse war im Vergleich zur Stauchung vermutlich weniger deutlich, weil die Anzahl der Blätter sich nicht verringerte, sondern die Stauchung vor allem den Stängel bei Raps bzw. die Blattstängel und Blattgröße bei Arabidopsis betraf.

Der Chlorophyllgehalt von Pfefferpflanzen war ab 21 Tage nach Inokulation mit $V$. dahliae im Vergleich zu Kontrollpflanzen reduziert (Goicoechea et al., 2001). In Raps und Arabidopsis konnten wir ebenfalls 21 Tage nach Inokulation eine geringfügige, aber signifikante Reduktion des Chlorophyllgehalts bei Verticillium-inokulierten im Vergleich zu den mockinokulierten Pflanzen nachweisen. Vermutlich fiel die Erniedrigung deshalb so gering aus, weil nur einzelne Blätter, vor allem im unteren Bereich der Pflanze von Vergilbungen betroffen waren. Eine Mischprobe aus Blättern zur Messung des Chlorophyllgehaltes führte daher dazu, dass nur eine geringe Abnahme des Chlorophyllgehaltes beobachtet werden konnte. Die Einbußen im Chlorophyllgehalt legten die Frage nahe, ob die VerticilliumInfektion die Photosynthese beeinflusste. Ebenfalls an V. dahliae infizierten Pfefferpflanzen wurde beobachtet, dass die Photosyntheserate ab der ersten Woche nach Inokulation in den infizierten Pflanzen signifikant geringer war, während die Transpirationsrate pro Blattflächeneinheit 21 Tage nach Inokulation keine Reduzierung aufwies (Goicoechea et al., 2001). Bei den Verticillium-inokulierten Rapspflanzen konnten wir 21 Tage nach Inokulation weder eine Reduktion der Photosynthese, noch eine Reduktion der Transpiration feststellen. Es zeigte sich aber ab der ersten Woche nach Inokulation bei Raps und bei Arabidopsis ein geringer Unterschied in der Chlorophylffluoreszenz, die ein Indikator für die Aktivität des Photosystems II ist. Die Chlorophyllfluoreszenz-Messung erfolgte an einzelnen Blättern und da nicht alle Blätter von Symptomen betroffen waren, war bei diesen Messungen je nach ausgewähltem Blatt für die Messung die Schwankungsbreite sehr groß. Bei Arabidopsis erwies sich die Messung der Chlorophyllfluoreszenz als schwierig, da nur ausreichend große Blätter in die Halterung des Gerätes passten. Die an Rapsblättern durchgeführten Gaswechselmessungen konnten bei Arabidopsis aufgrund der Gerätegröße nicht durchgeführt werden, aber die geringen Effekte auf die Chlorophyllfluoreszenz und die 
Ergebnisse der Messungen an Raps lassen keine größeren Auswirkungen auf den photosynthetischen Gaswechsel erwarten.

Obgleich die Symptome an den Verticillium-inokulierten Rapspflanzen eine erfolgreiche Infektion mit Verticillium anzeigen, konnten 21 Tage nach Inokulation keine signifikanten Mengen an Verticillium-DNA in den Stängeln der infizierten Pflanzen nachgewiesen werden. Das zeigt, dass zu diesem Zeitpunkt der Pilz noch nicht bis in den Stängel vorgedrungen war, sondern sich vermutlich im Wurzelxylem oder im Hyokotyl befand. Eynck et al. (2007) untersuchten die Verticillium-DNA Menge in Blättern und im Hypokotyl von Raps im Zeitraum zwischen 7 und 35 Tage nach Inokulation mit V. longisporum. In dieser Studie zeigte sich, dass der Pilz schon 7 Tage nach Inokulation im Hypokotyl und 21 Tage nach Inokulation in sehr geringen Mengen in Blättern nachweisbar war. Erst 35 Tage nach Inokulation wurden größere Mengen V. longisporum DNA in den Rapsblättern gefunden (Eynck et al., 2007). Die Kolonisierung von Arabidopsis mit V. dahliae wurde von Veronese et al. (2003) anhand von Verticillium-Kolonien, die aus Arabidopsis-Sprossmaterial auf Agarplatten gewachsen waren, ermittelt. 14 Tage nach Inokulation waren einige wenige Kolonien gewachsen, aber ein deutlicher Anstieg der Kolonienzahl trat erst 35 Tage nach Inokulation ein (Veronese et al., 2003). In der vorliegenden Arbeit wurden 25 Tage nach Inokulation Verticillium Iongisporum infizierte Arabidopsis thaliana hinsichtlich der in Blättern und Blattstängeln enthaltenen Verticillium-DNA untersucht. Während zu diesem Zeitpunkt in den Blättern nur sehr geringe Mengen an Verticillium-DNA nachzuweisen waren, wurden im Hypokotyl und den Blattstängeln bereits signifikante Mengen Verticillium-DNA gefunden. Setzte man die Menge an Pilz-DNA in den Blattstängeln mit der Rosettengröße in Relation so zeigte sich nur eine sehr geringe Korrelation. Bei einigen der Pflanzen, die besonders stark ausgeprägte Symptome zeigten, war überhaupt keine Pilz-DNA in den Blattstängeln nachweisbar. Diese Ergebnisse legen nahe, dass sowohl bei Raps als auch bei Arabidopsis die Symptome nicht direkt durch den Pilz ausgelöst werden, sondern direkt oder indirekt durch Signale bzw. Toxine des in den Wurzeln befindlichen Pilzes.

\subsubsection{Die Nährelementsituation in Arabidopsis thaliana}

Über die Ursachen von Kümmerwuchs und Stauchung gibt es verschiedene Spekulationen. So könnte z.B. ein Nährstoffmangel durch eine Verstopfung von Gefäßen mit Pilzhyphen oder durch Thyllenbildung der Pflanzen hervorgerufen werden. Auch eine verfrühte Seneszenz im Zusammenhang mit $V$. longisporum Infektion könnte sich in verminderten Nährstoffen widerspiegeln. Bisher ist wenig über die Nährstoffsituation in Verticilliuminfizierten Pflanzen bekannt. Mit einer Nährelementanalyse an Blättern Verticillium-infizierter Arabidopsis wurde überprüft, ob die beobachteten Symptome möglicherweise auf einen Nährstoffmangel zurückzuführen sind. Sowohl bei den Haupt- als auch bei den untersuchten Spurenelementen konnte in unserer Untersuchung keine wesentliche Reduktion durch die Verticillium-Infektion nachgewiesen werden. Diese Ergebnisse sprechen dagegen, dass mögliche Verstopfungen der Gefäße zu Nährstofflimitierungen führen. Es handelt sich bei den durch Verticillium hervorgerufenen Symptomen also nicht um einen Mangel an Nährstoffen. 
Interessanterweise war die Konzentration der Elemente Phosphat und Calcium ab 25 bzw. 28 Tage nach Inokulation bei den Verticillium-infizierten Arabidopsis deutlich höher als bei den Kontrollen. 35 Tage nach Inokulation war der Calciumgehalt in den Verticillium-infizierten Arabidopsis-Blättern um $7 \%$ erhöht, der Phosphatgehalt um 14 \%. Eine mögliche Erklärung hierfür ist, dass Elemente, die nicht umverteilt werden wie z.B. $\mathrm{Ca}^{2+}$ akkumulieren und wegen einer geringeren Biomasse der Pflanzen eine höhere Konzentration erreichen.

Wenn auch wenig über die Nährstoffsituation in Verticillium-infizierten Pflanzen bekannt ist, so wurde doch der Einfluss von Nährstoffmangel oder -überschuss im Boden oder Medium auf Verticillium induzierte Symptome vielfach untersucht (Ashworth et al., 1985; Burge \& Simmons, 1982; Kudela \& Pirkl, 1978; Sivaprakasam \& Rajagopa, 1974; Walker et al., 1954). Durch Kalken des Bodens konnte die Resistenz in Medicago sativa gegen V. albo atrum erhöht werden (Kudela \& Pirkl, 1978). Bei Auberginen- bzw. Tomatenpflanzen führte die erhöhte Zugabe von Stickstoff, Kalium und Phosphor zu einer Verstärkung von Verticillium-induzierten Symptomen (Sivaprakasam \& Rajagopa, 1974; Walker et al., 1954). Ebenfalls bei Tomaten- und Auberginenpflanzen führte ein Eisenmangel in Nährmedium oder Erde zur Verstärkung V. dahliae induzierter Symptome (Macur et al., 1991, Barash et al., 1988). Der Einfluss von Kalium- und Phosphor auf Verticillium-infizierte Tomatenpflanzen wurde von Burge and Simmons (1982) untersucht. Hier zeigte sich eine erhöhte Resistenz der Pflanzen unter Kaliummangel, aber eine stärkere Empfindlichkeit bei Phosphormangel.

Himelblau und Amasino (2001) untersuchten die Blattseneszenz bei Arabidopsis und konnten zeigen, dass in seneszenten Blättern die Level an $\mathrm{C}, \mathrm{N}, \mathrm{P}, \mathrm{S}, \mathrm{K}, \mathrm{Fe}, \mathrm{Cu}, \mathrm{Cr}$ und Zn um mehr als $40 \%$ im Vergleich zu nicht-seneszenten Blättern sanken. Dies ist wohl darauf zurückzuführen, dass während der Blattseneszenz die Nährstoffe in andere Pflanzenteile, wie z.B. Samen transportiert werden. Die Elemente C, N, P, S, K und Fe wurden bei unserer Analyse ebenfalls berücksichtigt und zeigten bis auf eine leichte Reduktion (unter $8 \%$ zum Zeitpunkt 35 Tage nach Infektion) im Stickstoff und Kohlenstoffgehalt keine Absenkung. Eine frühzeitige Seneszenz der Blätter, hervorgerufen durch Verticillium longisporum Infektion scheint also, zumindest auf Ebene der Nährelemente, nicht vorzuliegen.

\subsubsection{Der Wasserhaushalt in Arabidopsis thaliana}

Eine Vermutung beinhaltet, dass Wassermangel eine Ursache für Verticillium-bedingte Welkeerscheinungen ist. Daher wurde der Wasserhaushalt der Arabidopsis thaliana Blätter in dieser Arbeit untersucht. Wie für den unter 5.1.2 diskutierten Nährstoffmangel könnte auch für einen Wassermangel die Verstopfung von Gefäßen durch Pilzhyphen oder durch Thyllenbildung der Pflanzen verantwortlich sein. Eynck et al. (2007) hatte an Rapspflanzen allerdings gezeigt, dass die V. Iongisporum Infektion nur einzelne Xylemelemente betraf, während benachbarte Gefäße völlig frei von Hyphen blieben. In einer Microarray-Analyse V. longisporum infizierter Arabidopsis wurden keine typischen Trockenstressgene gefunden, die verstärkt exprimiert waren (Tappe et al., submitted). Eine von uns durchgeführte elektronenmikroskopische Untersuchung an Blattstängeln von Arabidopsis zeigte keine Hinweise auf Thyllenbildung und bei Betrachtung des Trockenmasseanteils der Blätter konnten wir keinen Unterschied zwischen Verticillium-infizierten und Kontrollpflanzen beobachten. Ebenfalls gegen einen Wassermangel sprach der osmotische Druck in den 
Arabidopsis Blättern, der bei den infizierten Pflanzen sogar unter denen der Kontrollen lag. Bei Trockenstress würde man einen erhöhten osmotischen Druck erwarten. Daher sprechen diese Ergebnisse insgesamt dagegen, dass V. Iongisporum Wassermangel hervorruft.

\subsection{Das extrazelluläre Proteom von Arabidopsis thaliana und Raps}

\subsubsection{Apoplasten-spezifische Proteine in Arabidopsis thaliana}

In den letzten Jahren wurden mehrere Proteomanalysen über das extrazelluläre Proteom von Arabidopsis veröffentlicht (Basu et al., 2006; Bayer et al., 2006; Borderies et al., 2003; Boudart et al., 2005; Charmont et al., 2005; Chivasa et al., 2002; Haslam et al., 2001). Die Methoden zur Gewinnung extrazellulärer Proteine unterscheiden sich dabei deutlich. Während für einige Proteomanalysen die Proteine aus pulverisierten und mehrfach gereinigten Zellwänden stammten (Bayer et al., 2006; Chivasa et al., 2002), wurden für anderen Proteomanalysen apoplastische Waschflüssigkeiten mittels einer Infiltrations-I Zentifugationstechnik gewonnen (Boudart et al., 2005; Haslam et al., 2001). Extrazelluläre Proteine, die über mehrere Tage in ein flüssiges Kulturmedium sekretiert worden waren, wurden ebenfalls untersucht (Basu et al., 2006; Charmont et al., 2005).

Die in diesen Studien identifizierten Proteine überschneiden sich untereinander nur teilweise und es konnten zwischen 16 Proteinen (Haslam et al., 2001) und 89 Proteinen (Bayer et al., 2006) identifiziert werden (Tab. 5.1). Die vorliegende Arbeit nimmt mit 39 identifizierten Proteinen (plus sechs weiteren unter Verticillium-Infektion identifizierten Proteinen) eine mittlere Position ein. In Tabelle 5.1 sind die wichtigsten Studien aufgeführt und es ist die Anzahl der Proteine mit den zugehörigen AGI-Nummern angegeben, die auch in der von uns durchgeführten Untersuchung identifiziert wurden. Die größte Überschneidung ergab sich mit 16 Proteinen zwischen den Publikationen von Bayer et al. (2006) und Borderies et al. (2003), bei denen Zellwandproteine untersucht worden waren. Eine Erklärung dafür ist, dass bei den Untersuchungen der Zellwandproteine (Bayer et al., 2006; Borderies et al., 2003; Chivasa et al., 2002) mit der Zellwand verbundene Proteine erfasst wurden, während bei den anderen Studien (Basu et al., 2006; Boudart et al., 2005; Charmont et al., 2005) sowie bei unserer Untersuchung sekretierte bzw. sehr leicht aus der Zellwand lösliche Proteine gefunden wurden.

Insgesamt wurden 15 der in der vorliegenden Arbeit identifizierten Proteine auch in vorherigen Untersuchungen gefunden. Die größten Übereinstimmungen ergaben sich mit sechs Proteinen mit der Studie von Boudart et al. (2005), in der apoplastische Waschflüssigkeiten aus Rosetten untersucht wurden, wie mit sechs Proteinen, die von Arabidopsis-Keimlingen in das verwendete Kulturmedium sezerniert wurden (Charmont et al., 2005). Weniger Übereinstimmungen (2-4 Proteine) zeigten sich im Vergleich mit den Studien, bei denen Zellwände isoliert worden waren (Bayer et al., 2006; Borderies et al., 2003; Chivasa et al., 2002). Zwischen Zellwand Untersuchungen und Analysen von löslichen Proteinen ergaben sich also weniger Übereinstimmungen.

Es gab drei Proteine, die in vier Untersuchungen, diese eingeschlossen, gefunden wurden. Dazu gehören ein Thaumatin-ähnliches PR5 Protein (At1g75040), ein Curculin-ähnliches 
Protein (At1g78830) und eine Serinprotease (At5g67360). Alle anderen Proteine tauchten weniger häufig auf. Die geringe Anzahl an Überlappungen zwischen den einzelnen Untersuchungen wirft die Frage auf, wie viele Proteine im extrazelluären Raum noch nicht identifiziert wurden. Die Annotation des Arabidopsis Genoms zeigte, dass ca. $17 \%$ des Genoms, d.h. etwa 5000 Gene, für Proteine mit einem Signalpeptid für den sekretorischen Weg kodieren (Jamet et al., 2006). Unter Berücksichtigung alternativen Splicings und posttranslationaler Modifikationen wurde das Zellwandproteom auf 1000-2000 verschiedene Proteine geschätzt (Jamet et al., 2006). Davon wurden bisher insgesamt etwa 300 identifiziert. Dies deutet darauf hin, dass noch deutlich mehr extrazelluläre Proteine identifiziert werden können.

Tab. 5.1: Veröffentlichungen zum extrazellulären Proteom von Arabidopsis thaliana aus den letzten Jahren. Proteine, die sowohl in den Veröffentlichungen, als auch in unserer Untersuchung gefunden wurden, sind mit AGI-Nummern angegeben.

\begin{tabular}{|c|c|c|c|c|}
\hline Publikation & Untersuchung & $\begin{array}{c}\text { Anzahl } \\
\text { identifizierter } \\
\text { Proteine }\end{array}$ & $\begin{array}{c}\text { Überlappung mit } \\
\text { dieser } \\
\text { Untersuchung }\end{array}$ & AGI-Nummern \\
\hline Chivasa et al. 2002 & Zellwandproteine & 41 & 3 & $\begin{array}{l}\text { At1g78830; At3g08030; } \\
\text { At4g30270 }\end{array}$ \\
\hline Bayer et al. 2006 & Zellwandproteine & 89 & 2 & At1g78830; At5g08370 \\
\hline Borderies et al. 2003 & Zellwandproteine & 50 & 4 & $\begin{array}{l}\text { At1g78830; At3g15356; } \\
\text { At5g05340; At3g49120 }\end{array}$ \\
\hline Boudart et al. 2005 & $\begin{array}{l}\text { AWF aus } \\
\text { Rosetten }\end{array}$ & 87 & 6 & $\begin{array}{l}\text { At5g67360; At3g57260; } \\
\text { At1g75040; At1g09750; } \\
\text { At1g17860; At5g20630 }\end{array}$ \\
\hline Charmont et al. 2005 & $\begin{array}{l}\text { sekretierte } \\
\text { Proteine }\end{array}$ & 44 & 6 & $\begin{array}{l}\text { At5g67360; At1g75040; } \\
\text { At5g06720; At4g12910; } \\
\text { At5g20630; At3g49120 }\end{array}$ \\
\hline Basu et al. 2006 & Wurzelexudate & 52 & 4 & $\begin{array}{l}\text { At5g67360; At3g57260; } \\
\text { At1g75040; (AtCg00490) }\end{array}$ \\
\hline
\end{tabular}

Aus den zweidimensionalen Gelen der apoplastischen Waschflüssigkeiten (AWF) von Arabidopsis Blättern konnten wir 39 Proteinspots identifizieren (Tab. 4.8). Für eine Anzahl von Proteinen, wurde dasselbe Protein in mehreren Spots desselben Gels gefunden. Möglicherweise sind posttranslationale Modifikationen der Grund dafür. Die relative Position von Spots desselben Proteins in einem zwei dimensionalen Gel deutet darauf hin, dass posttranslationale Veränderungen den isoelektrischen Punkt oder das Molekulargewicht oder beides beeinflussen. Beispielsweise handelt es sich bei den Spots Nr. 10 und 11 (Abb. 4.22), um dasselbe Curculin-ähnliche Protein aus der Lektin-Familie, aber sie unterscheiden sich in ihrem isoelektrische Punkt und auch geringfügig im Molekulargewicht. Bekannte posttranslationale Modifikationen von Proteinen sind beispielsweise Phosphorylierungen, Hydroxylierungen und $\mathrm{N}$ - und O-Glycolysierungen. Diese Modifikationen beeinflussen die Struktur, Lokalisierung und Funktion von Proteinen (Jamet et al., 2006). Eine speziell bei 
extrazellulären Proteinen vorkommende postranslationale Modifikation betrifft Proteine, die mit einem Glycosylphosphatidylinositol (GPI)-Anker an die Plasmamembran gekoppelt sind. Der GPI-Anker befindet sich am C-Terminus und wird aus einer Peptidkette von 30-40 Aminosäuren gebildet. Der Phosphatidylinositol-Teil des Ankers kann durch spezifische Phospholipasen abgespalten werden, so dass GPI-Anker-Proteine als membrangebundene und als lösliche Form vorkommen können (Bayer et al., 2006; Jamet et al., 2006; Schultz et al., 2004). Für die sekretorischen Proteine, die in der vorliegenden Arbeit identifiziert wurden, konnten mit Hilfe des Programms DGPI zur GPI-Anker-Vorhersage (http://129.194.185.165/dgpi/index_en.html) keine Hinweise auf GPI-Verankerungen gefunden werden.

In dieser Untersuchung wurden auch einige Proteine im Apoplasten gefunden, bei denen es sich vermutlich um intrazelluläre Kontaminationen handelt. Diese werden in Kapitel 5.2.3 näher betrachtet. Proteine, die mit hoher Wahrscheinlichkeit extrazellulär lokalisiert sind, wurden nach ihren Funktionen in verschiedene Gruppen eingeteilt (Tab. 5.2). Eine Gruppe bilden die proteolytischen Enzyme wie die Subtilisin-ähnliche Serinprotease (At5g67360) und die Aspartylproteasen (At5g10760, At3g18490, At1g09750). Weiterhin wurden an der Abwehr beteiligte Proteine gefunden, darunter das Thaumatin-ähnliche PR5 Protein (At1g75040), eine PR2 $\beta$-1,3-Glucanase (At3g57260), eine Chitinase (At2g43590) und ein Proteinase Inhibitor, der Endopeptidase Inhibitor (At1g17860). Darüber hinaus wurde ein Proteinbindeprotein (At3g20820) und eine Peroxidase (At5g06720) mit nicht näher untersuchter Funktion gefunden, die aber möglicherweise auch zu den Abwehrproteinen gezählt werden können. Zu den hydrolytischen Proteinen gehören die Hydrolase At4g30270 und die Carboxyester Hydrolasen At1g29660, At1g29670 und At2g46930. Es wurden auch Mitglieder der Glycosylhydrolase Familie gefunden und zwar eine Thioglucosidase (At5g26000) aus der Glycosylhydolase Familie 1 und eine $\beta-1,4-X y l o s i d a s e ~(A t 3 g 19620)$ aus der Glycosylhydrolase Familie 3. Vier Proteine At3g15356, At3g16530, At5g03350 und das Curculin-ähnliche Protein At1g78830 wurden als Mitglieder der Lektin-Familie identifiziert. Lektine sind zuckerbindende Proteine, die gebundene Kohlenhydrate aber nicht verändern und deren nähere Funktion häufig ungeklärt ist (Rüdiger \& Gabius, 2001). Darüber hinaus wurden zwei Proteine (At3g08030 und At1g33640) mit völlig unbekannter Funktion gefunden.

Insgesamt wurden in der vorliegenden Untersuchung zehn sekretorische Proteine identifiziert, die in keiner der anderen hier diskutierten Proteomanalysen gefunden wurden. Diese Proteine sind in Tabelle 5.2 mit einem Stern gekennzeichnet. Es handelt sich dabei vorwiegend um Lectin-ähnliche Proteine und Hydrolasen. 
Tab. 5.2: Funktionseinteilung der identifizierten extrazellulär lokalisierten Arabidopsis thaliana Proteine. Proteine, die in keiner der anderen hier diskutierten Proteomanalysen gefunden wurden, sind mit einem Stern gekennzeichnet

\begin{tabular}{|c|c|c|}
\hline Funktion & Protein & AGI-Nummer \\
\hline \multirow[t]{2}{*}{ Proteolyse } & Serinprotease & At5g67360 \\
\hline & Aspartylprotease & At5g10760*, At3g18490, At1g09750 \\
\hline \multirow[t]{4}{*}{ Abwehr } & Thaumatin-ähnlich, PR5 & At1g75040 \\
\hline & $\beta-1,3-$-Glucanase, PR2 & At3g57260 \\
\hline & Chitinase & At2g $43590^{*}$ \\
\hline & Endopeptidase Inhibitor & At1g17860 \\
\hline Proteinbindung & Proteinbindeprotein & A3g20820 \\
\hline Peroxidase & Peroxidase & At5g06720 \\
\hline \multirow[t]{4}{*}{ Hydrolyse } & Hydrolase (MERI5b) & At4g30270 \\
\hline & Carboxyester Hydrolase & At1g29660*, At1g29670*, At2g46930* \\
\hline & Thioglucosidase & At5g26000* \\
\hline & $\beta-1,4-X y l o s i d a s e$ & At3g19620* \\
\hline \multirow[t]{2}{*}{ Kohlenhydrat-Bindung } & Lektin-ähnlich & At3g15356, At3g16530*, At5g03350* \\
\hline & Curculin-ähnlich & At1g78830 \\
\hline Unbekannt & unbekanntes Protein & At3g08030, At1g33640* \\
\hline
\end{tabular}

\subsubsection{Apoplasten-spezifische Proteine in Raps}

Zur Proteinzusammensetzung im Xylemsaft von Raps liegen bereits umfassende Untersuchungen vor (Buhtz et al., 2004; Kehr et al., 2005). So konnten aus zweidimensionalen Gelen 69 der häufigsten Proteine identifiziert werden (Kehr et al., 2005), darunter Peroxidasen, Proteasen, PR-Proteine, Lektin-ähnliche Proteine und Proteine, die möglicherweise an Zellwandmodifikationen beteiligt sind, d. h. offenbar ein ähnliches Spektrum wie hier im Arabidopsis-Apoplasten gefunden wurde (siehe 5.2.1). Dagegen wurde die Proteinzusammensetzung in apoplastischen Waschflüssigkeiten von Raps noch nicht näher untersucht. Daher wurde in der vorliegenden Arbeit versucht, die dominanten Proteine aus den apoplastischen Waschflüssigkeiten von Raps zu identifizieren. Aus einem zweidimensionalen Gel von apoplastischen Rapsproteinen konnten 18 Spots identifiziert werden (Tab. 4.4), die neun verschiedenen Proteinen zuzuordnen waren. Vermutlich liegen hier, wie bereits unter 5.2.1 beschrieben, posttranslationale Modifikationen der Proteine vor, die zu Verschiebungen im Molekulargewicht und beim isoelektrischen Punkt führen. So wiesen beispielsweise die Proteine aus drei Spots Ähnlichkeit zu einer $\alpha$ Arabinofuranosidase aus Arabidopsis (ARAf; At3g10740) bzw. Raphanus sativus auf. Das Gen At3g10740 kodiert für eine bifunktionale $\alpha$-Arabinofuranosidase/ $\beta$-D-Xylosidase, die zur Glycosylhydrolase Familie 51 gehört und möglicherweise am Zellwandumbau mitwirkt (Minic et al., 2004). Bei der Untersuchung sekretierter Arabidopsis Proteine wurde diese $\alpha$ Arabinofuranosidase ebenfalls gefunden (Charmont el al., 2005), wobei sie in Raps 
wesentlich dominanter vorzukommen scheint. Möglicherweise spielt das Protein in Raps eine wichtigere Rolle als in Arabidopsis.

Es wurden außerdem an der pflanzlichen Abwehr beteiligte Proteine gefunden, darunter eine Glucanase, eine Chitinase und eine Peroxidase (At2g18150). In den Arabidopsis Proteomstudien von Borderies et al. (2003) und Charmont el al. (2005) wurde die Peroxidase (At2g18150) ebenfalls identifiziert. Die im Blattapoplasten von Raps gefundene Aspartylprotease (At5g10760) und Carboxyl-Ester Hydrolase (At1g29660) wurden in der vorliegenden Arbeit ebenfalls im Blattapoplasten von Arabidopsis identifiziert, aber in keiner der anderen erwähnten Analysen zu extrazellulären Proteomen. Das Ortholog des im extrazellulären Rapsproteom identifizierten Germins (At5g20630) wurde in Arabidopsis unter Verticillium-Einfluss verändert und konnte außerdem in den Studien von Boudart et al. (2005) und Charmont el al. (2005) identifiziert werden. Im Rapsapoplasten wurden darüber hinaus zwei Proteine mit unbekannter Funktion (At2g15130, At5g09770) gefunden, die in keiner der Arabidopsis Proteomanalysen oder den Xylemsaftanalysen in Raps gefunden wurden.

Fünf der im Rapsapoplasten dominant vorkommenden Proteine, waren auch bei Arabidopsis dominant vorhanden, ein Hinweis darauf, dass sich die extrazellulären Proteome von Raps und Arabidopsis stark ähneln.

\subsubsection{Kontamination mit intrazellulären Proteinen}

In den AWF von Arabidopsis wurden mehrere Proteine gefunden, für die Signalpeptide für einen Transport in die Mitochondrien oder Chloroplasten vorhergesagt wurden (Tab. 4.8). Daher könnte es sich bei diesen um symplastische Kontaminationen handeln. Jedoch ist die Vorhersage auch mit Unsicherheiten versehen. Im Gegensatz zu der apoplastischen Proteomanalyse in Arabidopsis konnten in den apoplastischen Waschflüssigkeiten von Raps keine eindeutigen symplastischen Kontaminationen wie z.B. mit Rubisco nachgewiesen werden. Es wurden lediglich Ähnlichkeiten zu zwei Proteinen aus Brassica rapa bzw. Raphanus sativus gefunden, die kein Signalpeptid für den sekretorischen Weg aufwiesen. Eine Analyse der Malatdehydrogenase Aktivitäten ergab für Arabidopsis im Schnitt 0,003\% (Tab. 4.6) Kontamination und für Raps 0,006 \% (Tab. 4.1). Obwohl sich die Größenordnung der Kontamination bei der Analyse der beiden Pflanzenarten nicht unterschied, waren in den AWF von Arabidopsis im Gegensatz zu Raps eindeutige Kontaminationen vor allem durch das dominante intrazelluläre Protein Rubisco im Gel nachzuweisen. Um die Kontaminationen durch symplastische Proteine in den AWF von Arabidopsis näher zu untersuchen, wurden die relativen Intensitäten von 3 Hauptproteinen in Gesamtblattextrakten mit deren Intensitäten in den AWF verglichen (Abb. 4.23 und Tab. 4.10). Diese Kontaminationsanalyse ergab eine Kontamination von ca. 0,05 \% was einer etwa 10fach höheren Kontamination entspricht, als aus den Malatdehydrogenase-Aktivitäten berechnet wurde.

Die Problematik völlig reine apoplastische Proteinextrakte zu erhalten, zeigte sich bereits in anderen extrazellulären Proteomstudien (Haslam et al., 2003; Basu et al., 2006). Haslam et al. (2003) verglichen zweidimensional aufgetrennte Proteine aus Gesamtblattextrakten mit apoplastischen Waschflüssigkeiten und hatten massive intrazelluläre Kontaminationen in ihren AWF, was vor allem am dominanten Spot für Rubisco im Apoplasten-Gel deutlich wurde. In der Studie von Basu et al. (2006) wurde sogar in Wurzelexudaten von Arabidopsis 
Rubisco gefunden, ebenso wie einige andere Proteine mit Signalpeptiden zu nichtsekretorischen Orten.

Bei einigen der in dieser Arbeit identifizierten Proteine ist die Vorhersage für das Signalpeptid ziemlich unsicher, besonders wenn die Sicherheit der Signalpeptidvorhersage mit einer reliability class von 3 bis 5 als gering eingestuft wurde. Dies trifft ebenfalls bei der Analyse von Basu et al. (2006) für mehrere Proteine zu. So weisen bei unserer Untersuchung beispielsweise die Proteine Serin-Hydroxylmethyltransferase (SHM 1; At4g37930), Chaperonin 10 (At1g14980) und eine Aspartylprotease (At3g18490 bzw. At3g18500) unsichere Signalpeptidvorhersagen auf. Bei der Identifizierung der Aspartylprotease konnte nicht eindeutig zwischen den Aspartylproteasen At3g18490 und At3g18500 unterschieden werden. Die beiden Proteine weisen aber unterschiedliche Signalpeptide auf. Für At3g18490 wurde ein Signalpeptid für Chloroplasten (RC 5) vorhergesagt, für At3g18500 ein Signalpeptid für Mitochondrien (RC 4). Die Signalpeptidvorhersagen waren für beide Proteine unsicher. Außerdem weist die Aspartylprotease At3g18490 auch eine starke Homologie zu zwei weiteren Aspartylproteasen mit Signalpeptid für den sekretorischen Weg auf, und zwar mit den AGINummern At1g25510 (RC 4) und At3g20015 (RC 2). In diesem Fall konnte durch unsere Analyse nicht abschließend geklärt werden, um welche der Aspartylproteasen es sich handelt.

Wie bereits erwähnt, wurden auch in anderen Untersuchungen des extrazellulären Proteoms Proteine ohne eindeutiges Signalpeptid gefunden, weshalb diskutiert wurde, ob diese Proteine über alternatives Gewebe-spezifisches Splicing oder einen alternativen Signalweg aus der Zelle geschleust werden (Basu et al., 2006; Chivasa et al. 2002; Slabas et al., 2004). Außerdem wurden Proteine gefunden, die verschiedene Funktionen in unterschiedlichen Kompartimenten haben. Ein klassisches Beispiel hierfür ist eine tierische Laktatdehydrogenase, die als glycolytisches Enzym im Cytosol und als Strukturprotein in den Linsen tierischer Augen vorkommt (Brunekreef et al., 1996). Damit wurde gezeigt, dass ein Protein sowohl katalytische, als auch strukturelle Funktion in unterschiedlichen Kompartimenten haben kann. Slabas et al. (2004) diskutierten das Vorkommen des gleichen Proteins in unterschiedlichen Kompartimenten anhand einer mitochondrialen Citratsynthase und eines luminalen Bindeproteins aus dem Endoplasmatischen Retikulum, welche sie im Zellwandproteom von Arabidopsis thaliana gefunden hatten. Letztendlich bleibt für die Zukunft zu klären, über welche alternativen Wege Proteine möglicherweise aus der pflanzlichen Zelle in den extrazellulären Raum geschleust werden können.

\subsection{Proteinantworten auf $V$. longisporum Infektion und mögliche Funktionen der differentiell auftretenden Proteine}

\subsubsection{Das extrazelluläre Proteom von Arabidopsis unter Verticillium-Einfluss}

Unter Verticillium-Einfluss wurden im Blattapoplasten von Arabidopsis sieben differentiell auftretende Proteine durch Proteomanalyse identifiziert. Sechs davon traten durch Verticillium-Infektion verstärkt auf, ein Protein in geringerem Maß. Zusätzlich wurden in einer 
Expressionsanalyse unter Verticillium-Einfluss erhöhte mRNA-Level für eine Chitinase beobachtet. Tappe et al. (submitted) wiesen in einer Microarray-Analyse 18 Tage nach $V$. longisporum Infektion 52 differentiell regulierte Gene nach, wovon 48 hoch- und 4 herabreguliert waren. Ein in der Microarray-Analyse hochreguliertes Gen (At4g37520 bzw. At4g37530) und ein herabreguliertes Gen (At3g16530) wurden in der vorliegenden Arbeit im Apoplasten ebenfalls als differentiell auftretende Proteine identifiziert. In der Proteomanalyse wurden nur apoplastische Proteine mit einem Molekulargewicht zwischen 20 und $97 \mathrm{kDa}$ erfasst. Stark saure oder alkalische apoplastische Proteine wurden nicht erfasst, ebenso wie in geringer Kopienzahl auftretende Proteine wie die nur durch Expressionsanalyse erfasste Chitinase. Bezogen auf die Anzahl der in der Microarray-Analyse (Tappe et al., submitted) differentiell exprimierten Gene ist die geringe Anzahl der im Apoplasten differentiell aufgetretenen Proteine also nicht verwunderlich. Allerdings scheint die Anzahl der durch Verticillium-Infektion differentiell regulierten Gene mit 52 generell niedrig zu liegen. Im Vergleich wurden beispielsweise bei Infektion mit dem nekrotrophischen Pilz Botrytis cinerea 621 hochregulierte Gene gefunden (AbuQamar et al., 2006). Mittels Proteomanalyse wurden bei Behandlung von Arabidopsis-Zellkulturen mit pilzlichem Elicitor aus Fusarium 154 differentiell auftretende Proteine gefunden (ca. $10 \%$ der insgesamt gefundenen Proteine), von denen 45 (3\% der insgesamt gefundenen Proteine) identifiziert werden konnten (Chivasa et al., 2006). In unserer Untersuchung lag die Anzahl der differentiell auftretenden Proteine mit 9 von 220 bei $4,1 \%$, und mit 7 Proteinen konnten 3,2\% identifiziert werden. Möglicherweise ist die vorwiegende Lokalisation von Verticillium im Xylem der Grund für die weniger starke Pathogenantwort von Arabidopsis beispielsweise im Vergleich zu nekrotischen Pilzen.

Im Folgenden werden die in der Proteomanalyse des Arabidopsis-Apoplasten durch V. longisporum Infektion differentiell aufgetretenen Proteine einzeln diskutiert. Die wichtigsten Veröffentlichungen im Zusammenhang mit diesen Proteinen sind in Tabelle 5.3 zusammengestellt.

Unter den in der vorliegenden Proteomanalyse verstärkt auftretenden Proteinen befand sich ein Serin-Carboxypeptidase-ähnliches Protein (At4g12910). Die Serin-Carboxypeptidasen sind Mitglieder der $\alpha / \beta$ Hydrolase Familie, die eine Ser-Asp-His Abfolge zur Spaltung von carboxyterminalen Peptidbindungen ihrer Substrate nutzen (Liao \& Remington, 1990; Ollis et al., 1992). Eine bioinformatische Analyse der Serin-Carboxypeptidase ähnlichen Genfamilie aus Arabidopsis wurde von Fraser et al. (2005) veröffentlicht. Diese Autoren identifizierten insgesamt 51 Mitglieder von Serin-Carboxypeptidase ähnlichen Proteinen (SCLPs). Dabei zeigte eine phylogenetische Analyse, dass sich die Mehrheit der SCLPs in zwei Hauptgruppen einteilen ließ (Fraser et al., 2005). Nach dieser Einteilung gehört die von uns identifizierte Serin-Carboxypeptidase der ersten Klasse an, wobei diese nach Fraser et al. (2005) in zwei Untergruppen zerfiel. Hierbei gehört die Serin-Carboxypeptidase At4g12910 in die Gruppe IB, in der sich nur die beiden Proteine At4g12910 und At3g25420 befinden. Die beiden Proteine weisen eine hohe Ähnlichkeit ihrer Aminosäuresequenzen von $62 \%$ bzw. $66 \%$ mit einem Wund- und Jasmonat-induzierbaren SCLP aus Tomate (Acc. No. AF242849) auf (Moura et al., 2001; Fraser et al., 2005). Die Ähnlichkeit der von uns unter Verticillium Stress als stärker exprimiert identifizierten SCLP At4g12910 zu der Wund- und Jasmonat 
(JA)-induzierbaren SCLP aus Tomate spricht für eine Rolle von SCLP At4g12910 in der Abwehr von Arabidopsis. Ab 28 Tage nach Inokulation wurden erhöhte JA-Level in $V$. longisporum infizierten Arabidopsis nachgewiesen (Tappe et al., submitted). Die unveränderten Krankheitssymptome bei Arabidopsis Mutanten, denen JA fehlte, deuteten aber darauf hin, dass JA für die Arabidopsis/Verticillium Interaktion nicht relevant ist (Tappe et al., submitted). Laut Genevestigator Analyse war das Gen At4g12910 durch JA nicht induzierbar, aber durch eine Mischung aus Brassinoliden und $\mathrm{H}_{3} \mathrm{BO}_{3}$ und auch durch Abscisinsäure. Dies spricht dafür, dass das Gen SCLP At4g12910 in Arabidopsis anders reguliert wird als das SCLP AF242849 in Tomate. In der Genevestigator Analyse (Abb. 4.27) war der einzige biotische Stress unter der das Gen hochreguliert vorlag, die Infektion mit dem pilzlichen Pathogen Botrytis cinerea, während Agrobacterium tumefaciens, Pseudomonas syringae und Mykorrhiza keine Auswirkung auf SCLP At4g12910 hatten und Nematoden, sowie der Oomycet Phytophtera infestans (Krautfäule) und der Pilz Erysiphe persicae (Mehltau) zu einer Herabregulation führten.

Ein weiteres durch Verticillium-Infektion in Arabidopsis verstärkt auftretendes Protein war eine $\alpha$-Galactosidase (At5g08370). Das Protein wurde bei Proteomanalysen der Zellwand nachgewiesen und der Glycosylhydrolase Familie 27 zugeordnet (Bayer et al., 2006). Die Lokalisation des Proteins in der Zellwand von Arabidopsis wurde von Chrost et al. (2007) mittels GUS-Reporter bestätigt. Heterozygote At5g08370 T-DNA Insertionsmutanten hatten eine größere Anzahl an Rosettenblättern mit einer gewellten Oberfläche. Daher wurde eine mögliche Rolle der $\alpha$-Galactosidase (At5g08370) in der Blattentwicklung durch Lockerung der Zellwand und Zellwandausdehnung diskutiert (Chrost et al., 2007). Der Einfluss einer Überexpression dieses Gens auf die Blattmorphologie wurde bisher noch nicht untersucht, aber die veränderte Blattmorphologie, kleinere und gewölbte Blätter bei Verticilliuminfizierten Arabidopsis in unserer Untersuchung, könnte möglicherweise im Zusammenhang mit der verstärken Expression des Gens At5g08370 stehen.

Das hier verstärkt aufgetretene Germin-ähnliche Protein (At5g20630) wurde auch in anderen Proteomstudien als sekretiertes Protein gefunden (Boudart et al., 2005; Charmont et al., 2005). Die Expression des Gens At5g20630 war in Arabidopsis durch Inokulation mit dem pilzlichen Brassicaceen Schädling Colletotrichum higginsianum signifikant induziert (Narusaka et al., 2004). Die Genevestigator Analyse (Abb. 4.27) zeigte vor allem eine Hochregulierung des Gens durch Lichtstress, aber auch durch biotischen Stress mit Mehltau (Erysiphe orontii). Von Carter et al. (1998) wurde die Funktion von Germin und Germinähnlichen Proteinen diskutiert. Germine wurden als Oxalatoxidasen beschrieben (Lane, 1994), die die Oxidation von Oxalat zu $\mathrm{CO}_{2}$ und $\mathrm{H}_{2} \mathrm{O}_{2}$ katalysieren. Da die Produktion von $\mathrm{H}_{2} \mathrm{O}_{2}$ für die Peroxidase katalysierte Vernetzung von Zellwandkomponenten erforderlich ist, könnte Germin so zur Verstärkung von Zellwänden und zur Pathogenabwehr beitragen. Alternative Funktionen in der Pathogenabwehr wären die Produktion von $\mathrm{H}_{2} \mathrm{O}_{2}$ als antimikrobielle Substanz und als Signalgeber für Abwehrreaktionen wie z.B. Phytoalexinsynthese (Carter et al., 1998). Bei dem in dieser Untersuchung gefundenen Germin-ähnlichen Protein handelt es sich um das GER3 Protein, das bereits von Membré et al. (2000) untersucht wurde. Es konnte gezeigt werden, dass GER3 nicht in die $\mathrm{H}_{2} \mathrm{O}_{2}$-Bildung 
mit Oxalat als Substrat involviert ist (Membré et al., 2000). Es ist aber nicht ausgeschlossen, dass andere Co-Substrate zur $\mathrm{H}_{2} \mathrm{O}_{2}$ Produktion verwendet werden können.

Es wurde auch ein Germin-artiges Protein mit Aktivität als Protease-Inhibitor im Blattapoplasten von Weizen nach Infektion mit Septoria tritici nachgewiesen (Segarra et al., 2003). In dieser Studie inhibiert das Germin-ähnliche Protein die Aktivität einer Serinprotease im Apoplasten. Dagegen wurde in unserer Untersuchung eine verstärkt auftretende SerinCarboxypeptidase gefunden. In einer Untersuchung von Staiger et al. (1999) wurde beobachtet, dass das GER3-Gen eine zyklisch-regulierte Transkription aufwies, wobei die höchste Expression zu Beginn der Dunkelphase lag.

Unter Verticillium-Infektion traten im Blattapoplasten von Arabidopsis drei Peroxidasen verstärkt auf. Durch Aktivitätsmessungen wurde zusätzlich gezeigt, dass die PeroxidaseAktivität im Blattapoplasten von Arabidopsis stark erhöht war. Die klassischen Pflanzenperoxidasen gehören der Klasse III an und werden über das Endoplasmatische Reticulum aus der Zelle in die Zellwand oder in die Vakuole transportiert. Die Analyse des Arabidopsis Genoms ergab, dass dort 73 Gene für Volllängen Klasse III vorhanden sind (Welinder et al., 2002). In zahlreichen Studien wurde die Funktion von Peroxidasen beschrieben, einige dieser Funktionen stehen im Zusammenhang mit der Abwehr von Pathogenen wie die Verstärkung von Zellwänden als physikalische Barrieren durch Lignifizierung und Suberinisierung, die erhöhte Produktion von reaktiven Sauerstoffspezies als Signalübermittler bzw. antimikrobielle Substanzen und die erhöhte Produktion von Phytoalexinen (Hiraga et al., 2001). Da Peroxidasen praktisch immer bei der Pathogenabwehr involviert sind, wurden sie als PR 9 Proteine klassifiziert (van Loon et al., 1994). Unter Pathogeneinfluss werden Peroxidasen sezerniert und bei dem vaskulären Pathogen Xanthomonas oryzae akkumulierte eine kationischen Peroxidase im Apoplasten von Mesophyllzellen sowie in Zellwänden und Gefäßlumina von Xylemelementen (Young et al., 1995). Laut Genevestigator Analyse (Abb. 4.27) werden alle drei in dieser Untersuchung unter Verticillium-Stress hochregulierten Peroxidasen auch bei biotischem Stress durch Botrytis cinerea und Agrobacterium tumefaciens hochreguliert. Die Peroxidase At5g05340 wurde außerdem im Zusammenhang mit Ozon-induziertem oxidativen Stress induziert (Ludwikow et al., 2004). Die Peroxidase At3g49120 dagegen scheint in die Wurzelelongation involviert zu sein (Passardi et al., 2006) und wurde mit der Pathogenantwort auf Pseudomonas syringae in Zusammenhang gebracht (Bindschedler et al., 2006). Die Gensequenz der Peroxidase At4g37530 wies $92 \%$ Homologie zu der Peroxidase At4g37520 auf (Yang et al., 2005). Die in dieser Arbeit gefundenen Peptide könnten also sowohl zu der Peroxidase At4g37530 als auch zu At4g37520 gehören. Welche Funktionen, die drei unter Verticillium-Stress verstärkt auftretende Peroxidase-Proteine übernehmen ist noch offen. Der erhöhte Ligningehalt in Verticillium-infizierten Arabidopsis (Abb. 4.28) spricht für eine Funktion einer oder mehrerer verstärkt auftretender Peroxidasen, eventuell auch im Zusammenspiel mit dem Germin-ähnlichen Protein, in der Lignifizierung. Durch die Lignifizierung könnte die Ausdehnung der Zellen verhindert werden und so zu dem beobachteten reduzierten Wuchs führen. In früheren Untersuchungen wurde ebenfalls über die Rolle der Lignifizierung des Xylems als erste physikalische Barriere gegen eine Infektion mit Verticillium dahliae diskutiert (Smith \& Dubery, 1997; Pomar et al., 2004). An 
Pfefferpflanzen zeigten Pomar et al. (2004), dass im gleichen Zeitraum in dem die Peroxidase-Aktivität nach Inokulation mit Verticillium dahliae anstieg der Gesamtligningehalt in den Stängeln signifikant erhöht wurde. Nach 28 Tagen betrug der Ligninanstieg sogar bis zu 40 \% im Vergleich zu Kontrollpflanzen. Dies könnte auf eine Schutzfunktion von Lignin hinweisen. So zeigten Debode et al. (2004), dass durch Lignin-reiche Substrate in der Erde die Anzahl der Verticillium longisporum Mikrosklerotien reduziert werden konnte.

Unter Verticillium-Einfluss trat ein Lectin-ähnliches Protein (At3g16530) weniger stark auf als in den Kontrollen. Dies war überraschend, da dieses Protein durch Behandlung mit ChitinOligomeren induziert wird (Zhang et al., 2002; Ramonell et al., 2005). Die beschriebene Induktion des Lectin-ähnlichen Proteins mit Chitin ließe erwarten, dass bei Infektion mit einem Pilz wie Verticillium, der Chitin in der Zellwand enthält (Pegg \& Brady, 2002), das Protein vermehrt auftreten würde. Allerdings wurde die Induzierbarkeit mit Chitin-Oligomeren nach 30 min überprüft (Zhang et al., 2002). Vielleicht tritt die verstärkte Expression des Gens At3g16530 nur zu sehr frühen Zeitpunkten vorübergehend auf. Die Genevestigator Analyse (Abb. 4.27) zeigt, dass das Gen At3g16530 bei den meisten biotischen und chemischen Stresssituationen stärker exprimiert wird, während eine Herabregulierung vor allem bei Lichtund Hitzestress erfolgt. Die beiden letztgenannten Stressfaktoren können hier mit Sicherheit ausgeschlossen werden da die Anzucht der Arabidopsis unter kontrollierten Licht- $(120 \mu \mathrm{mol}$ $\left.\mathrm{m}^{-2} \mathrm{~s}^{-1}\right)$ und Temperaturbedingungen $\left(20^{\circ} \mathrm{C}\right)$ in einem Klimaschrank zusammen mit den Kontrollpflanzen erfolgte. Die geringere Expression über den gesamten von uns untersuchten Verlauf von 10 bis 35 Tage nach Infektion ist verwunderlich und legt nahe, dass $V$. longisporum in der Lage ist die Expression dieses Gens zu unterdrücken. Ob dies für die erfolgreiche Besiedelung durch den Pilz von Bedeutung ist, bleibt zu untersuchen.

Eine erhöhte Chitinase-Aktivität als Antwort auf pilzliche Pathogene wurde vielfach beschrieben (Li et al., 2003; Samac und Shah, 1991; Yun et al., 1996). Die Akkumulation von Chitinasen nach Pathogeninfektion wurde von Joosten und De Wit (1989) und von Rep et al. (2002) beschrieben und auch bereits im Zusammenhang mit Verticillium dahliae diskutiert (Berg et al., 2001; McFadden et al., 2001). Bei einer Untersuchung der Proteine des Xylemsaftes von Fusarium oxysporum infizierten Tomaten war die Chitinase aufgrund geringer Expression nur mittels Immunodetektion nachzuweisen (Rep et al., 2002). Auch die von uns untersuchte Chitinase At5g24090 wurde nur gering exprimiert, weshalb das Protein im Gel nicht nachzuweisen war. Mittels Genexpressionsanalyse konnten wir aber das erhöhte Vorkommen von RNA für diese Chitinase (At5g24090) in Verticillium-infizierten Pflanzen nachweisen. Das Gen für diese Endochitinase wurde ebenfalls durch Infektion mit dem Pathogen Rhizoctonia solani induziert (Samac \& Shah,1991).

Es wurde gezeigt, dass die Überexpression von Chitinasen das Pilzwachstum in transgenen Pflanzen hemmen kann (Broglie et al., 1991; Jach et al., 1995). Daher untersuchten wir die Chitinase T-DNA Insertionsmutante im Hinblick auf ihre Empfindlichkeit gegenüber dem Pilz Verticillium longisporum. Eine Überexpression des Chitinase-Gens At5g24090 in der Mutante eröffnete die Möglichkeit, dass die Mutante weniger empfindlich auf die Pilzinfektion reagiert. Allerdings konnte in der vorliegenden Untersuchung keine erhöhte Resistenz bei Infektion mit Verticillium longisporum durch die Überexpression der Chitinase At5g24090 im Vergleich zum Wildtyp festgestellt werden. 
Die Chitinase-Aktivität in den Gesamtblattextrakten der T-DNA Insertionsmutante war deutlich erhöht gegenüber dem Wildtyp, dagegen war die Aktivität in der AWF nicht erhöht. Eventuell ist die Chitinase (At5g24090) also nicht im Apoplasten sondern in der Vakuole lokalisiert. Dagegen spricht allerdings, dass die meisten sauren Chitinasen in den Apoplasten sekretiert werden, während in der Vakuole vor allem basische Chitinasen zu finden sind (Kasprzewska, 2003). Eine andere Vermutung ist, dass die Chitinase durch die Insertion der T-DNA in das zugehörige Gen so verändert wurde, dass sie nicht mehr in den Apoplasten sekretiert werden konnte, sondern sich im Cytoplasma anreicherte. Abschließend bleibt auf jeden Fall festzuhalten, dass die Überexpression des Gens At5g24090 für die Chitinase keinen erkennbaren Schutz gegen die Infektion mit Verticillium longisporum bot.

Tab. 5.3: Zusammenstellung der Publikationen zu den unter Verticillium-Einfluss differentiell aufgetretenen Proteinen mit dem Namen des Erstautors und einer kurzen Beschreibung des hier relevanten Inhalts der Publikation.

\begin{tabular}{|c|c|c|c|}
\hline Protein & AGI-Nummer & Autor & Inhalt \\
\hline $\begin{array}{l}\text { Serin-Carboxy- } \\
\text { peptidase }\end{array}$ & At4g12910 & Fraser et al. 2005 & $\begin{array}{l}\text { Weist Ähnlichkeit zu einer Wund- und } \\
\text { Jasmonat-induzierbaren Serin- } \\
\text { Carboxypeptidase in Tomate auf }\end{array}$ \\
\hline \multirow[t]{7}{*}{$\begin{array}{l}\text { Germin-ähnliches } \\
\text { Protein (GER 3) }\end{array}$} & At5g20630 & Boudart et al. 2005 & $\begin{array}{l}\text { In AWF von Arabidopsis thaliana Rosetten } \\
\text { gefunden }\end{array}$ \\
\hline & & Carter et al. 1998 & Beschreibung von 12 Germin Proteinen \\
\hline & & Chamont et al. 2005 & Unter sekretierten Proteinen gefunden \\
\hline & & Membré et al. 2000 & Beschreibung von GER 1,2,3 \\
\hline & & Narusaka et al. 2004 & $\begin{array}{l}\text { Induzierbar durch Colletotrichum } \\
\text { higginsianum }\end{array}$ \\
\hline & & Segarra et al. 2003 & $\begin{array}{l}\text { Germin als Protease-Inhibitor im } \\
\text { Blattapoplasten }\end{array}$ \\
\hline & & Staiger et al. 1999 & Zyklische Regulation von GER3 \\
\hline Peroxidase 52 & At5g05340 & Ludwikow et al. 2004 & $\begin{array}{l}\text { Verstärktes Auftreten unter Ozon- } \\
\text { induziertem oxidativen Stress }\end{array}$ \\
\hline \multirow[t]{2}{*}{ Peroxidase 34} & At3g49120 & $\begin{array}{l}\text { Bindschedler et al. } \\
2006\end{array}$ & $\begin{array}{l}\text { Untersuchung von Peroxidase- } \\
\text { abhängigem oxidativem burst in } \\
\text { Arabidopsis }\end{array}$ \\
\hline & & Passardi et al. 2006 & Involviert in Wurzelstreckung \\
\hline Peroxidase & At4g37530 & Yang et al. 2005 & $\begin{array}{l}\text { Gensequenzen von At4g37520 und } \\
\text { At } 4 \text { g37530 zu } 92 \% \text { homolog }\end{array}$ \\
\hline \multirow[t]{2}{*}{$\alpha$-Galactosidase } & At5g08370 & Chrost et al. 2007 & Funktion in der Blattentwicklung \\
\hline & & Bayer et al. 2006 & Im Zellwandproteom gefunden \\
\hline Chitinase & At5g24090 & $\begin{array}{l}\text { Passarinho \& de Vries } \\
2002 \\
\text { Samac \& Shah, } 1991\end{array}$ & $\begin{array}{l}\text { Identifikation von } 24 \text { Chitinasen in } \\
\text { Arabidopsis } \\
\text { Induktion durch Rhizoctonia solani }\end{array}$ \\
\hline \multirow{2}{*}{$\begin{array}{l}\text { Lektin-ähnliches } \\
\text { Protein }\end{array}$} & At3g16530 & Ramonell et al. 2005 & Chitin induzierbar \\
\hline & & Zhang et al. 2002 & Chitin induzierbar \\
\hline
\end{tabular}




\subsubsection{Das extrazelluläre Proteom von Raps unter Verticillium-Einfluss}

In verschiedenen Pflanzen wurde nachgewiesen, dass die Infektion mit $V$. dahliae zu einer verstärkten Expression bzw. Aktivität von Glucanasen führt (McFadden et al., 2001; Dubery \& Slater, 1997). Im Xylemsaft und in der AWF von Raps konnten wir unter VerticilliumEinfluss ebenfalls ein Protein mit Ähnlichkeit zu einer basischen Glucanase aus Brassica juncea bzw. zu einer $\beta-1,3-G l u c a n a s e ~(A t 3 g 57240)$ aus Arabidopsis identifizieren. Die Expression dieses Proteins war auch unter dem Einfluss von Pseudomonas syringae erhöht

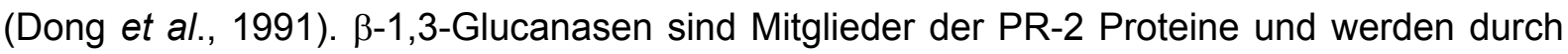
Pathogen-Infektion induziert. Sie hydrolysieren $\beta-1,3-G l u c a n$, eine Hauptstrukturkomponente in pilzlichen Zellwänden (Doxey et al., 2007). So konnten beispielsweise auch Rep et al. (2002) bei Fusarium oxysporum infizierten Tomaten das verstärkte Auftreten einer sauren und einer basischen Glucanase im Xylemsaft nachweisen.

Ein weiteres im Xylemsaft und Blattapoplasten von Raps unter Verticillium-Einfluss verstärkt vorkommendes Protein wies Ähnlichkeit zu einem PR-4 Protein (AF528181) aus Brassica rapa auf. In Brassica rapa wurde gezeigt, dass dieses PR-4 Protein durch Infektion mit Pseudomonas syringae induzierbar ist (Park et al., 2005; Ryang et al., 2002). Die Expression des kodierenden Gens für PR-4 wurde durch Ethephon, eine Ethylen-freisetzende Substanz induziert, aber nicht durch SA oder Methyljasmonat (Park et al., 2003; Park et al., 2005). Die genauere Funktion dieses PR-4 Proteins bleibt noch zu klären. Die verstärkte Expression eines PR-4 Proteins wurde außerdem von Fidantsef et al. (1999) bei pilzlicher und bakterieller Infektion sowie bei Insektenfraß an Tomaten beobachtet. In Arabidopsis zeigte Johansson et al. (2006), dass in Verticillium-infizierten Pflanzen 7 Tage nach Inokulation die Expression eines Ethylen-abhängigen PR-4 Proteins stark erhöht war. Eine umfassende Analyse von Raps-Xylemsäften wurde von Kehr et al. (2005) durchgeführt. Unter den dort identifizierten Proteinen befand sich ebenfalls die von uns identifizierte Glucanase (At3g57240), jedoch nicht das von uns identifizierte PR-4 Protein.

Im Rapsapoplasten konnten weitere differentiell auftretende Proteine identifiziert werden. Dabei handelte es sich um eine Peroxidase und eine basische Endochitinase. Möglicherweise handelt es sich bei der nicht-identifizierten Proteinbande im Xylemsaft mit einem Molekulargewicht von $19 \mathrm{kDa}$ ebenfalls um die mit dem gleichen Molekulargewicht in der AWF auftretende Endochitinase (Abb. 4.2). In Höhe des Molekulargewichts des als Peroxidase im AWF identifizierten Proteins zeigte sich im Xylemsaft unter VerticilliumInfektion keine verstärkte Proteinbande.

Ein Protein, dass bei Kontrollpflanzen eine weniger starke Bande bildete, wurde im Apoplasten Verticillium-infizierter Rapspflanzen aus einem eindimensionalen Gel identifiziert. Dieses Protein wies Ähnlichkeit zu einem hier in Arabidopsis gefundenen Germin-ähnlichen Protein auf (GER3, At5g20630; siehe auch Tab. 4.9). Für dieses Protein konnte im Xylemsaft keine Bande beobachtet werden. Auch in den zweidimensionalen Gelen der AWF wurde das Protein nicht als differentiell identifiziert. Wie bereits unter 5.3.1 erwähnt, unterliegt dieses GER3-Gen einer zyklisch-regulierte Transkription (Staiger et al., 1999) mit einer hohen Expression zu Beginn der Dunkelphase. Alle Pflanzen in der vorliegenden Arbeit wurden zwar vormittags, während der Lichtphase geerntet, aber möglicherweise hat sich hier trotzdem ein leichter Effekt durch eine zyklisch-regulierte Transkription gezeigt. 
Im Zusammenhang mit der Untersuchung von Xylemsaft und AWF tauchte die Frage auf, inwiefern der Xylemsaft ein Kontinuum mit den Proteinen des Blattapoplasten bildet. Insgesamt betrachtet unterscheiden sich die Proteinmuster in den Gelen von Xylemsaft und AWF zwar deutlich (Abb. 4.7), was gegen ein absolutes Kontinuum von Xylemsaft- und AWF-Proteinen spricht, aber die V. longisporum induzierten Proteinantworten gehen, wie die Beispiele Glucanase und PR-4 Protein zeigen, zumindest zum Teil ineinander über.

\subsubsection{Verticillium-induzierte Antworten in Raps und Arabidopsis im Vergleich}

Bei der Untersuchung der beiden Brassicaceen Arabidopsis und Raps stellte sich die Frage, ob und inwiefern sich die Spezies in ihrer Reaktion auf $V$. Iongisporum unterscheiden. Im Hinblick auf die extrazelluläre Proteinantwort wurden sowohl Unterschiede wie auch Gemeinsamkeiten gefunden. In Tabelle 5.4 sind die unter Verticillium-Einfluss in Arabidopsis und Raps differentiell aufgetretenen Proteine im Vergleich dargestellt.

Tab. 5.4: Unter Verticillium-Einfluss in Arabidopsis thaliana und Brassica napus differentiell aufgetretene Proteine im Vergleich. $\uparrow$ bedeutet, ein verstärktes Auftreten des Proteins durch Verticillium-Infektion, $\downarrow$ ein vermindertes Auftreten.

\begin{tabular}{llll}
\hline Arabidopsis thaliana & & Brassica napus \\
\hline Serin Carboxypeptidase & $\uparrow$ & Glucanase & $\uparrow$ \\
$\alpha$-Galactosidase & $\uparrow$ & PR-4 Protein & $\uparrow$ \\
Peroxidase (At5g05340) & $\uparrow$ & Chitinase & $\uparrow$ \\
Peroxidase (At3g49120) & $\uparrow$ & Peroxidase (At5g05340) & $\uparrow$ \\
Peroxidase (At4g37530) & $\uparrow$ & & \\
Chitinase & $\uparrow$ & & \\
Germin-ähnliches Protein (GER3) & $\uparrow$ & & \\
Lektin-ähnliches Protein & $\downarrow$ & & \\
\hline
\end{tabular}

In Arabidopsis konnten in der AWF als Reaktion auf Verticillium drei verstärkt auftretende Peroxidasen gefunden werden, im Rapsapoplasten wurde eine verstärkt auftretende Peroxidase identifiziert. Diese wies Ähnlichkeit zu der Peroxidase At5g05340 aus Arabidopsis auf, die auch in Verticillium-infizierten Arabidopsis als besonders stark hochreguliert identifiziert wurde. Die Peroxidase-Aktivität war in Verticillium-infizierten Arabidopsis-Pflanzen stark erhöht, was bei Raps nicht nachgewiesen werden konnte. Das Germin-ähnliche Protein (At5g20630), das bei Verticillium-Infektion in Arabidopsis 25 Tage nach Inokulation verstärkt auftrat, trat dagegen in Raps nicht verstärkt auf. Bei Betrachtung der Expression des Gens At5g20630 in Verticillium-infizierten Arabidopsis im Infektionsverlauf (Abb. 4.25), wird allerdings deutlich, dass die Expression dieses Gens stark 
schwankte und nur zu den Zeitpunkten 25 und 35 Tage nach Inokulation signifikant verstärkt auftrat. Auch andere Proteine, wie die Serin Carboxypeptidase, die $\alpha$-Galactosidase und das Lektin-ähnliche Protein, die im Apoplasten von Arabidopsis unter Verticillium-Einfluss differentiell auftraten, zeigten sich in Raps nicht differentiell. Dagegen wurden die in Raps durch die Infektion am deutlichsten verstärkten Proteine, die Glucanase und das PR-4 Protein in Arabidopsis nicht als differentiell auftretende Proteine identifiziert. Die Reaktionen von Arabidopsis und Raps auf Verticillium zeigten demnach deutliche Unterschiede. Eine Erklärung dafür könnte sein, dass die Infektion in Raps sich in einem anderen Stadium befand als in Arabidopsis. Ein Indiz für eine weniger fortgeschrittene Infektion bei Raps ist, dass noch keine Pilz-DNA in den Stängeln nachgewiesen werden konnte, während in den Blattstängeln von Arabidopsis zum Untersuchungszeitpunkt deutlich nachweisbare Mengen Verticillium-DNA vorhanden waren. 


\section{ZUSAMMENFASSUNG}

Verticillium-Arten sind weltweit in gemäßigten und subtropischen Regionen verbreitete xylembesiedelnde Pilze, die viele ökonomisch bedeutsame Kulturpflanzen befallen. Verticillium longisporum ist vor allem auf Brassicaceen, wie z.B. Blumenkohl, Senf und Raps spezialisiert. Besonders mit der Intensivierung des Rapsanbaus in Europa wurde ein verstärktes Auftreten von V. longisporum zum Problem. Die Bekämpfung des Pilzes in der Landwirtschaft wird sowohl durch die lange Lebensdauer von Verticillium-Dauerformen im Boden, als auch durch seine Lebensweise im Xylem erschwert. Ein besseres Verständnis der Interaktionen zwischen $V$. Iongisporum und seinen Wirtspflanzen ist wichtig, um in Zukunft Strategien zu entwickeln, die eine weitere Verbreitung des Pilzes verhindern.

Das Hauptziel der vorliegenden Arbeit war die Beschreibung des extrazellulären Proteoms der Brassicaceen Raps (Brassica napus) und Arabidopsis thaliana unter Einfluss von Verticillium longisporum. Raps wurde dabei als Beispiel für eine landwirtschaftlich bedeutsame Pflanze herangezogen, während die Modellpflanze Arabidopsis thaliana eine geeignete Plattform für molekulare Analysen bot. Methodisch musste für die extrazellulären Proteomanalysen zunächst die Gewinnung von apoplastischen Waschflüssigkeiten und von Xylemsäften optimiert werden. V. longisporum bedingte Schäden an den Pflanzen sollten umfassend mit Hilfe ökophysiologische Parameter charakterisiert und in Relation zur Infektionsdauer gesetzt werden. Dies sollte den Vergleich der Arabidopsis thaliana Ökotypen Columbia und Landsberg erecta hinsichtlich ihrer Empfindlichkeit gegenüber Verticillium longisporum ermöglichen und die Grundlage zur Etablierung geeigneter Anzuchtbedingungen für die späteren Proteomanalysen bilden.

Die beiden Arabidopsis-Ökotypen Columbia und Landsberg erecta zeigten eine ähnliche Empfindlichkeit gegenüber $V$. longisporum. Aufgrund einer größeren Biomasseproduktion wurde für weitere Analysen der Ökotyp Columbia bevorzugt. Zur Bildung großer Rosetten wurden die Arabidopsis-Pflanzen unter Kurztagsbedingungen (8 h Licht) angezogen, im Gegensatz zu den sonst üblichen Langtagsbedingungen (16 h Licht). So konnten auch Interferenzen der Pilzinfektion mit einer vorzeitigen Blüte verhindert werden.

Zur Charakterisierung von Krankheitssymptomen an V. longisporum infizierten Raps- und Arabidopsis-Pflanzen wurden Chlorophyllgehalte, Chlorophyllfluoreszenz, Photosynthese, Frischmassen und Blattflächen bzw. Sprosshöhen der Pflanzen gemessen. Besonders deutlich war eine durch den Pilz hervorgerufene Reduktion der Rosettenfläche bei Arabidopsis und eine Reduktion der Sprosshöhe bei Raps, die im weiteren Infektionsverlauf auch als Frischmassenverlust nachweisbar war. Bei beiden Pflanzenarten waren durch die Infektion sowohl der Chlorophyllgehalt als auch die mittels Chlorophyllfluoreszenz gemessene maximale photosynthetische Quantenausbeute der Blätter reduziert. Anhand von Elektrolytleitfähigkeitsmessungen konnte gezeigt werden, dass die Zellmembranen der Blätter zum Untersuchungszeitpunkt durch den Pilz nicht geschädigt waren. 
Eine Quantifizierung von Verticillium-DNA in den oberen Pflanzenteilen mittels quantitativer real time PCR zeigte, dass die Symptomausprägung in keinem direkten Zusammenhang mit der Pilzmenge stand. Dies ist ein Hinweis darauf, dass nicht der direkte Pilzkontakt sondern von V. longisporum ausgehende Signale, direkt oder indirekt über die Pflanze, die Symptome an den oberirdischen Pflanzenteilen auslösen. In Arabidopsis thaliana wurden zusätzlich der Wasserhaushalt und die Nährstoffsituation in den Blättern überprüft. Dadurch konnte ausgeschlossen werden, dass ein möglicherweise durch den Pilz hervorgerufener Trockenstress oder Nährstoffmangel zur Symptomausprägung führt.

Die Anzucht- und Inokulationsbedingungen wurden sowohl für Raps als auch für Arabidopsis dahingehend optimiert, dass sich deutlich sichtbare Infektionssymptome zeigten, aber gleichzeitig zur Durchführung von Proteomanalysen genügend Material zur Verfügung stand. $\mathrm{Zu}$ einem geeigneten Zeitpunkt wurden apoplastische Waschflüssigkeiten (AWF) mit Hilfe einer Infiltrations-/Zentrifugationstechnik aus Blättern von Raps und Arabidopsis zur Charakterisierung und Identifizierung extrazellulärer Proteine gewonnen. Mittels einer Scholander-Druckbombe wurden Xylemsäfte aus Raps extrahiert, aus denen ebenfalls extrazelluläre Proteine identifiziert wurden. Kontaminationen mit symplastischen Proteinen konnten nicht vollständig vermieden werden, obwohl die Aktivität des Markerenzyms Malatdehydrogenase in der AWF mit etwa 0,005 \% der Aktivität aus Gesamtblattextrakten vergleichsweise gering war.

Da die Zusammensetzung der extrazellulären Proteome von Pflanzen noch nicht vollständig geklärt ist, wurden dominante apoplastische Proteine der nicht-infizierten Pflanzen aus zweidimensionalen Gelen identifiziert. Dieses gelang durch massenspektrometrische Analysen mit anschließender Recherche in der NCBI-Datenbank für 19 Raps- und 39 Arabidopsis-Proteine. Bei den identifizierten sekretorischen Proteinen handelte es sich vor allem um proteolytische, hydrolytische, Kohlenhydrat-bindende und an Abwehrreaktionen beteiligte Proteine.

Zur Identifizierung differentiell auftretender apoplastischer Proteine aus V. Iongisporuminfizierten Pflanzen und Kontrollpflanzen wurden jeweils sechs zweidimensionale Gele mittels Proteomweaver Software verglichen und statistisch ausgewertet. Im ArabidopsisApoplasten konnten durch massenspektrometrische Analysen und anschließende NCBIDatenbank-Recherche sieben, durch $V$. longisporum Infektion differentiell auftretende Proteine, identifiziert werden. Verstärkt traten eine Serin Carboxypeptidase, eine $\alpha$ Galactosidase, ein Germin-ähnliches Protein und drei Peroxidasen auf. Quantitative real time PCR Analysen untermauerten die Ergebnisse der Proteomanalyse. Durch Aktivitätsmessungen in den AWF aus infizierten Pflanzen konnten zehnfach erhöhte Peroxidase-Aktivitäten nachgewiesen werden. Ein erhöhter Ligningehalt in den Zellwänden infizierter Arabidopsis deutete auf eine Funktion der Peroxidasen in der Verstärkung von Zellwänden zum Schutz vor einem Eindringen des Pilzes hin. Ein Lektin-ähnliches, als Chitin induzierbar beschriebenes Protein, trat im Arabidopsis-Apoplasten unter Verticillium-Einfluss schwächer auf. Die geringere Expression dieses Gens über den gesamten untersuchten 
Infektionsverlauf legte die Vermutung nahe, dass $V$. longisporum in der Lage ist, die Expression des Gens zu unterdrücken. Ob dies für die erfolgreiche Besiedelung durch den Pilz von Bedeutung ist, bleibt zu klären.

Der Raps-Apoplast wies unter Verticillium-Einfluss eine verstärkt auftretende Glucanase, eine Chitinase, eine Peroxidase und ein PR4-Protein auf. Im Xylemsaft der infizierten Rapspflanzen konnten die gleiche Glucanase und das gleiche PR4-Protein wie in der AWF als differentiell auftretende Proteine identifiziert werden.

Da Chitinasen häufig im Zusammenhang mit Verticillium-Infektionen beschrieben wurden, hier auch in Raps, war das Fehlen von verstärkt vorkommenden Chitinasen im Apoplasten von Arabidopsis unerwartet. Genexpressionsanalysen für eine saure Endochitinase mit der AGI-Nummer At5g24090 zeigten nach Verticillium-Inokulation eine deutlich erhöhte Expression. Die Überexpression dieses Chitinase-Gens in einer T-DNA Insertionsmutante führte aber im Vergleich zum Wildtyp zu keiner erhöhten Resistenz gegenüber $V$. longisporum.

Die Gesamtbetrachtung der Ergebnisse zeigte, dass eine Infektion mit $V$. Iongisporum bei Raps und Arabidopsis zu einer ähnlichen Symptomausprägung führte. Eine Symptomausprägung durch pilzlich bedingten Trockenstress oder Nährstoffmangel konnte ausgeschlossen werden. Ein direkter Pilzkontakt in den betreffenden Pflanzenteilen ist nach vorliegenden Erkenntnissen für die Symptomausprägung nicht erforderlich. Die Ergebnisse stützen die Vermutung, dass von $V$. longisporum ausgehende Signale, direkt oder indirekt die Symptomausprägung bewirken. Trotz ähnlicher Symptomausprägungen waren die extrazellulären Proteinantworten der beiden Pflanzenarten teilweise verschieden, was eventuell auf unterschiedliche Infektionsstadien zurückzuführen ist. Die nähere Funktion, der unter Verticillium-Einfluss differentiell auftretenden Proteine, muss nun funktionell untersucht werden. Für Arabidopsis deuten die vorliegenden Ergebnisse auf eine Funktion der Peroxidasen in der Verstärkung von Zellwänden hin. 


\section{LITERATUR}

Abeles, F. B., Dunn, L. J., Morgens, P., Callahan, A., Dinterman, R. E. \& Schmidt, J. (1988). Induction of 33-kd and 60-kd peroxidases during ethylene-induced senescence of cucumber cotyledons. Plant Physiology 87, 609-615.

AbuQamar, S., Chen, X., Dhawan, R., Bluhm, B., Salmeron, J., Lam, S., Dietrich, R. A. \& Mengiste, T. (2006). Expression profiling and mutant analysis reveals complex regulatory networks involved in Arabidopsis response to Botrytis infection. Plant Journal 48, 28-44.

Agrios G.N., (1997). Plant diseases caused by fungi: Verticillium wilts. In Agrios G.N. (ed.): Plant Pathology 346, Academic Press, San Diego.

Amaya, I., Botella, M. A., de la Calle, M., Medina, M. I., Heredia, A., Bressan, R. A., Hasegawa, P. M., Quesada, M. A. \& Valpuesta, V. (1999). Improved germination under osmotic stress of tobacco plants overexpressing a cell wall peroxidase. Febs Letters 457, 80-84.

Antoniw, J. F., Ritter, C. E., Pierpoint, W. S. \& van Loon, L. C. (1980). Comparison of 3 pathogenesisrelated proteins from plants of 2 cultivars of tobacco infected with TMV. Journal of General Virology 47, 79-87.

Ashworth, L. J., Gaona, S. A. \& Surber, E. (1985). Verticillium wilt of pistachio - the influence of potassium nutrition on susceptibility to infection by Verticillium dahliae. Phytopathology 75, 1091-1093.

Baker, C. J. \& Orlandi, E. W. (1995). Active oxygen in plant pathogenesis. Annual Review of Phytopathology 33, 299-321.

Barash, I., Zion, R., Krikun, J. \& Nachmias, A. (1988). Effect of iron status on Verticillium wilt disease and on in vitro production of siderophores by Verticillium dahliae. Journal of Plant Nutrition 11, 893905.

Barbara, D. J. \& Clewes, E. (2003). Plant pathogenic Verticillium species: how many of them are there? Molecular Plant Pathology 4, 297-305.

Barbara, D. J., Morton, A. \& Miller, N. J. (2005). Isolation of microsatellite markers from an interspecific hybrid isolate of the fungal plant pathogen Verticillium dahliae. Molecular Ecology Notes 5, 854-856.

Basu, U., Francis, J. L., Whittal, R. M., Stephens, J. L., Wang, Y., Zaiane, O. R., Goebel, R., Muench, D. G., Good, A. G. \& Taylor, G. J. (2006). Extracellular proteomes of Arabidopsis thaliana and Brassica napus roots: analysis and comparison by MudPIT and LC-MS/MS. Plant and Soil 286, 357376.

Bayer, E. M., Bottrill, A. R., Walshaw, J., Vigouroux, M., Naldrett, M. J., Thomas, C. L. \& Maule, A. J. (2006). Arabidopsis cell wall proteome defined using multidimensional protein identification technology. Proteomics 6, 301-311.

Beckman, C.H. (1964). Host responses to vascular infection. Annual Review of Phytopathology 2: 231-252.

Benhamou, N. (1995). Immunocytochemistry of plant defense mechanisms induced upon microbial attack. Microsc. Res. Tech. 31, 63-78.

Berg, G., Fritze, A., Roskot, N. \& Smalla, K. (2001). Evaluation of potential biocontrol rhizobacteria from different host plants of Verticillium dahliae Kleb. Journal of Applied Microbiology 91, 963-971.

Bergmeyer, H. U. \& Rozalskis, G. (1975). Km of malate dehydrogenase from pig heart with oxaloacetate as substrate. Zeitschrift für klinische Chemie und klinische Biochemie 13, 509.

Bhat, R. G. \& Subbarao, K. V. (1999). Host range specificity in Verticillium dahliae. Phytopathology 89, 1218-1225. 
Blödner, C., Majcherczyk, A., Kües, U. \& Polle, A. (2007). Mild drought stress affects the proteome of spruce needles. Tree Physiology 27, 1423-1431.

Bindschedler, L. V., Dewdney, J., Blee, K. A., Stone, J. M., Asai, T., Plotnikov, J., Denoux, C., Hayes, T., Gerrish, C., Davies, D. R., Ausubel, F. M. \& Bolwell, G. P. (2006). Peroxidase-dependent apoplastic oxidative burst in Arabidopsis required for pathogen resistance. Plant Journal 47, 851-863.

Blum, H., Beier, H., \& Gross, H. J. (1987). Improved silver staining of plant-proteins, RNA and DNA in polyacrylamide gels. Electrophoresis 8, 93-99.

Bohlmann, H. (1994). The role of thionins in plant-protection. Critical Reviews in Plant Sciences 13, 116.

Bolwell, G. P., Bindschedler, L. V., Blee, K. A., Butt, V. S., Davies, D. R., Gardner, S. L., Gerrish, C. \& Minibayeva, F. (2002). The apoplastic oxidative burst in response to biotic stress in plants: a threecomponent system. Journal of Experimental Botany 53, 1367-1376.

Borderies, G., Jamet, E., Lafitte, C., Rossignol, M., Jauneau, A., Boudart, G., Monsarrat, B., EsquerreTugaye, M. T., Boudet, A. \& Pont-Lezica, R. (2003). Proteomics of loosely bound cell wall proteins of Arabidopsis thaliana cell suspension cultures: A critical analysis. Electrophoresis 24, 3421-3432.

Boudart, G., Jamet, E., Rossignol, M., Lafitte, C., Borderies, G., Jauneau, A., Esquerre-Tugaye, M. T. \& Pont-Lezica, R. (2005). Cell wall proteins in apoplastic fluids of Arabidopsis thaliana rosettes: Identification by mass spectrometry and bioinformatics. Proteomics 5, 212-221.

Bowers, J. H., Nameth, S. T., Riedel, R. M. \& Rowe, R. C. (1996). Infection and colonization of potato roots by Verticillium dahliae as affected by Pratylenchus penetrans and $P$. crenatus. Phytopathology 86, 614-621.

Bradley, D. J., Kjellbom, P. \& Lamb, C. J. (1992). Elicitor-induced and wound-induced oxidative crosslinking of a proline-rich plant-cell wall protein - a novel, rapid defense response. Cell 70, 21-30.

Brinkmann, K., Blaschke, L. \& Polle, A. (2002). Comparison of different methods for lignin determination as a basis for calibration of near-infrared reflectance spectroscopy and implications of lignoproteins. Journal of Chemical Ecology 28, 2483-2501.

Broekaert, W. F. \& Peumans, W. J. (1988). Pectic polysaccharides elicit chitinase accumulation in tobacco. Physiologia Plantarum 74, 740-744.

Broglie, K., Chet, I., Holliday, M., Cressman, R., Biddle, P., Knowlton, S., Mauvais, C. J. \& Broglie, R. (1991). Transgenic plants with enhanced resistance to the fungal pathogen Rhizoctonia solani. Science 254, 1194-1197.

Brunekreef, G. A., Kraft, H. J., Schoenmakers, J. G. G. \& Lubsen, N. H. (1996). The mechanism of recruitment of the lactate dehydrogenase-B/epsilon-crystallin gene by the duck lens. Journal of Molecular Biology 262, 629-639.

Brunner, F., Stintzi, A., Fritig, B. \& Legrand, M. (1998). Substrate specificities of tobacco chitinases. Plant Journal 14, 225-234.

Buhtz, A., Kolasa, A., Arlt, K., Walz, C. \& Kehr, J. (2004). Xylem sap protein composition is conserved among different plant species. Planta 219, 610-618.

Burge, M. N. \& Simmons, J. R. (1982). The influence of potassium and phosphorus in predisposition of tomato to Verticillium wilt, Chemistry and Ecology, 1:2, $83-92$.

Campos, P. S., Quartin, V., Ramalho, J. C. \& Nunes, M. A. (2003). Electrolyte leakage and lipid degradation account for cold sensitivity in leaves of Coffea sp. plants. Journal of Plant Physiology 160, 283-292. 
Carter, C., Graham, R. A. \& Thornburg, R. W. (1998). Arabidopsis thaliana contains a large family of germin-like proteins: characterization of cDNA and genomic sequences encoding 12 unique family members. Plant Molecular Biology 38, 929-943.

Chalmers, J.M. \& Griffiths, P.R. (2002). Handbook of vibrational spectroscopy. Vol 1-5. Wiley, Chichester, UK.

Chang S., Puryear J. \& Cairney J. (1993): A simple and efficient method for isolating RNA from pine trees. Plant Molecular Biology Reports 11: 113-116.

Charmont, S., Jamet, E., Pont-Lezica, R. \& Canut, H. (2005). Proteomic analysis of secreted proteins from Arabidopsis thaliana seedlings: improved recovery following removal of phenolic compounds. Phytochemistry 66, 453-461.

Chen, P., Lee, B. \& Robb, J. (2004). Tolerance to a non-host isolate of Verticillium dahliae in tomato. Physiological and Molecular Plant Pathology 64, 283-291.

Chittoor, J. M., Leach, J. E. \& White, F. F. (1997). Differential induction of a peroxidase gene family during infection of rice by Xanthomonas oryzae pv. oryzae. Molecular Plant-Microbe Interactions 10, 861-871.

Chivasa, S., Ndimba, B. K., Simon, W. J., Robertson, D., Yu, X. L., Yu, X. L., Knox, J. P., Bolwell, P. \& Slabas, A. R. (2002). Proteomic analysis of the Arabidopsis thaliana cell wall. Electrophoresis 23, 1754-1765.

Chivasa, S., Hamilton, J. M., Pringle, R. S., Ndimba, B. K., Simon, W. J., Lindsey, K. \& Slabas, A. R. (2006). Proteomic analysis of differentially expressed proteins in fungal elicitor-treated Arabidopsis cell cultures. Journal of Experimental Botany 57, 1553-1562.

Chrost, B., Kolukisaoglu, U., Schulz, B., \& Krupinska, K. (2007). An $\alpha$-galactosidase with an essential function during leaf development. Planta 225, 311-320.

Cohen-Kupiec, R. \& Chet, I. (1998). The molecular biology of chitin digestion. Current Opinion in Biotechnology 9, 270-277.

Collinge, D. B., Kragh, K. M., Mikkelsen, J. D., Nielsen, K. K., Rasmussen, U. \& Vad, K. (1993). Plant chitinases. Plant Journal 3, 31-40.

Collins, A., Okoli, C. A. N., Morton, A., Parry, D., Edwards, S. G. \& Barbara, D. J. (2003). Isolates of Verticillium dahliae pathogenic to crucifers are of at least three distinct molecular types. Phytopathology 93, 364-376.

Cooper, R. M., Resende, M. L. V., Flood, J., Rowan, M. G., Beale, M. H. \& Potter, U. (1996). Detection and cellular localization of elemental sulphur in disease-resistant genotypes of Theobroma cacao. Nature 379, 159-162.

Daayf, F., Nicole, M., Boher, B., Pando, A. \& Geiger, J. P. (1997). Early vascular defense reactions of cotton roots infected with a defoliating mutant strain of Verticillium dahliae. European Journal of Plant Pathology 103, 125-136.

Dangl, J. L. \& Jones, J. D. G. (2001). Plant pathogens and integrated defence responses to infection. Nature 411, 826-833.

Debode, J., Claeys, D. \& Höfte, M. (2004). Control of Verticillium wilt of cauliflower with crop residues, lignin and microbial antagonists. IOBC WPRS Bull 27, 41-45.

De Boer, A. H. \& Volkov, V. (2003). Logistics of water and salt transport through the plant: structure and functioning of the xylem. Plant Cell and Environment 26, 87-101.

De Gara, L. (2004). Class III peroxidases and ascorbate matabolism in plants. Phytochemistry Reviews 3:195-205. 
Dempsey, D. A., Shah, J. \& Klessig, D. F. (1999). Salicylic acid and disease resistance in plants. Critical Reviews in Plant Sciences 18, 547-575.

Dietrich, A., Mayer, J. E. \& Hahlbrock, K. (1990). Fungal elicitor triggers rapid, transient, and specific protein-phosphorylation in parsley cell-suspension cultures. Journal of Biological Chemistry 265, 63606368.

Dietz, K.J. (1997). Functions and responses of the leaf apoplast under stress. Prog Bot 58: 221-254.

Dixelius, C., Happstadius, I. \& Berg, G. (2005). Verticillium wilt on Brassica oilseed crops - A Swedish perspective. Journal of Swedish Seed Association 115:36-48.

Dixon, R. A., Harrison, M. J. \& Lamb, C. J. (1994). Early events in the activation of plant defense responses. Annual Review of Phytopathology 32, 479-501.

Dixon, R. A. (2001). Natural products and plant disease resistance. Nature 411, 843-847.

Dong, X. N., Mindrinos, M., Davis, K. R. \& Ausubel, F. M. (1991). Induction of Arabidopsis defense genes by virulent and avirulent Pseudomonas syringae strains and by a cloned avirulence gene. Plant Cell 3, 61-72.

Doxey, A. C., Yaish, M. W. F., Moffatt, B. A., Griffith, M. \& McConkey, B. J. (2007). Functional divergence in the Arabidopsis $\beta$-1,3-glucanase gene family inferred by phylogenetic reconstruction of expression states. Mol. Biol. Evol. 24, 1045-1055.

Dubery, I. A. \& Slater, V. (1997). Induced defence responses in cotton leaf disks by elicitors from Verticillium dahliae. Phytochemistry 44, 1429-1434.

Emanuelsson, O., Nielsen, H., Brunak, S. \& von Heijne, G. (2000). Predicting subcellular localization of proteins based on their $\mathrm{N}$-terminal amino acid sequence. Journal of Molecular Biology $300,1005-$ 1016.

Epple, P., Apel, K. \& Bohlmann, H. (1995). An Arabidopsis thaliana thionin gene is inducible via a signal-transduction pathway different from that for pathogenesis-related proteins. Plant Physiology $109,813-820$.

Epple, P., Apel, K. \& Bohlmann, H. (1997). Overexpression of an endogenous thionin enhances resistance of Arabidopsis against Fusarium oxysporum. Plant Cell 9, 509-520.

Espelie, K. E., Franceschi, V. R. \& Kolattukudy, P. E. (1986). Immunocytochemical localization and time course of appearance of an anionic peroxidase associated with suberization in wound-healing potato-tuber tissue. Plant Physiology 81, 487-492.

Eynck, C., Koopmann, B., Grunewaldt-Stoecker, G., Karlovsky, P. \& von Tiedemann, A. (2007). Differential interactions of Verticillium longisporum and $V$. dahliae with Brassica napus detected with molecular and histological techniques. European Journal of Plant Pathology 118, 259-274.

Fahleson, J., Lagercrantz, U., Hu, Q., Steventon, L. A. \& Dixelius, C. (2003). Estimation of genetic variation among Verticillium isolates using AFLP analysis. European Journal of Plant Pathology 109, 361-371.

Faix, O. (1991). Condensation Indexes of Lignins Determined by FTIR-Spectroscopy. Holz als Rohund Werkstoff 49, 356.

Feys, B. J. \& Parker, J. E. (2000). Interplay of signaling pathways in plant disease resistance. Trends in Genetics 16, 449-455.

Fradin, E. F. \& Thomma, B. P. H. J. (2006). Physiology and molecular aspects of Verticillium wilt diseases caused by $V$. dahliae and $V$. albo-atrum. Molecular Plant Pathology 7, 71-86. 
Fraser, C. M., Rider, L. W. \& Chapple, C. (2005). An expression and bioinformatics analysis of the Arabidopsis serine carboxypeptidase-like gene family. Plant Physiology 138, 1136-1148.

Fry, S. C. (1986). In vivo formation of xyloglucan nonasaccharide - a possible biologically-active cellwall fragment. Planta 169, 443-453.

García-Olmedo, F., Molina, A., Segura, A. \& Moreno, M. (1995). The defensive role of nonspecific lipid-transfer proteins in plants. Trends Microbiol. 3: 72-74.

Gelli, A., Higgins, V. J. \& Blumwald, E. (1997). Activation of plant plasma membrane $\mathrm{Ca}^{2+}$-permeable channels by race-specific fungal elicitors. Plant Physiology 113, 269-279.

Gerhardt, L. B. D., Magioli, C., Perez, A. B. U. C., Margis, R., Sachetto-Martins, G. \& Margis-Pinheiro, M. (2004). AtchitlV gene expression is stimulated under abiotic stresses and is spatially and temporally regulated during embryo development. Genetics and Molecular Biology 27, 118-123.

Goicoechea, N., Aguirreolea, J., Cenoz, S. \& Garcia-Mina, J. M. (2001). Gas exchange and flowering in Verticillium-wilted pepper plants. Journal of Phytopathology 149, 281-286.

Gold, J. \& Robb, J. (1995). The role of the coating response in Craigella tomatoes infected with Verticillium dahliae, race-1 and race-2. Physiological and Molecular Plant Pathology 47, 141-157.

Görg, A., Obermaier, C., Boguth, G., Harder, A., Scheibe, B., Wildgruber, R. \& Weiss, W. (2000). The current state of two-dimensional electrophoresis with immobilized $\mathrm{pH}$ gradients. Electrophoresis 21, 1037-1053.

Görg, A. \& Weiss, W. (2000). Two-dimensional electrophoresis with Immobilized pH gradients. In: Proteom research: Two-dimensional gelelectrophoresis and identification methods. Rabilloud (ed.). Springer Verlag Berlin Heidelberg, pp 57-106.

Green, T.R. \& Ryan, C.A. (1972). Wound-induced proteinase inhibitor in plant leaves: a possible defense mechanism against insects. Science 175: 776-777.

Grignon, C. \& Sentenac, H. (1991). PH and ionic conditions in the apoplast. Annual Review of Plant Physiology and Plant Molecular Biology 42, 103-128.

Günzler, H. \& Gremlich, H.-U. (2002). IR spectroscopy: An Introduction. Wiley-VCH, Weinheim, Germany.

Hamel, F., Boivin, R., Tremblay, C. \& Bellemare, G. (1997). Structural and evolutionary relationships among chitinases of flowering plants. Journal of Molecular Evolution 44, 614-624.

Hammond-Kosack, K. E. \& Parker, J. E. (2003). Deciphering plant-pathogen communication: fresh perspectives for molecular resistance breeding. Current Opinion in Biotechnology 14, 177-193.

Harrison, S. J., Curtis, M. D., Mcintyre, C. L., Maclean, D. J. \& Manners, J. M. (1995). Differential expression of peroxidase isogenes during the early stages of infection of the tropical forage legume stylosanthes humilis by Colletotrichum gloeosporioides. Molecular Plant-Microbe Interactions 8, 398406.

Haslam, R. P., Downie, A. L., Raveton, M., Gallardo, K., Job, D., Pallett, K. E., John, P., Parry, M. A. J. \& Coleman, J. O. D. (2003). The assessment of enriched apoplastic extracts using proteomic approaches. Annals of Applied Biology 143, 81-91.

Havlis, J., Thomas, H., Sebela, M. \& Shevchenko, A. (2003). Fast-response proteomics by accelerated in-gel digestion of proteins. Analytical Chemistry 75, 1300-1306.

Heath, M. C. (1998). Apoptosis, programmed cell death and the hypersensitive response. European Journal of Plant Pathology 104, 117-124. 
Heinrichs, H., Brumsack, H.J., Loftfield, N. \& König, N. (1986). Verbessertes Druckaufschlusssystem für biologische und anorganische Materialien. Zeitschrift für Pflanzenernähung und Bodenkunde 149: 350-353.

Heinz, R., Lee, S. W., Saparno, A., Nazar, R. N. \& Robb, J. (1998). Cyclical systemic colonization in Verticillium-infected tomato. Physiological and Molecular Plant Pathology 52, 385-396.

Henrissat, B. (1991). A classification of glycosyl hydrolases based on amino-acid-sequence similarities. Biochemical Journal 280, 309-316.

Himelblau, E. \& Amasino, R. M. (2001). Nutrients mobilized from leaves of Arabidopsis thaliana during leaf senescence. Journal of Plant Physiology 158, 1317-1323.

Hiraga, S., Sasaki, K., Ito, H., Ohashi, Y. \& Matsui, H. (2001). A large family of class III plant peroxidases. Plant Cell Physiol. 42, 462-468.

Hong, J. K., Jung, H. W., Kim, Y. J. \& Hwang, B. K. (2000). Pepper gene encoding a basic class II chitinase is inducible by pathogen and ethephon. Plant Science 159, 39-49.

Jabs, T., Dietrich, R. A. \& Dangl, J. L. (1996). Initiation of runaway cell death in an Arabidopsis mutant by extracellular superoxide. Science $273,1853-1856$.

Jabs, T., Tschope, M., Colling, C., Hahlbrock, K. \& Scheel, D. (1997). Elicitor-stimulated ion fluxes and $\mathrm{O}_{2}^{-}$from the oxidative burst are essential components in triggering defense gene activation and phytoalexin synthesis in parsley. Proceedings of the National Academy of Sciences of the United States of America 94, 4800-4805.

Jach, G., Gornhardt, B., Mundy, J., Logemann, J., Pinsdorf, P., Leah, R., Schell, J. \& Maas, C. (1995). Enhanced quantitative resistance against fungal disease by combinatorial expression of different barley antifungal proteins in transgenic tobacco. Plant Journal 8, 97-109.

Jamet, E., Canut, H., Boudart, G. \& Pont-Lezica, R. F. (2006). Cell wall proteins: a new insight through proteomics. Trends in Plant Science 11, 33-39.

Johansson, A., Staal, J. \& Dixelius C. (2006).Early responses in the Arabidopsis-Verticillium longisporum pathosystem are dependent on NDR1, JA- and ET-associated signals via cytosolic NPR1 and RFO1. MPMI 19, 958-969.

Joosten, M. H. A. J. \& De Wit, P. J. G. M. (1989). Identification of several pathogenesis-related proteins in tomato leaves inoculated with Cladosporium fulvum (syn. Fulvia fulva) as 1,3- $\beta$-glucanases and chitinases. Plant Physiology 89, 945-951.

Jung, H. W. \& Hwang, B. K. (2000). Pepper gene encoding a basic $\beta-1,3-$ glucanase is differentially expressed in pepper tissues upon pathogen infection and ethephon or methyl jasmonate treatment. Plant Science 159, 97-106.

Karapapa, V. K., Bainbridge, B. W. \& Heale, J. B. (1997). Morphological and molecular characterization of Verticillium longisporum comb. nov., pathogenic to oilseed rape. Mycological Research 101, 1281-1294.

Kasprzewska, A. (2003). Plant chitinases - Regulation and function. Cellular \& Molecular Biology Letters 8, 809-824.

Kehr, J., Buhtz, A. \& Giavalisco, P. (2005). Analysis of xylem sap proteins from Brassica napus. BMC Plant Biology 5.

Kitajima, M. \& Butler, W.L. (1975). Quenching of chlorophyll fluorescence and primary photochemistry in chloroplasts by dibromothyquinone. Biochim biophys Acta 376: 105-115.

Kombrick, E., Schroder, M. \& Hahlbrock, K. (1988). Several pathogenesis-related proteins in potato are $\beta$-1,3-glucanases and chitinases. Proc Natl Acad Sci USA 85:782-786. 
Kristensen, B. K., Bloch, H. \& Rasmussen, S. K. (1999). Barley coleoptile peroxidases. Purification, molecular cloning, and induction by pathogens. Plant Physiology 120, 501-512.

Krüger, W. (1989). Untersuchungen zur Verbreitung von Verticillium dahliae Kleb. und anderen Krankheits- und Schaderregern bei Raps in der Bundesrepublik Deutschland. Nachrichtenblatt des Deutschen Pflanzenschutzdienstes 41, 49-56.

Kruse, J., Hetzger, I., Mai, C., Polle, A. \& Rennenberg, H. (2003). Elevated $\mathrm{pCO}_{2}$ affects Nmetabolism of young poplar plants (Populus tremula $\times$ P. alba) differently at deficient and sufficient $\mathrm{N}$ supply. New Phytologist 157, 65-81.

Kudela, V. \& Pirkl, J. (1978). Influence of soil pH and calcium nutrition on resistance of alfalfa to bacterial and Verticillium wilt. Zentralbibliothek Bakteriologische Naturwissenschaften 133, 503-511.

Laemmli, U. K. (1970). Cleavage of structural proteins during the assembly of the head of bacteriophage T4. Nature 227, 680-685.

Lagrimini, L. M., Burkhart, W., Moyer, M. \& Rothstein, S. (1987). Molecular-cloning of complementaryDNA encoding the lignin-forming peroxidase from tobacco - Molecular analysis and tissue-specific expression. Proceedings of the National Academy of Sciences of the United States of America 84, 7542-7546

Lagrimini, L. M., Joly, R. J., Dunlap, J. R. \& Liu, T. T. Y. (1997). The consequence of peroxidase overexpression in transgenic plants on root growth and development. Plant Molecular Biology 33, 887895.

Lamb, C. \& Dixon, R. A. (1997). The oxidative burst in plant disease resistance. Annual Review of Plant Physiology and Plant Molecular Biology 48, 251-275.

Lane, B. G. (1994). Oxalate, germin, and the extracellular-matrix of higher-plants. FASEB Journal 8 , 294-301.

Lay, F. T. \& Anderson, M. A. (2005). Defensins - Components of the innate immune system in plants. Current Protein \& Peptide Science 6, 85-101.

Legrand, M., Kauffmann, S., Geoffroy, P. \& Fritig, B. (1987). Biological function of pathogenesisrelated proteins - 4 tobacco pathogenesis-related proteins are chitinases. Proceedings of the National Academy of Sciences of the United States of America 84, 6750-6754.

Li, Y. C., Chang, C. T., Hsiao, E. S. L., Hsu, J. S. F., Huang, J. W. \& Tzen, J. T. C. (2003). Purification and characterization of an antifungal chitinase in jelly fig (Ficus awkeotsang) achenes. Plant Cell Physiol. 44, 1162-1167.

Liao, D. I. \& Remington, S. J. (1990). Structure of wheat serine carboxypeptidase II at $3.5 \AA$ resolution - A new class of serine proteinase. Journal of Biological Chemistry 265, 6528-6531.

Lichtenthaler, H.K. \& Wellburn, A.R. (1983). Determinations of total carotenoids and chlorophylls a and $b$ of leaf extracts in different solvents. Biochem Soc Trans 11: 591-592.

Ludwikow, A., Gallois, P. \& Sadowski, J. (2004). Ozone-induced oxidative stress response in Arabidopsis: Transcription profiling by microarray approach. Cellular \& Molecular Biology Letters 9 , 829-842.

Macur, R. E., Mathre, D. E. \& Olsen, R. A. (1991). Interactions between iron nutrition and Verticillium wilt resistance in tomato. Plant and Soil 134, 281-286.

Mauch, F., Hadwiger, L. A., \& Boller, T. (1984). Ethylene - Symptom, not signal for the induction of chitinase and $\beta-1,3$-glucanase in pea pods by pathogens and elicitors. Plant Physiology 76, 607-611.

Mattsson, A. (1996). Predicting field performance using seedling quality assessment. New Forests 13: 223-248. 
Maxwell, K. \& Johnson, G.N. (2000). Chlorophyll fluorescence - a practical guide. Journal of Experimental Botany 51, 659-668.

McFadden, H. G., Chapple, R., de Feyter, R. \& Dennis, E. (2001). Expression of pathogenesis-related genes in cotton stems in response to infection by Verticillium dahliae. Physiological and Molecular Plant Pathology 58, 119-131.

McNabb, K. \& Takahashi, E. (2000). Freeze damage to loblolly pine seedlings as indicated by conductivity measurements and outplanting survival. Auburn University Southern Forest Nursery Management Cooperative. Research Report 00-4.

Melchers, L. S., Apotheker-de Groot, M., Vanderknaap, J., Ponstein, A. S., Selabuurlage, M. B., Bol, J. F., Cornelissen, B. J. C., Vandenelzen, P. J. M. \& Linthorst, H. J. M. (1994). A new class of tobacco chitinases homologous to bacterial exo-chitinases displays antifungal activity. Plant Journal 5, 469480.

Membré, N., Bernier, F., Staiger, D. \& Berna, A. (2000). Arabidopsis thaliana germin-like proteins: common and specific features point to a variety of functions. Planta 211, 345-354.

Metraux, J. P., Streit, L. \& Staub, T. (1988). A pathogenesis-related protein in cucumber is a chitinase. Physiological and Molecular Plant Pathology 33, 1-9.

Meyer, R., Slater, V. \& Dubery, I. A. (1994). A phytotoxic protein-lipopolysaccharide complex produced by Verticillium dahliae. Phytochemistry $35,1449-1453$.

Minic, Z., Rihouey, C., Do, C. T., Lerouge, P. \& Jouanin, L. (2004). Purification and characterization of enzymes exhibiting $\beta$-D-xylosidase activities in stem tissues of Arabidopsis. Plant Physiology 135, 867-878.

Mol, L. \& van Riessen, H. W. (1995). Effect of plant-roots on the germination of microsclerotia of Verticillium dahliae. European Journal of Plant Pathology 101, 673-678.

Mol, L. (1995). Effect of plant-roots on the germination of microsclerotia of Verticillium dahliae 2. Quantitative-analysis of the luring effect of crops. European Journal of Plant Pathology 101, 679-685.

Mouille, G., Robin, S., Lecomte, M., Pagant, S. \& Höfte, H. (2003). Classification and identification of Arabidopsis cell wall mutants using Fourier-Transform Infrared (FT-IR) microspectroscopy. The Plant Journal 35, 393-404.

Moura, D. S., Bergey, D. R. \& Ryan, C. A. (2001). Characterization and localization of a woundinducible type I serine-carboxypeptidase from leaves of tomato plants (Lycopersicon esculentum Mill.). Planta 212, 222-230.

Murashige, T. \& Skoog, F. (1962). A revised medium for rapid growth and bio assays with tobacco tissue cultures. Physiologia Plantarum 15, 473-497.

Musgrave, M. E. (2000). Realizing the potential of rapid-cycling Brassica as a model system for use in plant biology research. Journal of Plant Growth Regulation 19, 314-325.

Nachmias, A., Buchner, V., Tsror, L., Burstein, Y. \& Keen, N. (1987). Differential phytotoxicity of peptides from culture fluids of Verticillium dahliae races 1 and 2 and their relationship to pathogenicity of the fungi on tomato. Phytopathology $77,506-510$.

Nachmias, A., Orenstein, J., Tal, M. \& Goren, M. (1990). Reactions to a Verticillium dahliae phytotoxin in tissue-cultures derived from susceptible and tolerant potato. Plant Science 68, 123-130.

Narusaka, Y., Narusaka, M., Park, P., Kubo, Y., Hirayama, T., Seki, M., Shiraishi, T., Ishida, J., Nakashima, M., Enju, A., Sakurai, T., Satou, M., Kobayashi, M. \& Shinozaki, K. (2004). RCH1, a locus in Arabidopsis that confers resistance to the hemibiotrophic fungal pathogen Colletotrichum higginsianum. Molecular Plant-Microbe Interactions 17, 749-762. 
Naumann, A., Navarro-Gonzalez, M., Peddireddi, S., Kües, U. \& Polle, A. (2005). Fourier transform infrared microscopy and imaging: Detection of fungi in wood. Fungal Genetics and Biology 42, 829835.

Neuhaus, J. M., Fritig, B., Linthorst, H. J. M., Meins, F., Mikkelsen, J. D., \& Ryals, J. (1996). A revised nomenclature for chitinase genes. Plant Molecular Biology Reporter 14, 102-104.

Neuhoff, V. (1990). Colloid coomassie blue staining of proteins and peptides in polyacrylamide gels. Biological Chemistry Hoppe-Seyler 371, A10-A11.

Okushima, Y., Koizumi, N., Kusano, T. \& Sano, H. (2000). Secreted proteins of tobacco cultured BY2 cells: identification of a new member of pathogenesis-related proteins. Plant Molecular Biology 42, 479-488.

Ollis, D. L., Cheah, E., Cygler, M., Dijkstra, B., Frolow, F., Franken, S. M., Harel, M., Remington, S. J., Silman, I., Schrag, J., Sussman, J. L., Verschueren, K. H. G. \& Goldman, A. (1992). The $\alpha / \beta-$ hydrolase fold. Protein Engineering 5, 197-211.

Park, Y.-S. \& Cho, T.-J. (2003). Isolation and characterization of methyl jasmonate-inducible genes in chinese cabbage. Korean Journal of Biological Sciences 7: 337-343.

Park, Y.-S., Jeon, M. H., Lee, S.-H., Moon, J. S., Cha, J.-S., Kim H. Y. \& Cho, T.-J. (2005). Activation of defense responses in chinese cabbage by a nonhost pathogen, Pseudomonas syringae pv. tomato. Journal of Biochemistry and Molecular Biology 38, 748-754.

Passardi, F., Penel, C. \& Dunand, C. (2004). Performing the paradoxical: how plant peroxidases modify the cell wall. Trends in Plant Science 9, 534-540.

Passardi, F., Cosio, C., Penel, C. \& Dunand, C. (2005). Peroxidases have more functions than a swiss army knife. Plant Cell Reports 24, 255-265.

Passardi, F., Tognolli, M., De Meyer, M., Penel, C. \& Dunand, C. (2006). Two cell wall associated peroxidases from Arabidopsis influence root elongation. Planta 223, 965-974.

Passarinho, P.A. \& de Vries, S.C. (2002). Arabidopsis chitinases: A genomic survey. In CR Somerville, EM Meyerowitz, eds, The Arabidopsis Book.

Pegg, G. F. (1976). Response of ethylene-treated tomato plants to infection by Verticillium albo atrum. Physiological Plant Pathology 9, 215-872226.

Pegg, G.F. \& Brady, B.L. (2002). Verticillium wilts. Wallingford, UK: CABI Publishing.

Pfaffl, M. W. (2001). A new mathematical model for relative quantification in real-time RT-PCR. Nucleic Acids Research 29.

Pfaffl, M. W., Horgan, G. W. \& Dempfle, L. (2002). Relative expression software tool (REST ${ }^{\circ}$ ) for group-wise comparison and statistical analysis of relative expression results in real-time PCR. Nucleic Acids Research 30.

Plochl, M., Lyons, T., Ollerenshaw, J. \& Barnes, J. (2000). Simulating ozone detoxification in the leaf apoplast through the direct reaction with ascorbate. Planta 210, 454-467.

Polle, A., Chakrabarti, K., Schurmann, W. \& Rennenberg, H. (1990). Composition and properties of hydrogen-peroxide decomposing systems in extracellular and total extracts from needles of norway spruce (Picea-Abies L, Karst). Plant Physiology 94, 312-319.

Polle, A., Schwanz, P. \& Rudolf, C. (2001). Developmental and seasonal changes of stress responsiveness in beech leaves (Fagus sylvatica L.). Plant Cell and Environment 24, 821-829. 
Pomar, F., Novo, M., Bernal, M. A., Merino, F. \& Barcelo, A. R. (2004). Changes in stem lignins (monomer composition and crosslinking) and peroxidase are related with the maintenance of leaf photosynthetic integrity during Verticillium wilt in Capsicum annuum. New Phytologist 163, 111-123.

Pugin, A., Frachisse, J. M., Tavernier, E., Bligny, R., Gout, E., Douce, R. \& Guern, J. (1997). Early events induced by the elicitor cryptogein in tobacco cells: Involvement of a plasma membrane NADPH oxidase and activation of glycolysis and the pentose phosphate pathway. Plant Cell 9, 2077-2091.

Pütter, J. (1970). Peroxidasen. Methoden der enzymatischen Analyse. 3rd ed. H. U. Bergmayer, ed. Chemie, Weinheim, Germany, 725-731.

Ramonell, K., Berrocal-Lobo, M., Koh, S., Wan, J. R., Edwards, H., Stacey, G. \& Somerville, S. (2005). Loss-of-function mutations in chitin responsive genes show increased susceptibility to the powdery mildew pathogen Erysiphe cichoracearum. Plant Physiology 138, 1027-1036.

Rep, M., Dekker, H. L., Vossen, J. H., de Boer, A. D., Houterman, P. M., Speijer, D., Back, J. W., de Koster, C. G. \& Cornelissen, B. J. C. (2002). Mass spectrometric identification of isoforms of PR proteins in xylem sap of fungus-infected tomato. Plant Physiology 130, 904-917.

Rivera-Becerril, F., Metwally, A., Martin-Laurent, F., Van Tuinen, D., Dietz, K. J., Gianinazzi, S. \& Gianinazzi-Pearson, V. (2005). Molecular responses to cadmium in roots of Pisum sativum L. Water Air and Soil Pollution 168, 171-186.

Rohacek, K. (2002). Chlorophyll fluorescence parameters: the definitions, photosynthetic meaning, and mutual relationships. Photosynthetica 40, 13-29.

Rüdiger, H. \& Gabius, H. J. (2001). Plant lectins: Occurrence, biochemistry, functions and applications. Glycoconjugate Journal 18, 589-613.

Ryals, J. A., Neuenschwander, U. H., Willits, M. G., Molina, A., Steiner, H. Y. \& Hunt, M. D. (1996). Systemic acquired resistance. Plant Cell 8, 1809-1819.

Ryang, S.-H., Chung, S.-Y., Lee, S.-H., Cha, J.-S., Kim, H. Y. \& Cho, T.-J.(2002). Isolation of pathogen-induced chinese cabbage genes by subtractive hybridization employing selective adaptor ligation. Biochemical and Biophysical Research Communications 299, 352-359.

Samac, D. A. \& Shah, D. M. (1991). Developmental and pathogen-induced activation of the Arabidopsis acidic chitinase promoter. Plant Cell 3, 1063-1072.

Scheel, D. (1998). Resistance response physiology and signal transduction. Current Opinion in Plant Biology 1, 305-310.

Scholander, P. F., Hammel, H. T., Bradstre, E. D. \& Hemmings, E. A. (1965). Sap pressure in vascular plants - Negative hydrostatic pressure can be measured in plants. Science 148, 339-346.

Schraudner, M., Ernst, D., Langebartels, C. \& Sandermann, H. (1992). Biochemical-plant responses to ozone. Activation of the defense-related proteins $\beta$-1,3-glucanase and chitinase in tobacco-leaves. Plant Physiology 99, 1321-1328.

Schreiber, L.R. \& Green, R.J. (1969). Effect of root exudates on germination of conidia and microsclerotia of Verticillium albo-atrum inhibited by the soil fungistatic principle. Phytopathology 53, 260-264.

Schröder, M., Hahlbrock, K. \& Kombrink, E. (1992). Temporal and spatial patterns of 1,3- $\beta$-glucanase and chitinase induction in potato leaves infected by Phytophthora infestans. Plant Journal 2, 161-172.

Schultz, C. J., Ferguson, K. L., Lahnstein, J. \& Bacic, A. (2004). Post-translational modifications of arabinogalactan-peptides of Arabidopsis thaliana - Endoplasmic reticulum and glycosylphosphatidylinositol-anchor signal cleavage sites and hydroxylation of proline. Journal of Biological Chemistry 279, 45503-45511. 
Segarra, C. I., Casalongue, C. A., Pinedo, M. L., Ronchi, V. P. \& Conde, R. D. (2003). A germin-like protein of wheat leaf apoplast inhibits serine proteases. Journal of Experimental Botany 54, 13351341.

Séné, C. F. B., McCann, M. C., Wilson, R. H. \& Grinter, R. (1994). Fourier-transform raman and Fourier-transform infrared-spectroscopy - An Investigation of 5 higher-plant cell-walls and their components. Plant Physiology 106, 1623-1631.

Showalter, A. M. (1993). Structure and Function of Plant-Cell Wall Proteins. Plant Cell 5, 9-23.

Sivaprakasam, K. \& Rajagopa, C. K. (1974). Effect of nitrogen on incidence of Verticillium wilt disease of egg plant caused by Verticillium dahliae Kleb. Plant and Soil 40, 217-220.

Slabas, A. R., Ndimba, B., Simon, W. J. \& Chivasa, S. (2004). Proteomic analysis of the Arabidopsis cell wall reveals unexpected proteins with new cellular locations. Biochemical Society Transactions 32 , 524-528.

Smit, F. \& Dubery, I. A. (1997). Cell wall reinforcement in cotton hypocotyls in response to a Verticillium dahliae elicitor. Phytochemistry 44, 811-815.

Somerville, C. \& Koornneef, M. (2002). Timeline - A fortunate choice: the history of Arabidopsis as a model plant. Nature Reviews Genetics 3, 883-889.

Somssich, I. E., Schmelzer, E., Bollmann, J. \& Hahlbrock, K. (1986). Rapid activation by fungal elicitor of genes encoding pathogenesis-related proteins in cultured parsley cells. Proceedings of the National Academy of Sciences of the United States of America 83, 2427-2430.

Staiger, D., Apel, K. \& Trepp, G. (1999). The Atger3 promoter confers circadian clock-regulated transcription with peak expression at the beginning of the night. Plant Molecular Biology 40, 873-882.

Steventon, L. A., Okori, P. \& Dixelius, C. (2001). An investigation of the susceptibility of Arabidopsis thaliana to isolates of two species of Verticillium. Journal of Phytopathology 149, 395-401.

Steventon, L. A., Happstadius, I., Okori, P. \& Dixelius, C. (2002). Development of a rapid technique for the evaluation of the response of Brassica napus to Verticillium wilt. Plant Disease 86, 854-858.

Tappe, H., Floerl, S., Carsjens, J.G., Ratzinger, A., Dilcher, M., Karlovsky, P., Feussner, I., Polle, A. \& Gatz, C. (submitted). Expression profiling of Arabidopsis thaliana plants after infection with the xylemcolonizing fungus Verticillium longisporum.

Terras, F.R.G., Schoofs, H., De Bolle, M.F.C., Van Leuven, F., Rees, S.B., Vanderleyden, J., Cammue, B.P.A. \& Broekaert, W.F. (1992). Analysis of two novel classes of plant antifungal proteins from radish (Raphanus sativus L.) seeds. J. Biol. Chem. 267: 15301-15309.

Thordal-Christensen, H., Zhang, Z. G., Wei, Y. D. \& Collinge, D. B. (1997). Subcellular localization of $\mathrm{H}_{2} \mathrm{O}_{2}$ in plants. $\mathrm{H}_{2} \mathrm{O}_{2}$ accumulation in papillae and hypersensitive response during the barley-powdery mildew interaction. Plant Journal 11, 1187-1194.

Tjamos, E. C. \& Beckman, C. (1989). Problems and prospects in controlling Verticillium wilt. 441-456 in: Vascular Wilt Diseases of Plants. E. C. Tjamos and C. Beckman, eds. Springer-Verlag, Berlin, Germany.

Van Loon, L.C. (1982). Regulation of changes in proteins and enzymes associated with active defense against virus infection. In: Active Defense Mechanisms in Plants (R.K.S. Wood, ed.), pp. 247-273, Plenum Press, New York, USA.

Van Loon, L. C., Pierpoint, W., Boller, T. \& Conejero, V. (1994). Recommendations for naming plant pathogenesis-related proteins. Plant Molecular Biology Reporter 12, 245-264. 
Van Loon, L. C., Rep, M. \& Pieterse, C. M. J. (2006). Significance of inducible defense-related proteins in infected plants. Annual Review of Phytopathology 44, 135-162.

Vera, P. \& Conejero, V. (1988). Pathogenesis-related proteins of tomato - P-69 as an alkaline endoproteinase. Plant Physiology 87, 58-63.

Veronese, P., Narasimhan, M. L., Stevenson, R. A., Zhu, J. K., Weller, S. C., Subbarao, K. V. \& Bressan, R. A. (2003). Identification of a locus controlling Verticillium disease symptom response in Arabidopsis thaliana. Plant J. 35, 574-587.

Vitale, A. \& Denecke, J. (1999). The endoplasmic reticulum - Gateway of the secretory pathway. Plant Cell 11, 615-628.

Walker, J. C., Gallegly, M. E., Bloom, J. R. \& Scheffer, R. P. (1954). Relation of plant nutrition to disease development. Verticillium wilt of tomato. American Journal of Botany 41, 760-762.

Wei, Y. D., Zhang, Z. G., Andersen, C. H., Schmelzer, E., Gregersen, P. L., Collinge, D. B., Smedegaard-Petersen, V. \& Thordal-Christensen, H. (1998). An epidermis/papilla-specific oxalate oxidase-like protein in the defence response of barley attacked by the powdery mildew fungus. Plant Molecular Biology 36, 101-112.

Weigel, R. R., Pfitzner, U. M. \& Gatz, C. (2005). Interaction of NIMIN1 with NPR1 modulates PR gene expression in Arabidopsis. Plant Cell 17, 1279-1291.

Welinder, K. G. (1992). Superfamily of plant, fungal and bacterial peroxidases. Current Opinion of Structural Biology 2, 388-393.

Welinder, K. G., Justesen, A. F., Kjaersgard, I. V. H., Jensen, R. B., Rasmussen, S. K., Jespersen, H. M., \& Duroux, L. (2002). Structural diversity and transcription of class III peroxidases from Arabidopsis thaliana. European Journal of Biochemistry 269, 6063-6081.

Whetten, R. W., MacKay, J. J. \& Sederoff, R. R. (1998). Recent advances in understanding lignin biosynthesis. Annual Review of Plant Physiology and Plant Molecular Biology 49, 585-609.

Wilhelm, S. (1955). Longevity of the Verticillium wilt fungus in the laboratory and field. Phytopathology $45,180-181$.

Wilkinson, S. \& Davies, W. J. (2002). ABA-based chemical signalling: the co-ordination of responses to stress in plants. Plant Cell and Environment 25, 195-210.

Williams, J. S., Hall, S. A., Hawkesford, M. J., Beale, M. H. \& Cooper, R. M. (2002). Elemental sulfur and thiol accumulation in tomato and defense against a fungal vascular pathogen. Plant Physiology $128,150-159$.

Williams, P. H. \& Hill, C. B. (1986). Rapid-cycling populations of Brassica. Science 232, 1385-1389.

Yang, W., Jefferson, R. A., Huttner, E., Moore, J. M., Gagliano, W. B. \& Grossniklaus, U. (2005). An egg apparatus-specific enhancer of Arabidopsis, identified by enhancer detection. Plant Physiol. 139, $1421-1432$.

Young, S. A., Guo, A., Guikema, J. A., White, F. F. \& Leach, J. E. (1995). Rice cationic peroxidase accumulates in xylem vessels during incompatible interactions with Xanthomonas oryzae pv oryzae. Plant Physiol. 107, 1333-1341.

Yun, D. J., Durzo, M. P., Abad, L., Takeda, S., Salzman, R., Chen, Z. T., Lee, H., Hasegawa, P. M. \& Bressan, R. A. (1996). Novel osmotically induced antifungal chitinases and bacterial expression of an active recombinant isoform. Plant Physiology 111, 1219-1225.

Zeise, K. \& von Tiedemann, A. (2002). Application of RAPD-PCR for virulence type analysis within Verticillium dahliae and V. longisporum. Journal of Phytopathology 150, 557-563. 
Zhang, B., Ramonell, K., Somerville, S. \& Stacey, G. (2002). Characterization of early, chitin-induced gene expression in Arabidopsis. Molecular Plant-Microbe Interactions 15, 963-970.

Zhang, Z. G., Collinge, D. B. \& Thordal-Christensen, H. (1995). Germin-like oxalate oxidase, a $\mathrm{H}_{2} \mathrm{O}_{2-}$ producing enzyme, accumulates in barley attacked by the powdery mildew fungus. Plant Journal 8 , 139-145.

Zhou, Z. (2000). Untersuchungen zum Blatt- und Wurzelmetabolismus sowie zum Phloem- und Xylemtransport in Zusammenhang mit der Stickstoff-Effizienz bei Raps (Brassica napus L.). Dissertation, Georg-August-Universität Göttingen, 48-92.

Zimmermann, S., Nürnberger, T., Frachisse, J. M., Wirtz, W., Guern, J., Hedrich, R. \& Scheel, D. (1997). Receptor-mediated activation of a plant $\mathrm{Ca}^{2+}$-permeable ion channel involved in pathogen defense. Proceedings of the National Academy of Sciences of the United States of America 94, 27512755. 


\section{ABKÜRZUNGSVERZEICHNIS}

Abb.

AGI

al.

APS

AWF

BCA

BSA

bzw.

ca.

CBB

CDNA

CHAPS

$\mathrm{C} / \mathrm{N}$

CTAB

dd $\mathrm{H}_{2} \mathrm{O}$

d. h.

dNTPs

DNA

DTT

EDTA

ET

FM

$g$

GUPOD

GUS

$\mathrm{h}$

IEF

IPG

$J A$

$\mathrm{kDa}$

KPP

$\mathrm{L}$

LC-MS

$\mathrm{M}$

$\mathrm{MDH}$

$\mathrm{mg}$

$\mathrm{ml}$

MEA-Puffer

$\min$

MOPS

$\mathrm{MPa}$
Abbildung

Arabidopsis Genome Initiative

altera

Ammoniumpersulfat

apoplastische Waschflüssigkeit

Bicinchoninic acid

Rinderserumalbumin

beziehungsweise

cirka

Coomassie Brilliant Blue

komplementäre DNA

3-[(3-Cholamidopropyl)dimethylammonio]-1-propansulfat Kohlenstoff/Stickstoff

Cetyltrimethylammoniumchlorid

doppelt demineralisiertes Wasser

das heißt

Desoxynukleosidtriphosphate

Desoxyribonukleinsäure

1,4-Dithio-DL-threitol

Ethylendiamintetraacetat

Ethylen

Frischmasse

Gramm

Guajakolperoxidase

$\beta$-Glucuronidase

Stunde

Isoelektrische Fokussierung

Immobilisierter $\mathrm{pH}$-Gadient

jasmonic acid, Jasmonsäure

Kilodalton

Kaliumphosphatpuffer $\left(\mathrm{KH}_{2} \mathrm{PO}_{4} / \mathrm{K}_{2} \mathrm{HPO}_{4}\right.$-Puffer $)$

Liter

Flüssigkeitschromatographie-Massenspektrometrie

Molar, mol/L

Malatdehydrogenase

Milligramm

Milliliter

MOPS-EDTA-Natriumacetat Puffer

Minute

3-N-Morpholino-propansulfonsäure

Megapascal 


\begin{tabular}{|c|c|}
\hline MW & Molekulargewicht \\
\hline $\mathrm{n}$ & nano $\left(10^{-9}\right)$ \\
\hline NAD & Nicotinamidadenindinukleotid \\
\hline NCBI & National Center for Biotechnology Information \\
\hline PAA & Polyacrylamid \\
\hline PAGE & Polyacryamid-Gelelektrophorese \\
\hline PCR & Polymerasekettenreaktion \\
\hline PR & pathogen related \\
\hline PVPP & Polyvinylpolypyrrolidon \\
\hline RNA & Ribonukleinsäure \\
\hline RNase & Ribonuklease \\
\hline POX & Peroxidase \\
\hline rpm & Umdrehungen pro Minute \\
\hline RT & Raumtemperatur \\
\hline Rubisco & Ribulose-1,5-bisphosphatcarboxylase/-oxygenase \\
\hline s & Sekunde \\
\hline SA & salicylic acid, Salicylsäure \\
\hline SAR & systemic acquired resistance \\
\hline SCLP & Serin Carboxypeptidase ähnliches Protein \\
\hline SDS & sodiumdodecylsulfate, Natriumdodecylsulfat \\
\hline SE & Standardfehler \\
\hline SSTE-Puffer & Natriumchlorid-SDS-Tris-EDTA-Puffer \\
\hline Tab. & Tabelle \\
\hline TCA & Trichloressigsäure \\
\hline TEMED & Tetramethylethylendiamin \\
\hline TM & Trockenmasse \\
\hline $\mathrm{T}_{\mathrm{m}}$ & Schmelztemperatur \\
\hline Tris & Tris(hydroxymethyl)-aminomethan \\
\hline Triton $\mathrm{X}-100$ & Octylphenol-polyethylenglycol \\
\hline$U$ & Unit \\
\hline $\mathrm{v} / \mathrm{v}$ & Volumen pro Volumen \\
\hline VL43 & Verticillium longisporum Stamm 43 \\
\hline Vol & Volumen \\
\hline$w / v$ & Gewicht pro Volumen \\
\hline WT & Wildtyp \\
\hline z.B. & zum Beispiel \\
\hline$\mu$ & mikro $\left(10^{-6}\right)$ \\
\hline
\end{tabular}




\section{ANHANG}

\subsection{Peroxidasen Sequenzvergleich}

Der Sequenzabgleich wurde mit dem Programm CLUSTAL W (Version 1.83; multiple sequence alignment (cDNA)) durchgeführt. Die jeweiligen Primer wurden in der Sequenz markiert.

At 4937530 At 5906720 At 5905340

At 3949120

At 4937530 At 5906720 At $5 \mathrm{~g} 05340$ At 3949120

At 4g37530 At5g06720

At 5g05340

At 3949120

At 4937530 At 5906720 At5g05340 At 3949120

At 4g37530 At 5906720 At 5905340 At 3949120

At 4g37530 At 5906720 At5g05340 At 3g49120

At 4937530 At5g06720 At5g05340 At 3949120

At 4937530 At5g06720 At5g05340 At3g49120

At 4g37530 At 5g06720 At5g05340 At 3949120

At4g37530 At5g06720 At 5905340 At 3g49120

At 4g37530 At 5906720 At5g05340 At 3949120

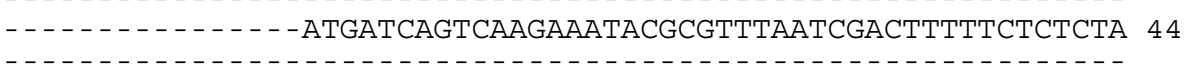

TATATACAATTCTTTCAAAATGATCAAACATAGTCATAAGTTCCGCACCAATCAGTGGAA 104

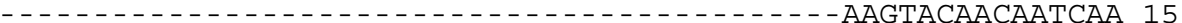
CCTCCAGCTTTGACCCGTTTTGCCTATAAAAGGATTCTCTAAGATATGGACTTTCCTCAT 120 ATAACTAATCAAAACTCTGTATCATCGTTTTCAAAACCTAATTAATGGCTGTAACAAATC 164 CT-CTAAGTCTATTATATTCAAGT--CTTTGTTTTAACCTAACAATGGCTTCAAATAAAC 72 CTTCTCGGGTAAACAGAATCAACTAGTTTTGTTTTTCCTCTTTCAAAAATGCATTTCTCT 180

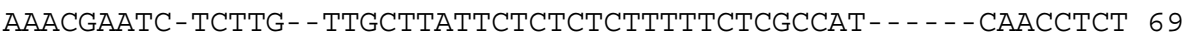
TTCCTACTTGTGATGGTTTGTTCATTATCAGTCTTATTGTCATCGTTTCT-TCAATATTT 223 TTATTTCGATTCTAGTTCTCGTAGTTACACTT--TTACTCCAAGGTG- - - -ATAACAATT 126 TCGTCTTCAACATCGTCCACTTGGACAATCTTAATCACATTGGGATGTCTTATGCTTCAT 240

- . - . - - - CCTCCGCTCAACTCCGCGGCGACTTCTACGCCGGAACTTGTCCGAACGTC 119 GGGACAT - - CATCTGCGCAACTAAACGCAACATTTTACTCTGGGACTTGTCCCAACGCC 280 ACGTCGT - - - CGAAGCACAACTCACGACTAACTTCTACTCAACCTCTTGCCCCAACCTC 182 GCATCTTTGTCCGCTGCTCAACTCACCCCTACCTTCTACGATAGGTCATGTCCTAATGTC 300 $\star * * * * * *$ $\star \star \star \star * *$ $\star * * * * * *$

GAGCAAATCGTCAGAAACGCCGTACAGAAAAAAATCCA-ACAAACTTTCACCACCATTCC 178 TCTGCCATCGTACGCAGCACTATTCAGCAAGCTCTTCA-ATCCGATACAAGAATCGGAGC 339 СTCTCCACCGTCCAAACCGCCGTTAAATCTGCCGTTAACAGCGAGGC-TCGAATGGGTGC 241 ACTAACATCGTACGAGAAACCATTGTAAATGA-GTTAAGGTCGGACCCTCGTATCGCTGC 359

CGCCACTCTACGCCTCTATTTCCATGATTGTTTCGTCAATGGATGTGATGCATCAGTGAT 238 CAGCCTCATCCGCCTTCATTTTCATGACTGTTTTGTTAATGGATGTGATGCATCGATCTT 399 ATCTATCCTCCGTCTCTTCTTCCACGATTGCTTTGTCAACGGATGCGACGGTTCGATTCT 301 GAGCATCCTTCGTCTTCACTTCCACGACTGCTTTGTTAATGGTTGTGACGCATCCATCTT 419

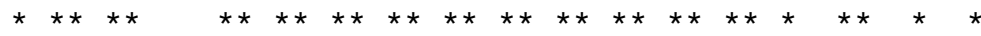

GATAGCGTCGACAAATACTAATAAGGCGGAGAAGGATCATGAGGATAATTTATCGTTGGC 298 GCTTGACGACACTGGAAGCATCCAGAGCGAGAAGAACGCTGGTCCGAATGTAAACTCAGC 459 ACTAGACGATACGTCAAGCTTCACAGGAGAACAAAACGCGGCTCCAAACCGCAATTCAGC 361 GTTAGACAACACGACATCATTTCGAACAGAGAAAGATGCGTTTGGAAACGCAAATTCGGC 479

$$
\begin{aligned}
& * * \\
& * *
\end{aligned}
$$

CGGAGATGGATTCGACACCGTCATTAAAGCTAAAGAAGCTGTTGACGCCGTCCCAAATTG 358 TAGAG - - -GATTCAACGTTGTTGATAATATCAAGACTGCCCTCGAAAACGC - - - - - TTG 510 TCGTG - - -GGTTTAATGTGATCGACAACATCAAATCAGCGGTTGAGAAAGC - - - - - ATG 412 TCGGG - - - GATTTCCAGTGATTGATAGAATGAAAGCTGCGGTGGAGAGGGC - - - - - - ATG 530

TCGTAACAAAGTTTCTTGCGCTGATATTCTCACGATGGCCACTCGTGACGTCGTTAATCT 418 CCCTGGTGTTGTCTCTTGCTCTGACGTTTTAGCCCTTGCCTCTGAGGCTTCTGTGTCTTT 570 TCCCGGGGTTGTGTCTTGTGCTGATATCTTAGCCATTGCTGCTAGAGACTCCGTCGTAGC 472 CCCAAGAACCGTTTCATGCGCAGATATGCTCACCATTGCAGCTCAACAATCTGTCACTTT 590

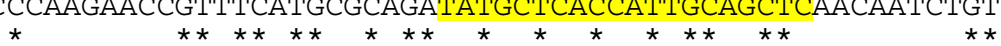

TGCGGGTGGACCACAATACGCCGTAGAATTGGGAAGGCGAGATGGACTTTCGTCGTCGGC 478 GGCAGGAGGGCCATCATGGACTGTATTATTAGGAAGAAGAGATAGTCTCACGGCCAACCT 630 CCTTGGAGGACCGAACTGGAATGTGAAAGTAGGAAGAAGAGATGCAAGAACGGCGAGTCA 532 GGCAGGAGGTCCTTCTTGGAGGGTTCCTTTGGGAAGGAGAGACAGTTTACAAGCATTCCT 650 
At 4g37530 At 5906720 At5g05340 At 3949120

At 4g37530 At 5906720 At5g05340 At 3949120

At 4937530 At 5906720 At5g05340 At 3949120

At 4937530 At 5906720 At5g05340 At 3g49120

At 4937530 At 5906720 At 5905340 At 3g49120

At 4937530 At 5906720 At5g05340 At 3949120

At 4937530 At5g06720 At5g05340 At 3949120

At 4937530 At5g06720 At 5g05340 At 3949120

At 4g37530 At 5g06720 At5g05340 At 3949120

At 4g37530 At 5g06720 At5g05340 At 3949120

At 4g37530 At5g06720 At5g05340 At 3g49120

At 4937530 At 5906720 At 5905340 At 3949120

At 4937530 At $5 \mathrm{~g} 06720$ At 5905340 At 3949120
TTCTAGCGTCACAGGGAAGCTACCCAAACCGACCTTTGATCTCAACCAACTCA-ATGCAC 537 CGCCGGTGCAAATTCGTCCATTCCTTCTCCCATCGAAAGCCTAAGCAACATCACATTTAA 690 AGCGGCAGCGAATAGTAACATTCCGGCACCGACTTCGAGTCTGAGCCAACTCA-TTAGTA 591 GGAACTCGCTAATGCAAATCTTCCAGCTCCATTCTTTACACTTCCACAACTTA-AAGCCA 709 * * * ** * * *

TTTTCGCAGAAAACGGTCTTA - - GCCCTAATGACATGATCGCTCTCTCCGGGGCACACA 594 ATTTT-CGGCTGTCGGGCTTA- - ATACAAACGATCTGGTAGCCTTATCTGGTGCGCATA 746 GTTTCAGTGCTGTTGGACTC- - TCCACCAGAGATATGGTTGCTCTCTCTGGCGCACACA 648 GCTTCAGAAATGTTGGTCTCGATCGTCCTTCTGATCTCGTTGCTCTCTCCGGTGGTCACA 769 **

$$
\text { **** * ** * ************ }
$$

CATTAGGATTCGCGCATTGCACAAAAGTTTTCAATCGGCTATACAATTTCAACAAGACAA 654 CGTTCGGGCGTGCTCGATGTGGAGTATTCAACAACAGACTATTTAACTTCAGCGGGACAG 806 CGATCGGACAATCCCGTTGCACGAACTTCCGAGCGAGAATCTACAA - - - - CGAGACAA 702 CATTTGGTAAAAATCAATGTCAGTTTATTCTTGACAGATTATACAATTTCAGCAACACAG 829 * * ** * * * * * * * ** * *

ATAACGTGGATCCCACGATTAACAAAGATTACGTGACAGAGCTAAAAGCGTCGTGTCCTC 714 GAAATCCCGATCCAACTCTAAACTCAACGCTTCTGAGCACTCTTCAACAGCTATGTCCTC 866 ACAT - - CAATGCCGCCTTCGCCACGACACGTCAACGAACTTGCCCTAGAGC---CTCCG 756 GTTTACCCGACCCTACACTCAACACTACTTACCTCCAAACTCTTCGTGGACTATGCCCCC 889

AAAACATAGATCCAAGAGTGGCTATTAACATGGATCCCAATACACCAAGACAATTCGACA 774 AAAACGGTAGCGCATCAACGATCACCAATCTTGATTTGAGCACACCAGATGCGTTCGATA 926 GTTCCGGCGACGGAAA - - CCTAGCTCCACTAGACGTCACCACGGCAGCTTCTTTCGACA 813 TTAATGGCAATCGAAGTGCCTTGGTAGATTTTGATCTACGTACGCCTACGGTTTTCGACA 949

ACGTTTACTACAAAAACTTGCAACAAGGGAAAGGATTGTTCACGTCTGATCAAG - - TCT 831 ACAATTACTTCGCCAACCTTCAGAGCAACGATGGACTTCTTCAGTCAGACCAAGAGCTGT 986 ACAACTACTTCAAGAATCTCATGACTCAGAGAGGGCTCCTCCATTCCGACCAAG - - TGC 870 ACAAATACTACGTGAATCTCAAAGAGCGAAAAGGTCTTATCCAGAGCGACCAAGAGTTGT 1009 $* * * * * * * * * * * * * * * * * * *$

TATTCACCGATAGTCGGTCAA - -AGC-CAACCGTTG- - - - - - ACTTATGGGCTAATAATG 882 TCTCTACCACCGGTTCATCCACCATCGCGATTGTTA--.----CTTCGTTCGCAAGTAACC 1040 TCTTCAACGGCGGC - - TCTACTGACTCCATCGTCC- - - - - GTGGATACAGCAACAATC 921 TCTCTAGCCCCAAT - - GCCACTGACACAATCCCCTTGGTGAGAGCATATGCTGATGGCA 1066 * * * * * * * * *

GACAGTTGTTTAATCAAGCTTTTATTAGCTCGATGATCAAGCTTGGTCGTGTTGGTGTTA 942 AGACTCTGTTTTTTCAGGCCTTTGCACAGTCCATGATCAATATGGGGAATATTAGTCCCT 1100 CGTCGAGCTTTAACTCTGACTTCACGGCGGCGATGATAAAAATGGGTGATATCAGCCCGT 981 CACAAACATTCTTCAATGCATTTGTGGAGGCAATGAATAGGATGGGAAACATTACACCAA 1126

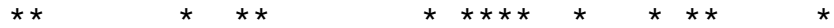

AAACTGGTAGTAATGGTAATATTCGTCGTGATTGCGGAGCTTTCAATT--AATTTAAATA 1000 TGACTGGGAGTAATGGAGAGATTAGGTTAGACTGTAAGAA - - - -GGTT - -AATGGAAGTT 1154 TGACTGGTAGTAGCGGTGAAATCCGCAAGGTTTGCGGGAGGACCAACT--GATTCAAGTC 1039 CTACAGGAACTCAAGGACAAATCAGATTGAACTGTAGAGTTGTGAACTCCAACTC- - TC 1183

***** ********

TATCTGTTTAAGATATTGTTTATTTGCACTCATTTGTATTGGGATTTGGGAATGGGATGG 1060 GATTTCCTTAAAGCTCATTTTCTTTGAAAAAACAT-TGGCAAGCTTTGG - - TTGAATAA 1210 TACTCCACGTGTCTTTTTCCTATTGGATTTACCTTTTATTATTTGAGTTGGTGAGTATAA 1099 TGCTCCATG-ATGTGGTGGATATCG- - TTGAC--TTTGTTAGCTCTAT--GTGAGAATTG 1236

GTCTCATGAAGCTGGTT-CAGCTAAAATGTA-ATAATTCTGGTT--TTGGGTTTTAGTT- 1115 TTTTTGTTATCATAATCACATCAAATCTGTA-TTGCACTTAAATCATTCTAAGCAAATT - 1268 TAAAGATTGATCTTCTCCAAAAAAATTCGAAGGTCCCTTTCAATGTTTTTTTTTTGTTTG 1159 TTTACCCAATATGTGGCTACAAGAATACATATATATTAATGAATAAAACTCTCAAGAC- - 1294 * *

- - - TGCTATATATCGCAAAACTAAATTGTAGATATGGAGTGGCAAAAAGGAAATAATATA 1172 - - - TATGATAAAT - - GAAATTAAATCAAAAC - - - - - - - - - - - - - - - - - 1294 CTTTGCTTTGTGTTGAAGTGTGTATTTCCGCATTAAAAATCTAATGAAAATTATTCCATT 1219

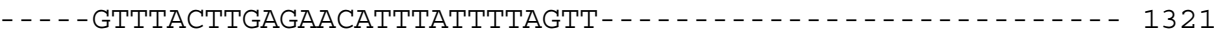

CATGATTAGTCCCAATGGGCAATGAC 1198

GA

TTG-

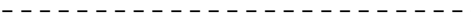




\section{2 Überprüfung der T-DNA Insertion in das Chitinase-Gen At5g24090}

Die Länge der codierenden Sequenz des Chitinase-Gens beträgt 909 bp, wobei die T-DNA nach Basenpaar $846 \mathrm{bp}$ inseriert ist. Mittels PCR-Analyse wurde die T-DNA Insertion in das Zielgen überprüft (Abb. 8.1). Mit den Gen-spezifischen Primern RP und dem T-DNA Primer LBb1 wurde ein 600 bp großes PCR-Produkt amplifiziert, welches zeigt, dass die untersuchten Pflanzen homozygot für die T-DNA Insertion in das Gen At5g24090 sind. Die Wildtyp (WT) Pflanzen dienten als Negativkontrolle, hier wurde kein PCR-Produkt im Gel sichtbar.

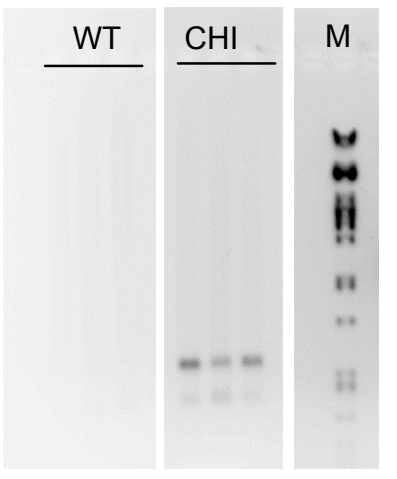

Abb. 8.1: Insertionsüberprüfung der T-DNA. Das Agarosegel zeigt Wildtyp (WT) Arabidopsis als negative Kontrolle und die Chitinase Mutante $(\mathrm{CHI})$ mit inserierter T-DNA jeweils aus drei Blattproben von verschiedenen Pflanzen. Zur Verfügung gestellt von Dr. Thomas Teichmann.

\subsection{Expressionsvergleich des Chitinase-Gens At5g24090 in Wildtyp- und Mutanten- Pflanzen}

In Abbildung 8.2 ist die Expression des Chitinase-Gens At5g24090 unter Einfluss von Verticillium longisporum dargestellt. In mock-inokulierten Wildtyp-Pflanzen war keine sichtbare Expression nachzuweisen. Die Behandlung mit Verticillium (VL43) führte bei den Wildtyp-Pflanzen zu einer verstärkten Expression. Bei der Chitinase-Mutante wurde erwartet, dass eine Insertion von T-DNA in ein Exon die Transkription des Gens verhindern würde. Stattdessen zeigte die T-DNA Insertionsmutante eine konstitutiv hochregulierte Expression, die durch Verticillium-Infektion nicht noch stärker erhöht wurde.

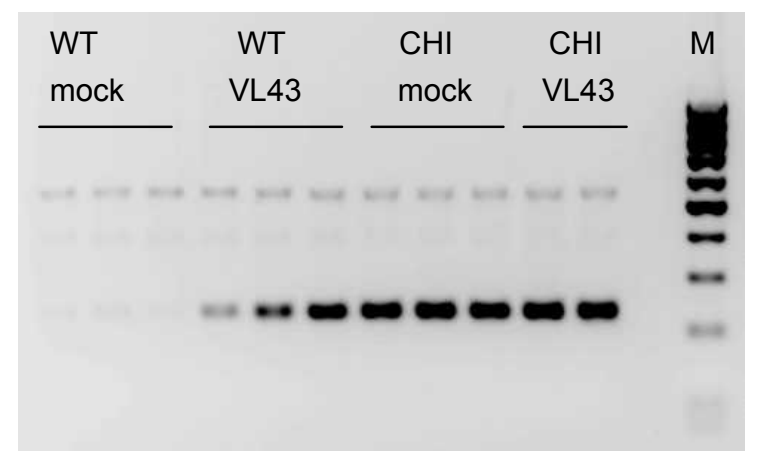

Abb. 8.2: Expressionsanalyse des Chitinase-Gens At5g24090 in mock- und Verticillium longisporum (VL43)-infizierten Wildtyp (WT) Arabidopsis und der Chitinase T-DNA Insertionsmutante (CHI) aus jeweils drei bzw. zwei unterschiedlichen Pflanzen. Zur Verfügung gestellt von Dr. Thomas Teichmann. 


\section{DANKSAGUNG}

Als erstes möchte ich mich bei Frau Prof. Polle für die Überlassung des interessanten Dissertationsthemas und die damit verbundene Betreuung dieser Arbeit bedanken. Außerdem danke ich Ihr für die vielen hilfreichen Anregungen, sowohl während der experimentellen Arbeit, als auch beim Schreiben dieses Manuskripts. Für weitere Anregungen möchte ich mich vor allem bei der gesamten Verticillium-Forschergruppe in Göttingen bedanken. Die monatlichen Treffen haben immer viele neue Aspekte ans Licht gebracht. Besonders möchte ich mich hier bei Hella Tappe und Jan-Gerrit Carsjens für die nette Zusammenarbeit während der großen Arabidopsis-Versuche bedanken und natürlich bei Nadine Riediger für ihre Hilfe und ihre Tipps zur Anzucht von Raps, der an unserem Institut bis dahin „fremd“ war. Der Arbeitsgruppe von Prof. Karlovsky danke ich für die vielen Verticillium real time Analysen. Frau Prof. Gatz möchte ich hier außerdem für die Übernahme des Korreferats danken. Für die finanzielle Unterstützung meines Projekts innerhalb der Verticillium-Forschergruppe danke ich der DFG.

In der Forstbotanik bedanke ich mich besonders bei Monika Franke-Klein für viele kleine und große Hilfestellungen im Labor und bei Thomas Klein für die Hilfe bei den Expressionsanalysen, verbunden mit der Weitergabe vieler kleiner nützlicher Tricks. Andrzej Majcherczyk und Mojtaba Zomorrodi danke ich für die massenspektrometrischen Analysen. Viele andere Mitarbeiter haben mich während meiner Arbeit unterstützt, denen ich hiermit allen Danke sagen möchte, vor allem aber Marianne Smiatasz für ihre ganzen „Heinzelmännchenarbeiten“ und Bernd Kopka für die Hilfe bei Computerproblemen und beim Drucken der Poster - und für den Kakao!

Allen Doktoranden und Mitarbeitern, die sich beinahe täglich mit mir auf den Weg in die Nordmensa gemacht haben, möchte ich für die vielen entspannten und oft spaßigen Mittagsstunden danken. Meinen Bürokollegen, insbesondere Rodica und Christine danke ich für die vielen hilfreichen Gespräche zu meiner Arbeit, aber natürlich auch zu Privatem. Für den nie versiegenden Kaffeestrom und die vielen lustigen Kaffeerunden danke ich Peter und Dennis - und natürlich Karl für eine „etwas andere Sicht auf die Dinge“, die immer viel Diskussionsstoff bot.

Meiner Familie, insbesondere Sebastian, aber auch allen meinen Freunden möchte ich für inre Unterstützung danken und dafür, dass es neben Verticillium immer viel anderes Wichtiges und Schönes zu entdecken gibt. 


\section{LEBENSLAUF}

\section{PERSÖNLICHE DATEN}

Vor- und Zuname:

Saskia Flörl

Geburtstag:

13.11.1975

Geburtsort:

Staatsangehörigkeit:

Bad Karlshafen

deutsch

\section{SCHULBILDUNG}

August 1982 bis Juli 1986

August 1986 bis Juni 1992

August 1992 bis Mai 1995

WISSENSCHAFTLICHER BILDUNGSGANG

August 1995 bis Juli 1997

August 1997 bis April 1999

Oktober 1999 bis Juni 2004

September 2003 bis Juni 2004

Seit Oktober 2004

\section{WEITERE TÄTIGKEITEN}

2000-2003

März bis Juni 2003

September 2002 \& Februar 2003
Grundschule Lippoldsberg

Heinrich-Roth-Gesamtschule Bodenfelde

Gymnasium Uslar

Ausbildung zur Biologisch-technischen-Assistentin an der Akademie für Umwelt und Technik in Hann. Münden

Anstellung als Biologisch-technische-Assistentin im Forschungslabor der Hautklinik in Göttingen

Studium der Biologie an der Universität Göttingen mit Diplomprüfungen in den Fächern Genetik (Hauptfach), Mikrobiologie und Anthropologie

Diplomarbeit in der Abteilung für Molekulare Genetik am Institut für Mikrobiologie und Genetik in Göttingen unter Anleitung von Dr. S. Behrens mit dem Titel: „Mutationsanalyse des periplasmatischen Chaperons SurA aus Escherichia coli zur Identifizierung funktions-relevanter Aminosäuren“"

Wissenschaftliche Mitarbeiterin am Institut für Forstbotanik (Abt. Baumphysiologie) bei Prof. A. Polle in Göttingen zur Anfertigung der Dissertation mit dem Thema: „Identifizierung und Charakterisierung extrazellulärer Proteine unter dem Einfluss von Verticillium Iongisporum in Arabidopsis thaliana und Raps (Brassica napus)“

Anstellung als wissenschaftliche/studentische Hilfskraft am Max-Planck-Institut für experimentelle Medizin in Göttingen

Anstellung als studentische Hilfskraft am Institut für Zoologie und Anthropologie in Göttingen

Anstellung als studentische Hilfskraft bei der iOnGen AG in Göttingen 